\title{
Does quality matter? An evaluation of the relationship between United Nations peacekeepers and civil war violence
}

\section{by}

Sean Winchester

A thesis submitted to the Faculty of Graduate and Postdoctoral Affairs in partial fulfillment of the requirements for the degree of

\author{
Doctor of Philosophy \\ in
}

\section{International Affairs}

Norman Paterson School of International Affairs

Carleton University

Ottawa, Ontario

(C) 2019

Sean Winchester 


\section{Abstract}

Why are some groups of peacekeepers more effective at managing civil war violence than others? Existing studies of operational effectiveness have focused on the quantity, profession, and geographic location of deployed personnel and have suggested that each of these is independently important. However, the relationship, if any, between the quality of UN peacekeepers and their ability to manage on-going violence remains critically understudied. To address this gap, this study begins by developing a novel definition of "peacekeeper quality" that consists of two key factors: professional capabilities and a willingness to act. It then evaluates the extent to which variation in peacekeeper quality contributes to operational effectiveness, at both the state-level and the local-level. I argue that higher quality peacekeepers are more effective than lower quality peacekeepers because they have an easier time coercing local conflict actors. To test this argument, I use an explanatory sequential methodology - a form of mixed-method research that uses qualitative data to help interpret the results of a primarily quantitative study. It starts with a cross-national analysis of all intrastate conflicts in sub-Saharan Africa from 1991-2017 to determine if variation in average operational quality affects the severity of violence at the state-level. It then proceeds to a geographically disaggregated analysis of three peacekeeping operations located in sub-Saharan Africa from 2010-2017 to determine if variation in the average quality of individual groups of peacekeepers affects the severity of violence at the local-level. Finally, it presents a process-tracing case study of MINUSCA's intervention in CAR from 2014-2018 that examines both overall trends and discrete conflict episodes. In short, this dissertation shows how and why peacekeeper quality matters. Specifically, it shows that the UN's highest quality peacekeepers are its 
most effective, that the quantity of peacekeepers continues to affect violence when controlling for quality and that peacekeepers are better at protecting civilians from harm than they are at managing battlefield violence. As a result, future attempts to evaluate the relationship between peacekeepers and violence, or to improve the UN's operational effectiveness, should also account for the role played by peacekeeper quality. 


\section{Acknowledgements}

This dissertation would not have been possible without the financial support provided by the Social Sciences and Humanities Research Council, the Ontario Graduate Scholarship program and the Norman Paterson School of International Affairs. Now that I have to work for a living, their support will be sorely missed.

I would also like to thank my supervisor, Dr. David Mendeloff, for encouraging me to enter the PhD program in the first place and for providing me with guidance and support along the way. He has done more than anyone to shape the way that I think and write, while also providing me with endless opportunities to grow as a scholar. Thank you for giving me the time and space that I needed to work through things on my own and for always being there with a helping hand whenever I asked.

To the members of my committee, your comments and suggestions were invaluable in bringing this project to completion. I was able to keep an eye on the big picture due to the feedback provided by Dr. Saideman, without losing track of the finer details due to the advice provided by Dr. Rowlands. Thank you both.

To Uri, Sarah and Michael, the first few years of the $\mathrm{PhD}$ program wouldn't have been the same without you. Thank you for reminding me to enjoy life on occasion amidst the endless flood of readings, papers and comps.

And to Rachael, whose own dissertation process so often served as the model for my own. Your love, patience and support over the past few years are what made this all possible. Thank you for providing me with the perfect environment in which to tackle this challenge and for giving me everything to look forward to in the future. I wouldn't have been able to do this without you. 


\section{Table of Contents}

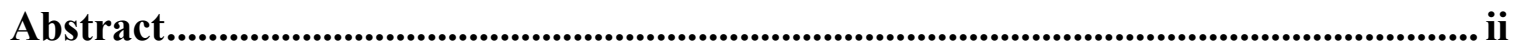

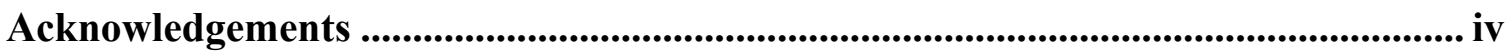





List of Figures......................................................................................................................... ix

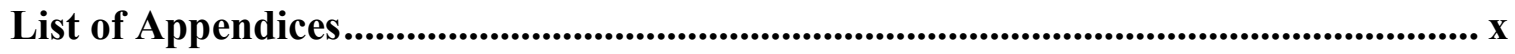

Chapter 1: Introduction .......................................................................................... 1



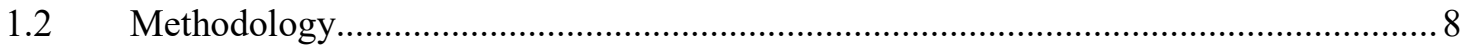

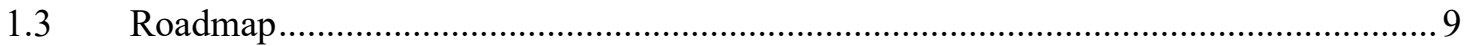

Chapter 2: Literature Review .................................................................................... 14

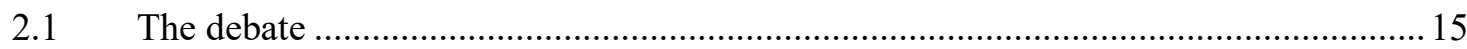

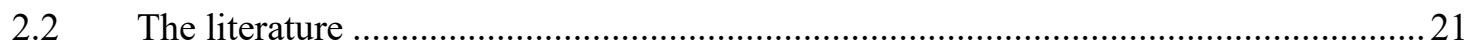

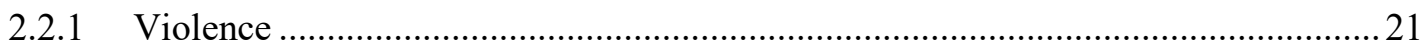

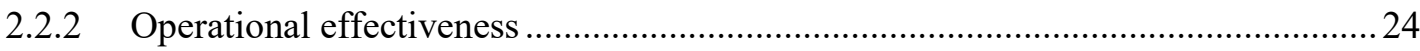

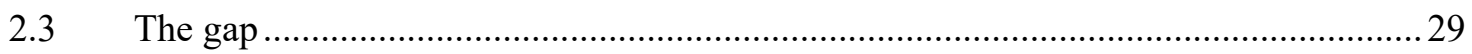

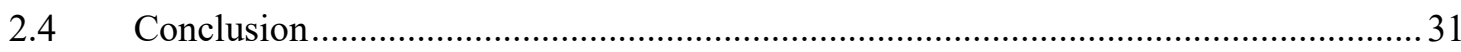

Chapter 3: Theory.......................................................................................................................... 33

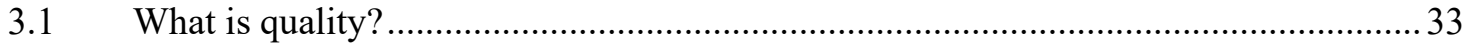

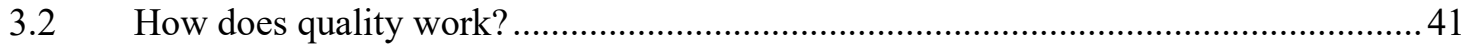

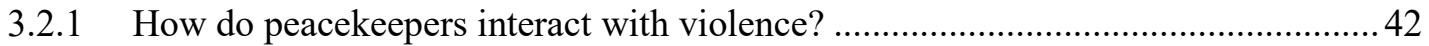

3.2.2 What role does quality play in this process? ...................................................... 46

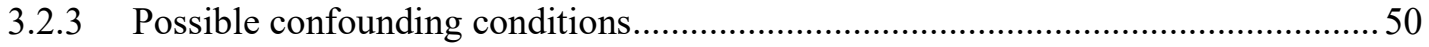

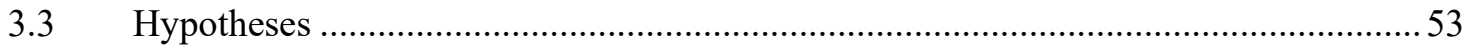




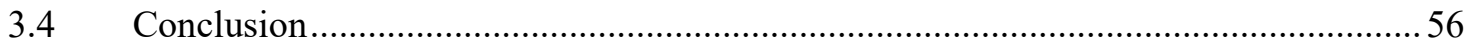

Chapter 4: State-level analysis......................................................................................... 58

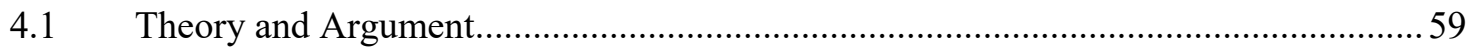

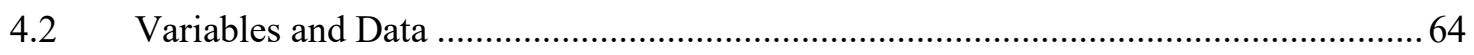





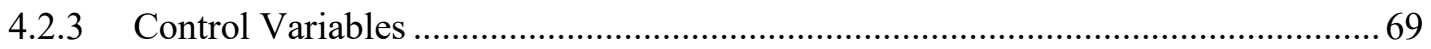

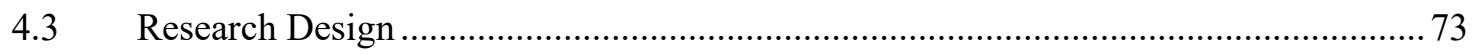

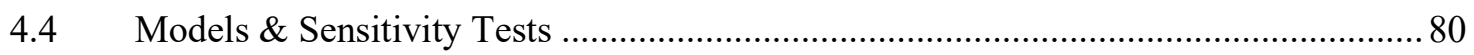

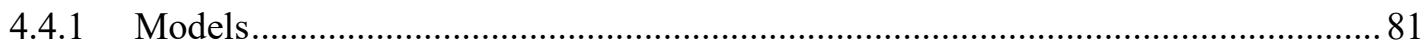

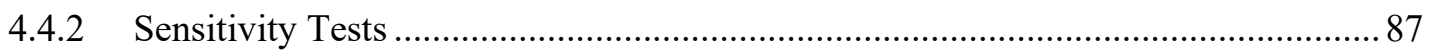

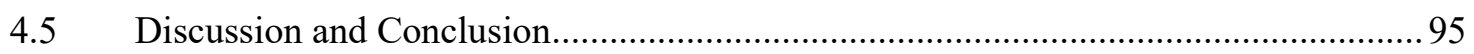

Chapter 5: Local-level Analysis ....................................................................................... 101

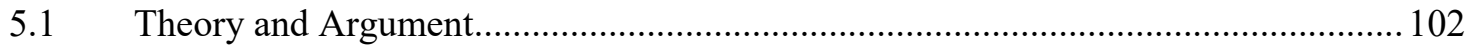

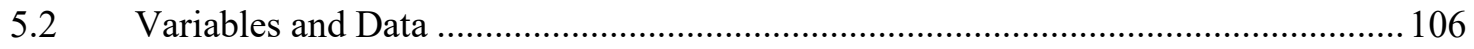

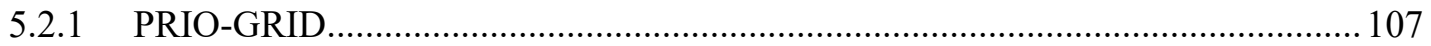

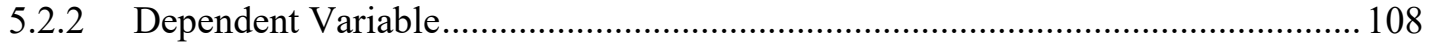

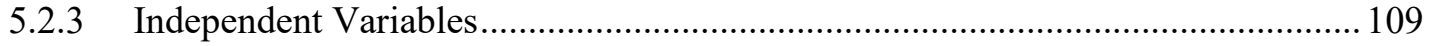

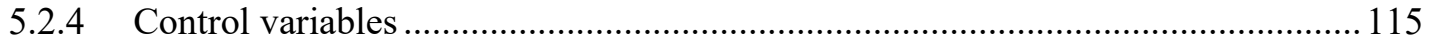

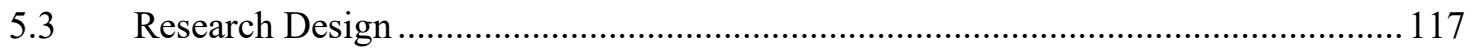

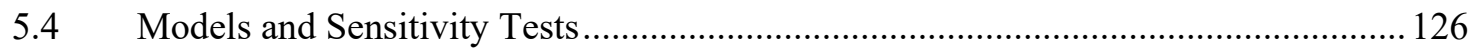

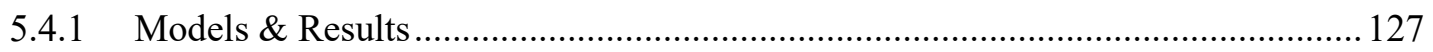

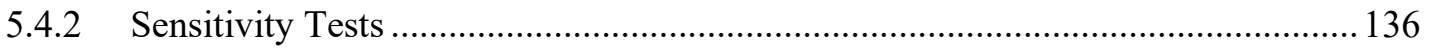

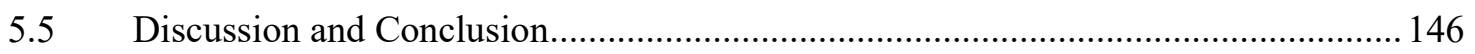

Chapter 6: Case Study (MINUSCA) .......................................................................... 152 


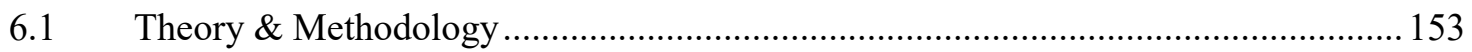



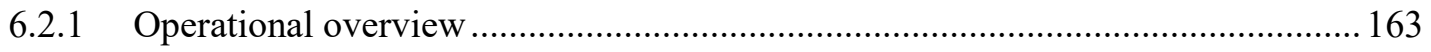

6.2.2 Deployment and Elections (April 2014 - March 2016) ........................................ 166

6.2.3 Drawdown and Stalemate (April 2016 - December 2018) .................................. 175

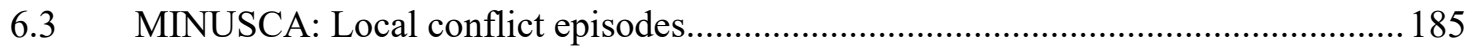

6.3.1 The advance on Bambari (February 2017)........................................................... 186

6.3.2 Attack on Alindao IDP camp (15 November 2018) ........................................... 192

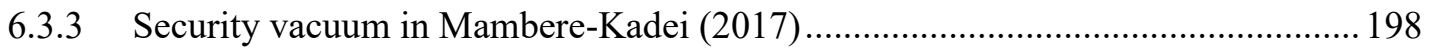



Chapter 7: Discussion and Conclusion ............................................................ 210

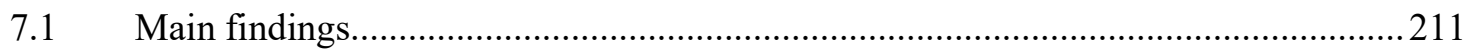

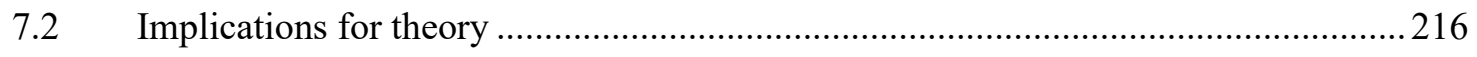

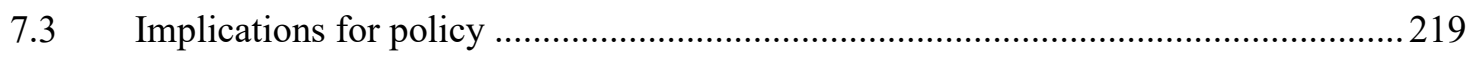

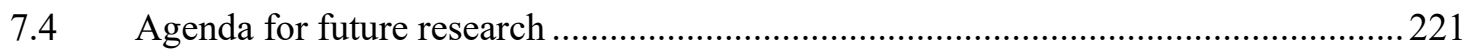

Appendices............................................................................................................. 225

References........................................................................................................... 229 


\section{List of Tables}

Table 1 - Peacekeeper Quality …………………………..................................... 54

Table 2 - Summary of variables, with descriptive statistics reported by sample ............. 72

Table 3 - Average values of operational quality based on mean of total violence per

month

Table 4 - Negative binomial regression models with fixed-effects (reported as IRRs) ... 82

Table 5 - Summary of variables and data, with descriptive statistics reported for the full

sample 116

Table 6 - Average quantity and quality values (split at the mean of total fatality rates per

grid cell) 125

Table 7 - Spatial autoregressive models estimated using fixed-effects

Table 8 - Marginal effects of peacekeepers on the reduced-form mean of violence 132

Table 9 - Summary of results for chapters four, five and six 


\section{List of Figures}

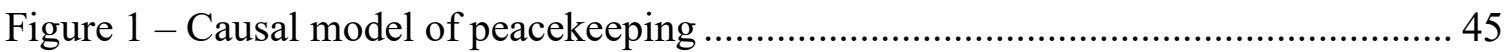

Figure 2 - Causal model of peacekeeping, plus peacekeeper quality............................... 50

Figure 3 - Causal model of peacekeeping, plus peacekeeper quality and confounding

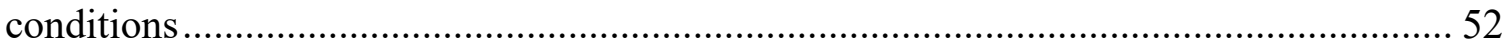

Figure 4 - Goodness of fit test for Poisson-based model .............................................. 75

Figure 5 - Marginal effects of operational capability on violence ……............................ 86

Figure 6 - MONUSCO Deployment Map (January 2016)............................................ 105

Figure 7 - Spatial clustering of civil war-related fatalities.............................................. 121

Figure 8 - Marginal effects of peacekeeper quality on violence …………................. 135

Figure 9 - Total number of battle-related fatalities and civilian killings reported in CAR

Figure 10 - Total fatalities between MINUSCA's authorization and President Touadera's

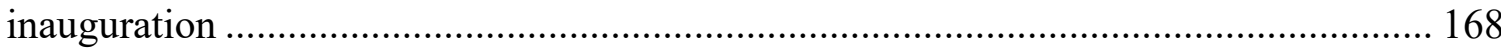

Figure 11 - The distribution of peacekeepers and violence in CAR (April 2014 to March 2016)

Figure 12 - Total fatalities between President Touadera's inauguration and the end of 2018.

Figure 13 - The distribution of peacekeepers and violence in CAR (March 2016

December 2016) 178 


\section{List of Appendices}

Appendix A - Model results from Chapter 4 with and without quality indicators.......225

Appendix B - Model results from Chapter 5 with and without quality indicators.......227 


\section{Chapter 1: Introduction}

Why are some peacekeepers more effective at managing civil war violence than others? In July 2016, for example, an outbreak of violence in Juba, the capital of South Sudan, occurred in close proximity to a major United Nations (UN) compound and its two adjacent civilian-protection sites. Despite its responsibility to protect both of these sites, the UN's performance during this crisis was mixed (UNSC 2016a; CIVIC 2016). Some of its peacekeepers remained at their positions and helped nearby civilians flee to safety, whereas others abandoned their posts and withdrew to the relative security of their compound. All of the contingents involved in this incident also refused multiple requests to intervene in violent situations occurring in nearby areas, preferring instead to focus on passive protection duties over more proactive forms of intervention. By contrast, the performance of the UN's peacekeepers in the Central African Republic (CAR) was exemplary when they prevented an attack on Bambari in February 2017 (UNSC 2017c; MINUSCA 2017e). Rather than retreating to the protection of a nearby compound, these troops undertook a combination of deterrent and compellent actions that halted the rebel advance towards the city and forced the target of the attack, a rival rebel commander, to withdraw from the area. As a result, the risk of open fighting in the streets of Bambari was avoided and numerous lives were saved.

Given the contradictory nature of these anecdotes, it is difficult to get a clear sense of the UN's ability to manage on-going violence. The first anecdote suggests that it is largely ineffectual beyond the protective confines of its own compounds, whereas the second anecdote suggests that it is capable of taking proactive steps to avert potential attacks. This lack of clarity is problematic for two reasons. First, the use of violence during 
civil war, whether on the battlefield or directed against civilians, is one of the most pressing issues facing the world today. Over the past two decades, the number of internal or internationalized internal conflicts has grown by roughly $40 \%$, from a low of 36 in 2000 to a high of 50 in $2018 .{ }^{1}$ These conflicts have collectively generated roughly one million battle-related fatalities, in addition to countless indirect deaths associated with disease, malnutrition, forced migration and the collapse of life critical infrastructure. ${ }^{2}$ The need to manage such violence effectively is therefore a clear and urgent priority of the international community, which makes the uncertainty surrounding the UN's capabilities in this regard highly problematic.

Second, unlike the missions of previous decades, the vast majority of UN peacekeepers today are stationed in countries where there is "little to no peace to keep" (UN 2015, 9). As a result, they are regularly confronted with the use of violence by local conflict actors, which they are then expected to prevent. However, there is currently a debate regarding whether the UN is equipped to undertake such a challenging task effectively and if it should even be intervening in such violent conflicts at all, particularly if it requires an increased reliance on the use of force. In order to help the UN address both

\footnotetext{
${ }^{1}$ These figures are based on an analysis of version 19.1 of the UCDP/PRIO Armed Conflict Dataset, which counts the number of conflict dyads that are active in any given year. As a result, it is possible for a single country to be the location for more than one conflict, such as if the government is fighting more than one rebel group at a time.

${ }^{2}$ This figure is based on an aggregation of battle-related fatality data contained in version 19.1 of UCDP's Battle-Related Deaths Dataset and Non-State Conflict Dataset for all intrastate and internationalized intrastate conflicts that occurred from 2000-2018. Not included in this figure is data on direct and deliberate civilian deaths or data on indirect fatalities, which would increase the total even further. For example, armed clashes during the 1998-2003 conflict in the DRC generated roughly 2.5 to 4.5 million war deaths, of which researchers estimate only $6 \%$ were the result of actual combat (Lacina and Gleditsch 2005, 159-160).
} 
of these problems, it is therefore important to develop a clearer understanding regarding why some groups of peacekeepers are more effective than others.

While scholars and UN policymakers have debated this topic for decades, the literature continues to suffer from a number of significant gaps. For example, conventional explanations of the relationship between peacekeepers and violence tend to focus on three different factors: the quantity of deployed personnel, their professional classification and their geographic location. Large operations that consist primarily of military personnel should therefore be more effective than small operations that consist primarily of unarmed observers or civilian police, provided that both operations have deployed their personnel within a similar proximity to the sources of violence. However, there is a lack of literature regarding the relationship, if any, between the relative quality of UN peacekeepers and their ability to manage on-going violence. To date, only a single study has evaluated this relationship explicitly (Haass and Ansorg 2018), which means that most knowledge on this topic is anecdotal in nature. As a result, there is currently a lack of consensus regarding whether peacekeeper quality contributes to operational effectiveness and, if so, why and how much.

Accordingly, the aim of this study is to answer the following research question: what effect does the quality of UN peacekeepers have on their ability to manage on-going violence? I argue that higher quality peacekeepers are more effective than lower quality peacekeepers because they have an easier time coercing local conflict actors. This advantage is helpful because the use of violence during wartime is typically motivated by an instrumental logic. If a conflict actor believes that they can benefit from the use of violence, whether on or off the battlefield, then they are likely to commit violent acts in the 
absence of an incentive not to do so. However, peacekeepers are rarely granted the kind of enforcement mandate that would allow them to eliminate violent actors entirely, so they must rely on the use of coercion to influence their behaviour instead. Since the success or failure of coercion relies on perceptions of credibility, anything that increases the severity, certainty or swiftness of a coercive act should increase the likelihood that it will be successful. Given this context, peacekeepers who possess a qualitative advantage over their peers, which I define in terms of their professional capabilities and willingness to act, should be more effective at managing on-going violence.

Of course, the success of coercion is far from guaranteed, so even the best peacekeepers may fail to halt or prevent violence under certain conditions, such as when conflict actors possess an advantage in terms of brute force, are capable of establishing escalation-dominance or are driven by overriding interests. But any improvement in the relative quality of the UN's peacekeeping personnel should nonetheless increase their ability to manage on-going violence.

The remainder of this chapter is divided into three sections. The first section includes a discussion of the scope conditions and definitions used in this study, the second section describes its chosen methodology and the third section provides an overview of the content contained in the following six chapters.

\subsection{Scope conditions and definitions}

Although the individual chapters of this study all adopt a different approach to the study of peacekeeper quality, its overall scope is bounded by the following three conditions. First, this study focuses solely on UN peacekeeping operations that have been 
deployed in the context of an intrastate conflict since the end of the Cold War. To start, the rationale behind excluding non-UN operations is relatively straightforward. The $\mathrm{UN}$ is the world's largest and most important peacekeeping organization, with approximately 85,000 uniformed personnel currently deployed to 14 operations on four different continents (DPKO 2019). Since its approach to peacekeeping differs from the approach taken by individual countries and regional organizations, the potential value of including non-UN operations in this study would be limited.

Similarly, the emphasis on intrastate conflicts rather than interstate conflicts is due to the many differences that exist between these distinct operational contexts. Although the full list of differences is too large to describe here, the most important distinction is that interstate operations are rarely, if ever, given mandates to address on-going violence, which means that they are irrelevant for the purposes of this study.

Finally, the decision to focus on operations deployed in the post-Cold War period is primarily motivated by how much the UN's policies and practices have evolved over time. Due to the lack of multidimensional operations and robust mandates during earlier time periods, it is unlikely that studying examples of more traditional operations would be useful when seeking to improve the operations of today. Having said that, the empirical elements of this study all focus on slightly different time periods, so there is some degree of variation from one chapter to the next. But they all share a common emphasis on UN peacekeeping operations that have been deployed in the context of an intrastate conflict since the end of the Cold War.

Second, the dependent variable used in this study, civil war violence, refers to all direct and deliberate fatalities caused by local conflict actors. Due to the relatively broad 
nature of this definition, it is divided into two distinct components: battlefield violence and one-sided violence. The former refers to any fatalities suffered by an organized actor when engaged in armed hostilities with another organized actor, as well as any civilian deaths caused by collateral damage during the fighting. Whereas the latter refers to any fatalities suffered by unarmed civilians as the result of a direct and deliberate attack by at least one organized actor. Both of these definitions are derived from the Uppsala Conflict Data Program's (UCDP) collection of datasets, which serve as the primary source of violence data used in this study.

Missing from these definitions is any mention of non-lethal violence, whether of a physical, psychological or sexual nature, as well as fatalities caused by indirect factors, such as famine or disease. This decision is not intended to downplay the significance of other forms of violence, regardless of the specific form that it takes. Instead, it reflects a recognition that the causes of, and solutions to, different forms of violence tend to follow a distinct causal logic. For example, the decision to execute civilians deliberately follows a different logic than unintentionally killing them while attacking a strategic location, even if the end result is the same. It is therefore important to account for these kinds of differences when asking questions related to effectiveness because it may turn out that peacekeepers are more or less effective at managing specific types of violence. In this case, the decision to adopt a narrow focus on the category of direct and deliberate fatalities was motivated by a combination of data availability and the relative severity of violent acts of this nature. All of the tests performed in this study are therefore limited to this particular category of civil war violence, rather than the full range of physical integrity abuses that may occur during wartime. 
Third, the main independent variable used in this study, peacekeeper quality, refers to the relative quality of the UN's military peacekeepers. It is based on a definition of 'quality' in a peacekeeping context that consists of two distinct factors: professional capabilities and a willingness to act. Both the underlying logic of this definition, as well as the manner in which it is hypothesized to operate, are discussed at length in Chapter 3. For now, however, it is worth emphasizing that this study is interested solely in the relative quality of military peacekeepers. No attempt is made to account for qualitative variation on the part of the UN's unarmed observers or civilian police, despite the fact that their presence may also contribute to the management of on-going violence.

The reasons for this restriction are both theoretical and practical in nature. In terms of theory, the UN's military peacekeepers are the best suited to coerce local conflict actors. The combination of their professional skillsets and military equipment means that they can both deter the use of future violence and compel an end to on-going violence, including through the use of force if necessary. They are also capable of engaging with conflict actors directly in order to help mediate local disputes, in addition to alleviating local security dilemmas that may be driving the use of violence. In terms of practicality, the professional composition of most peacekeeping operations is heavily skewed in favour of the UN's military peacekeepers, so any findings with regard to their relative effectiveness would be the most useful for the organization as a whole. There is also little data available on the relative quality of either civilian police or unarmed observers, which would make it difficult to evaluate them accurately in this context. As a result, this study looks solely at the relative quality of the UN's military peacekeepers, with the contribution made by non- 
military peacekeepers relegated to a supporting role rather than serving as a primary area of interest.

\subsection{Methodology}

To evaluate the relationship between peacekeeper quality and civil war violence, this study adopts a mixed-methods approach. Mixed-methods research relies on the collection, analysis and synthesis of quantitative and qualitative data within the context of a single study. Such studies must contain at least two different strands, one quantitative and one qualitative, each of which consists of posing a question, analyzing data and interpreting results (Teddlie and Tashakkori 2009). The exact number of strands in each study, as well as the order in which they are conducted, may vary depending on the nature of the question being asked, but the core requirement is that both types of data must be used. This degree of flexibility is one of the main benefits of mixed-methods research because it makes it possible to approach a single research question from a variety of different angles. However, it also means that the reasons for mixing quantitative and qualitative methods need to be stated explicitly, because many questions can be answered satisfactorily by relying solely on one or the other.

For the purposes of this study, I use an "explanatory sequential design" consisting of three distinct strands: two quantitative and one qualitative. This type of mixed-methods research uses qualitative data to help interpret the results of a primarily quantitative study (Cresswell and Plano Clark 2011: 71), with the two quantitative strands being conducted first and the single qualitative strand coming afterwards. The main benefit of adopting such an approach is the ability to triangulate findings in order to arrive at a more complete and 
credible answer than would otherwise be possible (Bryman 2006). This ability is particularly important when studying a phenomenon as complicated as civil war violence because it requires an understanding of both macro-level trends and micro-level processes (Kalyvas 2003; 2006), which is something that a single type of data would be unlikely to provide.

For example, the primary sources of quantitative data on civil war violence are all based on the aggregation of open-source news media reports, such as the UCDP's Georeferenced Event Dataset (GED). These kinds of datasets provide an excellent means of assessing the overall relationship between peacekeepers and violence, but they are poorly suited to providing a nuanced understanding of the underlying conflict dynamics. As a result, it is important to supplement the macro-level patterns revealed by these data with the kinds of micro-level insights generated by adopting a more qualitative approach. Otherwise, there is a risk that the UN's effectiveness may be exaggerated in some cases, such as when conflict actors are firmly committed to peace, and underestimated in others, such as when conflict actors have overriding incentives to commit violence. In sum, the core benefit of using a mixed-methods approach in the context of this study is that the more generalizable, but less nuanced, quantitative results can be complemented by the more nuanced, but less generalizable, qualitative results.

\subsection{Roadmap}

The remainder of this dissertation is laid out in the following manner. In Chapter Two, I provide an overview of contemporary debates and literature related to the field of operational effectiveness. The goal of this exercise is to shed light on the current state of 
knowledge regarding the puzzle raised at the start of this chapter, as well as to examine the two main factors that influence the UN's ability to manage on-going violence: the incentives that combatants have to use violence and the performance of its peacekeeping personnel. This chapter also highlights how little research has been conducted on the topic of peacekeeper quality and how the contribution made by this study is designed to help fill this gap.

In Chapter Three, I take the first step towards making this contribution by developing a novel definition of "quality" in a peacekeeping context that consists of the professional capabilities of the troops in question and their relative willingness to act when faced with violence. I then use this definition to develop a causal model of peacekeeping based on the theory of coercion, in which the power to hurt can be used to alter the behaviour of a targeted actor via the delivery of threats and assurances. Since the success or failure of coercion depends on perceptions of credibility, I argue that higher quality peacekeepers should have an easier time coercing conflict actors than lower quality peacekeepers because they can influence the certainty, severity and swiftness of their coercive messages with a greater degree of precision. As a result, I hypothesize that peacekeepers with high capabilities and a high willingness to act should be more effective at managing violence than peacekeepers with low capabilities and a low willingness to act. In Chapter Four, I use a cross-national dataset of all intrastate conflicts in subSaharan Africa from 1991-2017 to determine if variation in average operational quality has an effect on the severity of on-going violence at the state-level. This step is designed to replicate the results of the sole previous study on the relationship between peacekeeper quality and violence (Haass and Ansorg 2018), with the intention of either supporting or 
refuting their conclusion that an increase in average operational quality leads to a decrease in overall levels of violence. It begins by providing a brief overview of the UN's force generation system, which is the primary cause of qualitative variation from one peacekeeping operation to the next. It then reviews the variables and data used in this portion of the study, which are used to estimate a series of four negative binomial regression models and their accompanying sensitivity tests. Based on the results of these models, the main takeaway from this chapter is that quantity and quality both matter when it comes to determining operational effectiveness.

In Chapter Five, I use a geographically disaggregated dataset of three operational environments in sub-Saharan Africa from 2010-2017 (MINUSCA in CAR, MONUSCO in the DRC and UNMISS in South Sudan) to determine if variation in the average quality of individual groups of peacekeepers has an effect on the severity of violence at the locallevel. This step represents a unique contribution to the literature on operational effectiveness, which has yet to adopt such a fine-grained approach to the study of peacekeeper quality. Its primary advantage relative to the analysis conducted in the previous chapter is that accounting for the geospatial nature of this relationship makes it possible to develop indicators of quantity and quality that are tied to specific groups of peacekeeping personnel. In doing so, the focus is placed squarely on the relative effectiveness of individual groups of peacekeepers, without any interference from the kinds of operation-wide effects or force enablers that can influence outcomes at the state-level. It also allows for a more precise test of the hypothesized causal relationship between peacekeeper quality and violence, because spatial models are capable of isolating the impact of peacekeepers on nearby incidents of violence rather than their impact on overall 
levels of violence. After explaining the causes of qualitative variation at the local-level, the chapter describes the data and variables used in this portion of the study as well as how it intends to address the issue of spatial dependence. It then presents the results of two spatial autoregressive models, along with their accompanying sensitivity tests, which suggest that the relative quantity and quality of the UN's peacekeeping personnel matter when it comes to determining outcomes at the local-level as well.

In Chapter Six, I use a process-tracing case study of MINUSCA's intervention in CAR from 2014-2018 to assess the relationship between peacekeeper quality and violence in an even greater level of detail. The aim of this exercise is two-fold. First, it is intended to explore the question of how peacekeeper quality influences the use of violence, with the expectation that there will be significant evidence of coercive interaction between peacekeepers and local conflict actors. Second, it is intended to probe the accuracy of the results reported in the two quantitative chapters, as well as to determine the truth of any findings that may have differed from one chapter to the next. To this end, the chapter begins by providing a brief overview of the theoretical model developed in Chapter Three and then lays out the methodological justification for selecting the specific case of MINUSCA in CAR. It then divides the timeline of MINUSCA's intervention into two distinct time periods, using the inauguration of President Touadera in March 2016 as a dividing line, with the intention of identifying any overall lessons related to the relationship between peacekeeper quality and violence. After identifying a number of broad trends, the chapter then concludes by analyzing three discrete conflict episodes, each of which highlights that the success or failure of the UN's coercive efforts is influenced by the relative quantity and quality of its peacekeeping personnel. 
Finally, the results of all three empirical chapters are then summarized and discussed in Chapter 7, which serves as the concluding chapter for the dissertation as a whole. It begins by identifying the core conclusion of this dissertation, which is that some groups of peacekeepers are more effective at managing civil war violence than others due to variation in the underlying quality of the relevant personnel. It also highlights several other key findings, such as the fact that the UN's highest quality peacekeepers are its most effective, that the quantity of deployed personnel continues to have an effect on violence when controlling for quality, and that peacekeepers are better at protecting civilians from harm than they are at mitigating the severity of battlefield violence. It then lists the core contributions of this dissertation in terms of theory, which include the replication of previous results at the state-level of analysis, the extension of those results to the locallevel of analysis, the consideration of multiple types of civil war violence, and the development of a more nuanced understanding of the relationship between peacekeeper quality and violence. It then identifies several implications that this study has for policy, before concluding by presenting a brief agenda for future research.

In the following chapter, I take the first step towards writing this conclusion by reviewing the literature on operational effectiveness, identifying a gap with regard to our understanding of peacekeeper quality and explaining how the steps taken by this study are intended to help fill this gap. 


\section{Chapter 2: Literature Review}

This chapter provides an overview of contemporary debates and literature related to the field of operational effectiveness. The goal of this exercise is to shed light on the current state of knowledge regarding the puzzle raised in the previous chapter: why are some groups of peacekeepers more effective at managing violence than others? It is divided into three sections. The first section outlines how recent developments in the practice of UN peacekeeping have generated a debate that focuses on two related questions: first, should the UN intervene in conflicts experiencing on-going violence and, second, is it capable of operating effectively in such a challenging environment? Since this debate hinges, in part, on an accurate evaluation of the UN's operational potential, the second section reviews the literature related to the management of on-going violence. This review begins by highlighting the instrumental nature of most violent incidents during wartime, both on and off the battlefield, which suggests that the effective management of violence requires a clear understanding of the incentive structures of local conflict actors. It then discusses a series of studies related to the three core elements of operational effectiveness, which is believed to vary based on the internal composition, geographic location and overall quality of the UN's peacekeeping personnel. The third section then identifies several gaps in the effectiveness literature, with a particular emphasis on the relatively understudied relationship between peacekeeper quality and violence. The chapter concludes by outlining how the four main contributions made by this dissertation are intended to help fill these gaps, as well as to help inform contemporary debates regarding the future of peacekeeping. 


\subsection{The debate}

One of the most recent developments in the practice of UN peacekeeping is the need to manage on-going violence. Unlike the missions of previous decades, which were relatively straightforward affairs, $\mathrm{UN}$ missions today are routinely deployed into complex operating environments in which there is no clear peace to keep (UN 2015, 21). This shift in operational context has made missions more challenging at the same time that normative developments, such as the need to take proactive steps to protect civilians, have increased popular expectations regarding their performance (Bellamy and Hunt 2015). In an attempt to adapt to this new context, the UN has gradually shifted away from its core principles of impartiality and consent, as well as embraced the use of force (Sloan 2014). However, the underlying logic of this "robust turn" in UN peacekeeping has been subjected to considerable criticism and its long-term implications remain poorly understood (Hunt 2017). More specifically, many scholars question whether the potential benefits of these more robust operations are worth the potential risks, in addition to wondering whether the $\mathrm{UN}$ is even capable of carrying them out at all. Additional research is required, therefore, in order to determine if it is possible for the $\mathrm{UN}$ to operate effectively in non-permissive environments or if there is an upper limit to its operational potential.

The concept of robust peacekeeping initially evolved in response to the UN's postCold War experience. Prior to this point, the majority of UN operations could be clearly divided into one of two categories: traditional peacekeeping or peace enforcement. ${ }^{3}$ During

\footnotetext{
${ }^{3}$ The term 'traditional' in a peacekeeping context refers to operations that have been "deployed as an interim measure to help manage a conflict and create conditions in which the negotiation of a lasting settlement can proceed" (UN 2008, 21). They consist primarily of lightly armed or unarmed military personnel, whose main tasks include observation and reporting, ceasefire supervision, and the creation of physical buffer zones. Since these kinds of operations benefit from the existence of at least rough dividing
} 
the early 1990s, however, it became apparent that a conceptual "gray area" existed between these two extremes (Ruggie 1993). The UN's operations in Somalia and Bosnia, for example, were not wholly traditional because they involved elements of enforcement, but their adherence to the principles of impartiality, consent, and the minimum use of force meant that they were not wholly enforcement operations either (Goulding 1993). To address this conceptual confusion, the UN proposed the development of a more "robust force posture" in the so-called Brahimi Report (UN 2000a, 1; Weinlich 2012). Although the precise wording of this new doctrine would not be articulated until nearly a decade later, robust peacekeeping was eventually defined as "the use of force at the tactical level with the authorization of the Security Council and consent of the host nation and/or the main parties to the conflict" (UN 2008, 34). Robust operations would therefore be able to use force to coerce potential "spoilers" but, unlike enforcement operations, they would not be able to pursue the complete military defeat of major conflict actors (UN 2008, 35). ${ }^{4}$ As a result, the concept of robust peacekeeping did not represent a complete departure from more traditional forms of peacekeeping, but it did involve an increased willingness to use force.

More recently, the UN has developed an even more ambitious approach to peacekeeping that is intended to help stabilize fragile states. According to John Karlsrud, the purpose of these so-called 'stabilization' operations is to use "military means to

\footnotetext{
lines between warring parties, they have primarily been deployed in the context of interstate conflicts. Their lighter footprint also makes them suitable for intrastate conflicts in which rivals are able to exercise control over their respective territories, although these kinds of conflicts tend to be rare. As a result, traditional operations are not as common today as they were during the Cold War era, even though they continue to play a crucial role in several conflict zones around the world.

${ }^{4}$ Subsequent thinking on this topic, as noted in the DPKO's 'Concept Note on Robust Peacekeeping' (2010), further clarified that the resumption of violence by a major party to a conflict would also form a dividing line between 'robust' contexts and 'enforcement' contexts.
} 
stabilize a country, sometimes with all necessary means to neutralize potential 'spoilers' to a conflict" $(2015,42)$. Although they closely resemble standard multidimensional operations with robust mandates, ${ }^{5}$ this purpose sets them apart from their counterparts in three important aspects. First, stabilization operations are intended to be "self-consciously partial" (Bellamy and Hunt 2015, 1282). Rather than adhering to the UN's traditional norms of impartiality and consent, they are intended to facilitate the expansion of state authority at the expense of all other conflict actors. Second, stabilization operations are far more permissive regarding the use of force (Karlsrud 2015; Peter 2015). This shift is due to the fact that they are primarily deployed in the midst of on-going conflict, with contemporary examples including the UN's operations in Mali, the Central African Republic and the Democratic Republic of the Congo. Third, the challenges associated with stabilizing fragile states means that the mandates of these operations are significantly more ambitious. As a result, they often involve the use of tools, such as attack helicopters and aerial surveillance drones, and practices, such as counterinsurgency and counterterrorism, that fall outside of the UN's traditional capabilities and experiences. Having said that, these operations are also assigned a wide range of humanitarian and peacebuilding-related tasks as well, so they are not entirely different from their multidimensional counterparts. But

\footnotetext{
${ }^{5}$ According to the UN's Principles and Guidelines document, multidimensional operations are "typically deployed in the dangerous aftermath of a violent internal conflict and may employ a mix of military, police and civilian capabilities to support the implementation of a comprehensive peace agreement" (UN 2008, 22). The main difference between these operations and their more traditional counterparts is that they are intended to help resolve the underlying drivers of conflict. This role means that multidimensional operations are often responsible for a wide range of conflict-related tasks, such as the creation of a secure and stable post-conflict environment, the protection of civilians from violence, and the implementation of ceasefires or peace agreements. As a result, multidimensional operations are typically provided with robust mandates regarding the use of force, even though they must primarily rely on peaceful means to achieve their objectives rather than simply imposing solutions on unwilling participants through force of arms.
} 
their increased reliance on the use of force, their partiality towards one conflict actor over all others and the ambitious nature of their mandates represents a clear evolution in the UN's approach to peacekeeping.

In theory, the shift toward a more proactive form of UN peacekeeping seems like a reasonable solution to the challenges associated with managing on-going conflict. Providing operations with more ambitious mandates should allow them to undertake a wider range of tasks at the same time that increasing their ability to use force should allow them to perform those tasks in non-permissive environments. However, the long-term viability of this new approach has been subjected to two main criticisms.

First, many scholars fear that these changes may end up doing more harm than good. They acknowledge that embracing the use of force may increase the range of actions available to peacekeepers, but they fear that eroding core UN values such as impartiality, which has been described as the "oxygen" of peacekeeping (Findlay 2002, 4), may make the situation even worse. For example, Alex J. Bellamy and Charles T. Hunt (2015) identify five potential challenges associated with the UN's new approach to peacekeeping: decreased legal protections for peacekeepers; decreased safety of peacekeepers; increased strain on UN resources; increased international and domestic expectations; and increased vulnerability of humanitarian actors due to perceptions of co-option. These challenges echo those identified by several other scholars (Tardy 2011; Karlsurd 2015; Peter 2015; Hunt 2017; Rudolf 2017), all of whom emphasize that eroding the UN's core principles will have serious strategic, political, legal and ethical consequences. Although not all scholars agree that these challenges will be insurmountable (Nadin et al. 2014; Berdal and Ucko 2015), it is difficult to deny that these new stabilization operations come with a degree of risk. The 
question, therefore, is whether this more forceful approach to peacekeeping will serve to increase the UN's operational effectiveness or if it will be counterproductive due to diminished perceptions of impartiality and consent.

Second, even if the benefits of adopting these more ambitious mandates are assumed to be worth the costs, it is not clear that the $\mathrm{UN}$ is equipped to implement such mandates effectively in the field. Of the few scholars that have considered these issues in depth, there appear to be two main schools of thought. The first group of scholars are optimistic that the UN will be able to rise to the occasion (Nadin et al. 2014; Berdal and Ucko 2015). Since the UN has several decades' worth of experience in the field of peacekeeping and has successfully updated its policies and practices over time, these scholars argue that it is reasonable to assume that the UN will be able to address any new challenges that emerge as well. ${ }^{6}$ They acknowledge that this process may require additional changes to the UN's operational doctrine, but they nonetheless believe that "under the right circumstances and with a properly equipped and commanded force...it is possible to undertake coercive operations with decisive effects" (Berdal and Ucko 2015, 15). By contrast, the second group of scholars are pessimistic about the UN's ability to excel in this new context (Tardy 2011; Karlsrud 2015). They argue that the material, financial and structural requirements of these more ambitious operations are simply beyond the UN's potential capabilities (Claude 1984; Lipson 2007; de Coning and Friis 2011; Junk 2012; Karlsrud 2013), regardless of whether it implements additional reforms. ${ }^{7}$ As a result, they

\footnotetext{
${ }^{6}$ Although a complete overview of the UN's doctrinal evolution is not possible here, examples of recent innovations include the deployment of a Force Intervention Brigade to the Democratic Republic of the Congo and the initiation of counterterrorism operations in Mali (Tull 2017; Karlsrud 2017).

${ }^{7}$ The largest single impediment to the UN's ability to operate in complex environments is the fact that it relies entirely on the goodwill of its member states when it comes to securing the funds, equipment
} 
believe that the UN should stick to less challenging operational environments rather than risk setting itself up for a potentially catastrophic failure. However, given the relatively short amount of time that has passed since these operations were first deployed in the field, a clear answer regarding the UN's potential effectiveness has yet to emerge.

On the one hand, it is hard to fault the UN for wanting to adopt a more hands-on approach to peacekeeping. The opportunity to save lives and contain the spread of armed conflict aligns perfectly with its commitment to international peace and security, as well as with the underlying humanitarian imperative of the organization as a whole. The challenging nature of these operational environments also means that its member states are unlikely to intervene on their own, so the reversion to a more restrained approach would require the tacit acceptance of continued human suffering. On the other hand, the $\mathrm{UN}$ faces a number of financial, political and structural constraints that make it poorly suited to carrying out complex military operations. A large part of its comparative advantage in terms of peacekeeping is also derived from the strength of its three core principles, all of which are intended for use in more settled environments. The question of whether the UN should continue to intervene in situations involving on-going violence is therefore a reasonable one to ask.

However, it is difficult to answer this question directly without first developing a more complete understanding of the causes of operational effectiveness. If it turns out that the UN can increase its capability to carry out such operations, such as by improving the

and personnel necessary to conduct its peacekeeping operations. Its operations also suffer from a number of organizational dysfunctions, including a tendency on the part of deployed personnel to follow orders from their national capitals more readily than those delivered by their UN Force Commander in the field. Both of these issues are discussed in additional depth in the 'theory and argument' sections in Chapter 4 and Chapter 5. 
relative quality of its peacekeeping personnel, then that would remove one major objection to its continued engagement in situations involving on-going conflict. A more informed assessment regarding the upper limits of its operational capacity could then be conducted, which would help to inform the broader discussion regarding whether such operations should be deployed at all.

\subsection{The literature}

The success or failure of the UN's attempts to manage on-going violence is largely determined by a combination of two factors: the incentives that combatants have to use violence and the performance of its peacekeeping personnel. This section reviews relevant literature on both of these topics, starting first with the causes of civil war violence and then the determinants of operational effectiveness.

\subsubsection{Violence}

Although the use of violence during wartime is to some extent inevitable, it is important to recognize that not all violence is the same. Some conflict actors restrict their use of violence solely to the battlefield, whereas others deliberately target vulnerable civilians with the intention to do harm. If the UN wishes to manage on-going violence effectively, it must therefore be capable of determining what kind of violence is being used and why it is being used in the first place.

When it comes to battlefield violence, for example, the reasons for its use are often easy to understand. Armed clashes between rivals are typically linked to the underlying political or military objectives of the groups in question, which are themselves linked to 
the reasons that the conflict continues to exist. A full review of the relevant conflict literature is not possible here (Byman and Van Evera 1998; Brown 2001; Fearon and Laitin 2003), but common reasons for fighting include everything from a desire for state capture or territorial succession to the pursuit of greed or grievance. The use of violence to pursue these goals could therefore be part of a bargaining strategy on the part of local conflict actors (Schelling 1966; Byman and Waxman 2002), with an eye toward extracting better terms in a future negotiated settlement, or it could simply be an attempt to weaken their rivals in the hopes of securing their complete military defeat. Some conflict actors may also wish to avoid fighting entirely but are forced to continue doing so due to the presence of local security dilemmas or the difficulty of securing credible commitments from their rivals (Posen 1993; Kaufmann 1996; Walter 1999; Walter 2002). Adopting a strategy that is suited to addressing one motivation for battlefield violence may therefore backfire if that violence is being driven by another, so developing a firm grasp of local conflict dynamics is a necessary element of success.

For the same reason, it is also important to understand why conflict actors sometimes use violence against civilians. Violent acts of this nature may appear to be senseless at first, particularly if they are performed in an extremely brutal manner (Kalyvas 1999). But the literature on this topic suggests that violence against civilians largely follows an instrumental logic and is driven by two core motivations.

First, the use of violence against civilians is often determined by strategic considerations. For example, existing theories of bargaining (Boyle 2009; Wood and Kathman 2014), signalling (Hultman 2007; Hultman 2009), and labour market economics (Azam and Hoeffler 2002; Azam 2006) have all been used to explain the strategic use of 
violence during civil war. A number of studies have also been written about the phenomena of ethnic cleansing and mass killing (Kauffman 1996; Harff 2003; Valentino, Huth and Balch-Lindsay 2004; Sullivan 2012), which can explain the use of violence when seeking to capture a specific piece of territory or when attempting to suppress an elusive guerilla group. Other scholars have focused on the manner in which civilians tend to be attacked (Downes 2007; Lyall 2009; Kalyvas 2006; Kalyvas and Kocher 2009), with a distinction drawn between the indiscriminate use of violence against an entire population versus the selective use of violence against specific individuals. ${ }^{8}$ The question of who tends to be attacked has also been examined, with the majority of studies focused on the ethnic and political composition of civilian populations (Herreros and Criado 2009; Balcells 2010; Balcells 2011; Lilja and Hultman 2011; Fjelde and Hultman 2014). What all of these studies have in common is an emphasis on the strategic rationale for using violence, which stresses that the use of violence against civilians is often linked to the pursuit of concrete benefits. As a result, it should be possible for the UN to prevent at least some violence against civilians by altering the cost-benefit calculations of local conflict actors, provided they have a clear understanding of the underlying causal logic.

Second, the use of violence against civilians can also be linked to the organizational needs of conflict actors. Violent acts of this nature retain their instrumental logic, so they are still intended to achieve a specific purpose, but they tend to be tacitly permitted by a group's leadership rather than ordered directly. For example, the majority of violence in

\footnotetext{
${ }^{8}$ The former tends to be used in circumstances of imperfect information, with factors like ethnic identity and geographic location used as stand-ins for loyalty, whereas the latter tends to be used in circumstances when information is readily available or when indiscriminate attacks could encourage civilians to seek the protection of their rivals.
} 
some conflicts is due to the indiscipline of local conflict actors, which then manifests itself in the form of opportunistic attacks against civilians (Manekin 2013). These attacks may not serve a strategic purpose for the group as a whole, and could even be counterproductive in some cases, but they are often permitted to occur because policing such behaviour could threaten a group's survival by encouraging defections or leadership challenges (Humphreys and Weinstein 2006: Weinstein 2007). Similarly, some forms of violence are actually encouraged by a group's leadership because they are thought to increase the likelihood of organizational survival. An example of this type of violence is the phenomenon of wartime rape (Wood 2006; Wood 2009), which has been used by some groups to increase the internal cohesion of their fighting units so that they perform more effectively in battle (Cohen 2013a; Cohen 2013b). Given the instrumental nature of such acts, the UN should be capable of mitigating at least some incidents of organizationallydriven violence by manipulating the incentive structures of local conflict actors. However, if the use of violence is required to ensure a group's continued survival, whether for organizational or strategic reasons, then it is likely to be more difficult to stop (CroninFurman 2013). It is important, therefore, to understand both why violence is being used in a particular conflict as well as what steps the UN can take to increase its operational effectiveness.

\subsubsection{Operational effectiveness}

Contemporary explanations of operational effectiveness focus on three distinct elements of the relationship between peacekeepers and violence. The ability of all three of these factors to influence violence is necessarily linked to the incentive structures of local 
conflict actors, so there is no guarantee that the UN will be effective at all, but operations with appropriate mandates should nonetheless benefit from their impact (Hultman 2010).

First, the internal composition of an operation is viewed as being a core component of effectiveness. Since some operations are larger than others, or possess a higher ratio of combat to non-combat personnel, a number of recent studies have argued that it is important to account for any variation in these factors that may exist from one operation to the next (Hultman, Kathman and Shannon 2013; Hultman, Kathman and Shannon 2014; Kathman and Wood 2016). As a result, they hypothesize that the deployment of additional personnel should increase an operation's ability to manage on-going violence, particularly if those personnel consist primarily of military troops rather than unarmed observers or civilian police. To test this argument, these studies use a dataset developed by Jacob Kathman that looks at the quantity of military peacekeepers, military observers and civilian police deployed to all UN operations in sub-Saharan Africa from 1990-2011 (Kathman 2013). A series of econometric models are then estimated in each study, with the intention of determining whether increasing or decreasing personnel numbers in one month has an effect on the severity of violence in the following month. Although these studies all vary slightly in terms of scope, with some focusing on periods of active conflict and others looking at periods of post-conflict peace, they generally find that larger operations with plenty of troops are more effective than smaller operations with fewer troops. Any attempt to understand the relationship between peacekeepers and violence should therefore seek to account for the size and professional composition of the UN's peacekeeping operations.

Second, the ability of peacekeepers to mange on-going violence is also believed to depend on their geographic location. The logic underlying this position is relatively 
straightforward: if peacekeepers are not located in close proximity to violence, then they are unlikely to have an opportunity to influence the behaviour of local conflict actors. The most effective operations should therefore have the majority of their personnel located near potential 'hot spots' around the country, rather than deployed according to a 'convenience' logic that might see them stationed far away from the sources of violence (Ruggeri, Gizelis and Dorussen 2011; Townsen and Reeder 2014; Powers, Reeder and Townsen 2015; Ruggeri, Dorussen, Gizelis 2018). Although not all studies agree that peacekeepers are effective when co-located with violence (Costalli 2014), the majority have found that geographic location is an essential component of success. For example, the results of two recent studies demonstrate that the physical presence of peacekeepers on the ground can help to contain the geographic spread of violence from one area to the next (Beardsley and Gledistch 2015; Duursma and Read 2017). Similarly, a pair of other studies suggest that peacekeepers are capable of reducing the duration of nearby violent episodes (Ruggeri, Dorussen and Gizelis 2017), as well as the risk of violence against civilians by rebel actors (Fjelde, Hultman and Nilsson 2019). Assuming that peacekeepers are deployed to the right location, they should therefore be effective at reducing the geographic spread, temporal scope and likelihood of on-going violence. However, this literature has yet to address the question of whether peacekeepers are effective at decreasing the severity of on-going violence at the local-level, which is one of the gaps addressed by this dissertation.

Third, the relative quality of the UN's peacekeeping personnel is also thought to play a role in its ability to manage on-going violence. The basic argument made by these studies is that peacekeepers with better skills or equipment should be more effective at managing violence than their counterparts. Improving the overall capabilities possessed by 
an operation, or the capabilities of individual groups of peacekeeping personnel, should therefore lead to an increase in operational effectiveness. Despite the straightforward nature of this argument, the majority of interest in peacekeeper quality has been confined to the realm of illustrative anecdotes and qualitative case studies (Bratt 1997; Findlay 2002; Jett 1999; Holt, Taylor and Kelly 2009). These kinds of studies tend to emphasize the potential negative effects associated with shortfalls in troop quality, which can decrease the UN's ability to perform effectively in the field.

A more optimistic view of the role played by personnel quality is presented in a recent study by Vincenzo Bove and Andrea Ruggeri (2016), which asks whether operations with ethnically or linguistically diverse personnel are more or less effective at protecting civilians from violence. Although they do not measure quality directly, their argument does suggest that operational diversity may have a positive effect on performance if peacekeepers excel at complementary tasks: “...if peacekeepers from Country A have good communication and negotiating skills, while troops from Country B are relatively more combat capable, there are important gains to an operation of deploying troops from both countries rather than just one" (684-685). This suggestion is important because it formally recognizes that not all military peacekeepers are created equal, which is something that Ruggeri has noted in the past but never formally tested (Ruggeri, Gizelis and Dorussen 2011, 392). ${ }^{9}$ A subsequent study by these two authors further proposes that peacekeepers

\footnotetext{
${ }^{9}$ Although the importance of quality is mentioned in this study, it focuses solely on quantity instead. This decision was due to the authors' belief that variation in personnel quality would not be evident to opposing forces ahead of time, which would make it a non-factor during attempts at coercive action. However, while personnel quality may be an unknown factor during the first instance of contact, this level of uncertainty would surely become less relevant over time. It would also be possible for local actors to develop a general sense of the competence and capabilities of peacekeeping personnel by observing them from afar, which is something that any interested conflict actor would be expected to do.
} 
who are culturally and socially similar to local populations should have an easier time communicating with them, thereby increasing their ability to manage violence via conflict resolution (Bove and Ruggeri 2019). At the same time, however, these studies focus more on the effects of operational diversity, rather than on peacekeeper quality, which leaves ample room for subsequent inquiry into this topic.

The only study that looks explicitly at the relationship between peacekeeper quality and violence is a recent article written by Felix Haass and Nadine Ansorg (2018). The main argument in this study is that peacekeeping operations with higher quality troops should be more effective at reducing the severity of one-sided violence against civilians than operations with lower quality troops. This effect is attributed to the superior ability of higher quality troops to deter violence, establish buffer zones and monitor conflict actors, with the term 'quality' defined as the technical and personal capabilities of the relevant personnel combined with the political pressure provided by their home governments.

To test this argument, the authors estimate a series of negative binomial models using a dataset of all intrastate conflicts in Africa and Asia between 1991 and 2010, with conflict-month as their unit of observation. Their dependent variable, one-sided violence, was sourced from version 1.9 of the Uppsala Conflict Data Program Georeferenced Event Dataset (UCDP GED) and accounts for all direct and deliberate fatalities inflicted by an organized group against unarmed civilians in a given month. Their main independent variable, peacekeeping troop quality, consists of a weighted average of annual military spending for all troop contributing countries (TCCs) involved in a given operation, with the expenditure data sourced from the Stockholm Institute of Peace Research (SIPRI) and the personnel data from the International Peace Institute (IPI). After demonstrating that this 
indicator is positively associated with the presence of specialized equipment at the operational-level, the authors then report the results of five econometric models and their accompanying robustness tests. In all of these models, their chosen indicator of troop quality returns a negative and statistically significant relationship with one-sided violence, with subsequent tests demonstrating the existence of a substantively significant relationship as well. Overall, then, the combination of this single study with the qualitative studies cited above suggests that peacekeeper quality plays a role in determining operational effectiveness, rather than solely the quantity, profession and geographic location of the UN's peacekeeping personnel.

\subsection{The gap}

Although the available evidence suggests that all of these factors contribute to the UN's ability to manage on-going violence, there are nonetheless a number of gaps in this literature that would benefit from additional research. The most significant of these gaps is with regard to the potential role played by personnel quality, which has only been subjected to systematic analysis in the context of a single study. At the most basic level, therefore, it would be useful to conduct a second study on this topic to see if its results align closely with those of the first. Whether those results are negative or positive, the potential benefits in terms of either supporting or contesting the findings reported by Haass and Ansorg would represent a significant contribution to the field of operational effectiveness.

Beyond this general goal, however, there are a number of ways in which the approach adopted in this initial study would benefit from further extension and refinement. 
For example, the authors' chosen definition of quality combines the skills and technological capabilities possessed by military peacekeepers with the political pressure applied by their home governments, rather than attempting to disaggregate these factors into separate indicators. It also neglects the fact that some peacekeepers may be more motivated to act than others, which could lead to variation in performance that has nothing to do with their underlying capabilities. Similarly, the fact that only a single study has been conducted on this topic means that it could not possibly address every aspect of the literature on operational effectiveness. It neglects to consider the relationship between peacekeeper quality and battlefield violence, fails to incorporate any of the insights from the literature on geographic location and largely overlooks the important role played by combatant incentives. In order to fill these gaps, therefore, it is necessary to conduct additional research.

To this end, the methodological approach adopted in this study is designed to make four main contributions to the literature on operational effectiveness. First, it develops a more nuanced model of the relationship between peacekeeper quality and civil war violence that accounts for strategic interaction with local conflict actors. This model is based on the theory of coercion and uses an expanded definition of peacekeeper quality that consists of two core components: the capabilities of the troops in question and their willingness to act when faced with violence.

Second, it re-tests the relationship between peacekeeper quality and one-sided violence using a unique dataset of all intrastate conflicts in sub-Saharan Africa from 19912017. In addition to replicating the approach taken in the first study, this test also pushes 
one step further by evaluating the relationship between peacekeeper quality and battlefield violence as well.

Third, it tests the relationship between peacekeeper quality and both types of violence at the local-level using a unique, grid-based dataset for three peacekeeping operations deployed to sub-Saharan Africa from 2010-2017. This test provides an opportunity to control for the effects of geographic location when evaluating the role played by peacekeeper quality, which is important given that qualitative variation is largely a local phenomenon. It also affords an opportunity to address a gap in the geographic location literature, which has yet to evaluate the relationship between peacekeepers and the severity of on-going violence.

Fourth, it introduces fine-grained, qualitative data into the study of peacekeeper quality in the form of a process-tracing case study of the UN's on-going intervention in the Central African Republic. The use of qualitative data in this manner makes it possible to probe the underlying causal relationship between peacekeeper quality and civil war violence, as well as to highlight episodes of strategic interaction with specific conflict actors. In sum, the research design used in this study is intended to fill in some of the gaps that currently exist in the literature on operational effectiveness, with a specific focus on the relatively understudied topic of peacekeeper quality.

\subsection{Conclusion}

As reviewed above, one of the most pressing issues facing the UN today is whether it should continue to intervene in situations involving on-going violence. One aspect of this debate hinges on the question of whether the long-term benefits of eroding the UN's core 
values will be worth the costs, with the recent emergence of ambitious 'stabilization' mandates serving as a particular point of concern. Whereas the other aspect of this debate focuses on whether the UN possesses the capability to carry out such complex operations effectively, given its many financial, political and structural limitations.

To contribute to this debate, this dissertation addresses a major gap in the literature on operational effectiveness by conducting additional research on the relationship between peacekeeper quality and civil war violence. Due to the lack of research on this topic, it is currently unclear whether the relative quality of UN peacekeepers affects their ability to manage violence at either the operational-level or the local-level. The one study that has been written on this topic suggests that an increase in the average quality of an operation's peacekeeping personnel is associated with a decrease in one-sided violence against civilians. But it is unable to comment on other elements of this relationship, such as whether peacekeeper quality contributes to the performance of individual groups of peacekeepers on the ground. If it turns out that peacekeeper quality contributes significantly to operational effectiveness, then the debate regarding the UN's potential capabilities could shift to the question of how much the overall quality of its personnel could realistically be improved. The answer to this question would then, in turn, help to inform the overall debate regarding whether the UN should continue to intervene in situations involving on-going violence at all. In the following chapter, I take the first step toward making this contribution by identifying what "quality" means, explaining why it matters and describing how it works. 


\section{Chapter 3: Theory}

This chapter makes a contribution to the literature on operational effectiveness by developing a causal model of peacekeeping that accounts for the role played by peacekeeper quality. In doing so, it takes the first step towards filling the gap identified in the previous chapter, in addition to providing the theoretical framework for the empirical chapters that follow. It is organized into two sections. The first section begins by defining what the term "quality" means in a peacekeeping context. Drawing on insights from the relevant academic and policy literature, I present a definition of peacekeeper quality that consists of two core components: professional capabilities and a willingness to act. The second section incorporates this definition into a causal model of peacekeeping that is based on the theory of coercion, which accounts for the process of strategic interaction that takes place between peacekeepers and conflict actors. I then use this model to explain how variation in peacekeeper quality plays a major role in the management of violence because it can increase or decrease the credibility of their coercive threats and assurances. The chapter then concludes with a short list of hypotheses regarding the anticipated relationship between peacekeeper quality and violence, which collectively serve to guide the tests performed throughout the remainder of this dissertation.

\subsection{What is quality?}

The core argument advanced by this dissertation is that the relative quality of UN peacekeeping personnel plays a role in their ability to manage on-going violence. In making this argument, I am not seeking to downplay the importance of other factors, such as the location, profession or quantity of deployed personnel, which have previously been 
shown to affect the performance of $\mathrm{UN}$ peacekeepers. The rationale for including these variables is logical and the evidence is persuasive. Instead, I am merely pointing out that these factors alone are insufficient to explain the puzzling observation that some peacekeepers are more effective at managing violence than others. However, due to the lack of research on this topic, it is not clear what the term 'quality' actually means in a peacekeeping context. The single study by Haass and Ansorg (2018) develops a definition of quality that focuses primarily on the military skills and technological capabilities possessed by the troops in question, in addition to the political pressure exerted by their home governments. But the rationale provided for their chosen definition is relatively thin and they neglect to consider other potential elements of quality, such as the willingness to take action when faced with violence. Before explaining how quality works, therefore, it is important to take some time to identify precisely what the term means in the context of a UN peacekeeping operation.

The definition of peacekeeper quality used in this dissertation consists of two core elements. First, following the approach taken by Haass and Ansorg, one half of this definition focuses on the skills and equipment possessed by the UN's personnel. Although military capabilities are not the only factor that may influence the performance of different groups of peacekeepers, they are widely assumed to be important in both the academic and policy literature. For example, the literature on military theory has long acknowledged the benefits of deploying troops who possess superior skills or equipment. ${ }^{10}$ Much of this

\footnotetext{
${ }^{10}$ One of the main areas of contemporary debate on this topic has focused on the relative tradeoffs between quantity and quality in the context of military procurement decisions, with a notable bias in favour of quality often observed on the part of military officials. For examples of this literature, See Rogerson (1990), Lipow and Plessner (2008), and Lipow and Feinerman (2001).
} 
literature stems from the pioneering work of F. W. Lanchester (1916), whose tract on the use of air power in World War I included an innovative digression on how to calculate the outcome of a battle between two units of uneven fighting strength (47-53). Referred to as Lanchester's Square Rule, the basic insight behind this calculation was that troops with superior capabilities could be used to counter larger quantities of inferior troops. Although his initial example focused solely on technological differences, namely the relative firepower of rifles versus machine guns, subsequent scholars have used his model to evaluate the effects of a much wider range of factors, including tactics, training and morale. $^{11}$

Similarly, the UN's own policy documents have made repeated references over the past few decades to the desirability of deploying well-trained and equipped personnel. The Brahimi Report highlights the need for peacekeepers to possess sufficient capabilities (UN 2000a), the New Horizons non-paper proposes the development of a "capability-driven approach" to peacekeeping (DPKO 2009a, 29), and the report of the High-Level Independent Panel on Peacekeeping Operations emphasizes that increased capabilities are required for the more ambitious operations of today (UN 2015). Although work remains to be done in this regard, ${ }^{12}$ the shared consensus amongst academics and policy makers

\footnotetext{
${ }^{11}$ For a comprehensive overview of the various applications of Lanchester-type models, see Wrigge, Fransen and Wigg (1995) and Taylor (1980). Insights from this literature have also been used to develop a variety of other military analytic tools, such as game-theoretic models, probabilistic simulations and wargames (Washburn and Kress 2009).

${ }^{12}$ As part of its long-term efforts to improve operational effectiveness, the UN has made a deliberate effort over the past two decades to increase the amount of guidance that is available regarding the more practical elements of peacekeeping. Much of this effort has focused on the publication of policy directives by the DPKO/DFS, such as "Joint Operations Centres and Joint Mission Analysis Centres" in 2006, "Authority, Command and Control in United Nations Peacekeeping Operations" in 2008, and "Formed Police Units in United Nations Peacekeeping Operations" in 2009. In addition to these policy directives, the UN has also published manuals to outline its expectations for Contingent Owned Equipment (2011), United Nations Infantry Battalions (2012) and Military Reconnaissance Units (2015a), the
} 
regarding the benefits of deploying troops with superior capabilities suggests that this factor should be included in any definition of peacekeeper quality.

As a starting point, defining peacekeeper quality in terms of the relative capabilities possessed by the UN's personnel is a relatively safe choice. It aligns with the approach taken in the only previous study on this topic, as well as with a common sense understanding of what the term 'quality' means when applied in a military context. However, it is worth emphasizing that the capabilities required to be a good peacekeeper are not necessarily the same as the capabilities required to be a good solider. The many similarities that exist between these two occupations means that a significant amount of overlap is inevitable but it is nonetheless important to recognize that there are differences as well. For example, the United Nations Infantry Battalion Manual (2012) includes a list of eight core capabilities that all military peacekeepers are expected to possess. These capabilities include adequate firepower, mobility, force protection, tactical information, sustainment, interoperability, civil interaction and command, control and communications (68-71). Since many of these capabilities are also essential in a non-UN context, it supports the argument that a highly capable peacekeeper is more-or-less equivalent to a highly capable soldier.

Nonetheless, it would be a mistake to judge the quality of peacekeepers solely on the merits of their military prowess. The ability to communicate, for example, is one of the most important skills that a peacekeeper can possess (Autesserre 2014, 118-121). It can help peacekeepers to collect valuable intelligence regarding the perpetrators of violence, 
as well as to de-escalate potentially violent situations before they get out of hand. The ability to apply force in a restrained and non-lethal manner is also essential when operating in a UN context, despite the bias that the military profession as a whole possesses towards the use of overwhelming force (Hills 2001). Both of these skills may be useful in certain non-UN contexts, such as counterinsurgency or policing operations, but they are not typically included in the baseline training provided to military personnel. Therefore, in addition to being capable soldiers in the traditional sense, the best peacekeepers are also likely to possess specialized training or equipment that allows them to excel in the context of a UN peacekeeping operation.

Second, in a departure from the approach taken by Haass and Ansorg, the other half of this definition focuses on whether peacekeepers have an incentive to act when they are faced with violence. At first glance, the need to consider something like incentives may seem odd. Peacekeepers are soldiers, after all, so they should be used to following orders regardless of their personal preferences. Although this logic largely holds true in this context, peacekeepers often possess a significant amount of discretion when it comes to the management of on-going violence. For example, many of the orders that field-based peacekeepers receive are "out of touch with local situations and therefore inadequate or irrelevant... which le[aves] them without a concrete sense of how they [a]re supposed to carry out their duties on the ground" (Autesserre 2014, 27). Since many tasks related to the management of violence are time sensitive, these deficiencies mean that peacekeepers are often forced to act, or not to act, in response to violent episodes based primarily on their own discretion. This freedom of action raises the possibility that some troops may act to 
mitigate the effects of violence in a proactive manner, whereas others may prefer to adopt a more passive approach.

In addition, the standard reference documents that peacekeepers are asked to rely on in the field, such as operational mandates and rules of engagement, tend to lack sufficient guidance regarding when, why and how to use force during an operation (Blocq 2006). They also tend to provide a significant amount of leeway to local commanders on the ground, which may help or hinder operational effectiveness depending on whether they are willing to take robust action. Thus, when peacekeepers are confronted with a situation that may require the use of force, they risk finding themselves lost in what Daniel Blocq (2006) refers to as "the fog of UN peacekeeping" and then have little to fall back on aside from their own judgement. Since these kinds of choices will be faced by even the most capable peacekeepers, particularly in the absence of sufficiently timely or detailed orders, it seems reasonable to suggest that a truly excellent peacekeeper should also prefer action over inaction in such situations.

Of course, seeking to incorporate the incentive structures of UN peacekeepers into a definition of quality necessarily begs the question of where those incentives come from. Like individuals everywhere, the behaviour of peacekeepers may be motivated by multiple incentives at any one time, any one of which may tip the balance from action to inaction. Sorting through all of these potential influences would require a dissertation in itself, but a review of the relevant literature suggests that the two most important sources of peacekeeper incentives are their personal experiences during the operation and the policies of their home governments. 
In terms of personal experiences, a series of recent studies has shown that peacekeepers are commonly motivated by many of the same factors that appeal to military personnel anywhere. These factors include high levels of morale and unit cohesion (Maguen and Litz 2006), confidence in their military leadership (Galantino 2003), voluntary versus involuntary deployment (Juvan and Vuga 2011), and a desire for material gain, a sense of adventure or a chance to help others (Hedlund 2011). In addition, a number of other studies identify aspects of peacekeeper motivation that are more unique to a UN context. These aspects include a self-image that is suited to the humanitarian nature of peacekeeping (Franke 2003; Hedlund and Soeters 2010; Kold 2013; Sion 2006), levels of public and institutional support for the practice of peacekeeping (Franke 2003; Maguen and Litza 2006; Galantino 2003; Britt 2003), and a personal belief in the ethical or political objectives of the relevant operation (Britt 2003; Franke 2003; Troy 2017). All things equal, these studies suggest that peacekeepers will perform their duties more enthusiastically when they are invested in the success of an operation and feel supported while they are in the field. As a result, it is likely that peacekeepers who do not share these views will be less motivated to intervene in situations involving on-going violence than peacekeepers who do.

The other major source of peacekeeper incentives is linked to the policy objectives of their home governments. Unlike in the context of national military operations, where government policy is the only factor that matters, one of the unique aspects of operating in a multinational environment is that there may be competing priorities at work. Some troop contributing countries (TCCs) may have policy objectives that are wholly aligned with the UN's own priorities, which would be the ideal scenario, whereas other TCCs may only be 
interested in pursuing a handful of the UN's priorities or potentially even acting solely in their own self-interest. ${ }^{13}$

In theory, these kinds of policy differences should not manifest in the field because all peacekeeping personnel are placed under the command of a single UN Force Commander. In practice, however, TCCs often "deal directly with their contingents on the ground" and are capable of influencing their decision-making processes in a way that "sometimes confounds the force commander who is attempting to employ them within his plan" (Nadin et al 2014, 95). They also have the ability to shape behaviour through other means, such as the imposition of national caveats or the provision of incentives for "correct" behaviour (Auerswald and Saideman 2014), all of which could serve to encourage or discourage action in certain circumstances.

For example, there is a long-standing debate within the peacekeeping community regarding whether it is appropriate to pursue the UN's civilian protection agenda through the use of force (Tardy 2011). Some countries believe that the use of force, even in support of operational objectives, is a direct challenge to the fundamental nature of peacekeeping, while others believe that robust steps should be taken if civilian lives are at risk. Given the nature of this division, it is possible that peacekeepers from one country might be more willing to intervene in violent situations than peacekeepers from another country, based on nothing more than the stated policy preferences of their home government. Any attempt to

\footnotetext{
${ }^{13}$ A non-UN example of TCCs acting exclusively in their own interests is provided by the behaviour of Ethiopian and Kenyan peacekeepers in the context of the African Union Mission in Somalia (AMISOM). In this case, the combination of a weak central command and partisan personnel from selfinterested TCCs led to a fragmentation of effort at the operational-level, which led to the pursuit of policies that were completely contradictory to overall operational objectives. See Albrecht (2015) and Albrecht and Haenlein (2016).
} 
develop a definition of peacekeeper quality must therefore be able to take these policy preferences into account, particularly when dealing with a topic that is as controversial as the management of on-going violence.

In short, I propose a definition of peacekeeper quality that relies on two core characteristics: professional capabilities and a willingness to act. More specifically, I define a 'quality peacekeeper' as a peacekeeper that possesses a high degree of professional capabilities and a high willingness to act when faced with violence. Distilling everything down into these two characteristics obviously requires a degree of abstraction but attempting to account for everything at once would be far too unwieldly for the kind of analysis conducted in this dissertation.

\subsection{How does quality work?}

The next step in this process is to determine precisely how peacekeepers influence the production of violence. Conflict actors possess a variety of different incentives to use violence, whether it be used in the pursuit of strategic goals or to ensure organizational survival, which peacekeepers must be capable of overcoming if they wish to be effective in the field. To understand how this process occurs, this section draws upon the theory of coercion to develop a causal model of peacekeeping at the local-level. This model is developed in three steps, with additional information added at each step. In the first step, the model ignores quality entirely and focuses instead on the causal mechanisms that allow peacekeepers to interact with violence: deterrence and compellence. In the second step, I introduce the concept of quality into the model and explain how it affects the performance of peacekeepers by making their attempts at coercion more or less credible. In the third 
step, I complete the model by developing a series of testable hypotheses and listing the conditions under which even the most credible attempts at coercion might fail.

\subsubsection{How do peacekeepers interact with violence?}

Up until this point, I have been operating under the assumption that the relative effectiveness of UN peacekeepers depends solely on their own characteristics. Groups of peacekeepers that possess relatively large amounts of personnel, or that have personnel with superior capabilities or willingness to act, should therefore be more effective at managing violence than groups without such traits. Although this assumption has been useful from an analytical standpoint, it is fundamentally flawed for one key reason: it ignores the role played by local conflict actors. Their reasons for using, or not using, violence are just as important to the overall level of fatalities in an area as the actions of UN peacekeepers, who are only a single actor within an otherwise complex environment. The fact that peacekeepers are under the control of the international community still makes them worthy of study, particularly since they are one of the few levers that policy makers can manipulate directly in such situations, but their primary role in a conflict environment is to influence the behaviour of other actors rather than to control them entirely. Any attempt to understand why some peacekeepers are more effective than others must therefore recognize that the management of violence depends on a process of strategic bargaining with local conflict actors, rather than solely on the behaviour of peacekeepers themselves.

The perfect lens through which to view this relationship is the theory of coercion. According to Thomas Schelling, coercion is defined as using the "power to hurt" to 
influence the behaviour of a rival actor $(1966,3)$. This process can either be explicit, in the form of public statements or military strikes, or implicit, via troop deployments or aggressive posturing. The key element is that threats of future harm, or continued damage, be used by one party against another in an attempt to elicit compliance. In this sense, coercion differs from the use of brute force, which would remove all choice from the equation through sheer force of arms (1966, 2-6). However, the fact that coercion relies on interaction between independent actors means that it may not be possible in every situation. At the very least, the targeted actor must be willing to entertain the thought of altering their behaviour in response to a threat issued by the other side. If their sole objective is to frustrate or harm their foe, then it is unlikely that any form of agreement will be possible $(1966,4)$. In essence, then, coercion is about "finding a bargain" in which the targeted actor is "better off doing what we want - worse off not doing what we want - when he takes the threatened penalty into account" $(1966,4)$. Since peacekeepers are typically constrained from taking actions that would eliminate their opponents entirely, it is their ability to bargain, rather than to dominate, that allows them to manage violence effectively.

Although all acts of coercion rely on the power to hurt, it is possible for peacekeepers to exercise that power in one of two ways. First, peacekeepers are capable of deterring undesirable behaviour in the present by threatening to inflict harm against potential transgressors in the future. In fact, it is this "skillful nonuse of military forces" that has traditionally constituted the bulk of UN activity in this area (Schelling 1960, 9). Any time that a conflict actor decides not to attack one of its rivals or to prey on a group of civilians due to the presence of nearby peacekeepers is an example of deterrence. These decisions can either be due to the perceived strength of the peacekeepers in question, with 
any attack against them or the area under their protection unlikely to succeed, or they can be due to a reluctance on the part of the attacking party to incur the costs that would be required to succeed.

Second, peacekeepers are capable of compelling an actor to change their behaviour in the present by threatening to harm them in the future unless they comply. For example, if a conflict actor had raided and occupied a civilian community, peacekeepers could threaten to retaliate against one of the attacker's bases in an attempt to compel them to withdraw. The limited use of force could also be an asset in this kind of situation, such as firing a few shells in the vicinity of the threatened location, albeit not to the extent that it would remove all agency from the other side. It is also important to note that peacekeepers have the option of pairing their coercive threats with promises of positive inducements, such as material aid or political recognition. The use of such inducements can "encourage cooperation" from conflict actors by either increasing the value of concessions or decreasing the costs of capitulation (Byman and Waxman 2002, 9-10), which can make a positive outcome more likely than relying on the threat of harm alone. In sum, peacekeepers are capable of influencing the behaviour of local conflict actors through the use of either deterrence or compellence, both of which operate via the delivery of threats and assurances.

As shown in Figure 1, the causal model of peacekeeping is relatively straightforward when it is viewed through the lens of coercion. Once peacekeepers have been deployed to an area, they are then free to influence the behaviour of local conflict actors via threats and assurances. If those threats and assurances are used in an attempt to change future behaviour then they will be operating according to deterrence, whereas if 


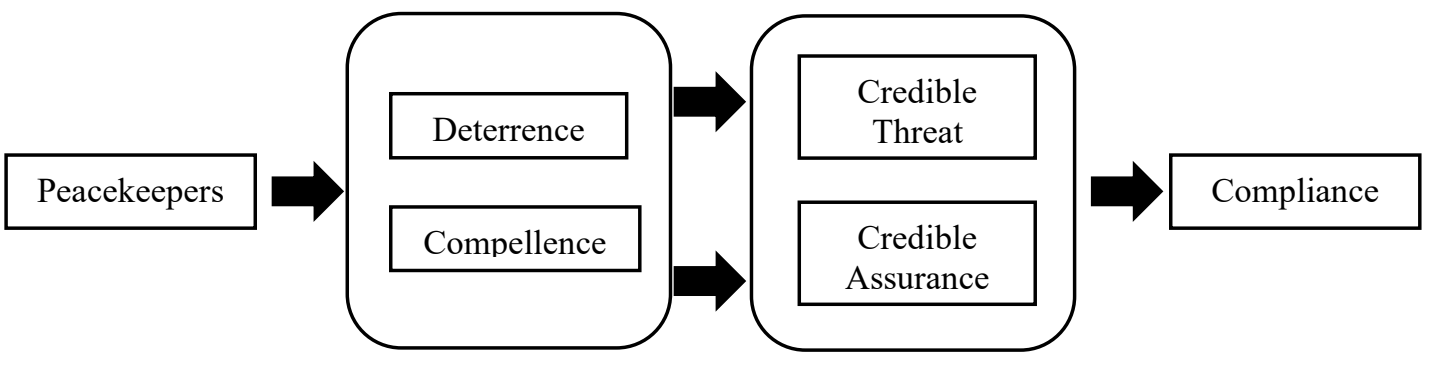

they are used in an attempt to change current behaviour than they will be operating according to compellence. These two options will typically be available to all peacekeeping personnel, regardless of their relative quantity or quality. However, the fact that they exist does not mean that they will always be successful. It all depends on how the targeted actor chooses to react. If the peacekeepers' threats and assurances are perceived as being credible, then they are likely to comply. But if they are not viewed as being credible, then they are likely to be ignored. The reason that credibility plays such an important role in this process is that coercion is largely a perceptual phenomenon. Unlike the use of brute force, in which the strength of one party is openly pitted against that of another, the success or failure of coercion depends entirely on whether the other party perceives compliance to be a better option than non-compliance. Objective measurements of strength certainly play a role in the establishment of such perceptions but only to the extent that they help to bolster, or undermine, the credibility of the stated threat or assurance. In order for coercion to be 
successful, therefore, peacekeepers must be capable of influencing local conflict actors in a manner that is perceived as being credible by the other side.

\subsubsection{What role does quality play in this process?}

The need to ensure that threats and assurances are perceived as being credible by the targeted party is where personnel quality enters the model. As noted above, all peacekeepers are capable of acting in a coercive manner but that does not mean that their attempts to influence local conflict actors will always be successful. It is only when their threats and assurances are perceived as being credible by the other side that they are likely to generate compliance. In order to influence these perceptions, peacekeepers must be capable of manipulating the three constituent elements of credibility, namely the certainty, severity and swiftness of the proposed action. ${ }^{14}$ If a punishment or inducement is perceived as meeting all three of these criteria, then the cost-benefit calculation of the targeted actor should result in compliance. Otherwise, it will not. My argument is that peacekeepers who possess a greater range of capabilities, or a higher willingness to act, should have an easier time manipulating these three factors than their less capable or enthusiastic counterparts. Their ability to coerce conflict actors in a credible manner should then be higher as a result, which would make them more effective at managing violence than their peers.

In order to understand why higher quality peacekeepers are likely to be perceived as being more credible than lower quality peacekeepers, it is useful to examine the three constituent elements of credibility in more depth. First, peacekeepers are capable of

\footnotetext{
${ }^{14}$ Although the origins of this theory are found in an enlightenment era essay by Cesare Bonesana di Beccaria (1764), it has come to play a central role in contemporary literature on criminal deterrence.
} 
manipulating the credibility of their threats and assurances by altering the certainty with which they will occur. A punishment or inducement that is believed to have only a ten percent chance of occurring will be far less credible than a punishment or inducement that has a one hundred percent chance of occurring, provided that their relative swiftness and severity are held equal. For example, if a conflict actor were interested in raiding a nearby village, then they would first need to determine the likelihood of being punished in response. Any signs of laziness or ill-discipline on the part of nearby peacekeepers would increase the likelihood of getting away unscathed, thereby decreasing the strength of the deterrent threat. Whereas any evidence of a rapid response capability or early warning system would decrease the likelihood of getting away unscathed, thereby increasing the strength of the deterrent threat. Peacekeepers can take advantage of this thought process by either taking steps to increase their threat profile, such as by tightening up their defenses, or by encouraging conflict actors not to attack through the offer of an appropriate inducement. Either option would have the potential to make the proposed attack less attractive, with the former making it less likely that the attackers would avoid damage and the latter decreasing the potential benefits that they would expect to obtain from a successful raid.

Second, peacekeepers are capable of manipulating the severity of their threats and assurances by altering the associated costs and benefits. All things equal, a punishment that is perceived as having a higher cost will be more credible than a punishment that is perceived as having a lower cost, with the perceived generosity of any associated inducements operating according to the same logic. Peacekeepers can manipulate this logic 
in one of two ways. The first option involves the process of target selection. ${ }^{15}$ For example, if peacekeepers were interested in using compellence to halt on-going violence, the threat of military strikes against a strategic target would typically be more credible than the threat of international condemnation. Both punishments would have the potential to harm the actor in question but the former would be more likely to cause a higher amount of damage than the latter, unless the target valued their international reputation more highly for some reason. ${ }^{16}$ The second option involves adjusting the magnitude of the potential punishment. Peacekeepers could either increase the damage associated with their threat, such as by threatening to attack two locations rather than one, or they could decrease the benefits of non-compliance by offering the targeted actor with a positive inducement or a means of 'saving face' (Byman and Waxman 2002, 9). Either option would affect the cost-benefit calculation of the targeted actor, with the threat of greater harm making it harder to refuse and the promise of compensatory benefits making it easier to comply.

Third, peacekeepers are capable of manipulating the swiftness of their threats and assurances by altering the timeframe within which they will be carried out. All things equal, a punishment or inducement that is believed to be imminent will be more credible than a

${ }^{15}$ According to Daniel Byman and Matthew Waxman (2002), a coercive threat will be most effective if it is targeted at an appropriate "pressure point" (44-46). In order to qualify as a pressure point, a target must meet two criteria: susceptibility and vulnerability. The former refers to a target that the conflict actor would be willing to view as a potential loss, whereas the latter refers to a situation in which it is possible to exploit that susceptibility in practice. For example, the leaders of a hierarchical organization are likely to be more susceptible to threats of targeted decapitation strikes than the members of a decentralized organization without clear leadership. However, if they have taken measures to guard against such strikes, perhaps by constructing multiple bases or employing body doubles, then they may not be vulnerable to them in practice.

${ }^{16}$ One reason that this situation could arise is if the conflict actor in question is heavily reliant on military or economic support provided by a foreign patron. Anything that threatened the durability of that relationship, such as international condemnation related to on-going atrocities, would therefore be far more harmful to the actor's interests than the loss of a fraction of their military assets. Other potential explanations include a desire to secure international support for secessionist movements or an attempt to minimize international support for domestic pressure groups. See Jo (2015) and Jo and Simmons (2016). 
punishment or inducement that is believed to be distant. For example, if a conflict actor is threatened with punishment today versus punishment one month in the future, they are far more likely to alter their behaviour in response to the immediate threat. The distant threat could be equally certain and severe, or potentially even more so, but it would not matter as much when ranked against more urgent priorities. The speed with which a threat is delivered is particularly important in a civil war context because the time-horizons of conflict actors typically shrink when they are struggling for survival. As a result, most conflict actors tend to discount the costs of future threats even more heavily than normal, which increases the importance of more immediate forms of punishment. Similarly, the potential benefits derived from an immediate inducement may be far more important than those provided by a more generous inducement several months down the road, particularly if the targeted actor requires something like additional food supplies in order to survive. As a result, any group of peacekeepers that lacks the ability to act quickly enough, whether due to insufficient capabilities or an unwillingness to take action, will have a difficult time delivering credible threats or assurances.

The fact that threats or assurances will not be effective unless they are perceived as being credible by the targeted party provides a clear boost to the coercive potential of any peacekeepers that possess a qualitative advantage over their peers. This advantage should operate regardless of the specific form of coercion that has been chosen, as depicted in Figure 2. If peacekeepers are highly trained, well-equipped and willing to act when faced with violence, then they should be more effective at increasing the certainty, severity and celerity of their threats and assurances. If not, then they are likely to be at a disadvantage when it comes to ensuring the credibility of their actions, thereby decreasing their ability 
to manage violence. Of course, not all situations can be solved through the use of coercion, nor is personnel quality the only factor that matters when it comes to determining credibility. But it appears reasonable to suggest that any variation in the quality of UN personnel may help to explain why some peacekeepers are more effective at managing violence than others.

Figure 2 - Causal model of peacekeeping, plus peacekeeper quality

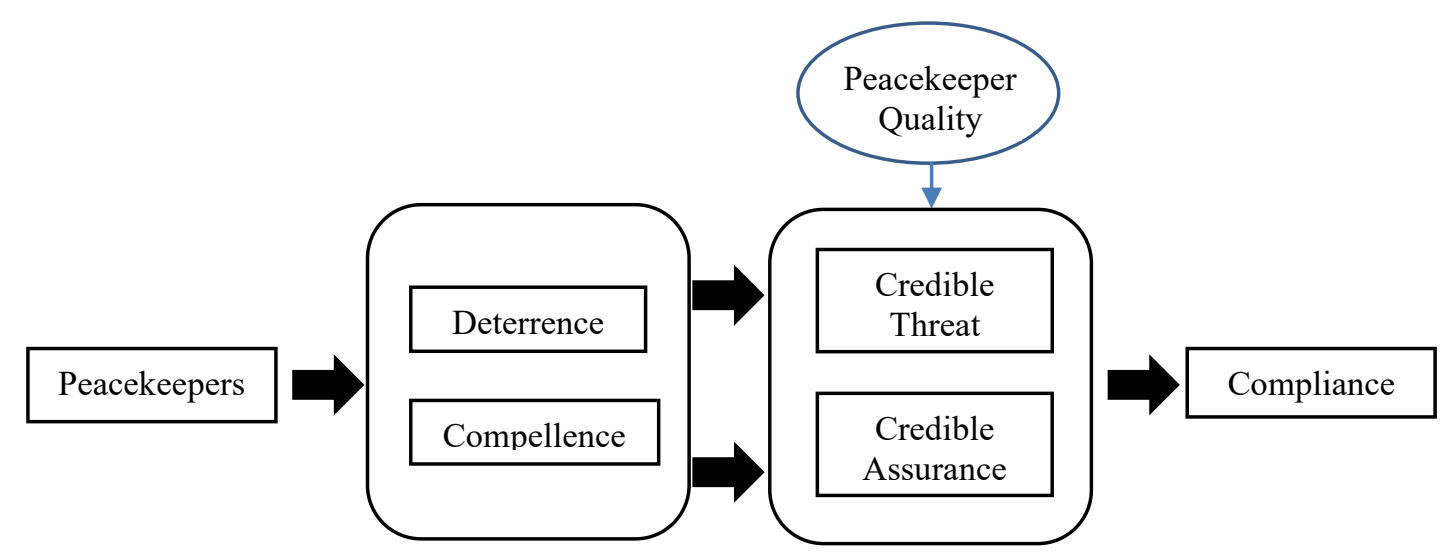

\subsubsection{Possible confounding conditions}

Of course, even the most capable and enthusiastic peacekeepers may prove to be ineffective unless conflict actors are willing to strike a bargain. This situation may arise for one of three reasons, as noted in Figure 3. First, conflict actors may choose to ignore the coercive threats delivered by peacekeepers if they possess a clear advantage with regard to the use of brute force. If any threat can be eliminated by simply overpowering nearby peacekeeping personnel, then the incentive to bargain with them at all would be diminished. It would also encourage peacekeepers to restrict their activities to more passive tasks, such as monitoring and reporting, or else risk facing retaliation from a militarily 
superior force. Therefore, any situation in which peacekeepers can be overcome through the use of brute force is likely to lower the effectiveness of even the best personnel.

Second, conflict actors may be able to immunize themselves from the threat of punishment by asserting "escalation dominance" over nearby groups of peacekeepers (Byman and Waxman 2002, 38-44). Rather than resorting to the use of brute force, this scenario would involve the reciprocal use of coercion by the target of a coercive threat. For example, peacekeepers regularly use the threat of punishment in order to protect civilians from harm, whether through deterrence or compellence. But, despite these threats, even the best peacekeepers are unable to protect all of the people all of the time. Most countries are simply too large, or too populous, for this to be an achievable outcome. As a result, it opens up an avenue for conflict actors to assert reciprocal coercive pressure against peacekeepers, such as by threatening to increase their attacks against vulnerable civilians. Rather than merely raiding nearby villages for loot and supplies, these groups could shift their focus to the wholesale massacre of civilians instead. Nearby peacekeepers would then be forced to either increase the credibility of their own threats, which might or might not halt the attacks, or to withdraw them entirely. At the same time, the targeted actor could also take steps to insulate themselves from the threat of future pressure, such as by dispersing their forces or holding hostages near strategic locations. Peacekeepers would then be denied even the option of engaging in counter-escalation, which would make them far less effective at managing on-going violence.

Finally, conflict actors may consider the coercive acts undertaken by peacekeepers to be irrelevant if they possess "overriding interests" to persist in their violent behaviour (Cronin-Furman 2013). In this case, the issue could be that the target derives so much utility 
from their use of violence that no possible threat or inducement would be sufficient to dissuade them from its use. As discussed in Chapter 2, the vast majority of violent acts during wartime follow some sort of instrumental logic. The use of battlefield violence is typically intended to secure a concrete military or political objective, such as a desire to stave off defeat at the hands of a militarily superior rival. Whereas the use of violence against civilians is commonly motivated by strategic considerations or a desire to preserve organizational cohesion, such as the tacit acceptance of atrocities in order to avoid the potential defection of troops interested in loot and murder. Thus, if the continued use of violence is the only way for a conflict actor to ensure its survival, then any threats or assurances delivered by nearby peacekeepers are likely to be undermined by the existence of this overriding interest.

Figure 3 - Causal model of peacekeeping, plus peacekeeper quality and confounding conditions

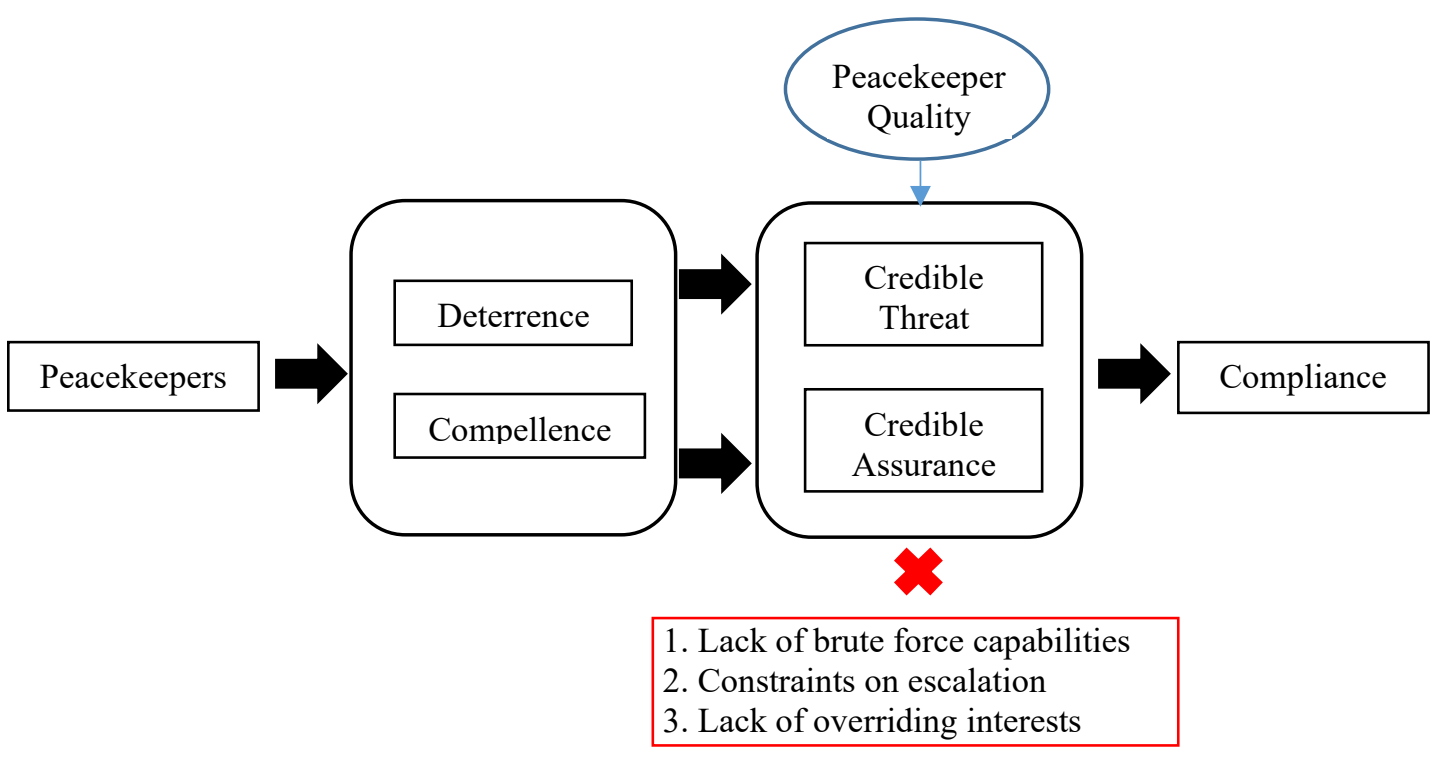




\subsection{Hypotheses}

At the most basic level, the argument presented in this dissertation is that quality matters. Its importance is due to the fact that peacekeepers primarily rely on the use of coercion to manage on-going violence, which means that they must be capable of delivering credible threats and assurances to local conflict actors. Since the credibility of a coercive act relies on the certainty, severity and swiftness of the associated threat or inducement, anything that provides peacekeepers with an advantage in those areas should improve their ability to manage on-going violence.

Current models of operational effectiveness primarily point to the benefits of deploying a larger quantity of personnel in this context, which is a reasonable position to take. Deploying more peacekeepers means more bases, more patrols and more guns, all of which can be leveraged to improve the credibility of a coercive act. However, there is a strong case to be made regarding the importance of peacekeeper quality as well. Deploying higher quality peacekeepers means better equipment, better training and a better chance that operational objectives will be pursued in a proactive manner, all of which should have similarly beneficial effects when it comes to the use of coercion. Therefore, it is important to account for both quantity and quality when it comes to evaluating the relationship between peacekeepers and violence, regardless of whether it turns out that one factor matters more than the other.

Hypothesis 1: The higher the quantity of peacekeeping personnel deployed to an operation, the lower the level of violence.

Hypothesis 2: The higher the quality of peacekeeping personnel deployed to an operation, the lower the level of violence. 
Having said that, the difficulty with evaluating the relationship between peacekeeper quality and violence is that 'quality' does not consist of a single characteristic. Some peacekeepers may be highly capable but poorly motivated, other peacekeepers may be less capable but highly motivated, and still others may either excel or be inferior in both categories. Any attempt to evaluate the role played by personnel quality must therefore be able to account for the variation that may exist in these two characteristics.

\begin{tabular}{|c|c|c|c|}
\hline & \multicolumn{2}{|c|}{ Peacekeeper Willingness } \\
\hline & & High & Low \\
\hline 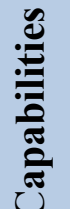 & $\stackrel{\overrightarrow{b 0}}{\overrightarrow{0}}$ & $\begin{array}{c}\text { High } \\
\text { Effectiveness }\end{array}$ & $\begin{array}{c}\text { Moderate } \\
\text { Effectiveness }\end{array}$ \\
\hline 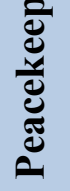 & 3 & $\begin{array}{c}\text { Moderate } \\
\text { Effectiveness }\end{array}$ & $\begin{array}{c}\text { Low } \\
\text { Effectiveness }\end{array}$ \\
\hline
\end{tabular}

As shown in Table 1, one way to achieve this objective is to insert both aspects of quality into a 2x2 matrix. Peacekeeper capabilities can then be listed along the y-axis and peacekeeper willingness along the $\mathrm{x}$-axis, with both characteristics divided between high and low. When both factors are high, peacekeepers should be highly effective at managing violence. They may not be able to eliminate fatalities entirely, as no regime is perfect, but a significant departure from the status quo would be expected. When at least one factor is high, peacekeepers should be moderately effective at managing violence. They may occasionally fail to perform their duties effectively but not to the extent that they would have no effect on violence at all. When both factors are low, however, peacekeepers should only be minimally effective. Anything beyond the preservation of their own lives would 
be called into doubt, with even that not guaranteed if faced with a determined foe. Given the wide variation in expected outcomes, anything that can isolate the interplay between these two characteristics should provide additional insight into the relationship between peacekeeper quality and violence.

Hypothesis 3: When peacekeepers possess high capabilities and a high willingness to act, then they should be highly effective at managing violence.

Hypothesis 4: When peacekeepers possess high capabilities and a low willingness to act, then they should be moderately effective at managing violence.

Hypothesis 5: When peacekeepers possess low capabilities and a high willingness to act, then they should be moderately effective at managing violence.

Hypothesis 6: When peacekeepers possess low capabilities and a low willingness to act, then they should be ineffective at managing violence.

In sum, the ability of peacekeepers to manage on-going violence is based on a combination of deterrence and compellence. These tools both operate according to the logic of coercion, which rely on perceptions of credibility in order to be effective. The importance of peacekeeper quality to this process is that it allows UN personnel to enhance the credibility of their coercive threats and assurances. Peacekeepers with high capabilities and a high willingness to act should be capable of delivering threats and assurances that are more certain, severe and swift than their peers, which should then make them more effective at managing on-going violence. However, even the most credible threats or assurances may fail unless the targeted actor has an incentive to comply. In cases where a conflict actor possesses an advantage in terms of brute force, is capable of establishing escalation-dominance or is driven by the survival-based imperatives of overriding interests, then any threats or assurances delivered by peacekeeping personnel are likely to be ineffective. Nonetheless, the coercive model developed in this section suggests that higher 
quality peacekeeper should be more effective at managing violence than lower quality peacekeepers, particularly if they excel in terms of both capabilities and willingness.

\subsection{Conclusion}

The theoretical model developed in this chapter has the potential to bring us one step closer to understanding why some peacekeepers are more effective at managing violence than others. Its main innovation compared to previous models of operational effectiveness is its ability to account for variation in the quality of UN peacekeepers. Earlier models were not wrong to consider other elements of effectiveness, such as the location, profession or quantity of deployed personnel, but the fact that not all peacekeepers are the same suggests that peacekeeper quality should be included as well. Some peacekeepers possess greater capabilities than others, whereas others are more willing to act when faced with violence. As a result, it seems reasonable to account for these kinds of characteristics when seeking to understand the relationship between peacekeepers and violence. In addition to the common sense appeal of this argument, the reliance of peacekeepers on the use of coercion makes the potential impact of peacekeeper quality even greater. Anything that can increase the certainty, severity or swiftness of a coercive threat or assurance should make peacekeepers more effective at managing on-going violence, which includes the relative capabilities and willingness of deployed personnel. However, due to the limited nature of study on this topic, there is currently a lack of consensus regarding the extent to which peacekeeper quality contributes to operational effectiveness or even whether it matters at all. In the following chapter, I begin to develop answers to these questions by 
evaluating the relationship between average operational quality and the severity of ongoing violence. 


\section{Chapter 4: State-level analysis}

In the previous chapter, I developed a theoretical model that identified how and why variation in the relative quality of UN peacekeepers is a core component of operational effectiveness. This model drew heavily on the theory of coercion, in which the power to hurt can be used to alter the behaviour of a targeted actor via the delivery of threats and assurances. Since the success or failure of such coercive messages depends on whether they are perceived as being credible by the targeted party, I argued that higher quality peacekeepers should be more effective at managing on-going violence than their lower quality counterparts. I attributed this divergence in effectiveness to the advantages that higher quality peacekeepers possess in terms of their military capabilities and willingness to act, which would allow them to manipulate the certainty, severity and swiftness of their coercive messages with a greater degree of precision. As a result, I hypothesized that peacekeepers with high capabilities and a high willingness to act should be more effective at managing violence than peacekeepers with low capabilities and a low willingness to act.

In this chapter, I take the first step towards testing this hypothesis by evaluating the role played by personnel quality at the state-level. More specifically, this chapter tests the relationship between operational quality and violence using a sample of all civil wars in sub-Saharan Africa from 1991-2017. It is organized into five sections. In the first section, I develop an argument for conducting such a test by explaining how and why the average quality of UN peacekeeping personnel varies from one operation to the next. In the second section, I describe the variables and data used in this chapter's econometric models. In the third section, I elaborate on the research design used to develop these models, including its relative strengths and weaknesses. In the fourth section, I present the results of four 
negative binomial regression models, two of which focus on battlefield violence and two of which focus on one-sided violence against civilians. I also present the details of seven sensitivity tests that were used to assess the robustness of these results. In the fifth section, I discuss the outcome of these models in additional depth and highlight the implications that they pose for the hypotheses developed in Chapter 3. I then conclude the chapter by noting that the results of these models should be treated with a degree of skepticism until they have been corroborated by the more fine-grained analysis contained in the remainder of this dissertation.

\subsection{Theory and Argument}

The management of violence is no easy task. It relies as much on the willingness of the "peacekept" to be managed as it does on the relative characteristics of UN peacekeeping operations, not to mention the need for continued political and financial support from members of the international community. ${ }^{17}$ Nonetheless, it is worth evaluating the contribution made by one small component of this process, namely the relative quality of UN peacekeeping personnel. As shown in Chapter 3, the quality of deployed personnel can vary in terms of two different characteristics: professional capabilities and willingness to act. Although the consequences of this variation are primarily manifested at the local-level, any variation in the performance of individual groups of peacekeepers will necessarily affect outcomes at the operational-level as well. It follows that operations with a higher average quality of peacekeeping personnel should be

\footnotetext{
17 The term 'peacekept' is used by Virginia Paige Fortna to "refer to decision makers within the government and rebel organizations" with the crucial powers over "whether to maintain peace or return to war" $(2008,8)$.
} 
more effective at reducing levels of on-going violence than operations with a lower average quality of peacekeeping personnel. Thus, any attempt to evaluate the relative effectiveness of UN peacekeeping operations would benefit from a consideration of both the quantity and the quality of deployed personnel.

Although this argument seems reasonable in theory, I have yet to demonstrate why it matters in practice. After all, the UN could simply choose to distribute its peacekeepers in a manner that eliminates any qualitative variation at the operational-level. All of its operations would then be equally capable of handling the challenges posed by on-going violence, which would render any discussion of quality at the operational-level moot. However, there is plenty of anecdotal evidence to suggest that this is not the case. Some operations have, collectively, performed to a high standard, whereas others have not. ${ }^{18} \mathrm{~A}$ recent study has also demonstrated that the relative capabilities of peacekeepers matter when they are assessed at the operational-level (Haass and Ansorg 2018), which suggests that they are not evenly distributed across all operational contexts. Before I test the argument laid out above, therefore, it is worth taking a brief moment to explain why the average quality of UN peacekeeping personnel typically varies from one operation to the next.

The first thing to note about this phenomenon is that qualitative variation is an inevitable consequence of the UN's force generation process. ${ }^{19}$ Since the UN does not

${ }^{18}$ For example, the authors of the HIPPO report note that some operations "have been successful in saving civilian lives through decisive action" whereas others have "struggle[d] simply to protect and resupply themselves" (UN 2015, 38).

${ }^{19}$ The process of force generation consists of everything related to the generation, rotation and repatriation of the military personnel and equipment deployed as part of a UN peacekeeping operation. In the UN's case, this process can be divided into three sequential steps: the receipt of a political mandate by the UN Security Council (UNSC), operational planning by members of the DPKO/DFS, and the 
possess a standing military force of its own, the defining feature of this process is that it relies entirely on voluntary contributions from UN member-states. ${ }^{20}$ Any operation that lacks sufficient buy-in from potential troop contributing countries (TCCs) is therefore unlikely to be deployed. In one sense, the challenges posed by this arrangement are not insurmountable. From 2001-2010 alone, the UN was able to recruit a total of 589,000 troops from 74 countries to serve as part of 18 different peacekeeping operations, so it is clearly capable of acquiring personnel whenever necessary (Daniel 2013, 30-31). In another sense, however, the need to solicit voluntary personnel contributions from individual TCCs is extremely problematic. It restricts the UN's ability to deploy operations on short notice, increases its vulnerability to global shortages in key military capabilities, and makes it difficult to ensure that all of its personnel are trained to a common standard and free from the burden of national caveats. ${ }^{21}$ As a result, the UN is often forced to privilege quantity over quality when it comes to the process of force generation, which has led to significant differences in the relative quality of its field-based personnel.

The second thing to note is that the UN does not have absolute control over where its peacekeepers are deployed. In fact, the decision of whether or not to contribute military resources to an operation is typically made by TCCs on a case-by-case basis rather than to the UN system as a whole. ${ }^{22}$ The consequences of this arrangement are two-fold. First, the

recruitment and deployment of peacekeeping personnel. For a more detailed explanation of the steps involved in this process, see Nilsson and Wiklund (2014) and Stutt (2006).

${ }^{20}$ The original intent was for the UN to possess some form of standing military force of its own, as laid out in Article 47 of the UN Charter. However, the potential implications of creating such a force made it a political non-starter.

${ }^{21}$ For a detailed discussion of these issues, see Daniel (2013) and Smith and Boutellis (2013).

${ }^{22}$ The UN attempted to address this issue by developing a centralized pool of available military capabilities in the mid-1990s, referred to as the UN Standby Arrangements System (UNSAS). The intent was for interested TCCs to pledge whatever spare military capabilities they had available, rather than 
ability of TCCs to choose where their peacekeepers are deployed risks creating a situation in which the UN's operational requirements are oversubscribed in some cases but undersubscribed in others. Any operation that is oversubscribed in this manner would be more likely to possess a higher average quality of personnel, since the UN can afford to be more selective when potential contributions are plentiful rather than when they are scarce. Second, any attempt to even out such qualitative disparity by transferring troops from one operation to another would be subject to a veto by the relevant TCC. Since many countries contribute military resources in order to fulfil specific political, economic or securityrelated objectives, the ability to shift their personnel from one operation to the next is likely to be severely restricted. ${ }^{23}$ Therefore, the existence of qualitative variation at the local-level is likely to be reflected at the operational-level because the UN lacks the ability to distribute its personnel however it sees fit.

The third thing to note is that even if the UN wanted to ensure a uniform quality of personnel, such a goal would neither be achievable nor desirable. In terms of achievability, there is always a risk that the UN will be provided with personnel or equipment that looks appropriate on paper but fails to meet expectations in the field. Any deficiencies of this nature should ideally be captured prior to deployment, but the necessary assessments are often performed so late in the force generation process that "there is no turning back even

needing to be contacted individually in advance of new operations. However, the database has not lived up to these initial expectations and tends to be chronically out of date. See Smith and Boutellis (2013).

${ }^{23}$ According to Alex J. Bellamy and Paul D. Williams (2013), there are five general concerns that motivate TCCs to provide military personnel and resources to UN peacekeeping operations. These concerns include issues of a political, economic, security, institutional or normative nature, some of which are likely to be more amenable to the possibility of troop transfer than others. For example, if a country is primarily interested in being perceived as a good global citizen, then they are probably less likely to object to having their personnel serve in a different operation than a country who is interested in currying favour with a specific government. 
if the [assessment] team finds a TCC unprepared to deploy or unable to perform well once deployed" (Smith and Boutellis 2013, 13). There is also little built-in incentive for peacekeepers to perform their duties effectively in the field, with the preference being to "sidelin[e] contingents known to be underequipped or underperforming" rather than to send them home (Smith and Boutellis 2013, 13). In terms of desirability, the goal of securing a uniform level of operational quality is also not necessarily the most efficient approach to take. If the mandate assigned to one operation is significantly more complicated or dangerous than the mandate assigned to another, then it would be reasonable to distribute personnel in whatever manner would allow them to have the greatest impact. Some level of variation in the average quality of UN peacekeeping operations is therefore likely to be desirable, although only to the extent that it is due to an efficient allocation of resources rather than due to unexpected deficiencies on the part of deployed personnel.

In sum, the average quality of peacekeeping personnel typically varies from one operation to the next due to the nature of the UN's force generation system. The features of this system include a complete dependence on voluntary contributions, a lack of absolute control over deployment decisions and an imperfect process of quality control, all of which make a certain level of qualitative variation inevitable at the operational-level. However, it is not yet clear whether operational quality actually matters when it comes to the management of violence, which is the question that I explore in the remainder of this chapter. 


\subsection{Variables and Data}

This section identifies the variables and data used to assess whether operations with a higher average quality of peacekeeping personnel are more effective at reducing violence than operations with a lower average quality of peacekeeping personnel. It begins by describing the two dependent variables used in this chapter and then proceeds to list the independent and control variables.

\subsubsection{Dependent Variable}

The dependent variable used in this chapter is civil war violence. More specifically, I seek to assess the relationship between peacekeeping operations and two different types of violence: battlefield violence and one-sided violence against civilians. The first type of violence, battlefield violence, is defined by the Uppsala Conflict Data Program (UCDP) as direct deaths suffered by an organized actor during an incident in which armed force is used by at least one organized actor against another (Mihai and Sundberg 2018). ${ }^{24}$ This definition includes a broad range of potential combatants, including the governments of independent states, formally organized non-state actors, and informally organized nonstate actors. The key factor is that each group be armed, relatively cohesive, and engaged in some form of violent clash with another organized group. The second type of violence, one-sided violence, refers to any fatalities suffered by unarmed civilians as the result of a direct and deliberate attack by at least one organized actor (Mihai and Sundberg 2018). The narrow scope of this definition excludes many other potential sources of civilian fatalities,

\footnotetext{
${ }^{24}$ Also included in this total are civilian deaths caused as collateral damage during fighting between armed actors, as aggregated together in the "best estimate" category for state and non-state based events in UCDP's Georeferenced Event Dataset.
} 
such as deaths resulting from collateral damage or the collapse of critical infrastructure, so it does not reflect the full extent of civilian suffering during wartime. However, the causal mechanisms that lead to intentional civilian fatalities differ from those that lead to unintentional civilian fatalities, so distinguishing between these different types of violence serves a useful analytical purpose. ${ }^{25}$

The primary source of data for both of these indicators is version 18.1 of UCDP's Geo-Referenced Event Dataset (UCDP GED). This dataset includes geo-coded event data that covers every country in the world from 1989-2017, with the exception of Syria. Each entry in this dataset includes information regarding the precise date and location of the relevant event, as well as the identities of all associated conflict actors and the number of resulting fatalities. Most of the information included in this dataset was collected by mining various news media publications (Sundberg and Melander 2013), but it also includes supplemental data from sources like NGO reports, historical archives and case studies. In cases where information was unclear or incomplete, the UCDP GED provides a range of estimates and precision indicators in order to preserve its overall accuracy. ${ }^{26}$ Nonetheless, it is important to note that relying primarily on media-based data does risk introducing several biases into the resulting dataset. These include various selection biases, such as

\footnotetext{
${ }^{25}$ The advantage of focusing solely on intentional civilian fatalities in this context is that the deliberate nature of such killings provides a more accurate means of gauging the effectiveness of any coercive interaction between peacekeepers and conflict actors. If the number of unintentional civilian fatalities were included in this indicator as well, then it would be impossible to distinguish between cases where violence persisted because coercion had failed versus cases in which armed groups were actively trying to minimize civilian casualties but ended up causing them anyway. Having said that, there is also value in evaluating the performance of peacekeepers according to a broader definition of violence, particularly if interested in judging the overall effect of their various diplomatic, humanitarian and military initiatives on the operational environment as a whole.

${ }^{26}$ The models in this chapter make use of the "best" estimate category for each type of violence, as opposed to the "high" or "low" categories.
} 
proximity bias and significance bias, and description biases, such as intensity bias and omission bias (Otto 2013; Weidmann 2014). ${ }^{27}$ Despite the existence of these issues, the data collected by UCDP remain the best available to the scholarly community and should provide a reasonably accurate representation of the underlying conflict dynamics associated with each peacekeeping operation.

\subsubsection{Independent Variables}

The primary independent variable used in this chapter is the relative quality of UN peacekeeping operations. Since the term 'quality' is composed of multiple characteristics, I have attempted to capture its various nuances by splitting it into two separate indicators: professional capability and willingness to act. Both indicators were constructed by using TCC-specific data to calculate weighted averages for each peacekeeping operation, the details of which are included below.

The first indicator of operational quality, capability, represents the average professional capability of deployed personnel. This indicator captures whether the peacekeepers deployed to an operation are well-trained or equipped on average, with more capable personnel presumed to be more effective at managing violence than their peers. At the state-level, this indicator also serves as a useful proxy for the number of specialized assets possessed by each operation (Haass and Ansorg 2018), such as transport helicopters

\footnotetext{
${ }^{27}$ As a result of these biases, the data included in UCDP's GED tends to overemphasize attacks that took place in close proximity to major urban areas (i.e., in proximity to reporters) as well as attacks that targeted particularly important individuals or that resulted in unusually large fatality counts. Similarly, it tends to underestimate the total number of attacks and fatalities that took place throughout the conflict as a whole, particularly if those attacks took place far from areas frequented by interested observers. These data are also unsuitable to exploring patterns of non-lethal violence, such as sexual violence or systematic exploitation, which is one of the main reasons that this chapter focuses solely on fatalities.
} 
or intelligence operators. In order to calculate the value of this indicator, I first collected data on annual military expenditure by country from SIPRI's Military Expenditure Dataset (2018) and data on the number of active armed forces per country from annual publications of The Military Balance by IISS. ${ }^{28}$ I then produced an estimate of annual military spending per active soldier for each country by dividing the expenditure data by the personnel data, which is a common proxy of a country's overall military potential. ${ }^{29}$ Countries with higher levels of per capita spending are more likely to possess fully professional militaries with access to a broad range of technologically sophisticated equipment, whereas countries with lower per capita spending are more likely to rely on a conscript military with sub-standard training and equipment (Daniel 2013, 36). Once these figures had been calculated, I used the values for each TCC to construct a monthly weighted average of per capita military spending for individual peacekeeping operations. ${ }^{30}$ If an operation had a large number of poorly trained troops and a small number of highly trained troops, the operational average would therefore be closer to the lower range of the spectrum.

${ }^{28}$ Although the data from SIPRI were available in an easily accessible dataset, the IISS data on military personnel had to be hand-coded by the author. This process was conducted by downloading the summary chapters from each annual edition of The Military Balance from 1991-2017 and then typing the relevant personnel data into a dedicated spreadsheet. Since the figures reported for the 'estimated reservists' and 'active paramilitary' categories varied significantly from one year to the next, presumably due to changes in the manner of classification or coding, I focused solely on the more consistent 'active armed forces' category. In addition, the editions published in 1993 and 2005 lacked summary tables for some reason so I coded those values from the individual country entries instead.

${ }^{29}$ Due to gaps in the data provided by SIPRI and IISS, a small number of observations had to be imputed based on the available data (i.e., values for 211 of the 4814 annual observations were imputed, of which only 57 involved a year in which the country actually contributed peacekeeping personnel). This process was conducted by taking the average of the preceding and following observations and then entering the new figure into the relevant cell, which made it possible to estimate a more accurate weighted average for each operation than would have been possible otherwise.

${ }^{30}$ The ability to use annual data to construct a monthly indicator of operational capability was made possible due to the fact that the national composition of peacekeeping operations tends to change on a fairly regular basis. As troops from one country depart and troops from another country arrive, the resulting monthly average therefore changes as a result. 
The second indicator of operational quality, willingness, represents the average likelihood that peacekeepers will act when faced with on-going violence. This indicator captures whether the peacekeepers deployed to an operation come from countries that respect the physical integrity rights of their citizens, with higher levels of respect for such rights expected to be associated with increased operational effectiveness. ${ }^{31}$ In order to construct this indicator, I relied on data from the "Physical Integrity Rights Index" developed by the Cingranelli-Richards (CIRI) Human Rights Data Project (Cingranelli and Richards 2010). This additive index is based on country-level performance in four key areas: torture, extrajudicial killings, political imprisonment and disappearances. Each country in this index first receives a score of 0,1 or 2 in all four categories, the end result of which is a cumulative ranking of somewhere between 0 and 8 . Countries that receive a score of 0 in this index are believed to have governments that show no respect for the physical integrity rights of their citizens, whereas countries that receive a score of 8 are believed to enjoy full government respect for these rights. Since the latest version of CIRI's dataset does not cover the full time period under consideration in this chapter, I estimated

${ }^{31}$ As outlined in Chapter 3, the incentive structures of UN peacekeeping personnel are primarily influenced by two key factors: their personal experiences while deployed in the field and the policy objectives of their home governments. The most motivated peacekeepers will therefore feel invested in the success of their operation and supported by their military and civilian establishments back home, as well as be contributed by a country whose policy objectives align with those of the UN. Although it is not perfect indicator, the level of respect for physical integrity rights in each country should serve as a reasonable proxy for all three of these factors. A number of studies have suggested that peacekeepers who identify with the need to protect civilians from harm on an ethical level are likely to be more motivated to act in the field (Blocq 2006; Blocq 2010; Franke 2003; Britt 2003; Galatino 2003; Maguen and Litza 2006; Troy 2017), which is a trait that is presumably more common in individuals from states that respect such rights rather than states that do not. Similarly, other studies have shown that the domestic policies of states necessarily inform their foreign policy behaviour abroad (Risse-Kappen 2016), particularly with regard to the protection and promotion of human rights (Sobek, Abouharb and Ingram 2006; Tomz and Weeks 2018; Peterson and Graham 2011; and Kreps and Maxey 2018). Peacekeepers from states with a higher level of respect for physical integrity rights should therefore be more willing to act when faced with violence, either due to their own personal preferences when the opportunity arises or due to the stated policies of their home government. 
the scores received by each country between 2012 and 2017 by taking the average value that they had been awarded during the previous five-year period. ${ }^{32}$ I then used the resulting values to construct an indicator reflecting the monthly weighted average of TCC respect for physical integrity rights for each peacekeeping operation, with higher values reflecting a higher respect for these rights and lower values reflecting a lower respect for these rights.

\subsubsection{Control Variables}

In addition to operational quality, the control variables used in this chapter seek to capture the effects of other factors that may affect the relationship between peacekeeping operations and civil war violence. The most important of these variables are the size and professional composition of the operation in question, both of which seek to capture the relationship between personnel quantity and the management of violence. The operational size indicator, total peacekeepers, is a count variable that consists of the total number of uniformed peacekeeping personnel deployed to an operation in a given month. This figure includes all military peacekeepers, military observers and civilian police deployed on the ground, with larger operations expected to be more effective at reducing violence than smaller operations.

By contrast, the operational composition variable is represented by a collection of three indicators, namely military, observers and police, one for each type of uniformed

\footnotetext{
32 Although there is some variation from year to year in this index, the changes are generally minor in nature. The average standard deviation of index scores per country was only 0.56 from 2007-2011 so it is unlikely that many countries strayed far from their mean value over the subsequent five-year period. In addition, the results of the models estimated later on in this chapter remained consistent when performed on a limited sample (i.e., 1991-2011 vs. 1991-2017) so this imputation process does not appear to have introduced any discernable bias. They also remained consistent when estimated using an alternative measure of this indicator, which simply extended the score that each country received in 2011 to the following five years rather than using their average score from 2007-2011.
} 
personnel. These indicators collectively represent the professional composition of an operation in a given month, with each one conveying the proportion of the personnel total that consists of its particular profession. Since military peacekeepers should have an easier time coercing combatants than unarmed observers or police, it is expected that operations with higher proportions of military peacekeepers should be more effective at managing violence. ${ }^{33}$ Data for these indicators were collected using monthly personnel data published by the UN DPKO, which includes information on the quantity, nationality and profession of all uniformed personnel deployed as part of a UN peacekeeping operation. Figures for the period 1990-2011 were derived from Jacob Kathman's UN Peacekeeping Personnel Commitments dataset (2013), whereas the figures for 2012-2017 were hand-coded by the author directly from the UN reports. ${ }^{34}$ Although these data do not account for the many non-uniformed personnel that participate in modern peacekeeping operations, they should

${ }^{33}$ Peacekeeping operations that possess higher proportions of military peacekeepers are expected to be more effective at managing violence than operations with higher proportions of unarmed observers or civilian police due to the greater range of coercive tools that armed troops have at their disposal. In addition to the deterrent and compellent effects derived from their ability to use force, they are also capable of mimicking the military observer's ability to threaten the legitimacy of excessively violent groups as well as the stabilizing role played by UN police, albeit imperfectly in the latter case. It is also worth noting that previous quantitative research on this topic has found that military peacekeepers typically have a negative and statistically significant effect on both types of civil war violence, whereas unarmed observers are associated with an increase in violence and civilian police with either a negative or statistically insignificant effect. So, although it has been demonstrated that even lightly armed peacekeepers or unarmed observers can contribute to the establishment of a lasting peace (Fortna 2008), they do not necessarily have the same effect when it comes to the management of on-going violence. See Hultman, Kathman and Shannon 2013, Hultman, Kathman and Shannon 2014, Kathman and Wood 2014, and Bove and Ruggeri 2016.

${ }^{34}$ When hand-coding the personnel data, I followed the same coding process as the one used to construct Kathman's original dataset. This process was objective in nature and consisted of copying the numbers for each personnel category directly from the UN's monthly PDF files into an Excel spreadsheet, primarily via copy and paste commands to limit the chance of coding error. Once this process had been completed, the resulting dataset consisted of 147,582 observations in the form of contributor country months spread across 80 peacekeeping operations and political missions from 1990-2017 (i.e., one observation per country that provided uniformed personnel to a given operation in a given month). The personnel figures recorded in this dataset were then aggregated for use at the operational-level, which is how the weighted averages for the three quality indicators discussed earlier in this section were calculated. 
nonetheless provide a reasonable representation of the size and composition of the UN's forces on the ground.

Each model also includes three additional indicators to help control for any variation in the underlying nature of violence. The first indicator, population, accounts for the total size of the population in each conflict affected country. It was sourced from the World Bank Population Data and is expected to return a positive relationship with violence, due to the fact that conflicts involving larger amounts of people have an increased likelihood of generating larger amounts of violence. The second indicator, conflict type, accounts for the nature of the incompatibility between the rival parties in each conflict dyad. It was sourced from version 18.1 of UCDP's Armed Conflict Dataset (ACD) and distinguishes between conflicts that were primarily concerned with territorial secession, which take the value of 1 , versus conflicts that were primarily concerned with state capture, which take the value of 0 (Themner 2018). Since conflicts concerned with territorial secession pose less of a threat to the continued survival of the government in question than conflicts over state capture, this indicator is expected to return a negative relationship with violence. The third indicator, personnel present, accounts for the presence or absence of uniformed peacekeeping personnel on the ground. It takes a value of 1 if peacekeepers are present and a value of 0 if they are not, with the expectation that conflicts with peacekeepers will be more violent than those without. ${ }^{35}$ Although these are not the only

\footnotetext{
${ }^{35}$ This indicator is necessary to ensure that values of ' 0 ' for the capability and willingness variables do not mistakenly suggest that very poor quality troops are present in a conflict that has not actually received a peacekeeping operation. For example, a score of ' 0 ' in the CIRI index that was used to construct willingness indicates that the TCC in question had an abysmal human rights record during that time period. However, since the absence of troops is also represented by a ' 0 ' in the underlying dataset, the failure to include an appropriate dummy variable would mean that a zero could either be referring to a conflict-month with very poor quality peacekeepers or no peacekeepers at all. The same logic works for the
} 
Table 2 - Summary of variables, with descriptive statistics reported by sample

\begin{tabular}{|c|c|c|c|c|c|}
\hline \multirow[t]{2}{*}{ Name } & \multirow[t]{2}{*}{ Definition } & \multicolumn{2}{|c|}{$\begin{array}{l}\text { Conflict-months } \\
\text { sample }\end{array}$} & \multicolumn{2}{|c|}{$\begin{array}{l}\text { Peacekeeping- } \\
\text { months sample }\end{array}$} \\
\hline & & Mean & Std. Dev. & Mean & Std. Dev \\
\hline $\begin{array}{l}\text { Battlefield } \\
\text { violence }\end{array}$ & $\begin{array}{l}\text { The number of battle-related } \\
\text { fatalities per month }\end{array}$ & 55.91 & 232.55 & 68.29 & 260.12 \\
\hline $\begin{array}{l}\text { One-sided } \\
\text { violence }\end{array}$ & $\begin{array}{l}\text { The number of direct and deliberate } \\
\text { civilian killings per month }\end{array}$ & 27.68 & 265.20 & 31.74 & 109.56 \\
\hline $\begin{array}{l}\text { Total } \\
\text { Peacekeepers }\end{array}$ & $\begin{array}{l}\text { The number of peacekeepers } \\
\text { deployed to a conflict per month } \\
(1000 \text { s) }\end{array}$ & 2.28 & 5.59 & 10.92 & 7.45 \\
\hline Military & $\begin{array}{l}\text { The percentage of military } \\
\text { peacekeepers deployed as part of the } \\
\text { total UN force }\end{array}$ & 16.10 & 33.87 & 76.92 & 28.47 \\
\hline Police & $\begin{array}{l}\text { The percentage of police } \\
\text { peacekeepers deployed as part of the } \\
\text { total UN force }\end{array}$ & 2.24 & 7.01 & 10.72 & 12.01 \\
\hline Observers & $\begin{array}{l}\text { The percentage of unarmed } \\
\text { observers deployed as part of the } \\
\text { total UN force }\end{array}$ & 1.91 & 10.18 & 9.13 & 20.75 \\
\hline Capability & $\begin{array}{l}\text { A monthly weighted average of } \\
\text { military spending per active soldier } \\
\text { for the TCCs that contributed } \\
\text { military personnel to each operation } \\
(\$ 1000 \text { s })\end{array}$ & 5.06 & 11.87 & 24.21 & 14.53 \\
\hline Willingness & $\begin{array}{l}\text { A monthly weighted average of the } \\
\text { level of respect for physical integrity } \\
\text { rights held by the TCCs that } \\
\text { contributed troops to each operation, } \\
\text { from } 0 \text { (low) to } 8 \text { (high) }\end{array}$ & 0.57 & 1.26 & 2.69 & 1.37 \\
\hline Conflict Type & $\begin{array}{l}\text { An indicator of conflict type, which } \\
\text { equals } 1 \text { if primarily about secession } \\
\text { and } 0 \text { if primarily about state capture }\end{array}$ & 0.34 & 0.47 & 0.28 & 0.45 \\
\hline Population & $\begin{array}{l}\text { The total population of each conflict } \\
\text { country in a given month (logged) }\end{array}$ & $3.09 \mathrm{e}+07$ & $3.55 \mathrm{e}+07$ & $2.92 \mathrm{e}+07$ & $2.29 \mathrm{e}+07$ \\
\hline $\begin{array}{l}\text { Personnel } \\
\text { present }\end{array}$ & $\begin{array}{l}\text { An indicator that takes a value of } 1 \text { if } \\
\text { uniformed peacekeepers are present } \\
\text { and } 0 \text { otherwise. }\end{array}$ & 0.20 & 0.40 & $0.97^{36}$ & 0.18 \\
\hline
\end{tabular}

capability indicator, in which a ' 0 ' could indicate a TCC that neglects to fund its military at all or merely an absence of troops in a given conflict-month.

${ }^{36}$ Despite consisting solely of months in which a peacekeeping operation was present, there are still a handful of months in which uniformed personnel had yet to be deployed on the ground. As a result, the mean value for this indicator is not quite equal to one, although it remains close nonetheless. 
variables that may influence levels of violence, they should serve as adequate controls when combined with the use of a fixed-effects estimator to account for any time-invariant differences between operational environments.

\subsection{Research Design}

The dataset used in this chapter includes all intrastate armed conflicts that took place in sub-Saharan Africa from 1991-2017. ${ }^{37}$ Its unit of analysis is the conflict-dyad month, which is derived from version 18.1 of UCDP's ACD. ${ }^{38}$ The resulting panel dataset consists of 6,216 observations spread across 54 conflict-dyads in 32 countries, with an additional two years added on to the end of each conflict episode in order to account for the potential resumption of fighting. ${ }^{39} \mathrm{~A}$ total of 1,279 of these observations account for the presence of a UN peacekeeping operation, of which there were 23 during this time period in 15 different countries. ${ }^{40}$ Although it would have been possible to expand this list

\footnotetext{
37 The definition of 'armed conflict' used by the UCDP is as follows: "a contested incompatibility that concerns government and/or territory where the use of armed force between two parties, of which at least one is the government of a state, results in at least 25 battle-related deaths in a calendar year" (Themner 2018, 1). In this case, I have merged UCDP's categories of 'internal armed conflict' and 'internationalized internal armed conflict' into a single 'intrastate armed conflict' category to serve as the basis of this dataset.

${ }^{38}$ A conflict dyad consists of any armed conflict in which there are at least two conflicting parties, one of which must be the government of a state. The emphasis of this dataset is therefore on the efficacy of peacekeeping operations in the context of conflicts that involve violence between governments and nonstate actors, rather than on dyads that focus exclusively on conflict between two or more non-state actors. However, in order to capture as much violence as possible, I also include the fatalities generated by fighting between non-state actors in the battlefield violence indicator if it occurred in a state with an active government versus non-state actor dyad.

${ }^{39}$ This approach is used in most of the related literature on this topic and helps to account for the presence of both post-conflict violence and the potential resumption of fighting. It also ensures that some conflicts do not periodically drop from the dataset when they dip below 25 battle-related deaths in a given year, which helps to increase the number of observations that contain a peacekeeping operation. For a more detailed discussion of the provided rationale, see Kathman and Wood (2016).

${ }^{40}$ The only operation excluded from this sample in the model's presented below is UNAMIR, which operated in Rwanda from October 1993 to March 1996. The rationale behind this exclusion is that the causes of genocide are typically distinct from the causes of other forms of civil war violence, in
} 
to include operations that took place outside of Africa, it already includes many of the largest, most complex and dangerous operations undertaken by the UN over the past few decades. Restricting the sample to a relatively confined geographic area also helps to keep the conflict environments as similar as possible, rather than attempting to generalize any findings across Africa, Asia, Europe, South America and the Middle East. Similarly, the selected time period encompasses the vast majority of interventions that the UN has made into intrastate conflicts so extending its temporal coverage backwards would have yielded little additional insight into the question at hand. There are also practical limitations with regard to data availability for earlier time periods, such as the violence data collected by UCDP and the personnel data provided by the DPKO. The resulting dataset should allow a clear assessment of the role played by personnel quality at the operational-level, both when seeking to compare performance between operations and when looking at conflicts that received an operation versus those that did not.

In order to analyze this data, I develop and test a series of negative binomial regression models in the following section. This estimation method is appropriate for use with dependent variables that take the form of count data, such as the fatality counts used in this study. Its advantage in this case over the more common Poisson model, which can also be used to work with count data, is that negative binomial models are better equipped to handle data that suffer from overdispersion and zero-inflation. When it comes to overdispersion, for example, both the one-sided violence and battlefield violence indicators have means that are nowhere near equal to their variance. Attempting to use a Poisson

addition to being such a large outlier in this case that including it would risk distorting the resulting coefficient estimates. 
model under such circumstances would typically result in coefficient estimates that have smaller standard errors than those present in the population at large, which could then lead to erroneous findings of statistical significance. Similarly, the fact that both indicators possess large numbers of months without any violence reported at all further undermines the assumptions on which the Poisson model is based.



Note: The mismatch between these two lines indicates that the use of a Poissonbased model would be a poor fit for the underlying violence data in this case.

The extent of this problem can be observed in Figure 4, which plots the observed versus predicted counts of the one-sided violence indicator if it were to follow a Poisson distribution. In this case, the predicted counts grossly underestimate the number of zeros present in the data and also perform poorly for all observations with between 1 and 15 civilian killings per month, which suggests that an alternative model would be preferable. ${ }^{41}$ I have opted to use a normal negative binomial model in this case, rather than its zero(2014).

${ }^{41}$ For a complete discussion of how to select the best model when using count data, see Hilbe 
inflated counterpart, because there is little theoretical justification for assuming that violence would never take a value of zero in some conflict-dyads but not others. ${ }^{42}$ In order to control for the potential effects of conflict-specific characteristics, all relevant models are also calculated using a fixed-effects estimator rather than its random-effects counterpart. ${ }^{43}$ It should also be noted that none of these models suffer from issues of multicollinearity, ${ }^{44}$ despite the potential for a positive relationship to exist between indicators such as capability and willingness.

Of course, all research designs have their strengths and weaknesses and the approach outlined in this section is no exception. In terms of strengths, the ability to assess the relative performance of a large number of peacekeeping operations, both in relation to each other and when compared to conflicts that did not receive an operation, is a clear advantage over adopting a more nuanced approach. It ensures that any findings are as generalizable as possible across different conflict environments, which is important when it comes to commenting on the UN's force generation process as a whole. If it turns out that personnel quality plays a significant role in the performance of UN peacekeeping operations, then there should be clear implications in terms of how the UN recruits and deploys its personnel.

\footnotetext{
${ }^{42}$ The use of a zero-inflated estimator is a common means of modeling count data that possess an unusually large number of observations that take the value of zero. It assumes that the underlying sample is derived from two different groups, one group in which the observation could never take the value of zero and one in which any zeroes are simply part of a normal distribution. However, the use of such a model would be inappropriate in this case because there is little reason to suspect that a particular conflict-dyad would never experience a level of violence greater than zero, whether in relation to battle-related deaths or one-sided violence against civilians.

${ }^{43}$ In addition to the theoretical rationale, the use of a fixed-effects estimator is also suggested by the results of a Hausman test.

${ }^{44}$ The mean VIF score for these models is approximately 8 in the full conflict-month sample versus a score of around 2 in the peacekeeping-month only sample.
} 
In terms of weaknesses, the level of analysis adopted in this chapter means that any findings should be treated with a degree of caution. The need to develop quality indicators for entire UN peacekeeping operations means that the resulting averages will inevitably mask a large amount of internal variation, particularly given the relative coarseness of the underlying data. Any attempt to aggregate violence data into a single, conflict-level figure also risks minimizing the role played by combatant incentives, which are typically the primary driver of local conflict dynamics. As a result, it will be important to revisit the findings of this chapter later on in the study so that they can be discussed alongside the results of the geospatial and qualitative components of this mixed-methods study.

It is also important to note that the results of these models may be subject to a degree of endogeneity bias. This form of bias arises when the relationship between variables is determined by processes that are internal to the model itself rather than due to truly external effects. In this case, it is likely that the relative quality of individual peacekeeping operations is at least partly informed by the level of violence found on the ground. The work of Virginia Page Fortna (2008) shows that peacekeepers tend to be deployed to harder cases rather than easier ones, so any dataset that includes conflicts with and without peacekeeping operations should control for this bias to some extent. However, there is still a risk that the UN, or individual TCCs, may choose to deploy their personnel in a manner that makes operational quality appear to play a larger role than it does in reality.

For example, if the UN decides to assess conflicts using the logic of a battlefield medic, it might choose to allocate its highest quality operations to conflicts with manageable levels of violence in order to ensure a greater likelihood of success. The existence of such a pre-selection process would then make it difficult to determine whether 
operational quality truly plays a role in the reduction of violence or if it only appears that way because higher quality operations tend to be sent to less violent conflicts in the first place. Similarly, the autonomy that individual TCCs have with regard to personnel deployment decisions could result in higher quality troops being sent to safer operations rather than more dangerous ones, which would once again be an example of an endogenous selection process. Any attempt to isolate the relationship between operational quality and violence must therefore seek to determine whether such a bias exists and, if so, to minimize its effects.

Although a certain level of bias is likely to be inevitable in this case, a quick look at some descriptive statistics reveals that it is unlikely to pose a major problem. As shown in Table 3, it is possible to split the conflicts included in the dataset into sub-samples based on whether they experienced levels of total violence that were above or below the mean. ${ }^{45}$ When looking at the full sample of conflict-months, the differences between the average capability and willingness scores for high versus low violence conflicts are quite stark. Conflicts with higher levels of violence received operations that were approximately $153 \%$ more capable and $138 \%$ more willing to act than conflicts with lower levels of violence, with the bias in this case towards harder conflicts rather than easier ones. Any findings with regard to operational quality using the full conflict-month sample should therefore represent a more difficult test of effectiveness rather than the other way around.

45 The term 'total violence' in this case refers to the total number of battlefield fatalities and civilian killings experienced in a given conflict-month, rather than solely one or the other. 
Table 3 - Average values of operational quality based on mean of total violence per month

\begin{tabular}{|r|c|c|}
\hline \multicolumn{1}{|c|}{ Sample } & Capability & Willingness \\
\hline All conflict-months & 5.06 & 0.57 \\
\hline High violence & 8.74 & 0.95 \\
\hline Low violence & 3.46 & 0.40 \\
\hline Peacekeeping only months & 24.21 & 2.69 \\
\hline High violence & 22.13 & 2.38 \\
\hline Low violence & 26.78 & 3.09 \\
\hline
\end{tabular}

Note: The 'capability' scores are based on a weighted average of per capita military spending, with each one-unit increase representing an additional \$1000 in constant 2016 USD, whereas the 'willingness' scores are based on a weighted average of CIRI's eight-point Physical Integrity Rights Index.

By contrast, the limited sample of peacekeeping-only conflict-months points to the opposite trend, with low violence conflicts receiving operations that were approximately $21 \%$ more capable and $30 \%$ more willing to act than high violence conflicts. These figures suggest that there may in fact be some slight bias towards deploying higher quality resources to easier operations rather than harder operations, either on the part of the UN or its TCCs. However, the large percentage point differences in this case distract from the relatively small differences that these numbers represent in terms of absolute values, which is only around $\$ 4000$ in terms of per capita spending and less than one rank on CIRI's Physical Integrity Rights Index. Since the total value of capability ranges from $\$ 0$ to $\$ 143,991$ in this sub-sample, along with a range of 0 to 7 for willingness, the level of actual bias represented by these figures is likely to be quite small. Nonetheless, in order to minimize the risks of endogeneity bias as much as possible, the four main models presented in the following section are also estimated using these high and low violence sub-samples so that their results can be compared to each other. 


\subsection{Models \& Sensitivity Tests}

I present the results of four econometric models in this section. ${ }^{46}$ All four models seek to evaluate the relationship between peacekeeping operations and violence, with the first two models concerned with battlefield violence and the second two models concerned with one-sided violence against civilians. Since the aim of these models is to identify the effect of peacekeeping operations on violence, all quantity and quality-related indicators have been lagged by one month in order to establish the desired temporal order. Any change in the personnel composition of a peacekeeping operation in a given month should therefore be reflected in the level of violence experienced in the following month. The only other indicator altered in this manner was population, which is presented in its logged form to even out significant variation in population size from one conflict country to the next. It is also important to note that the output of all four models is reported in the form of Incidence Rate Ratios (IRRs) rather than standard coefficient estimates, which are more straightforward to interpret when working with negative binomial models. ${ }^{47}$ After reporting the output of each model in this manner, I then present the details of seven sensitivity tests that were used to verify the robustness of their results.

\footnotetext{
${ }^{46}$ In addition to the results presented in this section, a more complete collection of models has also been included in Appendix A. These models show what happens to the relevant coefficient estimates as the models are built up more slowly over time, with the quantity-related variables taken as a base and then the quality-related variables added in afterwards. Although this process does reveal some instability in the relevant coefficient estimates, it is relatively mild for both types of violence. A certain degree of variation is also to be expected given the close relationship that exists between these two groups of variables, with any effects attributed to personnel quantity likely to vary once the relative quality of those personnel has also been taken into account.

${ }^{47}$ A coefficient estimate that produces an IRR equal to 1 is indicative of no change, a value above 1 indicates a positive change and a value below 1 indicates a negative change. For example, an IRR of 0.99 indicates that a one unit increase in the independent variable produces a one percent decrease in the dependent variable, whereas an IRR of 1.10 indicates that a one unit increase in the independent variable produces a ten percent increase in the dependent variable.
} 


\subsubsection{Models}

In order to control for potential selection effects regarding the distribution of peacekeeping operations more generally, the four models presented below were estimated using two different samples. Model 1 and Model 3 were estimated using the full sample of conflict-months, in which some conflicts received a peacekeeping operation and some conflicts did not, whereas Model 2 and Model 4 were estimated using a more restrictive sample consisting solely of peacekeeping months. The intuition behind this approach, as highlighted by Fortna (2008), is that there may be a bias in the overall deployment patterns of UN peacekeeping operations. If operations are largely deployed to easy cases rather than hard cases, or vice versa, then focusing solely on conflict-months in which peacekeepers are active might not convey an accurate picture of their effectiveness. Any attempt to assess whether operational quality plays a role in the effective management of violence should therefore consider the full range of available conflict-months, regardless of whether a peacekeeping operation was present or not. At the same time, however, conducting a narrower evaluation of operational effectiveness is useful if the goal is to determine the cause of variation in performance from one operation to the next. Since both of these objectives are of interest for the purposes of this study, the models presented below are estimated using both samples of conflict-months.

The first thing to note about these results is that the size of an operation alone is typically not a good predictor of operational effectiveness. As shown in Table 4, the total number of peacekeepers deployed to an operation has no effect on violence in three out of four models, with the only exception being a $4.5 \%$ reduction per 1000 personnel in the peacekeeping-month only model for one-sided violence. Instead, most of the role played 
Table 4 - Negative binomial regression models with fixed-effects (reported as IRRs)

\begin{tabular}{|c|c|c|c|c|}
\hline & $\begin{array}{c}\text { (1) } \\
\text { Battlefield } \\
\text { Violence } \\
\text { (all conflict- } \\
\text { months) } \\
\end{array}$ & $\begin{array}{c}\text { (2) } \\
\text { Battlefield } \\
\text { Violence } \\
\text { (PK conflict- } \\
\text { months) } \\
\end{array}$ & $\begin{array}{c}(3) \\
\text { One-sided } \\
\text { Violence } \\
\text { (all conflict- } \\
\text { months) } \\
\end{array}$ & $\begin{array}{c}\text { (4) } \\
\text { One-sided } \\
\text { Violence } \\
\text { (PK conflict- } \\
\text { months) } \\
\end{array}$ \\
\hline \multirow{2}{*}{$\begin{array}{l}\text { Total peacekeepers } \\
(1000 \mathrm{~s})\end{array}$} & 0.995 & 1.001 & 1.012 & $0.955^{* * *}$ \\
\hline & $(-0.65)$ & $(0.15)$ & $(1.56)$ & $(-4.39)$ \\
\hline Military (\%) & $\begin{array}{l}0.992^{* * *} \\
(-3.38)\end{array}$ & $\begin{array}{l}0.992^{* * *} \\
(-3.06)\end{array}$ & $\begin{array}{l}0.994^{* *} \\
(-2.45)\end{array}$ & $\begin{array}{l}1.004 \\
(1.25)\end{array}$ \\
\hline Police (\%) & $\begin{array}{l}1.002 \\
(0.44)\end{array}$ & $\begin{array}{l}1.000 \\
(-0.10)\end{array}$ & $\begin{array}{c}0.993 \\
(-1.39)\end{array}$ & $\begin{array}{l}1.005 \\
(0.71)\end{array}$ \\
\hline Capability (\$1000s) & $\begin{array}{l}1.026^{* * *} \\
(4.37)\end{array}$ & $\begin{array}{l}1.008^{* *} \\
(2.29)\end{array}$ & $\begin{array}{c}1.041^{* * *} \\
(5.37)\end{array}$ & $\begin{array}{c}0.997 \\
(-0.60)\end{array}$ \\
\hline Willingness & $\begin{array}{l}1.115^{* *} \\
(2.11)\end{array}$ & $\begin{array}{l}1.017 \\
(0.39)\end{array}$ & $\begin{array}{l}1.163^{* *} \\
(2.12)\end{array}$ & $\begin{array}{l}0.824^{* * *} \\
(-4.36)\end{array}$ \\
\hline \multirow{2}{*}{$\begin{array}{l}\text { Capability X } \\
\text { Willingness }\end{array}$} & $0.994^{* * *}$ & $0.995^{* * *}$ & $0.986^{* * *}$ & $0.992^{* *}$ \\
\hline & $(-3.87)$ & $(-2.69)$ & $(-5.07)$ & $(-2.38)$ \\
\hline Conflict Type & $\begin{array}{l}0.387^{* * *} \\
(-17.29)\end{array}$ & $\begin{array}{l}0.481^{* * *} \\
(-6.16)\end{array}$ & $\begin{array}{c}0.647^{* * *} \\
(-6.95)\end{array}$ & $\begin{array}{l}1.029 \\
(0.25)\end{array}$ \\
\hline Population (log) & $\begin{array}{l}1.502^{* * *} \\
(18.51)\end{array}$ & $\begin{array}{c}1.373^{* * *} \\
(4.88)\end{array}$ & $\begin{array}{c}1.259^{* * *} \\
(8.45)\end{array}$ & $\begin{array}{c}2.277^{* * *} \\
(10.35)\end{array}$ \\
\hline Personnel present & $\begin{array}{c}0.974 \\
(-0.12) \\
\end{array}$ & $\begin{array}{l}1.728 \\
(1.64) \\
\end{array}$ & $\begin{array}{c}0.940 \\
(-0.23) \\
\end{array}$ & $\begin{array}{c}3.944^{* * *} \\
(3.22)\end{array}$ \\
\hline Observations & 5866 & 1201 & 5479 & 1168 \\
\hline $\begin{array}{l}\text { Number of } \\
\text { conflicts }\end{array}$ & 53 & 19 & 46 & 18 \\
\hline $\begin{array}{l}\text { Min. months per } \\
\text { conflict }\end{array}$ & 11 & 11 & 11 & 11 \\
\hline $\begin{array}{l}\text { Max. months per } \\
\text { conflict }\end{array}$ & 323 & 193 & 323 & 193 \\
\hline Wald chi2 & 497.4 & 85.56 & 218.0 & 169.3 \\
\hline Prob $>$ chi 2 & $2.10 \mathrm{e}-101$ & $1.26 \mathrm{e}-14$ & $5.57 \mathrm{e}-42$ & $8.68 \mathrm{e}-32$ \\
\hline
\end{tabular}

Incident rate ratios; t-statistics in parentheses; $* p<0.10, * * p<0.05, * * * p<0.01$ 
by personnel quantity appears to be linked to the professional composition of the operation in question rather than strictly to how many personnel it possesses. Using the proportion of military observers as the baseline value, a $1 \%$ increase in the percentage of military peacekeepers is shown to reduce fatalities and killings by between $0.6 \%$ to $0.8 \%$ per month. Although this effect may not seem large, there were approximately 55.9 battlefield fatalities and 27.7 civilian killings per month in the full conflict-month sample so it suggests that even small shifts in the composition of an operation may have substantive effects on violence. For an average operation in the full conflict sample of 2280 peacekeepers with $16 \%$ military personnel, this would equate to a reduction of approximately 0.45 battlefield fatalities and 0.2 civilian killings per month for a proportional increase of around 23 military peacekeepers. This relationship is similar for battlefield fatalities in the peacekeeping-month only sample, in which a proportional increase of approximately 110 soldiers would reduce fatalities by 0.55 per month in an average operation of around 10920 peacekeepers with $77 \%$ military personnel.

However, the results of the fourth model suggest that a higher ratio of military peacekeepers may not always lead to a reduction in fatalities, at least when dealing with one-sided violence. Here it appears that the overall size of an operation matters more than the type of personnel that it possesses, which may reflect the presumed benefits associated with monitoring and protecting civilians over a wider range of territory in such contexts.

The second thing to note about these results is that peacekeeper quality is shown to play a role in the effectiveness of UN peacekeeping operations. The main effects of capability and willingness are both statistically and substantively significant in most models, which shows a direct relationship between the quality of UN personnel and levels 
of violence on the ground. However, the interpretation of the relevant coefficient estimates is less straightforward in this case because the interaction term between capability and willingness distorts the meaning of their main effects (i.e., the coefficient estimate for capability in this context would typically show the effect that it has on violence when willingness is set to zero and vice versa).

To overcome this issue, both indicators were mean-centered prior to carrying out the estimation process so that their coefficient estimates can be interpreted as the effect that one quality indicator has on violence when the value of the other quality indicator is held at its mean, which is a more interesting value than zero. ${ }^{48}$ This transformation reveals that a $\$ 1000$ increase in the weighted average of per capita defence spending for relevant TCCs increases violence by between $0.8 \%$ to $4.1 \%$ per month in operations with an average level of willingness, except in the peacekeeping only sample for one-sided violence shown in Model 4. Similarly, a one-point increase in the weighted average of respect for physical integrity rights for relevant TCCs is shown to increase violence by between $11.5 \%$ to $16.3 \%$ per month in the full sample when capability is held at its mean, and to decrease it by $17.6 \%$ in the limited sample. These results are somewhat puzzling at first glance because they suggest that deploying higher quality personnel may actually increase violence in many cases rather than decrease it. However, the negative and statistically significant coefficient sign for the interaction term suggests that operational capability contributes to

48 Although this transformation process generates more interesting results than would be reported otherwise, it is important to note that the mean values of both indicators are relatively low. The average value of capability is \$5056 in the full conflict-month sample versus \$24207 in the peacekeeping only sample, so the large reported effect of willingness in this context is based on a relatively low capability operation. Similarly, the average value of willingness is only 0.56 in the full conflict-month sample versus 2.69 in the peacekeeping only sample, both of which correspond to peacekeepers from TCCs that are relatively indifferent to physical integrity rights given the possible maximum score of 8 . 
the reduction of violence when operational willingness is increased, which makes sense given that both indicators represent a core element of peacekeeper quality.

To explore the relationship between these two indicators further, it is necessary to plot the marginal effects of capability on violence when willingness is held fixed at representative values. Relying solely on the value of the interaction term's coefficient estimate is not an option in this case because it does not convey a sufficient level of detail, such as the relative effectiveness of high versus low willingness troops for any given level of military capability. Once the relevant values have been plotted, however, it is possible to observe a clear divergence in the effectiveness of equally capable peacekeeping operations depending on their relative willingness to act.

As shown in Figure 5, this difference is negligible at relatively low levels of operational quality, with all operations performing more-or-less equally at roughly $\$ 23,000$ per capita when looking at battlefield violence and $\$ 16,000$ per capita when looking at onesided violence. But once an operation's average military capability has been increased to $\$ 50,000$ per capita, the effectiveness of troops from countries with the highest level of respect for human rights is predicted to be significantly greater than the effectiveness of troops from countries with the lowest level of respect for human rights. In more concrete terms, the difference between a low score of 0 and a high score of 8 on CIRI's 'Physical Integrity Rights Index' is equivalent to approximately 0.45 battlefield fatalities and 1.1 civilian killings per month. There is also a clear divergence in the performance of high versus low willingness operations more generally, with higher scorers performing more effectively as their military capability increases and lower scorers performing significantly worse. These results suggest that focusing exclusively on improving the training and 
equipment of deployed personnel may be counterproductive unless those personnel are actually willing to take action when confronted by violence.

Figure 5 - Marginal effects of operational capability on violence



Figure 5b - One-sided violence (all conflict months)



Note: Each line represents the marginal effects of military capability on violence when willingness is held fixed at representative values, as measured in the predicted number of fatalities per month. 


\subsubsection{Sensitivity Tests}

To assess the accuracy of the reported results, all four models were also subjected to a series of sensitivity tests. These tests were designed to assess the same general relationships as the models described above but each one was performed in a slightly different manner. The results for seven of these tests are reported below, all of which provide support for the robustness of the original four models.

First, I split the conflicts included in the dataset into two new sub-samples based on whether they had experienced levels of total violence that were above or below the mean. I then re-estimated all four models using these new sub-samples in order to determine whether the original results may have been biased by an endogenous selection process, such as a tendency to deploy higher quality operations to lower violence conflicts. As discussed above, the qualitative bias in the full conflict-month sample was in favour of higher violence conflicts, which would make for a harder test, whereas the qualitative bias in the peacekeeping only sample was in favour of lower violence conflicts, which would make for an easier test. So any variation between the results of the high versus low violence models for the peacekeeping only sample would be of particular relevance.

Interestingly, the results with regard to operational quality are almost entirely consistent across the board. Seven of the eight supplemental models returned a negative and statistically significant coefficient estimate for the interaction term between capability and willingness, with the battlefield violence model run using the more limited sample just barely missing out on statistical significance. These results provide strong support for the results of the original four models, which showed that peacekeeping operations are more effective at managing violence when their personnel are both highly capable and highly 
motivated. By contrast, the results with regard to operational size and composition were less consistent in this case, with the high violence models attributing negative effects to some of the quantity-related indicators and the low violence models attributing positive effects to them instead. Overall, then, the results of the interacted quality indicator remain consistent regardless of the chosen sample but the results of the operational size and composition indicators appear to be sensitive to the underlying conflict environment.

Second, I conducted a further test of endogeneity bias by inserting an additional independent variable into all four models based on the average level of pre-intervention violence experienced in each conflict. The indicator in question was constructed by calculating the average number of battlefield fatalities and civilian killings that occurred in each country during the six-month lead-up to intervention, with the goal being to see whether levels of violence during this limited time period had any effect on personnel deployment patterns. Once added into the models, any variation in the statistical or substantive significance of the original indicators could therefore be interpreted as evidence of an endogenous selection process towards a particular type of conflict environment.

Fortunately, the results of these new models provide additional support for the robustness of the initial results. The only change of note is that the proportion of police personnel becomes negative and statistically significant in the battlefield violence model, with a substantive effect of roughly $20 \%$ less than a similar increase in the proportion of military personnel. This finding suggests that there may be some slight bias against the effectiveness of police personnel in the original models, although it is not clear why this should manifest in the context of battle-related fatalities rather than violence against civilians. One potential explanation could be that the presence of civilian police acts as a 
deterrent to attack, particularly if the personnel in question were part of a more robust formed police unit. But it is difficult to comment more precisely at this level of analysis because the personnel data from the UN DPKO aggregates all types of civilian police into a single indicator. Otherwise, the results with regard to both quantity and quality remain unchanged when compared to the original four models, which provides further support for the idea that they adequately control for the potential effects of an endogenous selection process.

Third, I re-estimated the four original models using violence indicators based on the number of attacks experienced per month rather than the number of fatalities. Since it is possible to have a large number of attacks with a small amount of fatalities, and vice versa, any difference in the results of these new models would indicate that the original findings are sensitive to the chosen definition of violence. Surprisingly, the results of these new models were very close to the results of the original models, albeit with some minor variation in terms of the size of their relative IRR scores. The only change of note was the newfound significance of the police indicator, which became positive and statistically significant in both the full-sample battlefield violence model and the peacekeeping-month one-sided violence model. This change suggests that the third category of peacekeeping personnel, military observers, are more effective at reducing the overall number of attacks experienced by a given conflict than the UN's civilian police. Otherwise, the reported results with regard to operational size, composition and quality remain consistent so it is possible to conclude that the findings of the original four models are robust to alternative definitions of violence. 
Fourth, I re-estimated the two one-sided violence models to see whether their results were sensitive to who was doing the killing. These tests were conducted by splitting the one-sided violence indicator into two new indicators, one for government killings and one for killings by non-state actors. If the models estimated using these two new indicators return different results, then it would suggest that certain operational characteristics may be more or less important depending on the perpetrator of violence.

As it turns out, there appear to be clear differences in the effectiveness of UN peacekeeping operations depending on whether civilians are being killed by government or non-government actors. When it comes to government killings, the most effective strategy appears to be the deployment of large operations that possess high quality troops and a relatively high proportion of military observers. The importance of military observers in this context is somewhat surprising but it may indicate that government actors are less likely to kill civilians if they are worried about being observed. It is also an interesting finding because it suggests that peacekeeping operations can have an effect on government violence without needing to adopt a more forceful approach, which can be difficult politically due to the fact that operations commonly rely on the consent of their host country. When it comes to killings by non-state actors, the ability to reduce fatalities appears to be linked to a mixture of high quality troops combined with a relatively large proportion of police personnel. The total number of peacekeepers also appears to play a role, although only in the context of the peacekeeping-month only sample where it is negative. In sum, the deployment of high quality personnel is important regardless of who is doing the killing but the professional composition of each operation should vary based on the identity of the perpetrators. 
Fifth, I re-estimated all four models using alternative indicators of personnel quantity based on the raw counts of deployed personnel. This process involved the generation of new military, police and observer indicators for each model as well as the removal of the total peacekeepers indicator entirely. Since most of the literature on this topic uses the profession totals in this manner rather than accounting for their relative proportions, this test should clarify whether this chapter's findings with regard to personnel quality are also valid under these alternative specifications. In terms of their results, these new models continued to return a negative and statistically significant relationship for the interacted quality indicator, so the findings with regard to capability and willingness appear to be consistent regardless of the form taken by the personnel indicators. The continued importance of military peacekeepers is also demonstrated in these models, with the addition of 100 extra troops leading to a $0.3 \%$ to $0.4 \%$ drop in violence when controlling for quality. The substantive impact of this effect would be equal to approximately 0.2 battlefield fatalities or 0.1 civilian killings per month, which is roughly half of the drop attributed to a proportional increase of 110 soldiers in the main models reported above. ${ }^{49}$

Where these models differ, however, is in terms of the unusual effects attributed to the UN's military observers and civilian police. In three of the four models, the deployment of 100 additional police officers is shown to increase violence by between $0.8 \%$ to $2.6 \%$, whereas the deployment of 100 additional observers is shown to increase civilian killings by $12.1 \%$ and decrease battlefield fatalities by roughly $15 \%$. This last figure is particularly suspicious because it represents a substantive impact nearly 50 times greater than that

\footnotetext{
${ }^{49}$ These figures were calculated using the average 68.3 battlefield fatalities and 31.7 civilian killings that occurred every month in the sample that looked solely at conflict-months in which a peacekeeping operation was deployed.
} 
associated with the deployment of 100 additional troops, despite the passive nature of an observer's role. The only model to operate as expected looked at civilian killings in the context of the peacekeeping-month only sample, which showed no effect for civilian police or military observers at all. Although it is difficult to explain these divergent results, it is possible that these alternative indicators for observers and police may be picking up the effects of an omitted variable related to mission mandate, which the use of proportionbased data helps to control for. Nonetheless, it is worth emphasizing that the indicators for both operational quality and military peacekeepers continued to perform as expected despite the use of personnel numbers rather than proportions.

Sixth, I re-estimated all four models using alternative indicators of quality based on the proportion of high versus low quality troops deployed to each operation. The intuition behind this test is that even small numbers of highly trained and motivated troops may be capable of having a large effect on violence, which is something that an indicator based on operational averages would have a harder time identifying. The first step in this process was to determine a suitable cut-off point between high and low quality troops, which I set as being in the top $10 \%$ of the sample scores in terms of both capability and willingness. This resulted in troops from TCCs that spent more than $\$ 44,992$ per capita on their soldiers and that received a CIRI score of 4.32 or greater being labelled as 'high' quality troops. ${ }^{50}$ The models were then re-run using an indicator based on the proportion of high quality troops deployed to an operation each month rather than the original interaction term between capability and willingness.

\footnotetext{
50 The resulting averages were approximately 65 troops or $0.8 \%$ of the total in the full conflictmonth sample versus 312 troops or $3.7 \%$ of the total in the peacekeeping-month only sample.
} 
Interestingly, the results of these new models show that the proportion of high quality troops has no effect on battlefield violence but it does lead to an impressive 3.2\% reduction in one-sided violence. This means that the substantive effect of a $1 \%$ increase in the proportion of high quality troops is equal to a decrease of roughly 0.9 civilian killings per month, which is around four times the effect of a $1 \%$ increase in the proportion of average military troops reported in the original models. To probe these results further, I also re-ran the models using disaggregated indicators of troop quality that looked at the proportion of high capability troops versus the proportion of high willingness troops, rather than only troops that scored well in both categories. These results showed no effect of high capability troops on either type of violence and a roughly $1 \%$ reduction in civilian killings from a $1 \%$ increase in high willingness troops. Since the magnitude of this effect is significantly smaller than when troop quality was considered jointly in the previous test, it provides further evidence in support of the interaction term used in the original four models. However, the poor showing of these new quality indicators in the battlefield violence models suggests that the outsized benefits of deploying small groups of high quality personnel are limited to the management of one-sided violence against civilians, rather than to civil war violence more generally.

Finally, I re-ran the original models using an alternative estimation technique to assess the extent to which the reported results adequately account for the large number of zeroes present in the violence data. This test was performed by comparing the results of models run using a zero-inflated negative binomial estimator versus a normal negative binomial estimator, with the standard errors of both models clustered on a conflict id indicator in order to mimic the results of a panel data estimator as closely as possible. If 
the results of these two approaches are shown to differ considerably, then it would suggest that the original models may not adequately account for a process by which some conflictmonths would never be expected to experience violence and some would.

Fortunately, this does not appear to be the case. The results of both sets of models turned out to be nearly identical despite the underlying variation in terms of their estimation technique, with only minor differences in terms of the magnitude of their reported coefficient estimates and levels of statistical significance. These similarities remained constant despite the testing of different inflators for the zero-inflated model, with the most theoretically defensible being an inflator that accounted for the underlying level of conflict intensity in a given month. ${ }^{51}$ Although these inflators were not specifically constructed with the intention of dividing conflicts into different types, the resulting similarities in terms of their final output provides some level of reassurance with regard to the overall robustness of the original four models.

In sum, the results of the models tested in this section demonstrate that operational quality plays a major role in the UN's ability to manage civil war violence. The sensitivity tests performed on these models also show that these results are robust to alternative specifications, albeit with some minor variation observed from one model to the next.

${ }^{51}$ The data used to construct this conflict intensity inflator were derived from version 18.1 of UCDP's Armed Conflict Dataset. It takes a value of ' 0 ' if a conflict experienced less than 25 battle-related deaths in a given calendar year, a value of ' 1 ' if there were between 25 and 999 battle-related deaths per year, and a value of ' 2 ' if there were 1000 or more battle-related deaths per year. Once used as an inflator, the theoretical assumption at work is that conflicts with higher intensity levels should be more likely to have non-zero counts for violence than conflicts with lower intensity values. However, the fact that the underlying dataset is based on a sample of armed conflicts, which are themselves defined by the presence of battle-related deaths, means that this inflator is primarily useful when looking at the cause of zero versus non-zero counts of civilian killings. 


\subsection{Discussion and Conclusion}

The main takeaway from the tests performed in this chapter is that quantity and quality both matter when it comes to determining operational effectiveness. They may not always matter in the exact same way, or under the exact same conditions, but it is clear that focusing solely on the size of an operation will not provide an accurate assessment of the relationship between peacekeeping operations and violence. Below, I explore the implications of this conclusion in additional depth.

First, the tests conducted in this chapter demonstrate that the relative size of a peacekeeping operation matters. The deployment of 1000 additional peacekeeping personnel is associated with a $4.5 \%$ reduction in one-sided violence against civilians per month, with their ability to reduce killings perpetrated by non-state actors roughly twice as high as their ability to reduce killings by government actors. This translates into a reduction of approximately 1.4 civilian deaths per month if comparing outcomes between conflicts that have all received peacekeeping operations.

However, the total size of an operation does not appear to play a role in the management of battlefield violence at all, at least beyond the benefits provided by deploying an average number of peacekeeping personnel. Instead, it is the professional composition of an operation that matters in such contexts, with a $1 \%$ increase in the proportion of military personnel reducing battlefield fatalities by around 0.45 deaths per month in most contexts. The importance of operational composition is also evident in the context of violence against civilians but the role played by different types of personnel tends to vary depending on the underlying nature of violence. If the killings are being perpetrated by non-state actors then operations with higher proportions of military and 
police personnel should be more effective, whereas killings by government actors appear to respond more effectively to an increased ratio of military observers.

Overall, then, these results provide partial support for Hypothesis 1 from Chapter 3 (i.e., the higher the quantity of peacekeeping personnel, the lower the amount of violence). Although this conclusion should not be surprising given the previous studies conducted on this topic (Hultman 2010; Hultman, Kathman and Shannon 2013; Hultman, Kathman and Shannon 2014; Kathman and Wood 2014; Haass and Ansorg 2018), it is nonetheless significant to find that the size and composition of an operation continues to play a role in the management of violence when controlling for the relative quality of its peacekeeping personnel.

Second, the tests conducted in this chapter also demonstrate that the relative quality of a peacekeeping operation matters. The interacted effect between capability and willingness was consistently negative and statistically significant regardless of model specification, which provides support for Hypothesis 2 from Chapter 3 (i.e., the higher the quality of peacekeeping personnel, the lower the amount of violence). Although the precise magnitude of this effect varied depending on the relative combination of capability and willingness, the marginal effects plotted in Figure 5 above show a clear upward trend in the ability of operations to manage violence as their average quality increases.

In addition to this finding with regard to average effects, the sensitivity tests performed in this chapter also revealed that even small groups of highly capable and willing troops can have an outsized effect on violence. When compared to the performance of an average peacekeeper, the top $10 \%$ of the UN's peacekeepers in terms of both capability and willingness were found to be roughly four times as effective at reducing the severity 
of one-sided violence than their counterparts. This disparity was not observed in the context of battlefield violence, so there appears to be a limit on what these kinds of 'elite' troops can achieve, but it provides clear evidence that even small amounts of the highest quality personnel can make a difference under the right circumstances. The results of this chapter therefore provide additional support for the conclusions of the sole previous study on this topic (Haas and Ansorg 2018), which found that the severity of one-sided violence against civilians decreases as the average quality of an operation's peacekeepers increases.

Third, the results reported for the interacted quality term support the argument that 'quality' in a peacekeeping context consists of more than just raw military capability. The interaction term between capability and willingness remains negative and statistically significant regardless of changes in the underlying models, which suggests that the incentive structure of deployed personnel plays an important role in their overall effectiveness. The fact that operational effectiveness varies based on the interaction between capability and willingness also provides support for Hypotheses 3 to 6 from Chapter 3, which predicted that operations would perform better or worse depending on their relative scores in each category.

However, not all of these hypotheses appear to have fared equally well, with Hypothesis 3 the only one to truly hit its mark (i.e., when peacekeepers possess high capabilities and a high willingness to act, then they should be highly effective at managing violence). The marginal effects plotted in Figure 5 above suggest that operational effectiveness is more-or-less equal at lower levels of military capabilities, with the relative effect of high versus low willingness only coming into play as capability is increased. So the stark contrast predicted by Hypotheses 5 and 6 , in which high willingness troops would 
be more effective than low willingness troops if both possessed equally low capabilities, only comes into effect as capability reaches more moderate levels. Similarly, the positive relationship between peacekeeping operations and violence when capability is high and willingness is low calls into question Hypothesis 4, which predicted that the UN would be moderately effective in such circumstances. Nonetheless, the fact that operational quality consists of more than just a single factor is a significant finding in itself and suggests that future studies should adopt a similarly broad definition of quality.

Fourth, the results of this chapter also suggest that increasing the quantity of peacekeepers will almost always lead to reductions in one-sided violence against civilians, regardless of the underlying quality of the relevant personnel. As shown above, an increase of 1000 troops from the mean of 9500 is likely to result in around 1.4 less civilian killing per month for operations with average levels of capability and willingness. By contrast, the marginal effects plotted in Figure 5 suggest that doubling per capita spending from around $\$ 25,000$ to $\$ 50,000$ would lead to 0.039 less civilian killings per month for an operation with an above average willingness score of 4 and 9500 troops. So, provided the willingness score is held constant, the returns to greater quantity in this context are significantly higher than the returns provided by a substantial increase in per capita spending.

Even in the worst-case scenario, in which all 9500 troops are assumed to have a willingness score of 0 , doubling per capita spending for an average operation would only result in at most 0.79 more civilian killings per month. Since the monthly reduction for 1000 additional troops is equal to around 1.4 civilian fatalities, deploying even the least willing troops would therefore still result in a net reduction of around 0.61 deaths per month. Of course, it is difficult to place a high level of confidence in such calculations 
given the lack of nuance in the underlying data, but it at least provides some tentative support for the idea that deploying even the least ideal peacekeepers may be better than not deploying them at all.

In conclusion, the main takeaway from this chapter is that quantity and quality both matter when it comes to determining operational effectiveness. If an operation deploys a larger number of higher quality military personnel, then it will become more effective at reducing the severity of on-going violence. This finding applies equally to both battlefield violence and one-sided violence against civilians, although the substantive magnitude of this effect was slightly greater when applied in the context of civilian killings. Overall, then, this chapter provides a strong degree of support for the central argument advanced by this dissertation, namely that the relative quality of UN peacekeeping personnel contributes to operational effectiveness.

This chapter also makes three core contributions to the literature on peacekeeper quality. First, it corroborates the findings of the only previous study on this topic, which also found that the relative quality of UN peacekeepers matter when assessed at the operational-level. Second, it demonstrates that peacekeeper quality has an effect on both battlefield violence and one-sided violence against civilians, rather than merely the latter. And third, it provides support for the definition of peacekeeper quality developed in the previous chapter, which emphasized that the willingness to act when faced with violence is just as important as raw military capabilities. Having said that, the data used in this chapter were relatively coarse in nature, in addition to being aggregated at a level of analysis far removed from the hypothesized strategic interaction between peacekeepers and conflict actors. These results should therefore be viewed with a degree of skepticism until 
they have been corroborated by the more fine-grained analysis that follows. Accordingly, I turn in the following chapter to an evaluation of the role played by peacekeeper quality at the local-level, which should provide a greater level of insight into how the relationship between peacekeepers and violence plays out in the field. 


\section{Chapter 5: Local-level Analysis}

In the previous chapter, I demonstrated that the relative quantity and quality of UN peacekeepers both have an effect on operational effectiveness. If an operation is provided with an increased number of personnel, an increased proportion of military personnel or an increased quality of personnel, then it should become more effective at reducing on-going violence. The previous chapter also provided support for the theoretical model developed in Chapter 3, which defined 'quality' in a peacekeeping context as consisting of more than just the raw military capabilities of the personnel in question. Instead, it refers to peacekeepers who are both highly capable and highly willing to act when faced with violence, with the interaction between those two factors playing an important role in determining operational effectiveness. However, the level of analysis used to arrive at these conclusions was far removed from the hypothesized interaction between peacekeepers and conflict actors, so it remains to be seen whether these initial findings accurately reflect the situation on the ground.

In this chapter, I begin to address this shortcoming by evaluating the relationship between peacekeepers and civil war violence at the local-level. Shifting to a more detailed level of analysis should provide a greater level of insight into why the relative quantity and quality of UN peacekeepers affects operational performance, as well as how to improve that performance so that additional lives can be saved. Its primary advantage relative to the analysis conducted in the previous chapter is that accounting for the geospatial nature of this relationship makes it possible to develop indicators of quantity and quality that are tied to specific groups of peacekeeping personnel. In doing so, the focus is placed squarely on the relative effectiveness of individual groups of peacekeepers, without any interference 
from the kinds of operation-wide effects or force enablers that can influence outcomes at the state-level. It also allows for a more precise test of the hypothesized causal relationship between peacekeeper quality and violence, because spatial models are capable of isolating the impact of peacekeepers on nearby incidents of violence rather than their impact on overall levels of violence. In addition, the more nuanced personnel data that is available at this level of analysis makes it possible to divide military peacekeepers into two distinct categories, with combat troops expected to possess greater coercive potential than their support-oriented counterparts.

This chapter begins by briefly re-stating the overall theory and argument developed in this dissertation, with a specific focus on why personnel quality is likely to matter at the local-level. It then shifts to a discussion of the variables and data used to assess this relationship, the majority of which are based on geo-coded data for three adjacent operations: MINUSCA in CAR, MONUSCO in the DRC and UNMISS in South Sudan. It then describes the test of this relationship using a pair of spatial autoregressive models, one each for battlefield violence and one-sided violence, which are designed to control for any spatial dependence that may exist in the underlying dataset.

\subsection{Theory and Argument}

Any attempt to evaluate the effectiveness of UN peacekeeping operations must grapple with the fact that no two operations are the same. As shown in Chapter 4, individual operations typically vary in terms of both the quantity and the quality of their constituent personnel, which is an inevitable feature of the UN's force generation system. These differences contribute to substantial variation in outcomes at the operational-level, with 
operations that contain larger amounts of higher quality personnel shown to be more effective at managing on-going violence than those without. Although this finding is useful on its own, it is important to recognize that these operational-level outcomes are necessarily linked to the performance of individual groups of peacekeepers on the ground. In the same way that some operations will inevitably possess higher quality personnel than others, it is also inevitable that some groups of peacekeepers within each operation will be more highly trained or willing to act than others. These differences should then make some groups of peacekeepers more effective at managing violence than their counterparts, primarily due to the increased credibility of their coercive threats and assurances. However, since this argument relies on the assumption that these internal differences actually exist, it is worth providing a brief overview of how they commonly arise before proceeding to test the extent to which they matter.

At its core, the cause of internal variation in the quality of UN peacekeeping operations is related to the fact that peacekeeping is a multinational endeavour. The UN's need to solicit voluntary personnel contributions from its member-states means that the peacekeepers deployed to a single operation tend to come from a multitude of different countries, some of which possess personnel that are more capable or motivated than others. In 2016, for example, the UN's multidimensional operation in Mali consisted of approximately 13,250 uniformed and civilian personnel from 53 different countries (DPKO 2016). The size and diversity of this operation was by no means unusual and was similar to the approximately 12,000 peacekeeping personnel from 49 different countries deployed in CAR during the same time period (DPKO 2016). Of course, not all of these personnel would be expected to serve on the front-lines, with much of the observed 
diversity related to the phenomenon of "token contributions" consisting of staff officers and specialists (Coleman 2013). Nonetheless, it is not uncommon for UN operations to contain infantry personnel from more than a dozen countries at any one time. These personnel would then be expected to serve either individually or collectively in different locations across their peacekeeping host country, which introduces a clear potential for qualitative variation to exist from one location to the next.

To get a better sense of how this process works in practice, it is helpful to look at a typical deployment map for a large UN operation. In Figure 6, the UN's operation in the DRC is shown to spread across 20 different locations in 2016, with each location represented by a solid dot on the map and an accompanying list of military symbols. Most of these locations contain at least one unit of infantry personnel, as depicted by a rectangular box with an ' $\mathrm{x}$ ' inside of it, but they also include a number of other personnel types as well. These types include everything from military engineers to medical staff and transport helicopters, with each symbol representing the personnel contribution made by a single TCC. Given this level of diversity, it is unlikely that many locations within a single operation will regularly contain an identical quantity or quality profile when it comes to their peacekeeping personnel. There is simply too much variation in terms of the national composition and professional characteristics of individual units to enable generalizations about the operation as a whole. As a result, any variation in who is deployed to a specific location, as well as in the number of personnel that they possess, is likely to have an effect on the UN's ability to manage on-going violence. 
Figure 6 - MONUSCO Deployment Map (January 2016)

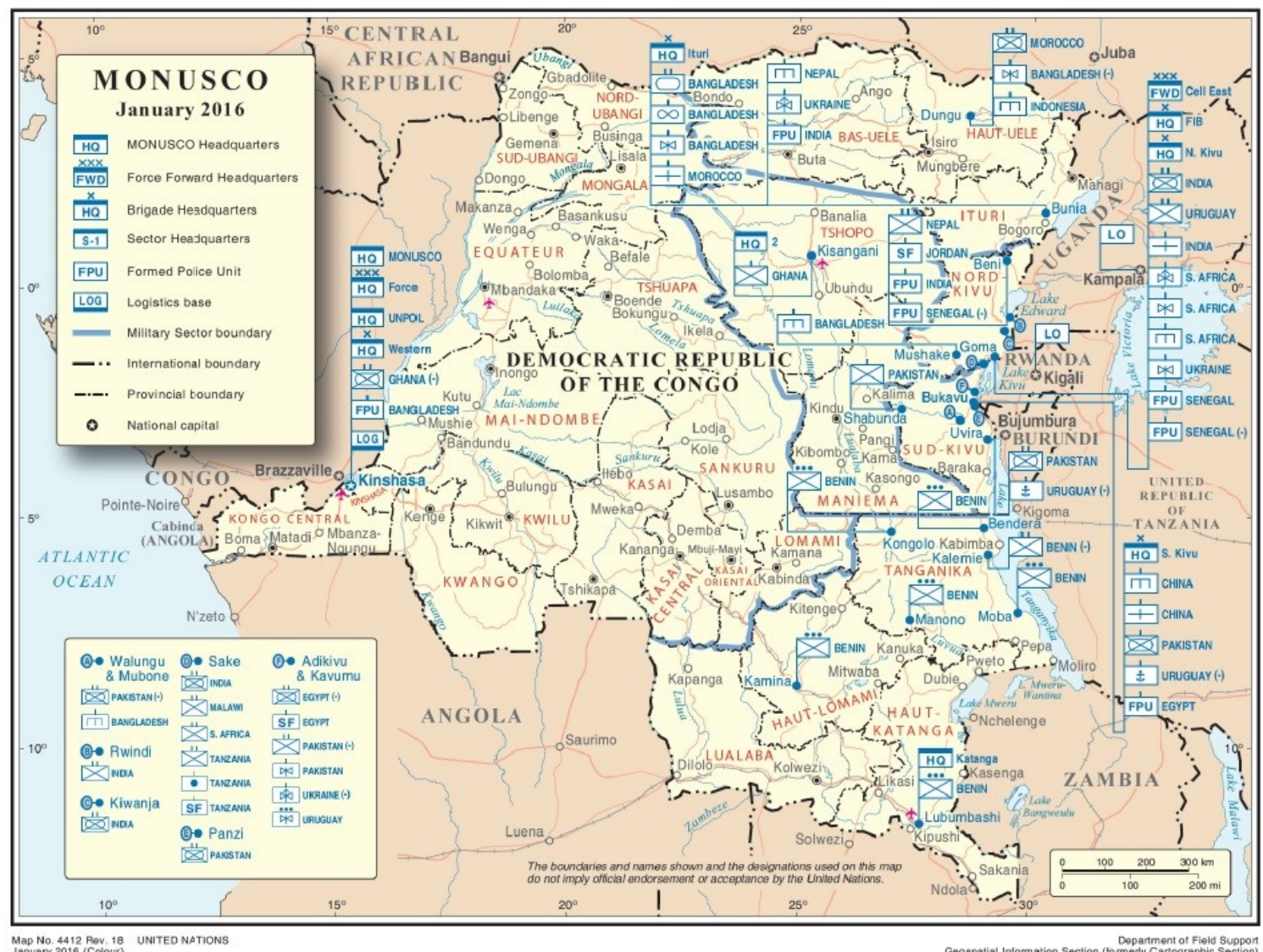

Note - This map shows the locations of the UN's uniformed personnel in the DRC as of January 2016. Each symbol depicted on the map indicates a unit of peacekeepers provided by a single TCC, as well as the locations of major logistics bases and operational command centres. The most common symbols include a diagonal cross for infantry, a diagonal cross with an oval for mechanized infantry, a horizontal cross for medical personnel, and a horizontal ' $E$ ' for engineering personnel. For a full list and description of the remaining symbols, see the United Nations Military Symbols Handbook (2000b).

More specifically, I argue that the quantitative and qualitative diversity that exists at the local-level has two main implications for the management of violence. First, any variation in the national identity of individual units has the potential to make some groups of peacekeepers more effective than others. These differences could either be due to the relative military capabilities of the units in question, with troops from some TCCs likely to be better trained and equipped than others, or due to variation in their willingness to act when faced with violence. The latter is likely to be particularly important at this level of 
analysis because peacekeepers are not always given orders that are in touch with local situations, which can leave them "without a concrete sense of how they [are] supposed to carry out their duties on the ground" (Autesserre 2014, 27). The resulting ambiguity means that the incentive structures of local-level commanders, as informed by both their personal views and those of their political masters back home, are likely to matter more than would otherwise be expected, particularly in the context of rapidly evolving crisis situations involving the use of force.

Second, any variation in the professional skillsets of peacekeepers is likely to have an effect on their ability to manage violence as well. This issue is masked somewhat at the operational-level, since all military personnel are lumped together into a single category, but it is hard to ignore the diversity of unit types when working at a more disaggregated level of analysis. All things equal, it is unlikely that the coercive potential of combat troops, such as infantry or armor, is likely to be the same as the coercive potential of support troops, such as medical staff and engineers. The latter may be able to deter violence through sheer force of numbers, or through the offer of positive inducements, but their inability to threaten conflict actors with harm is likely to limit their available range of action. In sum, the UN's effectiveness at the local-level is expected to vary based on the relative characteristics of its peacekeeping personnel, some of whom may be more or less suited to managing on-going violence.

\subsection{Variables and Data}

This section identifies the variables and data used to assess whether the relative quantity and quality of peacekeeping personnel has an effect on violence at the local-level. 
It begins by describing the geospatial grid structure used to code these data and then proceeds to list this chapter's dependent, independent and control variables.

\subsubsection{PRIO-GRID}

The first step in any geographically disaggregated analysis is to settle on an appropriate structure for the underlying dataset. In this case, I have chosen to use a geospatial grid structure developed by Peace Research Institute Oslo (PRIO), called PRIOGRID. This grid structure consists of a network of quadratic grid cells with a resolution of $0.5 \times 0.5$ decimal degrees that covers the world's entire landmass (Tollefsen, Strand and Buhaug 2012), which is equivalent to roughly 55 x 55 kilometers at the equator. Each grid cell comes with a unique identification code, as well as a range of other useful data, which can then serve as the panel-level identifier for the subsequent geostatistical analysis. Using these kinds of grid cells is often preferable to relying on local political units, such as provinces or districts, because they are exogenous to the conflict and should not influence the underlying structure of violence. However, since each grid cell can only be coded as belonging to a single political unit, the trade-off for eliminating this potential source of bias is that small pieces of territory belonging to one country may be assigned to neighbouring countries instead. For example, if seventy percent of a grid cell's land area was located in Country A and thirty percent was located in Country B, the entire cell would be coded as belonging to Country A rather than to Country B. Any peacekeepers or violence located in that grid cell would therefore be lost as well. To minimize this potential drawback, I have re-assigned bordering grid cells from one country to another in any case where the loss of 
these data would have been problematic. ${ }^{52}$ The end result is a grid-based dataset that is capable of accounting for the spatial dependence of complex phenomena such as civil war violence, the precise structure of which is discussed further in the following section.

\subsubsection{Dependent Variable}

The dependent variable in this chapter is once again civil war violence. It retains the separation between battlefield violence and one-sided violence that was used in Chapter 4, with the former referring to direct deaths caused during an armed clash between organized actors and the latter to the direct and deliberate killing of unarmed civilians. The source of these data also remains the same, namely version 18.1 of UCDP's GeoReferenced Event Dataset (UCDP GED), which means that the various selection biases related to the use of primarily media-based event data are relevant here as well. ${ }^{53}$ Where the indicators used in this chapter differ, however, is in terms of the form that they take in the models reported below. Rather than using raw fatality counts as I did in the previous chapter, the violence indicators used in this chapter have instead been converted into population-based fatality rates. Although not ideal, this transformation was necessary due to the lack of adequate estimation techniques for spatially-correlated count data that vary

\footnotetext{
${ }^{52}$ Of the roughly 1200 unique grid cells used below, it was only necessary to reassign the country codes of six cells in order to avoid the loss of peacekeeping personnel from one country to another. The most significant of these reassignments involved the grid cell that included the capital city of CAR, which had originally been coded as belonging to the DRC due to its close proximity to their shared border.

${ }^{53}$ To minimize these biases as much as possible, I only used data from the UCDP GED that was given an accuracy rating of ' 1 ' by its coders. This rating is given to attacks for which the "exact location of the event [was] known and coded" (Croicu and Sundberg 2018, 7), which ensures that the incident in question actually occurred within the borders of the associated grid cell. Although restricting the observations in this manner does lead to some loss of data, the effects are not severe. In CAR, for example, there were roughly 9647 total fatalities from 2010 to 2017, of which 7253 were assigned an accuracy rating of 1 . Including the additional 2394 fatalities would obviously be ideal but, in doing so, it would introduce a large bias towards locations containing local administrative centres or regional capitals, which is where less precisely coded events are typically assigned by default.
} 
in terms of both time and space. ${ }^{54}$ As a result, both battlefield violence and one-sided violence measure the number of fatalities that occurred in a given grid cell per 10,000 inhabitants, with the necessary population data obtained from Version 4.11 of the Gridded Population of the World dataset (GPWv4). ${ }^{55}$

\subsubsection{Independent Variables}

The primary independent variables of interest in this chapter are the relative quantity and quality of the UN's peacekeeping personnel. As discussed in the previous section, these personnel are often deployed across a wide area of their host country so the main challenge associated with constructing local-level indicators is to pinpoint the precise location of each unit of peacekeepers. Since no publicly available dataset of such information exists, I began by obtaining a collection of relevant deployment maps from the Cartographic Unit of the UN's Department of Field Support. These maps include detailed information regarding the precise location, nationality, size and profession of all formed units deployed within a particular country, as exemplified by the map shown in Figure 6.

54 The only estimation technique that is currently equipped to handle count-based panel data is the process of eigenvector spatial filtering developed by Daniel A. Griffith (see Griffith 2003). This approach works by selecting a sample of eigenvectors from a spatial weights matrix via stepwise regression and then using them as proxy variables in a non-spatial model to account for any spatial dependence that may exist in the underlying data. However, it is an imperfect option in this case because the process of creating a spatial filter must be performed individually for every time period in the dataset. Since the sources of spatial dependence may vary over time, it seemed unlikely that a single spatial filter would be capable of accounting for the unique dynamics of 32 different time periods.

55 This dataset was developed by NASA's Socioeconomic Data and Applications Centre (SEDAC) using the results of the 2010 round of Population and Housing Censuses. It contains population estimates for the entire surface of the world at five-year intervals from 2000 to 2020, with the process of merging these data with PRIO-GRID's cell structure conducted in QGIS. Since these years do not align precisely with the quarterly structure of this chapter's dataset, a process of linear interpolation was used to determine the grid-level population for each time period prior to the calculation of the subsequent fatality rates. It is also worth noting that this version of GPW has been adjusted in line with the UN's 2015 revision of its World Population Prospects data, which should minimize the effects of any reporting bias in the underlying data that may have been introduced by differing census practices from one country to the next. 
To prepare these maps for the subsequent geostatistical analysis, it was necessary to record all of the personnel data that they contained for each location over time. This process involved a significant amount of hand-coding, in which the information depicted for each location was converted into a single observation per unit of peacekeepers so that it would be possible to calculate weighted averages for any quality-related indicators. For example, if a map indicated that there were two units of infantry and one unit of engineers in a given location, the end product would be a total of three separate observations for that single location. Each observation would then contain data regarding the nationality, size and profession of the unit in question, as well as the GPS coordinates of the town or city in which it had been stationed. ${ }^{56}$ In this case, I hand-coded a total of 70 deployment maps for the three operations that are of interest in this chapter: MINUSCA in CAR, MONUSCO in the DRC and UNMISS in South Sudan. These data were coded on a monthly basis, with the publication date of each map serving as the recorded date for all relevant observations.

Although the data contained in these maps are accurate, it is important to note that they are not without their limitations. The first drawback of using these data is that the publication of revised maps is typically linked to periodic Reports of the Secretary-General, which are based on mission mandate cycles rather than regular monthly schedules. ${ }^{57}$ As a result, there are roughly three to four maps available for each operation per year, albeit not always on the same date or with the same amount of time between map revisions. Any

\footnotetext{
${ }^{56}$ The GPS coordinates for each peacekeeper deployment location were obtained from an online database called GeoNames: www.geonames.org. In cases where a country contained two locations with the same name, the latitude and longitude coordinates along the borders of the UN deployment maps were consulted in order to identify the correct location. Once the coordinates for each deployment location had been identified, they were then assigned to the relevant PRIO-GRID cell using the layer joining function in QGIS.

${ }^{57}$ Information obtained via e-mail communication with the UN's GIS office (14-18 December 2018).
} 
attempt to construct a dataset with evenly spaced time periods is therefore impossible without some method of data transformation. The second drawback of using these data is that maps are inherently limited to capturing only a single snapshot in time. This makes it difficult to determine the precise date that each unit of peacekeepers arrived in their recorded location, with troop movements having the potential to occur at any time since the previous map revision had been published. ${ }^{58}$

To address these issues, I first coded the information for each available map into a monthly dataset with the cells for non-map months left blank. I then populated these blank cells via a process of linear interpolation so that any changes between map revisions would be reflected gradually over time. These monthly data were then collapsed into a series of quarterly averages in order to minimize both the uncertainty introduced by uneven reporting periods and the risk that a unit of peacekeepers might be recorded in a location before it had arrived or after it had left. Thankfully, the fact that the Office of the Military Advisor has the option of requesting map revisions after large numbers of troops movements have occurred means that these limitations are unlikely to be a major source of bias. ${ }^{59}$ But it is nonetheless worth keeping in mind that these maps are not without their drawbacks, even though they remain the most accurate and comprehensive source of locallevel deployment data available to the scholarly community.

The first group of indicators created using these maps account for the relative quantity of the UN's peacekeeping personnel at the local-level. The most straightforward

\footnotetext{
${ }^{58}$ Information obtained via e-mail communication with the UN's GIS office (14-18 December 2018).

${ }^{59}$ Information obtained via e-mail communication with the UN's GIS office (14-18 December 2018).
} 
of these indicators is a simple score representing the size of the peacekeeper presence in each grid cell, total peacekeepers, with no distinction made regarding the underlying profession of the units in question. Platoon-size units were assigned a score of 0.5 , company-size units a score of 1 , and battalion-size units a score of 2 , all of which were then aggregated into a single figure for the grid cell in question. A grid cell with two battalions of infantry and a single company of engineers would therefore receive a cumulative size score of five. Although this ranking system does not capture the numerical differences between these unit sizes precisely, it should nonetheless serve as a reasonable proxy for the quantity of peacekeepers deployed in a given location. ${ }^{60}$ It is aided in this task by three proportion-based indicators for the different types of formed units deployed in the field: combat units, support units and police units. When distinguishing between the first two types of units, namely combat and support, I relied on the professional classification of the units in question as indicated by their unique map symbols. Any military units that were classified as infantry, mechanized infantry or, in rare cases, armour or artillery were assigned to the 'combat' category, whereas military units that consisted of engineering, transportation, aviation, signals, maintenance or medical personnel were assigned to the 'support' category. For the third type of unit, police, a similar classification process was unnecessary because this category consists solely of formed police units

${ }^{60}$ According to the Council on Foreign Relations, the average size of a modern military company is roughly 130 to 150 soldiers versus around 400 soldiers for a battalion:

https://www.cfr.org/backgrounder/modern-military-force-structures. Setting a one-unit increase in the total peacekeepers variable as being equivalent to a company-sized unit therefore risks slightly underestimating the number of troops deployed in a particular location. However, it is not uncommon for peacekeeping units to be relatively undermanned compared to their national counterparts, so it seemed prudent to err on the side of caution when developing a proxy for their overall size. Either way, the chosen indicator should still serve as a reasonably accurate proxy for the total number of UN personnel in a given location even if it is not quite as precise as the total count of personnel used in Chapter 4. 
(FPUs), which specialize in crowd control and the use of non-lethal force. In terms of anticipated effects, it is expected that larger groups of peacekeepers with higher proportions of combat or police personnel should perform more effectively than smaller groups of peacekeepers with lower proportions of combat or police personnel.

The second group of indicators based on these maps account for any qualitative differences that may exist between different groups of peacekeepers on the ground. These indicators are the same as the ones used in Chapter 4, albeit with some important differences in terms of how to interpret their effects. ${ }^{61}$ The first quality indicator, capability, represents the average level of training and equipment possessed by the combat personnel located in a particular grid cell. This indicator is based on a weighted average of annual defence spending per active soldier for relevant TCCs in \$1000s (USD), with the expenditure data obtained from SIPRI's Military Expenditure Dataset (2018) and the personnel data derived from annual publications of The Military Balance by IISS. Although not a perfect proxy of military capability, combat troops provided by TCCs with higher levels of per capita military spending are more likely to be part of fully professional militaries with access to a broad range of technologically sophisticated equipment. They

${ }^{61}$ Although the manner of calculating these two indicators is identical to the approach taken in the previous chapter, they differ in the sense that they are concerned with unit-level characteristics at this level of analysis rather than with the operation as a whole. The potential benefits of various operation-wide assets, such as transport helicopters or intelligence operators, are therefore less likely to play a role in any effects ascribed to these new indicators. Similarly, the fact that these indicators are based solely on the relative quality of combat personnel, rather than of military peacekeepers more generally, should provide a more precise test of the theorized causal mechanisms at work. After all, the coercive potential of support personnel is unlikely to be as substantial as the coercive potential of combat personnel, even if the former serves an important role as a force enabler. That is to say, the effects of something like a medical or aviation unit may provide a major boost to an operation's overall effectiveness, but attempting to pinpoint the precise geographic scope of their impact is a less straightforward task than when dealing with combat personnel. Incorporating anything beyond their physical presence in the grid cell of interest would therefore be difficult, which is why they are only represented in the total peacekeepers indicator rather than in the two quality-related indicators as well. 
should therefore be more effective at coercing local conflict actors than combat troops from TCCs with lower levels of per capita military spending, who are more likely to rely on conscript militaries which possess sub-standard training or equipment.

The second quality indicator, willingness, represents the average likelihood that peacekeepers will act when faced with violence. It is based on a weighted average of the "Physical Integrity Rights Index" score of all TCCs with combat personnel in a given grid cell, in which a cumulative score of 0 represents TCCs that have no respect for these rights and a score of 8 represents TCCs that have full respect for these rights (Cingranelli and Richards 2010). Combat troops from countries that score well on this index are expected to be more willing to intervene in violent situations, due to a mixture of their own personal preferences and the supportive policies of their home governments. At the same time, however, it is important to note that this indicator cannot account for all of the factors that may shape peacekeeper behaviour, as outlined in Chapter $3{ }^{62}$ Nonetheless, the combination of these two indicators should prove sufficient to distinguish between peacekeepers who are likely to be more or less effective at managing violence, with combat

\footnotetext{
${ }^{62}$ The theoretical discussion contained in Chapter 3 argues that the incentive structures of UN peacekeeping personnel are informed by two key factors: their personal experiences while they are deployed in the field and the policy objectives of their home governments. Although the CIRI data used in this chapter is an imperfect proxy of these two factors, there is a large body of research that supports the idea that states with higher levels of respect for physical integrity rights should both conduct their foreign policies in a manner that upholds such rights and produce soldiers who are more likely to view the protection of civilians as being an ethical imperative (Blocq 2006; Blocq 2010; Franke 2003; Britt 2003; Galatino 2003; Kreps and Maxey 2018; Maguen and Litza 2006; Peterson and Graham 2011; Risse-Kappen 2016; Sobek, Abouharb and Ingram 2006; Tomz and Weeks 2018; Troy 2017). Although it would be desirable to model these factors more directly, such as by including data on the individual policies or national caveats of specific troop contributing countries, there is unfortunately a lack of publicly available data on this topic that would be suitable for use in the geospatial models contained in this chapter. Attempting to code these data from scratch would also be difficult, both due to the large number of TCCs included in the overall dataset and the classified nature of most of the information of this nature. It is for this reason that the relationship between civil war violence and peacekeeper quality is analyzed in additional depth in the qualitative chapter that follows, which allows for a more nuanced treatment of this topic than is possible quantitatively.
} 
personnel who possess higher than average values of capability and willingness expected to perform more effectively than peacekeepers with lower than average values in either category.

\subsubsection{Control variables}

In addition to these quantity and quality-related variables, the models presented below also include two additional control variables. The first variable, conflict, seeks to control for the presence of an active armed conflict in the relevant peacekeeping host country. Following the definition of armed conflict provided by the UCDP, it is represented by a binary indicator that takes a value of 1 if the country in question experienced more than 25 battle-related deaths in a particular year and 0 otherwise. Although this variable could be coded more precisely for each country of interest, such as by noting the duration of specific peace initiatives or military campaigns, its more general nature makes it easier to compare outcomes from one conflict environment to the next. ${ }^{63}$ Countries in the midst of an active conflict year are therefore expected to experience higher fatality rates than countries that are either at peace or suffering from only occasional acts of violence. The second variable, personnel present, is once again designed to control for the physical

\footnotetext{
${ }^{63}$ It is also worth noting that the results of unreported sensitivity tests indicate that the models presented below perform consistently when the cut-off point for an active armed conflict is set at a higher threshold. These tests were conducted using thresholds of both 100 battle-related fatalities in a given year and 500 battle-related fatalities in a given year, neither of which resulted in any statistically nor substantially significant changes to the reported results. In the absence of any meaningfully different effects, the preference is to retain the lower threshold of 25 battle-related deaths set by the UCDP, particularly since this threshold played a key role in the process of sample selection used in the previous chapter.
} 
Table 5 - Summary of variables and data, with descriptive statistics reported for the full sample

\begin{tabular}{|c|c|c|c|c|c|}
\hline \multirow[b]{2}{*}{ Name } & \multirow[b]{2}{*}{ Definition } & \multicolumn{4}{|c|}{ Full sample of grid cells } \\
\hline & & Mean & $\begin{array}{l}\text { Std. } \\
\text { Dev. }\end{array}$ & Min. & Max. \\
\hline $\begin{array}{l}\text { Battlefield } \\
\text { violence }\end{array}$ & $\begin{array}{l}\text { The quarterly rate of battle-related } \\
\text { fatalities per } 10,000 \text { people in each } \\
\text { grid cell }\end{array}$ & 0.06 & 2.02 & 0 & 212.23 \\
\hline $\begin{array}{l}\text { One-sided } \\
\text { violence }\end{array}$ & $\begin{array}{l}\text { The quarterly rate of direct and } \\
\text { deliberate civilian killings per } \\
10,000 \text { people in each grid cell }\end{array}$ & 0.05 & 1.38 & 0 & 132.64 \\
\hline $\begin{array}{l}\text { Total } \\
\text { Peacekeepers }\end{array}$ & $\begin{array}{l}\text { The number of peacekeeping units } \\
\text { deployed in a given grid cell, with } \\
\text { each unit roughly equal in size to a } \\
\text { company (130-150 personnel) }\end{array}$ & 0.97 & 0.87 & 0 & 23 \\
\hline Combat & $\begin{array}{l}\text { The percentage of combat } \\
\text { peacekeepers deployed as part of } \\
\text { the forces in each grid cell }\end{array}$ & 2.55 & 14.89 & 0 & 100 \\
\hline Police & $\begin{array}{l}\text { The percentage of police } \\
\text { peacekeepers deployed as part of } \\
\text { the forces in each grid cell }\end{array}$ & 0.09 & 2.13 & 0 & 100 \\
\hline Support & $\begin{array}{l}\text { The percentage of support } \\
\text { peacekeepers deployed as part of } \\
\text { the forces in each grid cell. }\end{array}$ & 0.50 & 5.00 & 0 & 100 \\
\hline Capability & $\begin{array}{l}\text { A quarterly weighted average of } \\
\text { military spending per active } \\
\text { soldier for the TCCs that } \\
\text { contributed combat personnel to } \\
\text { the forces in each grid cell } \\
(\$ 1000 \mathrm{~s})\end{array}$ & 0.59 & 3.98 & 0 & 63.61 \\
\hline Willingness & $\begin{array}{l}\text { A quarterly weighted average of } \\
\text { the level of respect for physical } \\
\text { integrity rights held by the TCCs } \\
\text { that contributed combat troops to } \\
\text { the forces in each grid cell, from } 0 \\
\text { (low) to } 8 \text { (high) }\end{array}$ & 0.08 & 0.59 & 0 & 7.2 \\
\hline Conflict & $\begin{array}{l}\text { A binary indicator of an active } \\
\text { conflict, which equals } 1 \text { if } 25 \text { or } \\
\text { more battle-related fatalities } \\
\text { occurred in a given calendar year } \\
\text { and } 0 \text { otherwise }\end{array}$ & 0.70 & 0.46 & 0 & 1 \\
\hline $\begin{array}{l}\text { Personnel } \\
\text { present }\end{array}$ & $\begin{array}{l}\text { An indicator that takes a value of } 1 \\
\text { if uniformed peacekeepers are } \\
\text { present and } 0 \text { otherwise. }\end{array}$ & 0.03 & 0.17 & 0 & 1 \\
\hline
\end{tabular}


presence of peacekeepers in a particular area. ${ }^{64}$ It takes a value of 1 if peacekeepers are present and a value of 0 if they are not, with the expectation that grid cells with peacekeepers will be more violent than those without.

\subsection{Research Design}

The goal of this chapter is to evaluate the relationship between peacekeepers and civil war violence at the local-level. The main challenge with working at this level of analysis is that variables are often related to each other in terms of both time and space. Just as an area that experienced violence in a previous time period is more likely to experience violence in the next, so too are areas that are located in close proximity to violence. This observation is summed up by Tobler's first law of geography, which states that "everything is related to everything else, but near things are more related than distant things" $(1970,236)$. Although this is a rather obvious point to make, it is often ignored in the study of phenomena such as civil war violence despite the clear potential for spatial dependence to exist. Since the presence of peacekeepers may also have an effect on neighbouring areas in this manner, the necessity of accounting for these spatial dynamics is a key element of the research design adopted in this chapter. However, it also introduces novel challenges in terms of dataset construction and econometric analysis that were not an issue when working at a higher level of analysis.

In order to account for these spatio-temporal dynamics, the dataset built for this chapter divides the territory of three peacekeeping host countries into spatial units based

${ }^{64}$ As in the previous chapter, the underlying rationale for including this variable is to ensure that values of ' 0 ' in the capability and willingness indicators are actually equal to zero when no peacekeepers are present rather than indicative of extremely poor quality personnel. 
on PRIO-GRID's cell structure: CAR, the DRC and South Sudan. It contains information for 1,174 grid cells on a quarterly basis from 2010-2017, for a total of 37,568 observations. A total of 1,179 of these observations account for the presence of peacekeepers at the locallevel, with roughly $50 \%$ belonging to MONUSCO in the DRC, 36\% to UNMISS in South Sudan, and $14 \%$ to MINUSCA in CAR. The relatively small share of quarterly peacekeeper observations for MINUSCA in this case is primarily due to the fact that it did not arrive in CAR until September 2014, as compared to a deployment date of 2010 for MONUSCO and 2011 for UNMISS. This disparity does result in some degree of zero-inflation in the dataset, which is less than ideal, but the use of strongly balanced data is a strict requirement of the underlying statistical method. Jointly evaluating all three operations in this manner is also beneficial in the sense that it will lead to more generalizable results, which is a clear advantage over adopting a country-specific approach. Nonetheless, the individual results of all three countries are also presented in the sensitivity tests section below to ensure that any meaningful variation from one operation to the next is not lost in the aggregate results.

When selecting the underlying sample, the primary focus was on identifying a group of operations for which violence data were available and that exhibited sufficient variation in terms of both time and space. These objectives limited the choice to a handful of operations in sub-Saharan Africa, with the decision made to privilege more recent operations over older ones due to considerations of relevance and a desire to minimize bias associated with organizational reforms over time. These criteria led to the selection of CAR, the DRC and South Sudan, all of which experienced high amounts of violence during the last decade and were host to similarly large and ambitious UN operations. All three countries also have the added benefit of sharing land borders with each other, which makes 
the subsequent geostatistical analysis more straightforward ${ }^{65}$ The fact that they are all located in the central region of Africa should also help to control for as many non-conflict related factors as possible, such as geography, climate and weather. The only other operation that would have also fit these criteria was UNAMID in Sudan. However, it was ultimately excluded due to its unique nature as a joint venture between the African Union and the UN, as well as the fact that it would have required moving the start date for the entire dataset back from 2010 to 2008. The final sample therefore consists of the three most violent wholly-UN operations of the past decade, all of which contain significant spatial variation in terms of both violence and peacekeeper locations over time.

The chosen statistical method for this chapter is a form of spatial autoregressive (SAR) model run using the 'spxtregress' command introduced in Stata 15. The SAR model is flexible in the sense that it can account for spatial dependence caused by up to three different factors: outcomes in nearby areas, covariates from nearby areas, and errors from nearby areas. It is therefore capable of addressing both parts of Galton's problem, in which spatial dependence can either be linked to the diffusion of a phenomenon from one area to the next or to its independent emergence due to similarities in local conditions. ${ }^{66}$ It does this by introducing indicators that account for the average value of the dependent variable

\footnotetext{
${ }^{65}$ The primary benefit of using adjacent countries over more distant ones is that it minimizes the size of the spatial weights matrix required to estimate the spatial autoregressive models. For example, attempting to incorporate an operation like MINUSCA in Mali into the estimation sample would require also including grid cells for every other country along the way, which would end up including most of West Africa. Since most of these countries lack meaningful data during this time period, the end result would be to populate the dataset with irrelevant information. It is also worth noting that since the borders themselves are static throughout this time period, any effects associated with the presence of shared land borders between CAR, the DRC or South Sudan should be filtered out of the models due to the use of a fixedeffects estimator.

${ }^{66}$ For an overview of this problem and the context in which it was originally raised, see Narol (1965).
} 
and the error term observed in neighbouring areas, which are referred to as spatial lag and spatial error. The definition of a 'neighbouring' area in this context is determined by the contents of a spatial weights matrix, with both contiguity-based and distance-based matrices commonly employed. These matrices also allow SAR models to account for the effects of individual covariates on nearby areas, such as the relative quantity and quality of UN peacekeepers.

In this case, I have used a standard queen-contiguity weights matrix to construct the spatially-lagged dependent variables, spatially-lagged independent variables and spatially autoregressive error terms tested below. This matrix defines the eight adjacent grid cells for each spatial unit as being equivalent to neighbours and all other grid cells as being non-neighbours, with the total values for each row in the matrix standardized so that they sum to 1 . When used in combination with temporally-lagged independent variables, the resulting models should be capable of controlling for any spatial or temporal effects that might have otherwise biased the relationship between peacekeepers and violence. Of course, the issue of endogeneity bias is still likely to be a problem in this case, with large areas of all three countries unlikely to receive peacekeeping personnel due to a lack of ongoing violence. However, as I show below, the results of both SAR models remain reasonably consistent when the potential effects of this bias are taken into account, as well as when they are tested under a number of alternative specifications.

The use of a spatial model is recommended in this context because there are strong theoretical and statistical reasons to believe that spatial dependence exists in the underlying 
dataset. In terms of theory, the ability for violence to spread from one area to the next is relatively straightforward. It can either spread through a process of behavioural diffusion,

Figure 7 - Spatial clustering of civil war-related fatalities

Fatalities per grid cell

CAR, DRC and S. Sudan (2010-2017)

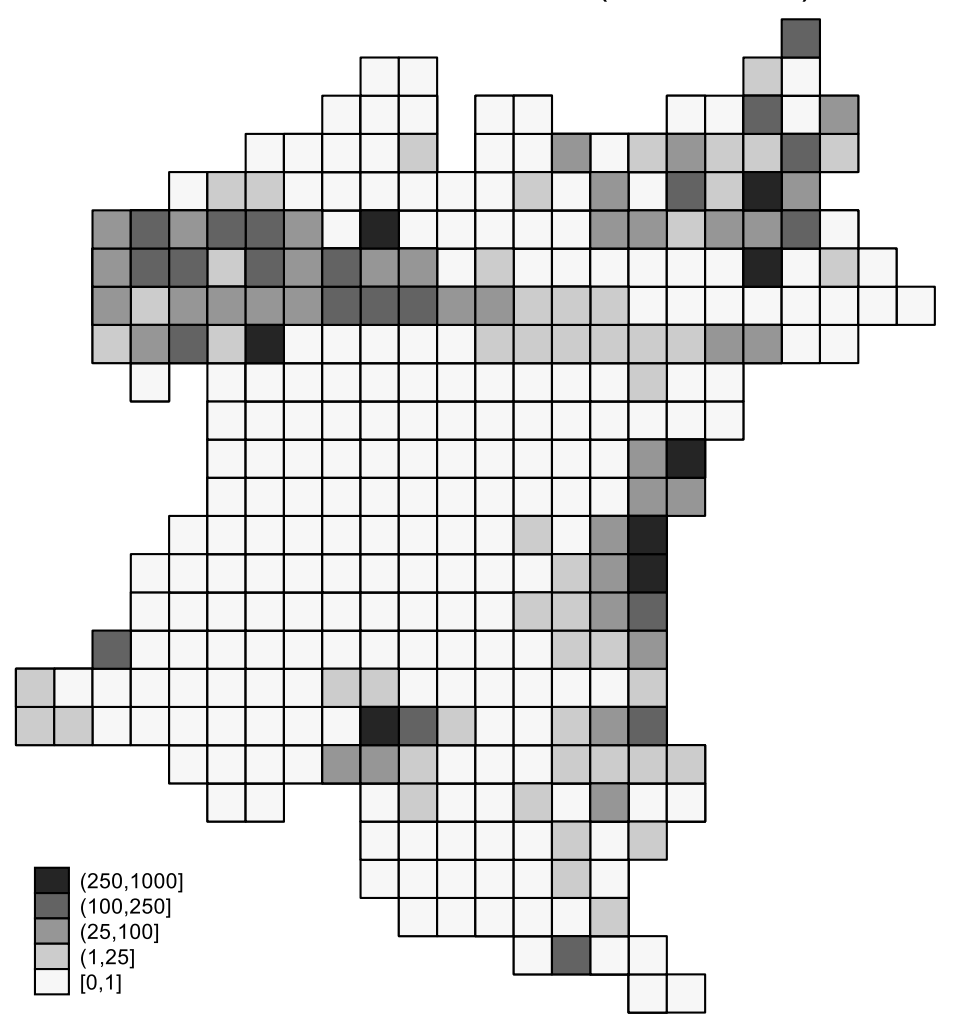

in which the use of violence in one area is mimicked in another, or through the physical movement of conflict actors or vulnerable populations from one location to the next. The ability for violence to emerge independently in multiple locations is also without controversy, such as when commonly-held grievances boil over or when state weakness invites the creation of rent-seeking militias. A failure to account for either form of spatial dependence would therefore risk introducing bias into the subsequent coefficient estimates, as would the omission of other relevant factors such as the presence of UN peacekeepers. 
In terms of statistics, the results of various diagnostic tests also suggest that failing to account for spatial dependence would be an issue in this case. Even a cursory visual inspection of the data depicted in Figure 7 suggests that incidents of violence tend to be clustered in space, with large areas of all three countries completely devoid of any lethal attacks over time. This conclusion is supported by the results of a global Moran's I test for each time period in the dataset, with the assumption of spatially independent and identically distributed errors rejected in 17 of 32 quarters for one-sided violence and 10 of 32 quarters for battlefield violence. Further tests based on the robust and non-robust versions of the Lagrange Multiplier statistic suggest that this problem is based on a mixture of both spatial lag and spatial error, both of which can be addressed in an appropriately structured SAR model. ${ }^{67}$ When considered as a whole, therefore, the case in favour of using a spatial model over a non-spatial variant is supported by a range of theoretical and statistical evidence.

The specific choice of a SAR model in this case versus some other form of spatial model was primarily motivated by the lack of viable alternatives. It is one of the only models that is capable of simultaneously accounting for spatial lag, spatial error and spatially lagged covariates, in addition to the effects of time. This relative lack of options is also the reason that the dependent variable in this chapter is based on the fatality rates observed in each grid cell rather than a raw count of the associated fatalities. Some alternatives do exist, which are primarily variants of geographically weighted regression (GWR), but they are based on the calculation of local coefficient estimates for each grid

\footnotetext{
${ }^{67}$ The process of model selection and diagnosis was implemented according to the steps laid out in David Darmofal's Spatial Analysis for the Social Sciences (2015). It is also worth noting that the joint spatial lag/spatial error model returned smaller AIC/BIC scores than models run using just one or the other, which provides further support for its relative goodness of fit.
} 
cell rather than a global average.$^{68}$ This feature makes them useful when seeking to identify areas that may exhibit unusually high or low coefficient estimates for a specific variable, as well as the existence of such variation more generally. However, the greater level of nuance associated with this approach tends to place a higher level of demand on the underlying data, which makes it less suitable in contexts where grid cells containing either the dependent or independent variables are relatively scarce. The relative novelty of GWR also means that there is still some debate regarding the best way to model panel data using this approach, with a few different variations being promoted by their respective creators. For these reasons, the models estimated in this chapter are based on the SAR approach available via Stata 15 rather than an alternative approach such as GWR.

The primary advantage of the approach used in this chapter is that it allows for a more nuanced assessment of the relationship between peacekeepers and violence than the state-level analysis conducted in the previous chapter. Rather than evaluating the performance of an operation as a whole, it is able to evaluate the relative performance of individual groups of peacekeepers within the context of their local conflict environments. The greater level of detail provided by the UN's deployment maps also allows for a meaningful distinction to be made between combat and non-combat personnel, as well as for a more precise test of the underlying argument regarding the importance of personnel quality.

However, this more nuanced approach does still share some of the weaknesses inherent in the previous chapter's research design, particularly with regard to the potential

${ }^{68}$ An overview of various GWR-based techniques, as well as the underlying logic of this approach, can be found in the following sources: Fotheringham, Brunsdon and Charlton (2002), Fotheringham, Crespot and Yao (2015), and Yu (2010). 
existence of endogeneity bias. Since deployment decisions are unlikely to be made without consideration of local conflict dynamics, there is always a possibility that units of a particular size or quality may be biased towards more or less violent locations. If such a bias exists, then the resulting coefficient estimates would risk either over- or underestimating the effectiveness of UN peacekeepers at the local-level. In addition, the lack of available data on the incentives of local conflict actors means that the analysis conducted in this chapter must still rely on the assumption that variation in violence is primarily due to the efforts of peacekeepers. The inclusion of spatially lagged dependent variables and error terms should account for local conflict dynamics to some extent, but they cannot replace the kind of analysis contained in the process-tracing case study presented in the following chapter. In sum, the more nuanced research design adopted in this chapter comes with substantial advantages but it is important to recognize that it is not without its limitations as well.

Fortunately, the data shown in Table 6 suggests that any issues caused by the existence of endogeneity bias in this case are unlikely to result in an easier test of effectiveness. Grid cells with higher than average levels of violence possess average capability and willingness scores that are roughly eleven and four times higher than grid cells with lower than average levels of violence. So any model estimated using the full sample of possible grid cells is likely to make for a more difficult test rather than an easier one. This difference is slightly less extreme when the sample is limited only to grid cells that either received peacekeepers or were located directly adjacent to them, but it still results in a qualitative bias towards high violence areas of roughly four times in terms of capability and two times in terms of willingness. Clearly, then, the best peacekeepers tend 
to be deployed to the most violent areas on average, rather than kept safe somewhere far away from the front-lines.

Table 6 - Average quantity and quality values (split at the mean of total fatality rates per grid cell)

\begin{tabular}{|r|c|c|c|c|}
\hline \multicolumn{1}{|c|}{ Sample } & Quantity & Combat (\%) & Capability & Willingness \\
\hline All grid cells & 0.10 & 2.55 & 0.59 & 0.08 \\
\hline High violence & 0.44 & 9.90 & 3.11 & 0.24 \\
\hline Low violence & 0.05 & 1.65 & 0.29 & 0.06 \\
\hline Peacekeeper \& adjacent & 0.26 & 6.79 & 1.58 & 0.21 \\
\hline High violence & 0.76 & 14.50 & 4.37 & 0.40 \\
\hline Low violence & 0.16 & 5.34 & 1.05 & 0.18 \\
\hline Peacekeeper cells only & 1.58 & 41.52 & 9.67 & 1.30 \\
\hline High violence & 1.56 & 35.20 & 9.49 & 0.99 \\
\hline Low violence & 1.59 & 43.79 & 9.73 & 1.42 \\
\hline
\end{tabular}

Note: The 'quantity' scores are based on the total number of peacekeeper units deployed to a particular location, the combat (\%) scores are based on the average proportion of combat troops in each location, the 'capability' scores are based on a weighted average of per capita military spending in \$1000s (USD), and the 'willingness' scores are based on a weighted average of CIRI's eight-point Physical Integrity Rights Index.

The only sample that showed a slight qualitative bias towards low violence grid cells was the peacekeeper-cell only sample, in which no consideration was given for the surrounding area at all. However, the differences between the values of the high and low violence sub-samples were significantly smaller in this case, with capability scores roughly $3 \%$ higher in low violence cells and around 43\% higher for willingness. Although these differences suggest that focusing on the precise deployment location of peacekeepers may offer a slightly easier test, attempting to estimate a model with such a limited sample would result in significant spatial bias anyway. As a result, the tests presented in the following section are estimated on the two samples that actually account for the spatial dynamics between peacekeepers and violence, both of which should pose a harder test for the hypothesized causal mechanisms. 


\subsection{Models and Sensitivity Tests}

The models presented in this section were all estimated using a SAR estimator with spatially lagged dependent variables, spatially lagged independent variables and spatially autoregressive errors. ${ }^{69}$ These spatial terms were created using a queen-contiguity spatial weights matrix, in which the spatial relationship between each location and its eight surrounding grid cells is incorporated into the estimation process, as well as its relative location within the broader matrix. All of the peacekeeper-related indicators have also been lagged by a single time period in order to establish the hypothesized causal relationship between peacekeepers and violence. Any changes in the relative quantity or quality of UN personnel in a given quarter should therefore be reflected in the fatality rates observed in the following quarter.

In addition, the main effects for the two quality-related indicators have once again been mean-centered. This transformation allows the main effects of capability and willingness to be interpreted as the effect of one variable on violence when the other is set at its mean, rather than when the other is set to zero. Finally, it is also important to note that all models were fit using a fixed-effects estimator to control for the potential confounding effects of any omitted time-invariant variables, such as the country that each grid cell belongs to, the physical characteristics of the local terrain or the presence of a

${ }^{69}$ Levels of multicollinearity in these models were minimal, with mean VIF scores of 9.66 reported when the two quality-related variables were interacted and 7.56 when they were not. However, some of the individual terms ended up returning VIF scores of closer to 20 due to a high level of correlation between the personnel present dummy variable and other quantity-related factors. As a result, a more complete collection of models has been included in Appendix B to show what happens to the relevant coefficient estimates as the models are built up more slowly over time. When viewed in this manner, it is possible to see that the results for all of the included indicators remain remarkably consistent from one model to the next, with only a couple of minor variations in terms of both statistical and substantive significance. 
permanent land border. ${ }^{70}$ This transformation is implemented via a quasi-maximum likelihood method developed by Lee and Yu (2010), which ensures that all panel-level effects are removed from the estimation process and that no distributional assumptions are made about them. Below, this section begins by presenting the results of two main models and then proceeds to a discussion of the eight accompanying sensitivity tests.

\subsubsection{Models \& Results}

The results of the two main models for this chapter, one each for battlefield violence and one-sided violence, are presented in Table $7 .{ }^{71}$ Both of these models were estimated using the full sample of grid cells, in which higher quality troops tend to be located in more violent areas rather than less violent areas, so they should pose a more difficult test of the relationship between peacekeepers and violence. The coefficient estimates for all quantity and quality-related variables are therefore more likely to be biased downwards in this case, which should lead to a higher chance of accepting the null hypothesis of no relationship between peacekeepers and violence.

It is also important to note that the effects of all spatially-lagged covariates have been divided into two categories: direct effects and indirect effects. The former refers to the effect that peacekeepers have on violence within their specific grid cell, whereas the

${ }^{70}$ In addition to being preferable in terms of theory, the choice of fixed-effects versus randomeffects was also based on the results of both a Hausman test and the robust Sargan-Hansen statistic generated by the user-written 'xtoverid' command in Stata.

${ }^{71}$ Before proceeding to explain the results, it is first worth noting that the removal of the conflict indicator from either model has no substantial effect on the reported coefficient estimates or marginal effects for the remaining indicators. However, the inclusion of the conflict indicator remains desirable in a theoretical sense because it helps to control for any major variation in conflict dynamics from one operational context to the next. It also leads to the generation of lower AIC/BIC scores for both models, which suggests a better goodness of fit. 
latter refers to any spill-over effects that they have on their surrounding area. For example, if the total peacekeepers indicator returns a direct effect that is negative and statistically significant, then it would suggest that increasing the number of units in a particular location should lead to a reduction of violence in that location. If the indirect effect of that indicator is similarly negative and statistically significant, then it would further suggest that increasing the number of units in a particular location should reduce violence in neighbouring locations as well. Although this example is relatively straightforward, it is also possible for a situation to arise in which the direct and indirect effects of an indicator are actually opposites instead. If it turned out that the indirect effect of total peacekeepers was positive rather than negative, then the net effect of deploying additional troops might simply be to shift violence from one area to another rather than to cause an overall decline. Any attempt to interpret the provided coefficient estimates must therefore keep the potential interplay between these two types of effects in mind, which is why a supplementary analysis based on the marginal effects for each indicator is also presented below.

Given the difficulty of interpreting these coefficient estimates directly, it is hard to draw firm conclusions regarding their statistical or substantive importance based on a visual inspection alone. Nonetheless, there are a few things about the results presented in Table 7 that are worth noting before moving on to the more meaningful discussion of their marginal effects. The first thing to note about these results is that both models confirm the existence of a significant amount of spatial dependence in the underlying data. The spatially lagged dependent variables are positive for both models, which suggests that violence spreads from one area to another via a pattern of diffusion, and the spatially lagged 
Table 7 - Spatial autoregressive models estimated using fixed-effects

\begin{tabular}{|c|c|c|c|c|}
\hline \multirow{2}{*}{ Direct Effects } & \multicolumn{2}{|c|}{$\begin{array}{c}\text { (1) } \\
\text { Battlefield Violence }\end{array}$} & \multicolumn{2}{|c|}{$\begin{array}{c}\text { (2) } \\
\text { One-sided Violence }\end{array}$} \\
\hline & & & & \\
\hline Total peacekeepers & 0.0313 & $(1.09)$ & $-0.0556^{* * *}$ & $(-2.89)$ \\
\hline Combat (\%) & $-0.0304^{* * *}$ & $(-7.29)$ & $-0.00888^{* * *}$ & $(-3.18)$ \\
\hline Police $(\%)$ & $-0.0309^{* * *}$ & $(-4.57)$ & $-0.00913^{* *}$ & $(-2.02)$ \\
\hline Capability & $0.0222^{*}$ & $(1.93)$ & 0.00400 & $(0.52)$ \\
\hline Willingness & $0.321^{* * *}$ & $(3.36)$ & -0.00634 & $(-0.10)$ \\
\hline Capability X Willingness & $-0.00800^{* *}$ & $(-2.08)$ & 0.000504 & $(0.20)$ \\
\hline Conflict & $0.0544^{* * *}$ & $(3.43)$ & $0.0252^{* * *}$ & $(2.83)$ \\
\hline Personnel present & $1.960^{* * *}$ & $(4.85)$ & $0.873^{* * *}$ & $(3.22)$ \\
\hline \multicolumn{5}{|l|}{ Indirect Effects } \\
\hline Total peacekeepers & -0.0153 & $(-0.20)$ & 0.0164 & $(0.36)$ \\
\hline Combat (\%) & $0.0184^{*}$ & $(1.81)$ & -0.00558 & $(-0.88)$ \\
\hline Police $(\%)$ & 0.0170 & $(1.06)$ & -0.00306 & $(-0.31)$ \\
\hline Capability & -0.0476 & $(-1.64)$ & 0.0199 & $(1.11)$ \\
\hline Willingness & -0.0947 & $(-0.42)$ & $0.346^{* *}$ & $(2.44)$ \\
\hline Capability X Willingness & 0.0105 & $(1.11)$ & $-0.0121^{* *}$ & $(-2.05)$ \\
\hline Personnel present & -1.263 & $(-1.27)$ & -0.269 & $(-0.44)$ \\
\hline Spatial lag of DV & $0.478^{* * *}$ & $(24.05)$ & $0.674^{* * *}$ & $(64.18)$ \\
\hline Spatial lag of error term & $-0.558^{* * *}$ & $(-18.77)$ & $-0.806^{* * *}$ & $(-39.96)$ \\
\hline Std. dev. of errors & $1.959^{* * *}$ & $(203.05)$ & $1.271^{* * *}$ & $(209.17)$ \\
\hline Observations & 36394 & & 36394 & \\
\hline Number of grid cells & 1174 & & 1174 & \\
\hline Wald chi2 & 740.8 & & 4295.0 & \\
\hline Prob $>$ chi 2 & $2.72 \mathrm{e}-147$ & & 0 & \\
\hline Wald test of spatial terms & 655.0 & & 4583.0 & \\
\hline Prob $>$ chi 2 & $3.19 \mathrm{e}-135$ & & 0 & \\
\hline
\end{tabular}

$z$ statistics in parentheses

${ }^{*} p<0.10,{ }^{* *} p<0.05,{ }^{* * *} p<0.01$

error terms are large and statistically significant as well. The statistical significance of the Wald spatial test statistic for both models also confirms that the spatially lagged 
independent variables can be accurately interpreted as having direct and indirect effects, all of which provides additional support for the use of a SAR-based estimation process.

The second thing to note about these results is that they provide support for the existence of a relationship between UN peacekeepers and civil war violence at the locallevel. The exact nature of this relationship differs depending on the type of violence being considered, as well as when assessing direct versus indirect effects, but the statistical significance of many of the included indicators provides clear evidence that one exists.

Finally, the third thing worth noting about these results is that the interaction term between capability and willingness is once again statistically significant for both types of violence. These models therefore provide additional support for the idea that 'quality' in a peacekeeping context is a multifaceted concept, as well as that it matters at all. However, it is difficult to provide a more precise comment on the nature of this relationship without first exploring the relevant marginal effects.

In order to interpret the overall effects of these first two models, it is necessary to calculate the average direct, indirect and total effects of each independent variable on the reduced-form mean of the dependent variables. This process can be achieved via the 'estat impact' command in Stata 15, with the resulting output shown in Table 8. In this case, direct effects refer to the average impact of a variable on its own location, indirect effects to the average spill-over of that variable into other locations, and total effects to a combination of direct and indirect effects for each variable. The total average effects for each indicator can therefore be interpreted as the average cumulative impact of $\mathrm{X}$ on $\mathrm{Y}$ across all grid cells given a one-unit increase of $\mathrm{X}$ in any given cell. 
Interestingly, the average total effects for the battlefield violence model suggest that peacekeepers have no effect on overall fatality rates at all. Not a single one of the quantity or quality-related indicators remains statistically significant once the combination of direct and indirect effects has been taken into account. Instead, it appears that peacekeepers are only capable of reducing fatality rates within the context of their immediate location, with a negative and statistically significant direct effect reported for combat, police and the interacted quality term. The fact that these direct effects do not lead to an overall decline in violence suggests that peacekeepers are effective at displacing fighting from one area to another, but not at eliminating it altogether. This effect seems reasonable given that peacekeepers are often deployed to protect specific areas or to act as a buffer between combatants, particularly since local conflict actors are likely to have strong incentives to continue fighting elsewhere, if possible, in the pursuit of their own goals.

By contrast, the average total effects for the one-sided violence model indicate that overall rates of civilian killing can be reduced if the UN deploys high quality troops that consist predominantly of combat personnel. The total number of peacekeepers stationed in an area also appears to play a role in this process, as does the relative proportion of formed police units, albeit only in the context of their immediate location. These differences between the direct and total average effects for the one-sided violence model suggest that it is quality, rather than quantity, that allows peacekeepers to reduce rates of killing in neighboring areas. This effect is presumably due to the advantages that high quality peacekeepers possess in terms of either motivation, equipment or training, all of which 
would allow them to coerce conflict actors more effectively over a geographic area. ${ }^{72}$ In sum, the results of these models suggest that peacekeepers are capable of displacing battlerelated fatalities from one area to another and reducing overall rates of civilian killing.

Table 8 - Marginal effects of peacekeepers on the reduced-form mean of violence

\begin{tabular}{|c|c|c|c|c|}
\hline \multirow{2}{*}{ Average direct effects } & \multicolumn{2}{|c|}{$\begin{array}{c}\text { (1) } \\
\text { Battlefield violence }\end{array}$} & \multicolumn{2}{|c|}{$\begin{array}{c}(2) \\
\text { One-sided violence }\end{array}$} \\
\hline & $\mathrm{dy} / \mathrm{dx}$ & Z-score & $\mathrm{dy} / \mathrm{dx}$ & z-score \\
\hline Total peacekeepers & .0312865 & 1.09 & $-.0583808 * * *$ & -3.04 \\
\hline Combat (\%) & $-.0300847 * * *$ & -7.28 & $-.0103934 * * *$ & -3.73 \\
\hline Police (\%) & $-.0306893 * * *$ & -4.58 & $-.0103363 * *$ & -2.29 \\
\hline Capability $(\$ 1000 s)$ & $.0194452^{*}$ & 1.72 & .0069618 & 0.92 \\
\hline Willingness & $.325616^{* * *}$ & 3.47 & .0385267 & 0.61 \\
\hline Capability X Willingness & $-.0074969 * *$ & -1.97 & -.0010453 & -0.41 \\
\hline Conflict & $.056376^{* * *}$ & 3.44 & $.0274189 * * *$ & 2.83 \\
\hline Personnel present & $1.935536^{* * *}$ & 4.80 & $.9144594 * * *$ & 3.36 \\
\hline \multicolumn{5}{|l|}{ Average indirect effects } \\
\hline Total peacekeepers & -.0004695 & -0.00 & -.0549295 & -0.49 \\
\hline Combat $(\%)$ & .0065287 & 0.40 & $-.0301672 * *$ & -2.01 \\
\hline Police $(\%)$ & .0038227 & 0.15 & -.0240346 & -1.02 \\
\hline Capability (\$1000s) & -.062068 & -1.34 & .0589257 & 1.39 \\
\hline Willingness & .099156 & 0.27 & $.8913221 * * *$ & 2.70 \\
\hline Capability X Willingness & .0112703 & 0.74 & $-.0307746^{* *}$ & -2.21 \\
\hline Conflict & $.0437763 * * *$ & 3.42 & $.0443152 * * *$ & 2.84 \\
\hline Personnel present & -.5469728 & -0.34 & .833504 & 0.56 \\
\hline \multicolumn{5}{|l|}{ Average total effects } \\
\hline Total peacekeepers & .0308171 & 0.24 & -.1133103 & -0.98 \\
\hline Combat (\%) & -.0235561 & -1.38 & $-.0405607 * * *$ & -2.60 \\
\hline Police $(\%)$ & -.0268666 & -1.00 & -.0343709 & -1.41 \\
\hline Capability (\$1000s) & -.0426227 & -0.89 & .0658875 & 1.50 \\
\hline Willingness & .4247719 & 1.14 & $.9298488 * * *$ & 2.73 \\
\hline Capability X Willingness & .0037734 & 0.24 & $-.0318198 * *$ & -2.20 \\
\hline Conflict & $.1001523 * * *$ & 3.45 & $.0717341 * * *$ & 2.84 \\
\hline Personnel present & 1.388563 & 0.82 & 1.747963 & 1.13 \\
\hline
\end{tabular}
${ }^{*} p<0.10,{ }^{* *} p<0.05,{ }^{* * *} p<0.01$

72 The lack of information regarding combatant incentives and peacekeeper behaviour in these models means that it is impossible to offer a more precise explanation of this relationship. The ability of higher quality peacekeepers to reduce violence in neighbouring areas could be due to deterrent effects, perhaps due to something like an increase in the relative range or frequency of their patrols, or it could be due to the increased credibility of their compellent threats. It could also be due to some other factor entirely. It is for this reason that the precise causal mechanisms by which this relationship is presumed to operate, as outlined in Chapter 3, are explored in additional depth via the use of a process-tracing case study in the following chapter. 
To provide more context for this conclusion, it is useful to take a closer look at the substantive effects of the various quantity and quality-related indicators included in these two models. When interpreting these effects, the provided figures can be read as the effect of a 1 unit increase in $\mathrm{X}$ on the reduced-form mean of $\mathrm{Y}$, which is measured in units of 1 fatality per 10,000 people. In terms of quantity, for example, the direct effect of a one-unit increase in total peacekeepers for the one-sided violence model is a decrease in the average rate of killing by roughly 0.058 killings. Although this effect may not seem large, the average rate of civilian killing across the full sample of grid cells was approximately 0.06 fatalities per 10,000 people so it represents a significant decline in violence. The lack of an indirect or total effect for this indicator suggests that this reduction is fairly localized in nature, with civilian killing only declining within the immediate vicinity of UN personnel, but it is significant nonetheless.

In addition, the results of both models also suggest that the professional composition of local peacekeeping units plays a role in the management of violence as well. The direct effect of an increase in the proportion of either combat or police peacekeepers is negative and statistically significant in both models, with the substantive impact of each personnel type roughly equivalent for each type of violence. The fact that formed police units appear to be just as effective at reducing battle-related fatalities as combat troops may seem odd at first glance, but it is likely to suggest that the direct effects of peacekeepers on violence operate more through deterrence than compellence. By contrast, the ability of combat personnel to decrease rates of civilian killing through both direct and indirect effects suggests that they are more effective then police personnel at projecting control into nearby areas, which could be due to a mixture of deterrent patrols 
and compellent threats. Overall, then, it appears that increasing the proportion of either police or combat peacekeepers has a direct effect on both types of violence, but it is only through the deployment of combat personnel that overall levels of violence against civilians can be reduced.

The figures presented in Table 8 also suggest that personnel quality plays a role in the management of violence. The interacted term between capability and willingness is negative and statistically significant in both models, which suggests that peacekeepers become more effective at reducing violence as their relative quality increases. However, the provided figures do not reveal much regarding the substantive significance of this relationship because the ability of peacekeepers to reduce violence may vary depending on their relative values of capability and willingness. If this relationship is examined in additional detail, it quickly becomes clear that combat troops perform more effectively when they are both highly trained and willing to take action. ${ }^{73}$ For example, if the value of capability is set at its mean, a $\$ 1000$ increase in average per capita defence spending leads to very different outcomes depending on the relative willingness scores of the troops in question. Combat troops with the lowest possible CIRI score of 0 are predicted to increase

\footnotetext{
${ }^{73}$ Although the interacted quality indicator was shown to be negative and statistically significant in the context of the battlefield violence model, it was only the average direct effects of this indicator that mattered rather than its average total effects. As a result, the relative quality of combat personnel appears to play a role in the reduction of battle-related fatalities within the immediate vicinity of a UN base but not overall. Unfortunately, the 'margins' and 'marginsplot' commands used to analyze the marginal effects of the interacted quality variable in Stata can only be applied to the total effects of a particular indicator, rather than only its direct or indirect effects. The analysis in this paragraph is therefore focused solely on the relationship between personnel quality and one-sided violence, which was found to have a negative and statistically significant average total effect. Having said that, the dynamics between capability and willingness are likely to be similar regardless of the type of violence in question, as suggested by the similarities between the two margin plots presented in Chapter 4. But the inability to target the Stata commands more precisely means that this assumption cannot be backed up with the kind of detailed figures provided by analyzing the effects of one indicator when the other is set equal to various representative values.
} 
rates of civilian killing by roughly 0.07 for each $\$ 1000$ increase, whereas combat troops with the highest possible CIRI score of 8 are predicted to decrease rates of killing by roughly 0.19 instead. Although these are extreme examples, they suggest that the most willing troops are nearly three times as effective at reducing one-sided violence as the least willing troops, provided their relative military capability is held constant.

Figure 8 - Marginal effects of peacekeeper quality on violence

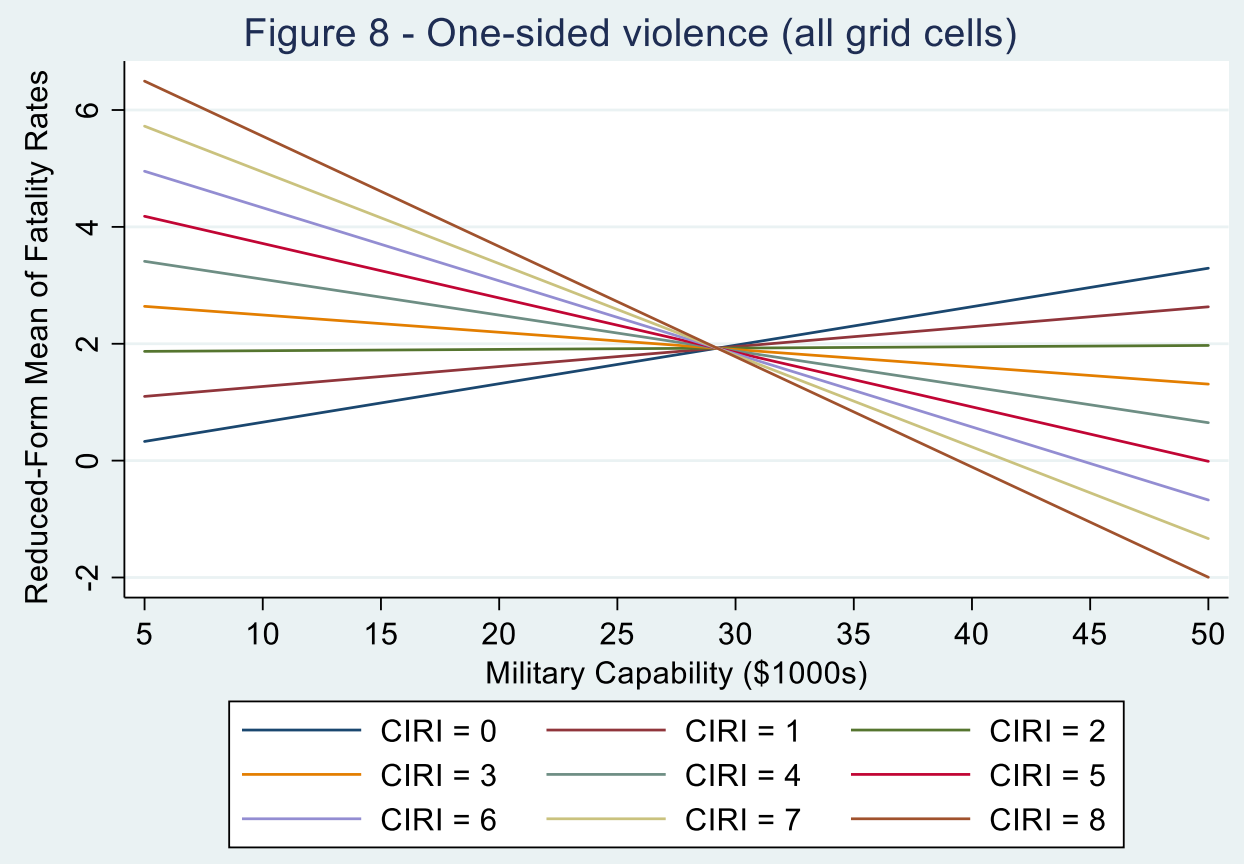

Note: Each line represents the marginal effects of military capability on violence when willingness is held fixed at representative values, as measured in the predicted average fatality rate per 10,000 people in each grid cell.

As shown in Figure 8, this divergence in effectiveness persists if the value of capability is allowed to vary as well. If per capita defence spending is increased from $\$ 5,000$ to $\$ 50,000$, troops with lower CIRI scores become less effective and troops with higher CIRI scores become more effective. In substantive terms, this amounts to a decline in average rates of civilian killings by roughly 8 per quarter for the highest willingness troops when their capability is increased as compared to an increase of roughly 3 per 
quarter for the lowest willingness troops. These substantive effects provide additional support for the idea that the relative quality of UN peacekeepers matters at the local-level, with the most effective troops found to be both highly capable and highly willing to take action.

\subsubsection{Sensitivity Tests}

The two main models presented above were also subjected to a series of sensitivity tests in order to probe the accuracy of their results. These tests were run using a mixture of different samples, spatial weight matrices, and dependent and independent variables, the majority of which provide support for the robustness of the original two models. The results for eight of these tests are reported below.

The first sensitivity test looked at the relationship between peacekeepers and violence when using attack rates per 10,000 people as the dependent variable. The motivation behind this test was to determine whether peacekeepers are capable of reducing the rate of attacks experienced at the local-level or if their effects are solely limited to the mitigation of lethality. Any variation in the performance of these new models would therefore suggest a sensitivity to the chosen definition of violence. As it turns out, the results of these new models are nearly identical when comparing violence against civilians but very different when looking at battle-related attacks. For the civilian attacks model, the total average effects of combat and the interacted quality term remain negative and statistically significant so the importance of high quality combat personnel remains unchanged. The only difference in these new results is the loss of statistical significance for the total peacekeepers indicator when looking at direct effects and the combat indicator 
when looking at indirect effects, although the latter remains relatively close to conventional levels of statistical significance.

However, for the battle-related attacks model, there is a loss of statistical significance for every indicator that had previously been shown to have a direct effect on violence aside from the proportion of combat personnel. This single indicator retains its negative effect on violence, with a $1 \%$ increase in the ratio of combat personnel leading to a modest $0.001 \%$ decline in attacks, but it fails to gain statistically significant indirect or total effects. Given these results, it appears that peacekeepers are equally effective at reducing the frequency and lethality of attacks against civilians, but that they are less effective when it comes to reducing the number of battle-related attacks. Although the reasons for this diminished effectiveness are not immediately clear, it may indicate that peacekeepers have a difficult time preventing the outbreak of fighting altogether but that they can typically act quickly enough to minimize the lethality of armed clashes whenever they do occur.

The second sensitivity test continued to probe the chosen definition of violence by splitting one-sided violence into two different indicators based on who was doing the killing. The first indicator represented the rate of killing perpetrated by government actors whereas the second indicator looked at the rate of killing by non-state actors. If it turns out that the means of reducing one type of violence differ significantly from the means of reducing the other, then it would suggest that the UN should vary its local deployment patterns based on the relevant conflict characteristics. Interestingly, the average total effects of these new models closely resembled those of the original model. The only changes worth noting were the loss of statistical significance for the indirect and total 
effects of quality in the government killings model, as well as the gain of a negative total effect for the amount of deployed personnel. These findings suggest that only quantityrelated factors matter when it comes to reducing killings by government actors, whereas both quantity and quality matter when dealing with non-state actors. This difference may be due to the differing incentive structures of the two types of actors, with government killings less likely to occur when there is a risk of being observed by nearby groups of peacekeepers versus killings by non-state actors that may require more active forms of intervention.

Although this finding is interesting on its own, where these two new models differ completely is in the nature of their direct and indirect effects. The ability of peacekeepers to reduce government killings is driven entirely by the direct effects that they have on their own grid cells, whereas their ability to reduce killings by non-state actors is driven entirely by their indirect effects on neighbouring grid cells. Despite being puzzling at first glance, this stark contrast in the manner of reducing violence is likely due to the fact that peacekeepers are commonly stationed in government-held territory rather than territory controlled by rebel groups or militia. It would therefore be relatively straightforward for them to deter government violence within their immediate area, whether through direct intervention or passive observation, but the management of violence by non-state actors would require intervention into adjacent areas instead.

The third sensitivity test moved beyond definitions of violence and focused instead on the effects of changes to the underlying sample. Rather than estimating the models using the full sample of available grid cells, the objective here was to see if the relationship between peacekeepers and violence varied if limited solely to areas that had hosted UN 
personnel at some point in time. Since the underlying statistical model requires strongly balanced data to function, this more limited sample ended up consisting of 13,640 observations for the 440 grid cells that had ever contained a group of peacekeepers or been located immediately adjacent to them. Although removing any spill-over effects from the excluded grid cells is not recommended ${ }^{74}$ the deployment bias in this sample remains in favour of more violent locations rather than less violent locations so it should pose a similarly tough test of effectiveness.

In terms of their results, the new battlefield violence model was virtually identical to the original, with no changes in terms of either statistical or substantive results, but the new one-sided violence model revealed some minor variation. This variation included a loss of the direct effects of police, the indirect effects of combat and the interacted quality indicator, as well as the total effects of the interacted quality indicator. However, all of these terms remained close to conventional levels of statistical significance, with p-values of between 0.159 and 0.168 reported for all four indicators. Given how close these values were to the 0.10 threshold, it seems reasonable to suggest that the stronger deployment bias towards more violent locations in this sample may have played a role in eliminating the previously significant results. Nonetheless, the relative proportion of combat personnel continued to have a negative and statistically significant effect on violence despite these other changes, so peacekeepers were still able to have an effect on the rate of civilian killing

\footnotetext{
${ }^{74}$ Due to the spatial nature of the underlying estimation technique, any changes in the direct or indirect effects of any one grid cell have the potential to affect outcomes in every other grid cell. Removing non-neighbouring grid cells from the sample is therefore problematic because it means that the contribution of any spillover effects from more distant grid cells will not be accounted for in the final results. Nonetheless, testing the main models using a more limited sample still has value, even if it risks introducing a larger degree of spatial bias into the subsequent results.
} 
even in this more limited sample. In sum, there appears to be a minor amount of sensitivity to the chosen sample in the case of violence against civilians but none at all when looking at rates of battle-related fatalities. ${ }^{75}$

The fourth sensitivity test adopted a similar focus on sample selection by seeking to identify the potential effects of endogeneity bias related to the deployment patterns of UN personnel. The dataset was therefore split into grid cells that had experienced average rates of violence that were either above or below the sample mean throughout the full eightyear sample period. Although spitting the sample in this manner is not recommended due to the loss of spillover effects from excluded grids, it is nonetheless worth a quick test to see if any obvious sources of endogeneity bias can be identified. It is also worth noting that, as discussed above, the existence of such a bias is unlikely to make for an easier test of effectiveness because larger numbers of higher quality peacekeepers tend be found in more violent locations rather than less violent locations.

Once tested in this manner, the differences between the two new battlefield violence models were relatively limited, with no changes observed in the total average effects for either sample. For the one-sided violence models, however, the differences between the high and low violence samples were starker. The high violence model gained a negative and statistically significant total effect for the police indicator and continued to return negative total effects for combat and the interacted quality term. But the low violence model saw a loss of statistical significance for all quantity and quality-related indicators

\footnotetext{
75 These conclusions remained unchanged when an additional variable was inserted into both models to account for levels of pre-intervention violence in each grid cell. Regardless of whether the measure in question looked at average fatality rates over the previous six-month period or the previous three-month period, there were no changes in terms of either statistical or substantive significance relative to the results of the neighbouring-cell only models reported in this paragraph.
} 
aside from combat, which had a small positive total effect of 0.00049 rather than the anticipated negative. These differences suggest that peacekeepers are more effective at reducing rates of civilian killing in areas with higher average levels of violence, which is likely to do with the fact that they are more likely to be deployed to such locations in the first place. At the same time, however, the p-values of the interacted quality term in the low violence model were once again close to conventional levels of statistical significance, with a range of between 0.134 and 0.127 . So, although there continues to be some evidence of endogeneity bias in the one-sided violence models, the effects of the interacted quality indicator remained similar nonetheless.

The fifth sensitivity test finished off the analysis of different samples by running the models separately for each peacekeeping host country. ${ }^{76}$ This test was designed to provide insight into how accurate the aggregate findings were with respect to the specific conflict dynamics in CAR, the DRC and South Sudan. ${ }^{77}$ As expected, the results of these new models varied significantly from one country to the next. In terms of total effects, the reduction of battlefield violence in CAR is linked to the relative proportion of combat troops and formed police units, whereas it is linked solely to troop quality in the DRC and South Sudan. Similarly, the overall reduction of one-sided violence in CAR is once again

\footnotetext{
${ }^{76}$ The reported results remain consistent regardless of whether the conflict indicator is included in these models or not, with the sole exception being the loss of statistical significance for the total average effect of the total peacekeepers indicator in the South Sudan model.

${ }^{77}$ Due to the individual nature of these tests, there is less of a theoretical need to include a broader indicator to account for state-level conflict dynamics. The discussion in this paragraph is therefore based on the results of six county-specific models that were estimated without the previously included conflict indicator, which had been used in the main models to control for the presence or absence of armed conflict from one operational context to the next. At the same time, however, it is worth noting that the results of these models remain statistically and substantively consistent even when the conflict indicator is included. The sole exception is the one-sided violence model for South Sudan, which gains a negative and statistically significant total average effect for the total peacekeepers indicator when conflict is included and just barely misses out on one when it is not ( $p$-value of 0.119 ).
} 
linked to the effects of combat and police, whereas none of the indicators return a total average effect that is statistically significant in the case of South Sudan or the DRC. However, these overall effects, or lack thereof, also mask a significant amount of variation from one country to the next in terms of the direct and indirect effects reported for each indicator, with the interacted quality term mattering in most contexts but not all.

Interestingly, the country that most closely resembles the results of the original two models is actually CAR rather than the DRC, despite the fact that it represents only $14 \%$ of the total observations in the full sample of grid cells. So there does not appear to be a large bias in the original models in favour of the largest of the three operational environments. Nonetheless, the fact that this level of variation exists when the sample is broken down by country is a clear indication that local conflict dynamics play an important role in shaping the effectiveness of UN peacekeepers at the local-level. The aggregate results should therefore be viewed as a reasonable assessment of the effects that these quantity and quality-related indicators have on average, but that does not mean that they will have an identical effect in every context.

The sixth sensitivity test moves away from testing different samples in order to assess the impact of three additional independent variables. The first two variables were designed to account for any seasonal effects that might influence rates of killings, with one used to mark the start of the rainy season in each grid cell and the other the start of the growing season. The expectation with regard to the rainy season dummy variable is that it would coincide with decreased fatalities, since the poor infrastructure in all three countries makes it difficult to travel during this time of year, whereas the start of the growing season should similarly reduce violence due to a higher demand for labour. Once tested, however, 
it turns out that neither the onset of the rainy season nor the start of the growing season have a discernable effect on fatality rates within their respective grid cells. The lack of an effect in this case could either be evidence of a true underlying relationship, in which changes in the seasons have little impact on the incentives that combatants have to use violence in these conflicts, or it could be a by-product of the relatively coarse nature of the available data.

For the third variable, I coded each deployment location as being either multinational or not based on whether it contained uniformed personnel of any type from more than one country. The goal here was to test whether interoperability issues between contingents from different TCCs would hinder the UN's ability to manage on-going violence, with the expectation being that multinational units would be less effective than units supplied by a single country. Although the average total effect of this new indicator was not statistically significant for either type of violence, the direct effect of deploying a multinational unit was shown to increase rates of civilian killing by approximately 0.36 fatalities per 10,000 people. So, all things equal, the co-location of peacekeepers from different countries is associated with more violence against civilians rather than less, which calls into question previous findings regarding the desirability of ethnically or linguistically diverse operations (Bove and Ruggeri 2016). At the same time, however, this effect is counteracted somewhat by the fact that the direct effect of the total peacekeepers indicator remains statistically significant, with a decrease of 0.08 in rates of civilian killing per each additional unit. It should therefore be possible to mitigate the downsides of mixing together units from different countries as long as the number of peacekeepers stationed in that location is large enough. 
The seventh sensitivity test continued the assessment of additional variables by evaluating an alternative indicator of peacekeeper quality. The idea behind this test was to determine whether combat troops from the highest quality TCCs performed more effectively than their peers. After identifying the top 5 TCCs in terms of capability, willingness and overall quality, a percentage-based indicator was developed to identify the proportion of high quality troops located in each grid cell. The original two models were then re-run using these new indicators of quality rather than the interaction term between capability and willingness. Oddly enough, the results of these new models suggest that the presence of the highest quality combat troops has no discernable effect on either type of violence. The lack of an effect in this context suggests that the average quality of peacekeeping personnel is more important than their maximum quality when seeking to assess outcomes at the local-level. This finding differs from the results of the state-level model, in which the top $10 \%$ of peacekeepers were found to have an outsized effect on violence against civilians.

The reason for this difference is likely to be twofold. First, unlike in the state-level analysis, the chosen measure of quality in this chapter does not account for the relative characteristics of support personnel, some of whom come from countries with highly capable militaries and excellent human rights records. Excluding these personnel makes sense when seeking to evaluate the importance of quality at the local-level because the contribution of support troops, such as transport helicopters and intelligence personnel, is unlikely to be linked explicitly to a single location. But it does mean that the state-level models account for the operation-wide effects of such personnel whereas the local-level models do not, which could be the cause of this discrepancy in their results. Second, it is 
also possible that the static nature of the underlying map data is poorly suited to capturing the effects of the highest quality combat personnel. Many operations delegate a small number of high quality troops to act as a quick reaction force, who would then be expected to shift regularly from one location to the next. In fact, this is the exact relationship captured in the process-tracing case study that follows, in which MINUSCA's highest quality peacekeepers are constantly being redeployed. So it is entirely possible that the UN's highest quality troops are capable of having outsized effects on violence but that the quarterly deployment data is insufficiently nuanced to capture their presence.

Finally, the eighth sensitivity test sought to evaluate the consistency of the reported results when using an alternative spatial weights matrix. Since this matrix is responsible for defining all aspects of the spatial relationship between grid cells, it is possible that altering the nature of this matrix could lead to very different results. Two variants of the matrix were tested. The first variant treated first-order neighbours for each grid cell as being equal to 1 , second-order neighbours as being equal to 0.5 and all other cells as being equal to 0 . Once the new models were estimated, the only difference between this matrix and the original queen-contiguity matrix was that the total effect of the combat indicator in the battlefield violence model became negative and statistically significant. This indicator had been close to conventional levels of statistical significance in the original matrix, with a p-value of 0.168 , so slightly broadening the definition of what constitutes a neighbouring cell appears to have tipped the balance.

Similarly, the second variant defined first-order neighbours as being equal to 1 , second-order neighbours as also being equal to 1 , and all other grid cells as being equal to 0. So, it is similar to the first, albeit with the contribution of second-order neighbours 
treated as being equivalent to first-order neighbours rather than set to half to mimic a distance-decay function. Once again, the differences between this new matrix and the original matrix were minimal, with the total effect of the combat indicator becoming negative and statistically significant for the battlefield violence model and the total effect of the police indicator becoming negative and statistically significant for the one-sided violence model. These findings suggest that the results of the original models are robust to alternative matrix specifications, with the sole exception being some minor variation in the professional composition indicators when a broader definition of neighbouring cells is taken into account.

\subsection{Discussion and Conclusion}

The results of the models and sensitivity tests discussed above all point to a single conclusion: the UN's ability to manage violence at the local-level depends on both the relative quantity and quality of its peacekeeping personnel. This conclusion provides further support for the results of the state-level analysis conducted in Chapter 4, which identified a similarly important link between these two factors and an operation's overall performance. Where the results of these two chapters differ, however, is in terms of the relative precision of their chosen approach. The previous chapter looked solely at the effects that average levels of quantity and quality have on violence, whereas this chapter looks explicitly at the relative characteristics possessed by specific groups of personnel. It is therefore able to provide a greater level of insight into the question of why some groups of peacekeepers are more effective than others, which the previous chapter could hint at 
but not comment on precisely. Below, I expand on this point further by exploring the main findings from this chapter in additional depth.

First, the main finding related to quantity is that the relative effectiveness of different groups of peacekeepers varies based on the nature of their professional skillset. Peacekeepers who are suited to engaging directly with local conflict actors, such as infantry personnel and formed police units, have a statistically and substantively significant effect on violence, whereas peacekeepers who are suited to support roles typically do not. This finding provides partial support for Hypothesis 1 from Chapter 3 (i.e., the higher the quantity of peacekeeping personnel, the lower the amount of violence), with the sole exception being the relative ineffectiveness of support personnel. The only context in which the overall size of a local deployment matters is when it comes to the management of nearby rates of one-sided violence, which suggests that the presence of support troops may contribute to a localized deterrent effect in specific circumstances. However, this deterrent effect is not strong enough to reduce total rates of violence across the conflict as a whole, which suggests that increasing the overall number of troops in an area may simply force conflict actors to shift their predatory activity elsewhere.

By contrast, the consequences of increasing the proportion of combat or police personnel at the expense of support personnel almost always leads to a reduction in violence. These results suggest that aggregating military peacekeepers into a single variable at the state-level of analysis may be hiding potential sources of variation in operational effectiveness. They also suggest that particularly violent areas within each operation would benefit from the presence of peacekeeping personnel that are capable of coercing local conflict actors directly. Having said that, no operation is capable of 
functioning without the support provided by engineering, transportation, aviation, signals, maintenance and medical personnel. They serve a critical role in enabling the activities undertaken by their more combat-oriented counterparts, both at the local-level and when it comes to shaping operational outcomes as a whole. But their ability to influence levels of violence within their immediate area appears to be minimal relative to the contribution made by combat personnel and, in some cases, civilian police.

Second, the main finding related to peacekeeper quality is that it directly contributes to the effectiveness of individual groups of military peacekeepers. The results of the geospatial models demonstrate that combat troops from countries with highly capable militaries and strong human rights records are significantly more effective at reducing local fatality rates than their lower quality counterparts. These findings apply equally to both battlefield violence and one-sided violence against civilians, albeit only in a direct sense when it comes to the former. The deployment of high quality personnel is therefore essential when it comes to reducing overall rates of civilian killing, as well as when seeking to dissuade conflict actors from fighting within close proximity to a specific location. These findings provide direct support for Hypothesis 2 (i.e., the higher the quality of peacekeeping personnel, the lower the amount of violence), as well as the overall argument made by this dissertation.

In addition, the slope analysis presented in Figure 8 suggests that moderately capable peacekeepers perform more-or-less equally regardless of their underlying willingness to act, but that the most willing peacekeepers perform effectively regardless of whether they possess relatively high or low capabilities. These results provide support for Hypotheses 3 and 5, which expected that peacekeepers would either be highly or 
moderately effective when they possessed a high level of motivation. They also provide support for Hypothesis 6, which expected that the least effective peacekeepers would be ranked poorly in terms of both capabilities and willingness. However, it was surprising to discover the apparent ineffectiveness of 'elite' personnel when this indicator was assessed in the sensitivity test section, particularly given the opposite results reported in the previous chapter. One goal of the case study chapter that follows, therefore, will be to identify whether small groups of very high quality personnel are capable of having an outsized effect on violence.

Third, the other major finding from this chapter is that peacekeepers are not equally effective at addressing both types of civil war violence at the local-level. When it comes to civilian killings, the evidence shows that an increase in either the quality of nearby troops or the relative proportion of combat personnel is sufficient to reduce local fatality rates. This reduction takes place in both the immediate vicinity of peacekeeper locations as well as in surrounding areas, with the net effect leading to an overall decrease in rates of civilian fatalities across the country as a whole. This effect appears to operate differently depending on the perpetrators of violence, with violence by government actors reduced by co-located peacekeepers and violence by non-state actors reduced by nearby groups of peacekeepers. But it nonetheless results in an overall reduction in rates of civilian killings.

By contrast, the ability of peacekeepers to reduce battlefield violence appears to be more limited in scope. An increase in either the quality of nearby troops or their relative proportion of combat and police personnel appears to reduce local fatality rates, but only within the immediate vicinity of peacekeeper locations. These results suggest that peacekeepers can be used to mitigate the lethality of fighting within specific areas but that 
this effect is achieved by forcing local conflict actors to fight elsewhere rather than eliminating fighting altogether. In addition, the fact that these results clash with the findings of the state-level analysis, in which peacekeepers were found to be effective at reducing both types of violence, may indicate that some of the UN's ability to manage battlefield violence is due to operation-wide effects. These effects could be related to the efforts of more mobile groups of peacekeepers, whose movements may not be as well represented by the static nature of the deployment maps, or potentially something of a non-military nature, such as the UN's diplomatic or humanitarian initiatives. Based on the evidence in this chapter alone, however, it appears that the $\mathrm{UN}$ is more effective at reducing violence against civilians than it is at eliminating battlefield violence.

In conclusion, the main takeaway from this chapter is that the UN's ability to manage violence at the local-level depends on the relative quantity and quality of its peacekeeping personnel. If an operation deploys a larger proportion of higher quality combat personnel to a particular location, then the peacekeepers in that location should become more effective at reducing nearby rates of war-related fatalities. This effect appears to be greater when the UN is addressing rates of civilian killings, which it can decrease across the conflict as a whole, but it is still able to decrease rates of battle-related fatalities in nearby locations. Therefore, this chapter provides additional support for the overall argument made in this dissertation, namely that the relative quality of UN peacekeeping personnel contributes to operational effectiveness.

This chapter also makes four main contributions to the literature on peacekeeper quality. First, it represents a novel test of the relationship between peacekeepers and the severity of on-going violence, rather than its geographic scope, temporal duration or 
likelihood of occurring. Second, it evaluates the relationship between peacekeepers and battlefield violence, instead of focusing solely on violence against civilians. Third, it establishes that it is important to distinguish between different types of military personnel, with combat troops having a greater effect on violence than support troops. And fourth, it demonstrates that peacekeeper quality matters at the local-level in the same way that it does at the operational-level. However, the data used in this chapter remain relatively coarse and the chosen econometric method made it difficult to model the hypothesized relationship between peacekeepers and conflict actors. It is for this reason that the following chapter turns to a more detailed analysis of a single operational environment, which provides an opportunity to trace any strategic interaction that may take place between peacekeepers and conflict actors over time. 


\section{Chapter 6: Case Study (MINUSCA)}

In the previous chapter, I demonstrated that some groups of peacekeepers are more effective at managing violence than others. If the peacekeepers stationed in one location are relatively high quality and possess skillsets suited to direct engagement with conflict actors, then they should be more effective at reducing violence than lower quality peacekeepers stationed in another location who are suited to operational support. Although this conclusion was not surprising, its explicit focus on the relative characteristics possessed by different groups of peacekeepers represented a novel approach in the field of UN peacekeeping. In addition, the previous chapter also found that peacekeepers tend to be more effective at reducing rates of civilian killings rather than battle-related fatalities, as well as the fact that their performance tends to vary based on the unique nature of their underlying conflict environment. However, despite being estimated at a lower level of analysis, the geospatial models used to generate these results still lacked sufficient nuance to comment directly on the hypothesized process of coercive interaction between peacekeepers and conflict actors.

In this chapter, I assess this relationship directly by introducing fine-grained qualitative data in the form of a process-tracing case study. This exercise should make it possible to identify precisely how and why an increase in peacekeeper quality leads to a reduction in violence, as well as to probe the results of the previous two chapters in additional depth. To this end, the chapter begins with a brief overview of the theoretical model developed earlier in this study and then lays out the methodological justification for selecting the specific case of UN intervention in CAR. It then divides the timeline of MINUSCA's operations in CAR into two distinct time periods, with the intention of 
identifying any overall lessons related to the relationship between peacekeepers and violence. Finally, the chapter concludes by analyzing three discrete conflict episodes, each of which highlights that the success or failure of the UN's coercive efforts is influenced by the relative quantity and quality of its peacekeeping personnel

\subsection{Theory \& Methodology}

The core argument advanced in this dissertation is that the relative quality of UN peacekeepers plays a role in their ability to manage on-going violence. It naturally follows from this argument that groups of peacekeepers who possess a qualitative advantage over their peers, either with regard to their professional capabilities or their willingness to act when faced with violence, should be more effective at carrying out their duties than groups of peacekeepers who lack such an advantage. Although the results of the previous two chapters suggest that this relationship does in fact exist, they provide little insight into the specific mechanisms by which it takes place. This shortcoming is an inevitable consequence of evaluating something as complex as UN peacekeeping using quantitative data, in which the desire to produce a sufficiently generalizable result necessarily requires a degree of sacrifice with regard to the finer details. However, the use of a mixed-methods research design provides one means of overcoming such shortcomings, which is why this chapter introduces fine-grained qualitative data in the form of a process-tracing case study. Below, this section briefly expands on the rationale for introducing qualitative data at this point in the dissertation and then explains why I chose to focus on the single case of MINUSCA in CAR. 
The motivation for evaluating a specific case of UN intervention using qualitative data rests on two main points. First, the narrative structure of a case study should make it possible to identify precisely how and why an increase in peacekeeper quality results in decreased levels of violence. I argue that higher quality peacekeepers are more effective than their peers due to the advantages that they possess when it comes to coercion, as outlined in Chapter 3, but I have yet to demonstrate that this kind of interaction actually takes place on the ground. The absence of such details makes it difficult to build a compelling case in favour of the proposed causal mechanism, even though it seems to be theoretically plausible.

To review, this mechanism is presumed to operate through a process of strategic interaction between peacekeepers and conflict actors, in which the goal is to influence the behaviour of the other actor via the delivery of credible threats and assurances. Peacekeepers must therefore be capable of manipulating the three constituent elements of credibility, namely the certainty, severity and swiftness of the proposed action, if they wish to be effective at managing on-going violence. Since higher quality peacekeepers should have an easier time manipulating these three factors than lower quality peacekeepers, it seems reasonable to argue that this should provide them with an advantage when it comes to the management of on-going violence. Their attempts to coerce conflict actors may still fail in the presence of certain confounding factors, such as when peacekeepers lack superiority in terms of brute force, are unable to assert escalation dominance or are faced by armed groups who possess overriding incentives to use violence, but they should nonetheless be more effective at this task than their counterparts. But, the nature of the quantitative data used in the previous two chapters makes it difficult to identify precisely 
how this relationship operates in practice, which is why the insights provided by a qualitative case study are necessary.

Second, the inclusion of a case study also makes it possible to probe the results of the previous two chapters in additional depth. The use of a case study in this manner is referred to by Cresswell and Clark as an "explanatory sequential" process $(2011,82-86)$, in which the qualitative strand of a project is used to probe the accuracy of an initial set of quantitative results. In the context of this study, the most significant finding is that an increase in peacekeeper quality has a negative effect on violence at both the state-level and the local-level. However, it is possible that this relationship is either spurious in nature or the result of flaws in the proxy indicators that were used to represent peacekeepers and violence. One of the major benefits of engaging in a qualitative case study is therefore the opportunity to dig deeper into a specific operational context in order to see if evidence of such a relationship can be found. If not, then it would suggest that the results of the previous two chapters should be re-evaluated in this light. In addition, the use of a case study also provides an opportunity to determine the truth of any findings that may have differed from one chapter to the next. The most puzzling of these findings was the statistical and substantive significance of "elite" troops at the state-level but their apparent insignificance at the local-level. Others include the fact that peacekeepers were shown to have no total average effect on battlefield violence when assessed at the local-level, despite the fact that both the interacted quality term and the proportion of military personnel were shown to have a negative effect on battlefield violence at the state-level. Although it will not be possible to probe every outcome of the previous chapters in this manner, leveraging the 
benefits of qualitative data in a case study format should nonetheless serve to bolster the explanatory power provided by these initial quantitative results.

Since both of these motivations reflect a desire to examine the interaction between peacekeepers and conflict actors in additional detail, the appropriate tool to use is a processtracing case study. According to Stephen Van Evera, this type of case study is designed to explore "the chain of events or the decision-making process by which initial case conditions are translated into case outcomes" (1997). It is therefore the perfect tool by which to examine the causal relationship between an independent variable and a dependent variable, both in terms of identifying the relevant causal mechanisms and when seeking to verify whether such a relationship exists. It works by allowing the researcher to break down the causal chain between two variables into a series of smaller steps so that they can search for evidence of the proposed relationship along the way. It differs in this sense from other forms of case studies, such as congruence or controlled comparison, because it is designed to glean insight from tracing a specific sequence of events rather than through a comparison with another case or against a set of representative values.

In this case, the goal is to trace the conflict dynamics of a specific operational environment in order to determine how peacekeepers interact with conflict actors and whether higher quality peacekeepers are more effective than lower quality peacekeepers. If the argument that I have proposed is correct, this exercise should reveal that episodes of coercive interaction take place on a regular basis and that the relative quality of UN peacekeeping personnel plays a role in determining their outcome. By contrast, a negative finding would indicate that all groups of peacekeepers perform more-or-less equally when 
they are deployed in the field, despite any variation in their professional capabilities or willingness to act.

In terms of case selection, the single case of MINUSCA is an ideal operational environment to explore this topic for three main reasons. First, this case is data-rich. The fact that the conflict is still on-going means that it has not received as much academic attention as some of the earlier peacekeeping operations, but there is a wealth of primary material available that provides a clear picture of the underlying conflict dynamics. As a result, there should be ample opportunity to test the theory in question by tracing the interaction that has taken place between peacekeepers and conflict actors. Most of this information is contained in various UN reports, such as Reports of the Secretary-General to the UN Security Council, Reports of the Panel of Experts on the Central African Republic and Reports of the International Commission of Inquiry on the Central African Republic. These reports provide an excellent source of information with regard to the overall military-political narrative of the conflict in CAR, particularly when it comes to identifying the main drivers of violence in different regions of the country as well as notable instances of coercive interaction. They are complemented in this regard by a number of more targeted UN reports, such as audit and evaluation reports prepared by the UN's Office of Internal Oversight Services (OIOS), reports into specific incidents of violence prepared by the UN's Human Rights Division and even a leaked internal readiness assessment from MINUSCA's operational command. Although it would have been ideal to obtain even more information of this nature, the UN prefers to keep its operational reports classified in most cases rather than make them available to the public. Nonetheless, the combination of these $\mathrm{UN}$ reports with other relevant documents, such as NGO reports 
on violence, reporting by the international news media and statements made by members of armed groups, provides a compelling case for MINUSCA's suitability to serve as the subject of a process-tracing case study.

Second, this case contains a large amount of within-case variation. Since this variation can be observed in terms of both time and space, it provides numerous opportunities to explore the theoretical predictions made in this study. In terms of violence, for example, an analysis of the quantitative data reveals significant swings in violence over the course of the UN's intervention in CAR. There is also a significant amount of regional variation in violence during this time period, with some regions of the country generating more or less fatalities depending on shifts in their underlying conflict dynamics. Although these data are discussed in more detail below, it is worth noting for now that this variation exists and is an asset when it comes to exploring the interaction between peacekeepers and conflict actors.

Similarly, this operation also contains a significant amount of variation with regard to the relative quantity and quality of its peacekeeping personnel. This variation provides an opportunity to observe the effects of improvements in MINUSCA's overall quality, which relates to the state-level analysis conducted in Chapter 4, as well as the kinds of local-level dynamics assessed in Chapter 5. The sheer number of armed groups involved in this conflict also makes it an ideal environment to observe the interaction between the UN and conflict actors with different incentive structures. The need to keep track of all of these groups is a bit of a mixed blessing, but the combination of multiple conflict actors with significant variation in terms of quantity, quality and violence makes MINUSCA an ideal case for the purposes of this study. 
Third, this case touches on a number of issues that are currently of concern to policy makers. The results of any tests conducted in the context of this single case should therefore have policy implications for other cases as well, which makes it more attractive than some of the alternatives. The most important issue in this regard is related to MINUSCA's overall mandate in CAR, which places it firmly within the camp of the UN's new category of ‘stabilization' operations. This type of operation differs from a standard multidimensional operation in the sense that it is deliberately biased towards the extension of state authority and accepts the need for a more permissive attitude towards the use of force, both of which violate the UN's traditional approach to peacekeeping. Due to the controversial nature of these differences, the insights that this case provides regarding the overall efficacy, and viability, of deploying such operations should contribute to the contemporary academic and policy debates outlined in Chapter 2 .

In addition to contributing to these overarching debates, the experience of MINUSCA in CAR is also relevant to a number of more targeted issues as well. These issues include the practice of 're-hatting' troops from pre-existing operations, the phenomenon of multiple simultaneous peace operations, and the increasing number of deadly attacks being directed towards peacekeeping personnel. More fundamentally, the fact that MINUSCA remains an on-going operation, and looks set to continue for at least the next couple of years, means that any insights gleaned from this case should also have direct implications for its future activities. Overall, then, this operational context makes for a good case study because it touches on a number of issues that policy makers care about, both in CAR and elsewhere. 
Although the methodological approach laid out in this section has many strengths, it is also important to note that it is not without its weaknesses. The first weakness is that it primarily relies on documentary evidence to probe the relationship between peacekeepers and conflict actors, rather than drawing upon first-hand information in the form of interviews or questionnaires. Relying solely on documentary evidence is not necessarily a problem, particularly given the extensive amount of material that is available in this case, but it does limit the scope of inquiry to conflict episodes contained within UN reports, NGO publications and articles by the international news media. One way to address this shortcoming would be to incorporate information from MINUSCA's internal reports, which should presumably contain more detailed information regarding specific operational dynamics, but they are unfortunately kept classified for security reasons. As a result, both the selection of conflict episodes examined below and the depth in which they are analyzed necessarily varies based upon the nature of the available evidence, which is better in some cases and worse in others.

The second weakness is that despite being an ideal case for the purposes of this study, relying solely on the operational experience of MINUSCA does serve to limit the external validity of any findings. Its issues may resemble those faced by the UN elsewhere, but the fact that it is operating within a unique conflict environment makes it difficult to know definitively whether insights derived from this case will apply to others. At the same time, however, the objective of this case study is primarily to search for evidence of a causal relationship between quality and violence, rather than to replicate the more generalizable findings contained in the previous two chapters. So the question of how well the UN's experience in CAR will travel is less of an issue than if they were being presented 
on their own because this chapter is able to build upon, and probe, these more comprehensive results. Nonetheless, it is important to recognize that the analysis presented in this chapter is not without its limitations, despite being an ideal way to examine the hypothesized causal relationship.

In sum, the introduction of qualitative data at this point in the dissertation is intended to achieve two main objectives. The first objective is to evaluate the accuracy of the causal model developed earlier in this dissertation and the second objective is to probe the results of the previous two chapters in additional depth. The use of a process-tracing case study is an ideal method to achieve both of these objectives because it allows the proposed causal relationship to be broken down into a series of easily observable steps. If the causal model is accurate, it should be possible to observe evidence of coercive interaction between peacekeepers and conflict actors that is influenced by the relative quantity and quality of the UN's peacekeeping personnel. By contrast, a negative finding would suggest that all peacekeepers perform more-or-less equally when they are confronted with a similar set of circumstances. In terms of case selection, the single case of MINUSCA in CAR is a suitable subject for this purpose because it is data rich, contains a large amount of internal variation and pertains to issues that are of relevance to policy makers. However, the fact that most of the evidence for this case is documentary in nature and drawn from only a single operational context is a weakness of this particular methodology, which is balanced out by the more generalizable approach taken in the quantitative portion of this dissertation. 


\subsection{MINUSCA: Operational assessment}

This section begins the process of evaluating the relationship between MINUSCA and CAR's conflict actors by focusing on the overall impact that the operation has had on violence over time. The goal of this exercise is two-fold. First, it seeks to determine whether variation in the severity of violence can be attributed to the presence of MINUSCA and, if so, whether the use of coercion was involved. Second, it seeks to identify whether the relative quantity or quality of the operation's peacekeeping personnel played a role in its ability to manage on-going violence, as well as whether any lessons can be gleaned from its performance.

To achieve these goals, this section starts by providing an overview of MINUSCA's operational context, which includes a discussion of the steps that led to its initial authorization as well as the severity of violence in CAR over time. It then divides the postintervention period into two distinct segments in order to examine the relationship between MINUSCA and violence in additional depth. The first segment runs from April 2014 March 2016 and covers the events leading from MINUSCA's deployment to the successful conclusion of CAR's national elections. And the second segment runs from April 2016 December 2018, which covers the withdrawal of non-UN forces from the country and the subsequent state of stalemate between President Touadera's new government and CAR's conflict actors. After reviewing the conflict dynamics in both of these time periods, the section then concludes by emphasizing that MINUSCA's experience in CAR highlights the important role played by variation in operational quantity and quality when it come to the management of on-going violence. 


\subsubsection{Operational overview}

The authorization of MINUSCA's mandate on 10 April 2014 took place approximately one year after the capture of Bangui, CAR's capital, by a loose coalition of rebel groups known as the Séléka. ${ }^{78}$ Although this coalition had initially formed in hopes of addressing grievances related to a previous round of conflict, the combination of an unexpectedly poor performance on the part of CAR's military with an inability to find a diplomatic solution to the crisis culminated in a successful coup by Séléka forces on 24 March 2013. However, despite being recognized as the de facto government of CAR shortly thereafter, the members of this victorious alliance largely ignored their newfound responsibilities and proceeded to prey on the local civilian population instead. The areas around the capital were hit particularly hard, but extensive evidence of looting, sexualized violence and violent atrocities were documented throughout the country during this time period. ${ }^{79}$ Although efforts were made to halt these attacks over the next few months, including by formally disbanding the Séléka coalition in September 2013, they ultimately proved to be unsuccessful. As a result, a disparate collection of 'anti-balaka' militia groups began to emerge across the country in the latter half of 2013, who were interested in both protecting their communities from future attacks and seeking revenge for past atrocities. The resulting cycle of violence between these two groups then culminated in a series of

\footnotetext{
${ }^{78}$ An overview of the conditions that led to formation of the Séléka alliance, as well as the origins of its conflict with the anti-balaka, can be found in the UNSG's November 2013 report to the UNSC (S/2013/677). For additional details, see the following reports and policy briefings by the International Crisis Group (2013a; 2013b; 2014a; 2014b; 2015).

${ }^{79}$ Details of the resulting atrocities and human rights abuses can be found in relevant reports by Human Rights Watch (HRW), as well as a mapping exercise conducted by the UN's Office of the High Commission for Human Rights (OHCHR). See HRW (2013a; 2013b) and OHCHR (2017).
} 
deadly attacks on Bangui in December 2013, which served as the push that the United Nations Security Council (UNSC) needed to intervene.

The initial steps towards the deployment of a UN peacekeeping operation in CAR took place on the evening of 5 December 2013. Earlier that day, a temporary coalition of anti-balaka militia had launched a series of deadly attacks against ex-Séléka positions in Bangui, in which several hundred civilians were subsequently killed. In response, the UNSC immediately authorized the deployment of two non-UN peacekeeping operations: the African Union's (AU) African-led International Support Mission to the Central African Republic (MISCA) and France's Operation Sangaris. It then followed up three weeks later with the authorization of a third non-UN operation, the European Union Military Operation in the Central African Republic (EUFOR RCA). However, due to concerns that the situation in CAR might prove to be more than these operations could handle, the UNSC committed to "undertake the necessary preparations for the possible transformation of MISCA into a United Nations peacekeeping operation" in the authorizing resolution that it passed on the evening of 5 December 2013 (UNSC 2013b, 9). ${ }^{80}$ The end result of this process was a decision to authorize MINUSCA's initial mandate in April 2014, which resulted in the immediate absorption of the UN's existing peacebuilding office in the country and then the replacement of MISCA several months later.

After MINUSCA assumed operational command from MISCA in September 2014, its primary focus was to stabilize the political situation in CAR and bring an end to ongoing violence. To this end, its mandate provided it with the authority "to take all necessary

\footnotetext{
${ }^{80}$ This position was undoubtedly informed by the poor performance of the first regional operation sent to CAR, the Mission for the Consolidation of Peace in the Central African Republic (MICOPAX), which had struggled to contain the spread of violence following its arrival in late-2012.
} 
means" to protect civilians from the threat of physical violence, as well as to support the rapid extension of state authority and the delivery of humanitarian assistance (UNSC 2014b, 9). ${ }^{81}$ As shown in Figure 9, however, the years following MINUSCA's arrival continued to be marked by violence despite its mandated objectives. The first period of interest runs from MINUSCA's initial authorization in April 2014 until the inauguration of President Touadera in March 2016, during which the number of recorded fatalities declines to nearly zero. Since the core objective of the UN's involvement in CAR was to halt the use of violence, any insight that can be provided into the underlying causes of this decline, as well as MINUSCA's role in it, would be of particular interest.

Figure 9 - Total number of battle-related fatalities and civilian killings reported in CAR

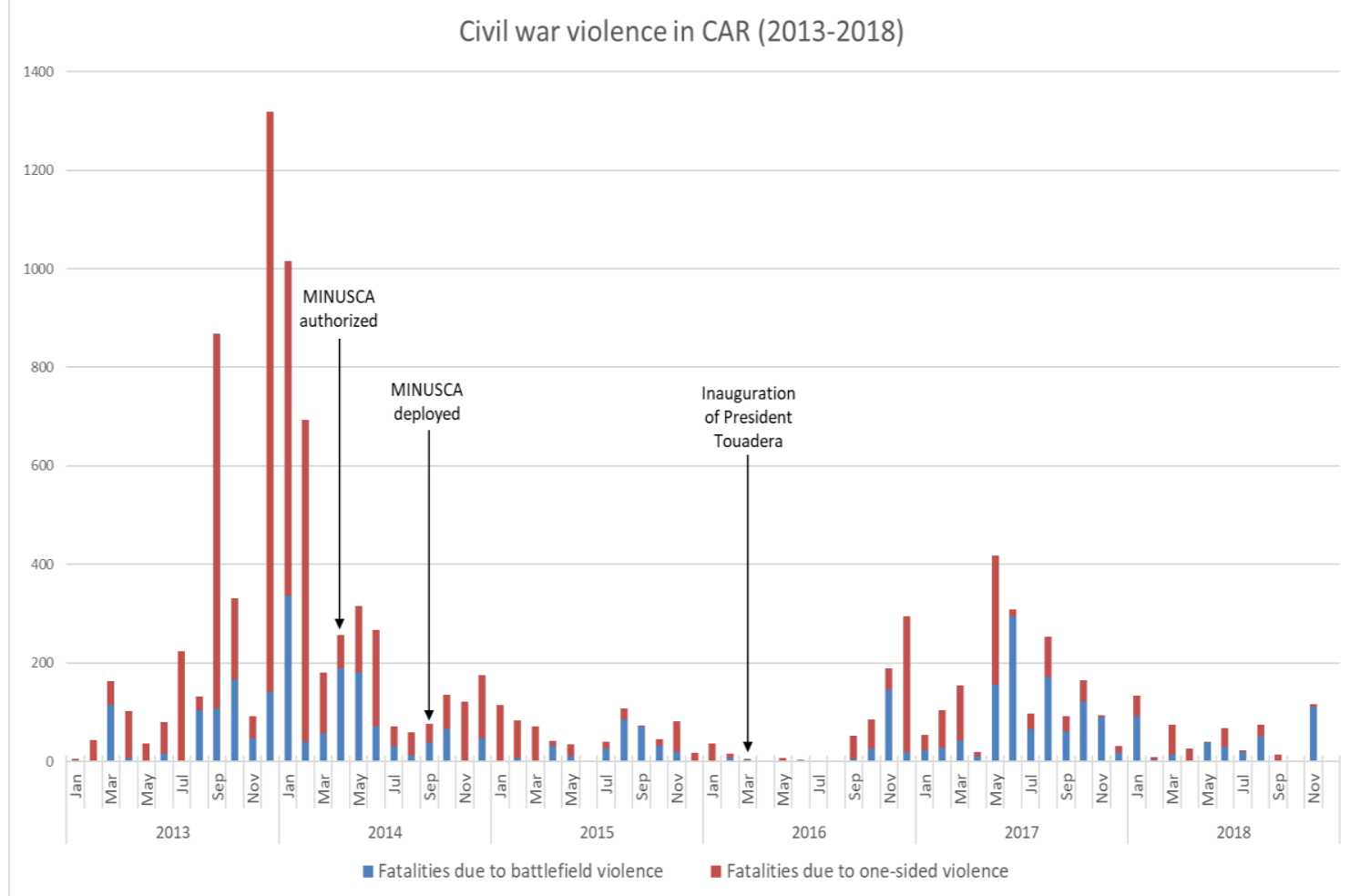

Note: Violence data sourced from version 19.1 of UCDP's Georeferenced Event Dataset.

${ }^{81}$ To complement these core objectives, MINUSCA was also assigned a broad range of additional tasks. Although these tasks are too numerous to list here in full, they included duties such as the promotion and protection of human rights, the overhaul of CAR's criminal justice system, and the development of a disarmament, demobilization, reintegration (DDR) and repatriation program (DDRR). 
By contrast, the second period of interest runs from the inauguration of President Touadera in March 2016 to the end of 2018, during which violence increases dramatically and then declines to a relatively low, but consistent, level. The inability of MINUSCA to prevent this spike in violence, as well as any contribution made towards its eventual decline, would therefore be of interest as well. When viewed as a whole, therefore, the presence of MINUSCA appears to have helped prevent the country from backsliding into levels of pre-intervention violence, but its ability to decrease overall levels of violence has been inconsistent over time.

\subsubsection{Deployment and Elections (April 2014 - March 2016)}

The formal handover of operational command from MISCA to MINUSCA took place on 15 September 2014. ${ }^{82}$ At its inception, MINUSCA's forces consisted of 6,590 troops and 1,083 police, the majority of whom were simply rolled over from the previous operation.$^{83}$ These personnel numbers were then gradually increased over time, reaching a total of 8,216 troops and 1,205 police by March 2015 and then climbing even further to approximately 10,065 troops and 1,900 police by mid-April 2016 (UNSC 2015b, 13; UNSC 2016b, 13). Other international forces in CAR during this time period included the French troops deployed as part of Operation Sangaris, who numbered approximately 2000 at their peak in early-2015 and then steadily declined until their complete withdrawal in

\footnotetext{
${ }^{82}$ Over the previous five months, the UN had slowly built up its force headquarters in Bangui and worked towards the establishment of three sector headquarters in Bria, Kaga Bandoro and Bouar. It had also undertaken a thorough review of MISCA's existing capabilities, with an eye towards 'rehatting' as many of the AU's troops as possible rather than replacing them with entirely new personnel.

${ }^{83}$ These personnel figures were derived from the monthly contribution reports available on the UN DPKO’s website: https://peacekeeping.un.org/en/troop-and-police-contributors.
} 
October 2016 (Ministère de la Défense 2016). There were also approximately 700 EU troops stationed in Bangui during MINUSCA's first year, who were then replaced with a much smaller advisory and training operation after the conclusion of EUFOR RCA's mandate in March 2015 (Ministère de la Défense 2016). The first two years of MINUSCA's operations in CAR were therefore supported by the presence of a large number of European personnel, all of whom were working collectively to stabilize the country and bring an end to on-going violence.

The combined impact of these international forces on violence appears to have been largely positive during this time period. As shown in Figure 10, the number of fatalities attributed to battlefield violence and one-sided killings declined from a peak of more than 300 per month in May 2014 to nearly zero in March 2016. This decline was far from steady, with a minor spike in violence following MINUSCA's deployment in September 2014 and then another in the second half of 2015, but the overall trend indicates a substantial decrease in violence over time.

Of course, not all of this decline can be attributed to the efforts of MINUSCA's personnel. The sharp decline in fatalities in mid-2014 coincided with the signing of a ceasefire agreement in Brazzaville on 23 July 2014, whereas the decline in violence in early-2015 occurred during the lead up to the Bangui Forum on National Reconciliation and the subsequent adoption of the Republican Pact for Peace. Although both of these agreements proved to be short-lived, they serve to highlight the importance of accounting for CAR's underlying political dynamics when seeking to understand the causes of violence. Other events of note include the holding of national elections from December 2015 to March 2016, which led to a decline in violence due to the participation of all major 
political parties and armed groups. As a result, it is hard to credit the overall decrease in violence solely to the efforts of international forces. At the same time, however, the sharp contrast between levels of pre- and post-intervention violence suggests that the presence of MINUSCA and its European allies helped to suppress the severity of violence during this two-year period, even if they were not able to stop it entirely.

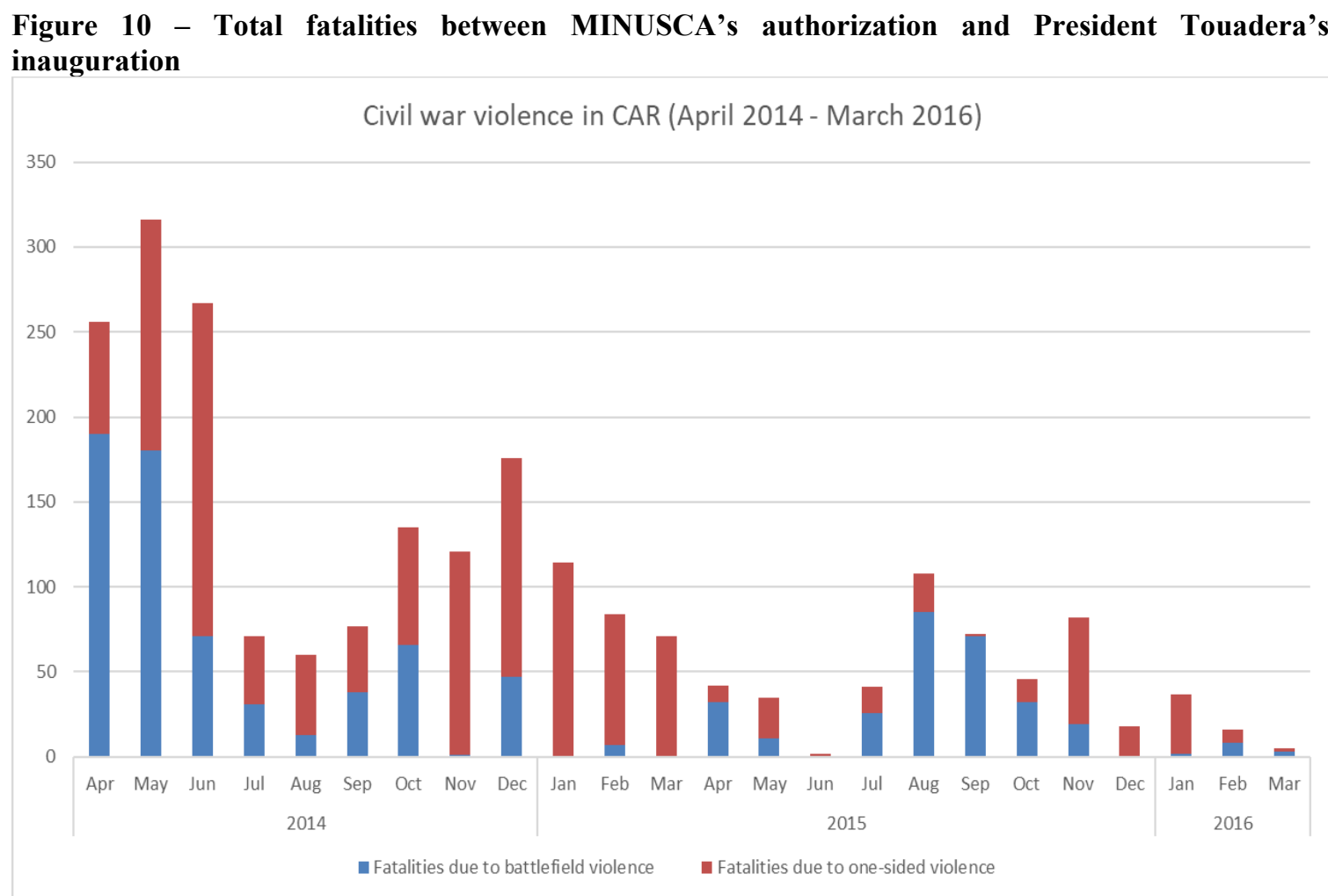

Note: Violence data sourced from version 19.1 of UCDP's Georeferenced Event Dataset.

As a first step towards unpacking this relationship, it is useful to start by looking at where MINUSCA's peacekeepers were deployed on the ground. As shown in Figure 11, the majority of its fixed operating bases were concentrated in western and central CAR during this time period, with the exception of Bria in the east and Birao in the north. Several of these bases were located in areas that experienced large amounts of violence, whereas others were located in the general vicinity of violence but were less directly involved. In 
central CAR, for example, the UN's peacekeepers were located at the epicenter of the conflict between the ex-Séléka and anti-balaka at this time, with the primary drivers of

Figure 11 - The distribution of peacekeepers and violence in CAR (April 2014 to March 2016)

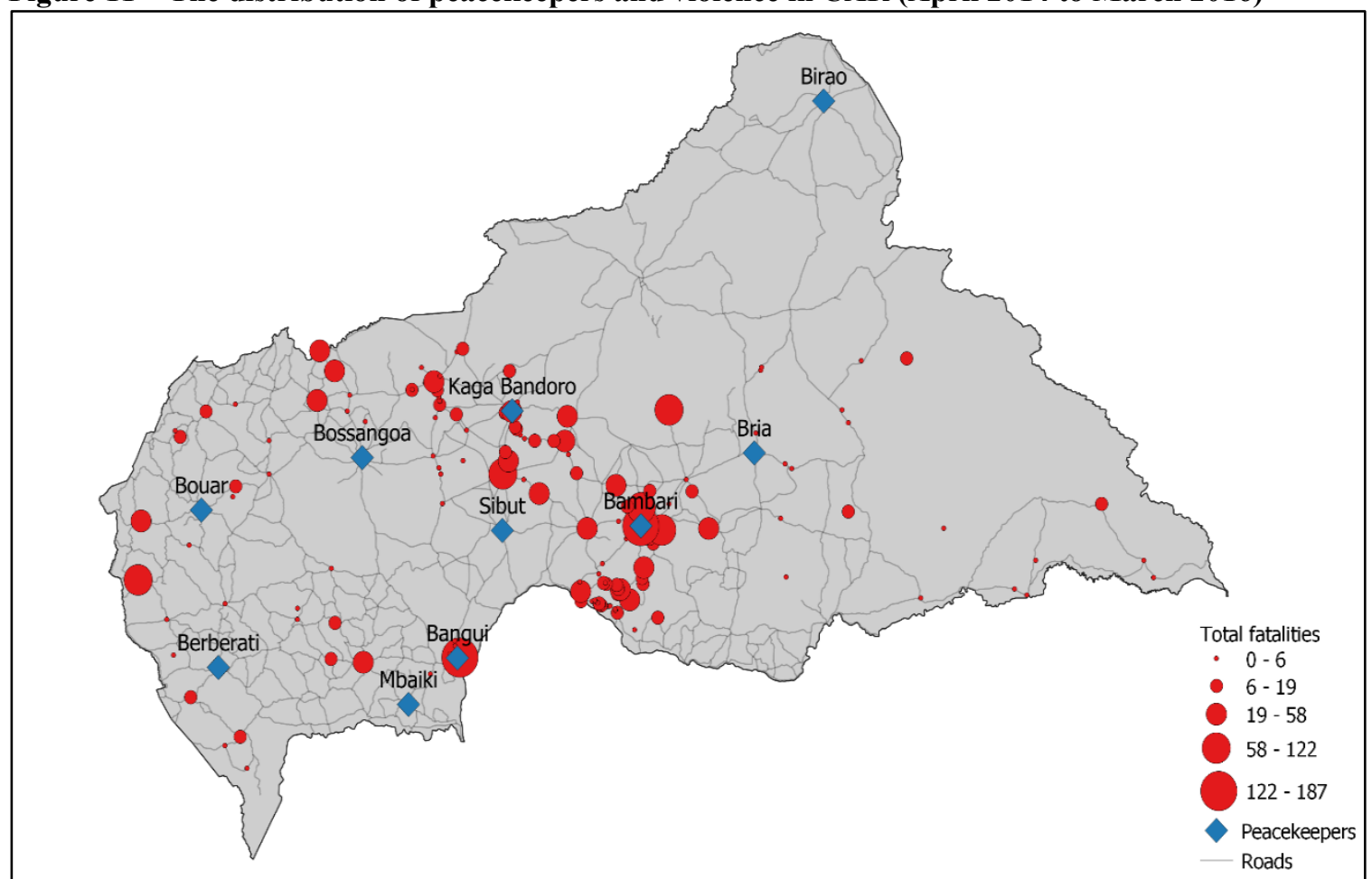

Note: The peacekeeper location data were obtained from deployment maps provided by the UN's GIS office and the violence data were sourced from version 19.1 of UCDP's Georeferenced Event Dataset. The map also shows some of the major road networks in CAR, which were obtained from an online repository of geospatial data hosted by the Biogeo laboratory at the University of California, Davis: https://data.biogeo.ucdavis.edu/data/diva/gaz/CAF_gaz.zip.

violence being competition over resources and territorial control as well as tit-for-tat reprisals along religious lines. Elsewhere, peacekeepers located in the northwestern region of the country were ideally placed to address violence associated with annual transhumance patterns, during which the arrival of Muslim cattle-herders from neighbouring countries provided tempting targets for local militia. And the peacekeepers stationed in the south and southwest of the country were positioned to protect the large civilian population in Bangui, as well as to prevent attacks along major supply routes in and out of the country. The only area not protected in this manner was CAR's sparsely populated eastern region, which 
experienced little violence during this time period and was the responsibility of a joint US-

AU taskforce assigned to hunt down the LRA. Overall, then, the impression left by MINUSCA's deployment pattern is that its peacekeepers would have had ample opportunity to influence the use of on-going violence, whether through passive deterrence or active compellence.

In addition to being deployed in close proximity to conflict hot spots, there is also evidence that MINUSCA took steps to mitigate the severity of on-going violence by engaging in coercive acts. At the operational-level, these efforts primarily consisted of public statements and press releases designed to condemn individual acts of violence and urge a return to calm. ${ }^{84}$ Although these statements were rarely targeted at members of specific armed groups, they often emphasized that such violent acts constituted war crimes and could result in punishment under international law. They also regularly reiterated that MINUSCA, and its European allies, possessed mandates to use all necessary means to protect civilians, strengthen state authority, and support the political process, with the implicit threat being that the UN would not hesitate to use force in the pursuit of its objectives. ${ }^{85}$ Other coercive tools at the UN's disposal included a variety of positive inducements, which were designed to provide local conflict actors with alternatives to violence. Examples of such inducements include a program to voluntarily relocate exSéléka fighters who had been cut-off from their home communities as well as the initiation

\footnotetext{
${ }^{84}$ Numerous examples of relevant statements and press releases can be found posted in the 'news' section of MINUSCA's website: https://minusca.unmissions.org/en/news-stories. However, as highlighted in the context of the conflict episode section below, this source is likely to underestimate the extent of the UN's coercive messaging due to incidents of in-person communication as well.

${ }^{85}$ These kinds of threats were also delivered explicitly in some cases, such as when the Special Representative of the Secretary-General (SRSG) warned that the UN would "continue to take robust action against criminal elements who threaten the peace" following an attack on UN peacekeepers in October 2014 (MINUSCA 2014).
} 
of "labor-intensive income generating projects" involving the employment of youth from armed groups (UNSC 2015b, 7). It is also worth noting that the UN supported the establishment of a new radio station during this time period, Guira FM, which provided it with a means of delivering these coercive threats and assurances throughout most of CAR's territory.

By contrast, the majority of MINUSCA's coercive acts at the local-level involved the threat, or actual use, of armed force. For example, the UN sought to deter the use of violence in Bambari in September 2015 by establishing a "weapons-free" zone along the bridge connecting the western and eastern halves of the city (UNSC 2015d, 6). This step was necessary to prevent armed clashes between rival factions, as well as to facilitate the safe movement of the city's civilian population (McCormick 2015). Other examples of deterrent action include the numerous armed escorts provided by MINUSCA's personnel, which were used to help secure the flow of goods in and out of Bangui. ${ }^{86}$ Similarly, the UN undertook numerous compellent operations during this time period, with their objective being to dissuade specific conflict actors from persisting in undesirable behaviour rather than eliminating them entirely. One such operation resulted in the expulsion of an exSéléka faction from the Baboua-Beloko route in mid-June 2015, which prevented them from launching further attacks against passing traffic due to the dismantlement of their nearby camp (UNSC 2015c, 5), whereas others were launched against the ex-Séléka in February 2015 and the anti-balaka in May 2015 (UNSC 2015c, 5). Although these examples merely scratch the surface of the coercive dynamics between MINUSCA and

\footnotetext{
${ }^{86}$ Although the majority of these escorts were successful, an increase in the number of attacks against UN-protected convoys actually led to strikes by Cameroonian truck drivers in mid-2015 (UNSC 2015c: 5; UNSC 2015a, 40-41).
} 
CAR's conflict actors, they serve as a clear indication that this kind of interaction actually took place.

There are also lessons to draw from this time period regarding the overall quantity and quality of MINUSCA's peacekeeping personnel. In terms of quantity, the gradual decline in violence was accompanied by a steady increase in the number of peacekeepers on the ground. The operation started with approximately 6,600 troops and 1,100 police in October 2014 and then grew to around 9,800 troops and 1,900 police by March 2016, making for a $48 \%$ increase in terms of military personnel and a $72 \%$ increase in terms of civilian police. ${ }^{87}$ However, it is important to recognize that the operation also benefited from the presence of a large number of European troops during this period, which provided it with the time needed to recruit and deploy additional personnel without the risk of being immediately overwhelmed. These additional troops were then withdrawn over time, with the approximately 2,500 French and EU troops present in early-2015 decreasing to roughly 700 by March 2016 (Ministère de la Défense 2016). The operation also benefited from temporary infusions of personnel at sensitive points in time, such as the transfer of a quick reaction force (QRF) from the UN's operation in Côte d'Ivoire during the national election period from late-2015 and early-2016 (UNSG 2016b: 13), in addition to a gradual increase in the capacity of CAR's internal security forces.$^{88}$ As a result, it is important to recognize that the steady decline in violence during this time period is not something that MINUSCA

\footnotetext{
${ }^{87}$ These personnel figures were derived from the monthly contribution reports available on the UN DPKO's website: https://peacekeeping.un.org/en/troop-and-police-contributors.

${ }^{88}$ Although the government's capacity was still limited during this time period, it had begun to contribute to the security of the national capital and its surrounding area by the end of the national elections. MINUSCA was still responsible for the bulk of the capital's security, which required the maintenance of a large garrison in the city, but it no longer had to secure the capital entirely on its own.
} 
was able to achieve entirely on its own, despite the substantial increase in the overall quantity of its peacekeeping personnel.

In terms of quality, there are two major trends worth noting regarding the relative performance of MINUSCA's personnel. First, the process of re-hatting several contingents from the AU's operation, MISCA, led to the deployment of large amounts of military personnel who failed to meet the UN's qualitative standards. These troops represented the vast majority of MINUSCA's military peacekeepers at the start of the operation, with the 4,784 re-hatted troops accounting for roughly $72 \%$ of the operational total (OIOS 2018 , 11). All six of these contingents, one each from the DRC, Cameroon, Rwanda, Congo, Gabon and Burundi, suffered from critical capability shortfalls for the first 18 months of the operation, which limited their ability to react swiftly to incidents of on-going violence (OIOS 2018, 27). Interviews conducted by the UN's Office of Internal Oversight Services indicate that these contingents also required a "disproportionate amount of time to prepare" when asked "to address imminent threats to civilians" and sometimes "failed to fully implement their orders" (OIOS 2018, 29). Five out of the six re-hatted contingents were also responsible for $99 \%$ of the sexual exploitation and abuse allegations leveled against the entire operation, which eroded trust with members of the local community (OIOS 2018, 21). ${ }^{89}$ Although both of these issues were slowly resolved over time, including through the repatriation of entire contingents in some cases, they serve to emphasize that the re-hatting

${ }^{89}$ The subsequent UN crackdown against this kind of behaviour also undermined the willingness of some re-hatted troops to interact with the local population at all, with the risk of potential punishment outweighing the potential benefits that could have been gained by building relationships with nearby communities and gathering human intelligence (OIOS 2018, 25). 
process caused a number of quality-related issues during the early years of MINUSCA's deployment.

Second, the UN was able to compensate for its early qualitative deficiencies by leaning heavily on the presence of French troops. These troops were well-trained and possessed a wide range of technological capabilities, which included armored personnel carriers, aerial surveillance drones, attack and transport helicopters, and fixed-wing aircraft donated by allied states (Ministère de la Défense 2016). Many of them had also served in either Afghanistan or Mali, which provided them with the practical experience necessary to improvise and adapt when faced with tactical challenges in the field (Hemez 2016: 76). Although these troops were used to secure large areas of CAR during the initial months of MINUSCA's deployment, they had transferred full control of the country to the UN by May 2015. ${ }^{90}$ After that point, their primary role was to deploy "small combined-armed tactical teams" to serve as a "reaction and reinsurance force in support of MINUSCA" (Hemez 2016, 76-78). For example, the intervention of a French QRF consisting of an armoured sub-unit and an infantry section played a key role in restoring calm to Bambari on 16 February 2015 (Sangaris 2015). ${ }^{91}$ There are also numerous examples of joint

${ }^{90}$ Prior to MINUSCA's arrival, the primary objective of Operation Sangaris was to serve as a "bridging operation" for other international forces by stabilizing key areas around the country (Hemez 2016, 73-78). Starting with Bangui and its immediate vicinity in December 2013, the French forces began to move west along the main supply route to Cameroon in February 2014 and then into the central region of the country in April 2014 (Ministère de la Défense 2016). They were therefore well-placed to hand over operational control of large parts of the country to MINUSCA following its deployment in September 2014. This process began with the transfer of authority for all of western CAR on 9 October 2014 and then all of central and eastern CAR by the end of May 2015, the latter of which occurred piecemeal from January to May rather than all at once (Ministère de la Défense 2016). As a result, Operation Sangaris largely operated in support of MINUSCA from mid-2015 until its withdrawal in mid-2016, rather than on its own in a separate piece of territory.

${ }^{91}$ Their intervention followed a request from one of MINUSCA's contingents stationed in the city, who feared that its position would be "overwhelmed" due to fighting between local conflict actors (Ministère de la Défense 2015). 
MINUSCA-Sangaris operations during this time period, many of which benefited from the superior technological capabilities possessed by the French troops. ${ }^{92}$ The presence of French forces in CAR was therefore a key factor in MINUSCA's ability to operate effectively in the field, primarily due to their ability to compensate for the operation's quantitative and qualitative shortcomings.

\subsubsection{Drawdown and Stalemate (April 2016 - December 2018)}

The investiture of President Touadera on 30 March 2016 marked the beginning of a shift in MINUSCA's operations in CAR. The initial hope was that this time period would be relatively peaceful, with the newly elected government managing to capitalize on the success of the recent election process by taking the steps necessary to forge a sustainable peace. These hopes led the UNSC to request a strategic review of MINUSCA's mandate in April 2016, which resulted in a shift towards a set of broad, long-term peacebuilding goals starting in July 2016 as well as plans for an eventual troop drawdown (UNSC 2016d). However, the resumption of fighting in late-2016 quickly dispelled these hopes and forced the UN to narrow MINUSCA's mandate, with its primary focus reverted to the management of violence.

To aid in this task, MINUSCA was provided with a slight increase in terms of overall force levels, which climbed from roughly 10,200 troops and 2,000 police in April 2016 to around 11,500 troops and 1,900 police in December $2018 .{ }^{93}$ But this increase was

\footnotetext{
92 On 10 October 2015, for example, the casualties inflicted by French attack helicopters helped the UN to halt a force of ex-Séléka fighters outside of Sibut, who would have otherwise continued to advance towards Bangui (UNSC 2015d, 5; Di Razza 2016).

93 These personnel figures were derived from the monthly contribution reports available on the UN DPKO's website: https://peacekeeping.un.org/en/troop-and-police-contributors.
} 
barely sufficient to compensate for the withdrawal of the remaining 700 French troops from May to October 2016, as well as the termination of the AU's anti-LRA taskforce in April 2017. This time period is therefore notable for the near absence of international forces in CAR aside from MINUSCA, with the sole exception being the EU's small military training operation located in Bangui.

Figure 12 - Total fatalities between President Touadera's inauguration and the end of 2018

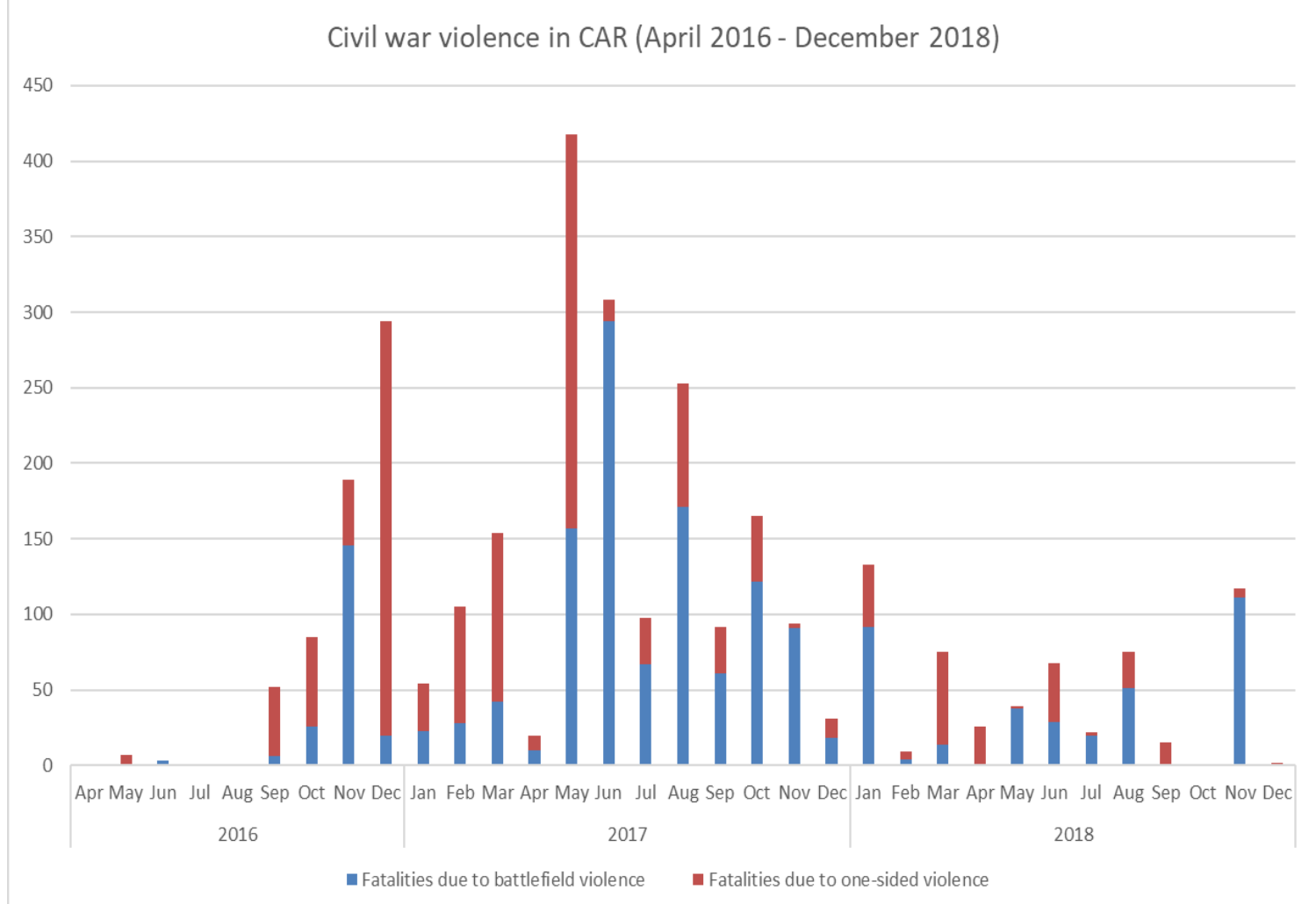

Note: Violence data sourced from version 19.1 of UCDP's Georeferenced Event Dataset.

The difficulties faced by MINUSCA during this time period are evident from the return to violence that occurred towards the end of 2016. As shown in Figure 12, the start of CAR's new government was nearly devoid of fighting, with no fatalities at all reported for three of its first five months. Violence then increased sharply in September 2016, reached a peak of more than 400 fatalities in May 2017, and then decreased gradually during the second half of 2017 before settling at an average of 48 fatalities per month in 
2018. It is therefore difficult to point to a straightforward relationship between peacekeepers and violence during this time period because fatality counts are observed to vary significantly from one year to the next, despite the relatively constant number of personnel.

However, there are clear links between the country's underlying political dynamics and violence during this time period, which collectively serve to explain much of the observed variation. For example, the absence of violence in mid-2016 coincided with a period of negotiations between President Touadera and CAR's armed groups regarding the terms of a future DDR agreement. The collapse of these talks in late-2016 then precipitated a return to the kind of self-interested violence that had been put on hold during the national election period, which MINUSCA was left to face alone due to the withdrawal of Operation Sangaris. Overall levels of violence then declined following the short-lived Entente de Sant'Egidio in June 2017 and the start of pilot DDR activities in September 2017, after which it remained relatively low during consultations hosted by the African Initiative for Peace from November - December 2017 and February - April 2018. Throughout all of these events, the efforts of MINUSCA's personnel were instrumental in holding the country together and preventing a return to even higher levels of violence. But its inability to eliminate violence entirely appears to have been linked to the difficulties posed by CAR's underlying conflict dynamics, which proved to be more than MINUSCA could handle once it had been left on its own.

To get a better sense of why MINUSCA struggled to eliminate violence during this time period, it is helpful to take a second look at where its peacekeeping personnel had been deployed. As shown in Figure 13, most of the UN's fixed operating bases remained 


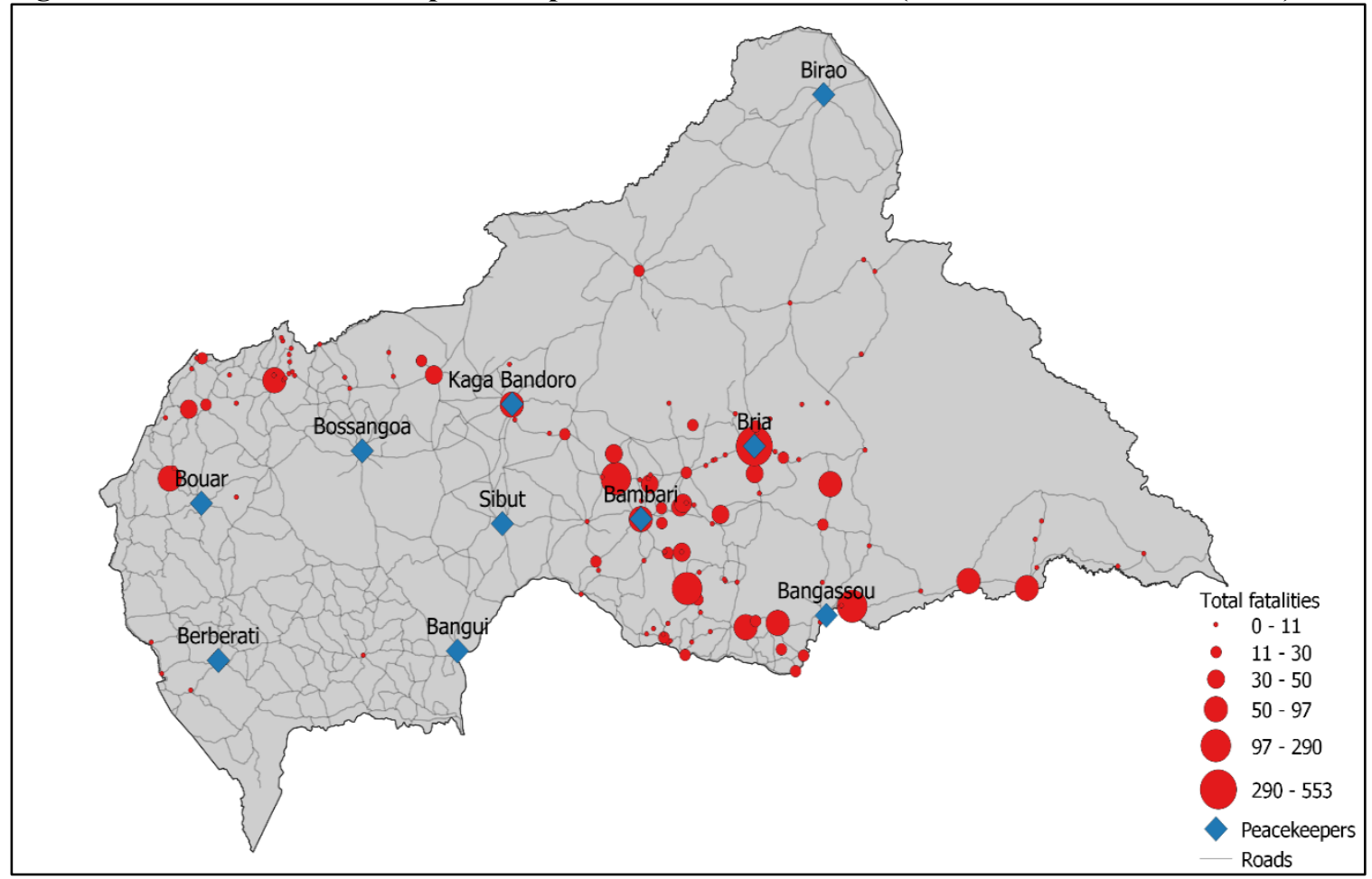

Note: The peacekeeper location data were obtained from deployment maps provided by the UN's GIS office and the violence data were sourced from version 19.1 of UCDP's Georeferenced Event Dataset. The map also shows some of the major road networks in CAR, which were obtained from an online repository of geospatial data hosted by the Biogeo laboratory at the University of California, Davis: https://data.biogeo.ucdavis.edu/data/diva/gaz/CAF_gaz.zip.

located in the central and western regions of CAR at this point in time, with the exception of Birao in the north and Bria and Bangassou in the east. However, the vast majority of war-related fatalities had shifted much further to the east when compared to the operation's first two years, with most incidents of violence now concentrated in the Bambari-BriaBangassou triangle. ${ }^{94}$ The withdrawal of the AU's anti-LRA taskforce from eastern CAR had also left MINUSCA with responsibility for a much larger geographic area, which it was unable to occupy directly due to a lack of personnel. This situation was not helped by the relatively poor state of the country's transportation infrastructure, which made it time

${ }^{94}$ The operation had therefore been successful at securing large areas of western and southwestern CAR but had proved unable to halt the transhumance-related violence in the northwest and the resource and territory-related violence in the southeast. 
consuming to travel anywhere by land. The increase in violence during this time period can therefore be attributed to a combination of CAR's political dynamics and the finite nature of MINUSCA's operational resources, which had been stretched to the limit following the withdrawal of French and AU forces from the country.

Despite these limitations, MINUSCA continued to deliver coercive threats and assurances to CAR's conflict actors in an attempt to manage on-going violence. At the operational-level, these efforts continued to rely on the use of press releases and radio broadcasts to condemn specific acts of violence and emphasize the risks of future prosecution. A good example of this kind of messaging occurred following an attack on Bangassou's civilian population from 12-13 May 2017, which included a sustained attack on the UN's local field office to prevent them from providing assistance. In response, the SRSG in charge of MINUSCA, Parfait Onanga-Anyanga, issued the following statement outlining the operation's next steps:

MINUSCA will do everything in its power together with the legitimate Central African authorities to arrest the perpetrators of these horrible acts. The international community will be relentless in apprehending the perpetrators of these crimes and all their commanders - I insist on their commanding officers - including some instigators who may be sponsoring these attacks from Bangui. Our actions will be relentless. The blood of peacekeepers and the blood of innocent Central Africans will not fall in vain in this country...Justice, one day or another, and sooner rather than later, will lay its hand on all the perpetrators of these horrible acts. (MINUSCA 2017d)

In addition to the explicit nature of this threat, it is also notable for the fact that it is directed at both the perpetrators of violence and their commanding officers. Other threats and warnings issued during this time period echoed this distinction, some of which even mentioned specific commanders by name and urged them to discipline their troops. ${ }^{95}$ The

\footnotetext{
${ }^{95}$ One of the clearest examples of commanders being linked to the crimes committed by their subordinates occurred following an attack on a civilian hospital in Ippy on 12 December 2017: "MINUSCA reminds the leaders of UPC and FPRC in Ippy, General Ahmat Wadal Woundal and Colonel Adam Mocktar respectively, that targeting hospitals, and using civilians as human shields, are grave violations of
} 
UN also continued to entice combatants with a range of positive inducements during this time period in the hopes of providing them with alternatives to violence. Examples of such inducements include pre-DDR programs, community violence reduction initiatives, and projects for at-risk youth, as well as assistance negotiating local ceasefire agreements between rival armed groups. ${ }^{96}$ So the sustained increase in violence starting in September 2016 does not appear to have been due to any behavioural change on the part of MINUSCA, which continued to make use of coercive threats and assurances in an attempt to influence CAR's conflict dynamics.

The UN also continued to engage in coercive behaviour at the local-level, which involved the liberal use of both deterrence and compellence. Examples of deterrence include the interception of an ex-Séléka convoy on its way out of Bangui in August 2016 (UNSC 2016c, 4-5), the establishment of a buffer zone between rival armed groups in November 2016 (UNSC 2017b, 5), and the defence of a Fulani neighbourhood from attack in March 2017 (UNSC 2017c, 4). Whereas examples of compellence include the numerous robust operations undertaken by MINUSCA's personnel during this time period, such as Operation Bekpa in February 2017, Operation Maraza in August 2017, Operation Damakongo in October 2017 and Operation Mbaranga in January 2018. However, the withdrawal of the UN's French allies made the execution of such operations more difficult than they had been in the past, particularly since MINUSCA now had responsibility for

\footnotetext{
international human rights law and may also constitute war crimes. MINUSCA further urges UPC and FPRC leadership to take immediate measures to minimize civilian casualties and to discipline combatants who were involved in the Ippy incident or other attacks against civilians" (MINUSCA 2018).

${ }^{96}$ Many of these programs were designed to persuade individual combatants not to fight, rather than to encourage the disarmament of entire armed groups. For example, the community violence reduction initiatives created by MINUSCA were designed to provide labour intensive employment for former combatants, with total participation rates numbering 2,800 as of June 2016 and then climbing to 5,100 by October 2018 (UNSC 2016d; UNSC 2018b).
} 
areas of the country where it did not always hold the balance of power (Di Razza 2016).

Its convoys and personnel were also subject to a large number of attacks during this time period, with at least 67 incidents involving live fire recorded between January and October 2018 alone. ${ }^{97}$ As a result of these developments, the UN's efforts to deter or compel conflict actors at the local-level were not always safe or successful. ${ }^{98}$ The overall impression is therefore of an operation that continued to engage in coercive behaviour at the local-level, albeit with mixed success due to growing challenges to its authority by CAR's conflict actors and the limitations that it faced in terms of brute force.

Although MINUSCA struggled to eliminate violence entirely during this time period, its performance nonetheless contains some important insights regarding the determinants of operational effectiveness. First, the operation's inability to secure eastern and southeastern CAR largely came down to a lack of personnel. The withdrawal of Operation Sangaris had made MINUSCA solely responsible for the stability of western and central CAR, and the termination of the AU's anti-LRA taskforce had forced MINUSCA to extend its area of operations further east. Attempting to address both of these developments at once had stretched the operation to the limits of its capacity, with only minimal support provided by the relevant national authorities.

${ }^{97}$ These figures are based on information received by the UN's Panel of Experts on the Central African Republic from a confidential source. As noted in the report, these figures do not include "exchanges of fire during operations carried out by MINUSCA, nor attacks by stones or machetes, abductions, robberies, hostile behavior and threatens (sic)" (UNSC 2018a, 151), so they are likely to underestimate the amount of violence directed at the operation's personnel during this time period. See pages $150-158$ of the report for full details of the relevant attacks.

${ }^{98}$ For example, one patrol's attempt to dismantle a pair of roadblocks outside of Grimari on 4 August 2018 ended in failure after members of the local anti-balaka group refused to disperse (UNSC 2018a, 157). They persisted in this position even after peacekeepers had fired warning shots into the air, choosing instead to respond with fire of their own until the patrol was forced to retreat. 
In recognition of this situation, the UNSC provided MINUSCA with the authority to deploy 900 additional military personnel on 15 November 2017, bringing its total mandated force level up to 11,650 troops (UNSC 2017d). However, the majority of these troops arrived too slowly to make an immediate impact on violence and approximately 500 were still missing one year later. Most of this delay can be attributed to a lack of followthrough on the part of individual TCCs, which left the UN scrambling to find alternative sources of personnel. For example, Brazil made an early offer of 750 troops on 27 November 2017 but this offer was subsequently terminated on 9 April 2018 (Cinq-Mars 2018). An offer to help fill this gap was then made by Côte d'Ivoire, who pledged a total of 450 troops on 26 April 2018, but this pledge was similarly rescinded (Cinq-Mars 2018). As a result, the UN was forced to make up for the shortfall by extending the deployment of 444 troops from Gabon, despite the fact that they had been scheduled to withdraw following allegations of sexual exploitation and abuse (Cinq-Mars 2018). The continued presence of this contingent in CAR as late as December 2018 serves to emphasize how important raw numbers are for an operation like MINUSCA, as well as the difficulties associated with the recruitment of suitable personnel.

Second, the UN was able to compensate for its lack of personnel to some extent by adopting a more flexible force posture. This new posture led to a reduction in the number of temporary operating bases located in western and central CAR, the creation of strategic reserve capacities in CAR's western, central and eastern regions, and the relocation of troops further east (UNSC 2017b, 6). Although these changes did not solve all of the issues caused by a lack of personnel, they freed up the capacity necessary to conduct long-range patrols into isolated areas of the country and provided the $\mathrm{UN}$ with the ability to redeploy 
its forces quickly in response to emerging conflict hotspots. The end result was a notable increase in MINUSCA's mobility and responsiveness, which allowed it to manage violence more effectively despite the lack of additional personnel.

Having said that, it is important to recognize that the UN's ability to adopt this kind of force posture was only possible due to the technological capabilities that it had acquired over time. For example, a key enabling factor at the operational-level was MINUSCA's aerial capacity, which included six military utility helicopters and two military attack helicopters as of June 2016 (OIOS 2016, 1). Without these capabilities, it would have been difficult for the UN to facilitate the rapid movement of its troops or to provide them with adequate support during robust operations. Similarly, MINUSCA had acquired a French UAV unit in April 2017, as well as a collection of small quadcopter drones and aerostat surveillance balloons over the course of the previous year (ADF 2017). These capabilities served to enhance the situational awareness of its peacekeeping personnel and allowed them to track the movements of local conflict actors, while also providing them with information regarding the location of damaged bridges and potential ambush sites. Therefore, in addition to the raw number of available personnel, this case suggests that the manner in which peacekeepers are used and the tools that they have at their disposal are also key determinants of operational effectiveness.

Third, the increased mobility and responsiveness associated with MINUSCA's new force posture also demonstrated the value of deploying high quality personnel. The clearest example of this phenomenon was the outsized role played by two specific groups of peacekeepers: a special operations force (SOF) from Bangladesh that arrived in mid-2016 and a QRF from Portugal that arrived in early-2017. The high level of training and 
enthusiasm possessed by both of these forces played a critical role in managing conflict hotspots around the country, which helped to save numerous civilian lives. For example, the performance of the Portuguese QRF has been praised since their arrival, with their very first operation resulting in a letter of commendation from MINUSCA's Force Commander (TPN 2017). Since then, they have continued to perform to a high collective standard in hotspots around the country, such as during a recent incident in Bambari where they engaged in a four-hour firefight while interposed between a group of ex-Séléka combatants and the nearby civilian population (Kelly 2019). Given that this force only consists of approximately 150-180 personnel, their experience suggests that even small groups of high quality personnel can have a significant effect on violence.

In addition, the UN also began to take steps to improve the overall quality of MINUSCA's peacekeepers during this time period, recognizing that its operational objectives required it to generate "the right troops with the right equipment and posture to be more mobile, proactive and agile" (UNSC 2018b, 15). Since acquiring these kinds of troops externally had proven to be difficult, it chose to focus instead on improving the performance of the troops that it already had. In September 2017, for example, it launched a pilot of the DPKO's new Comprehensive Performance Assessment System (UNSC 2018b, 11), which was a novel attempt to incentivize peacekeepers to perform more effectively in the field. Although it is difficult to measure the impact of these kinds of tools directly, it nonetheless serves as additional evidence regarding the presumed connection between peacekeeper quality and operational capacity.

In sum, the presence of MINUSCA in CAR played an important role in the management of violence. It may not have been the only factor at work in this conflict, with 
much of the observed variation in violence linked to the country's underlying political dynamics, but it likely helped to prevent the collapse of CAR's government. However, it was only able to have these effects due to the assistance of French, EU and AU troops, who served to fill in MINUSCA's quantitative and qualitative gaps during the first two years of its operation. Once these allied forces had been withdrawn, the subsequent spread of conflict then stretched the operation to the limit, which it was able to mitigate somewhat due to the advantages offered by a more mobile force posture, increased technological capabilities, and the deployment of small groups of high quality personnel.

Throughout all of these developments, MINUSCA made consistent use of compellent and deterrent actions at both the operational-level and the local-level, which included the use of positive inducements to provide conflict actors with alternatives to violence. However, the effectiveness of these coercive acts was not consistent over time. They were more effective when the relative quantity and quality of MINUSCA's personnel was high, and they were less effective when the relative quantity and quality of its personnel was low. The analysis contained in this section therefore provides an initial measure of support for the central argument advanced in this chapter, namely that the UN's ability to manage on-going violence is linked to the relative quantity and quality of its peacekeeping personnel.

\subsection{MINUSCA: Local conflict episodes}

This section continues to evaluate the relationship between MINUSCA and violence by analyzing a small selection of discrete conflict episodes. In doing so, it aims to build on the operational-level analysis conducted in the previous section by isolating the 
coercive dynamics between MINUSCA's peacekeepers and CAR's conflict actors at specific points in time. Three conflict episodes in total are examined in this manner. The first episode looks at successful examples of deterrence and compellence in Bambari, the second episode looks at a failed example of deterrence near Alindao and the third episode looks at the complete absence of coercive action in Mambere-Kadei prefecture, despite the presence of peacekeeping personnel. Each episode begins with a short summary of the relevant conflict dynamics and then proceeds to examine any coercive interaction that took place between MINUSCA and local conflict actors. It then explains the success or failure of coercion in each case by considering the incentive structures of the conflict actors in question, as well as the relative quantity and quality of the UN's peacekeeping personnel.

\subsubsection{The advance on Bambari (February 2017)}

The town of Bambari is located in the central prefecture of Ouaka, where it serves as the area's economic and administrative capital. Due to its strategic importance, the Union pour la Paix en Centrafrique (UPC), one of CAR's strongest ex-Séléka factions, decided to use Bambari as its main military stronghold following its formation in October 2014 (IPIS 2018, 26). However, the UPC's control over this area was challenged starting in late-2016 due to its rejection of a Séléka reunification effort in October, as well as lingering tensions caused by an attempt to expand its territorial holdings earlier that year (IPIS 2018, 27). This challenge was led by a rival ex-Séléka faction, the Front Populaire pour la Renaissance de la Centrafrique (FPRC), which had assembled a mixed exSéléka/anti-balaka coalition with the explicit goal of capturing Bambari and expelling the UPC from the city (UNSC 2017c, 3). Starting in November 2016, the coalition made its 
first move against the UPC in nearby Bria, which had long been controlled jointly by various ex-Séléka factions, and then pushed steadily west and southwest in order to capture UPC positions outside of Bambari. The FPRC-led coalition then shifted its focus to the city of Bambari itself, which it failed to capture twice in February 2017 due to the presence of MINUSCA. The subsequent withdrawal of the UPC's leadership from Bambari then pushed the conflict south and southeast of the city, where it continued for several weeks until the FPRC managed to secure control over the surrounding countryside around the end of March.

The attempted capture of Bambari unfolded in two distinct stages, each of which failed due to the efforts of MINUCA's personnel. The first attempt to capture the city took place on 11 February 2017 when a column of approximately 300 FPRC fighters advanced towards Bambari from the northeast. Prior to this point, the UN had attempted to resolve the situation peacefully by making diplomatic overtures to both sides of the conflict (MINUSCA 2017e, 36), as well as by establishing a pair of 'red lines' outside of the city that were intended to serve as a deterrent (UNSC 2017c, 3). However, the failure of these efforts became evident when the advancing FPRC forces deliberately breached one of these red lines on the afternoon of 11 February, despite repeated warnings that they would be fired on as a result (UNSC 2017c, 3). In response, the UN launched a limited attack on the advancing column with its armed helicopters, which resulted in the destruction of several vehicles and at least four deaths (Reuters 2017). It also reinforced its presence in the nearby town of Ippy to deter a continued advance (UNSC 2017c, 3), which was located roughly 12 kilometers west of the FPRC column. Due to the continued threat posed by MINUSCA's armed helicopters, as well as the reinforcement of Ippy, the FPRC then decided to halt its 
march near where it had been attacked by the UN, which lay roughly 100 kilometers to the northeast of Bambari. The initial failure of MINUSCA's deterrent posture was therefore mitigated by the subsequent success of its compellent threat, which foiled the FPRC's first attempt to capture Bambari by preventing them from advancing towards the city.

However, rather than backing down entirely, the FPRC quickly developed a new plan of attack and resumed their efforts to capture Bambari. The first step in their plan involved a period of counter-escalation against MINUSCA's personnel, with the intended goal of intimidating nearby groups of peacekeepers so that they would refuse to block the FPRC's advance towards the city. To this end, one of the FPRC's leaders in Bria delivered a message to MINUSCA two days later, on 13 February, threatening to attack its peacekeepers directly if they continued to block access to Bambari (MINUSCA 2017e, 36). This threat was then followed up several days later, on 21 February, by an ambush against a group of peacekeepers who were patrolling the road between Bambari and Ippy, which resulted in four injuries (UNSC 2017c, 3). When these threats failed, the FPRC then moved onto the second step in their plan which involved an attempted infiltration of Bambari from an alternative direction. Rather than continuing to advance from the northeast, a small group of approximately 40 coalition fighters was sent through the countryside to loop around the city and sneak in from the northwest (MINUSCA 2017c). These fighters emerged from the bush on 26 February roughly 5 kilometers north of Bambari, in violation of the second of the UN's two red lines, and were immediately engaged by a combination of MINUSCA's armed helicopters and ground forces. Once this attack had been halted through sheer brute force, the FPRC then abandoned its plans to 
capture the city and shifted its attention towards the pursuit of the fleeing UPC leadership instead.

Although the UN's actions in this case were instrumental in protecting Bambari's civilian population from harm, its success was far from guaranteed and can largely be attributed to a combination of three different factors. First, the UN was able to decrease the FPRC's incentive to launch a third attack on Bambari by compelling the UPC's leadership to leave town. They took this action as part of Operation Bekpa, which was intended to turn Bambari into a "city without arms and without armed groups" so that it would be a less tempting target for armed groups to attack (MINUSCA 2017e, 36). Since the FPRC were primarily interested in driving the UPC out of Bambari rather than capturing the town themselves, it was hoped that the removal of the UPC's leadership would serve both the short-term goal of preventing an attacking on the city and the long-term goal of establishing a weapons free zone. To drive their message home, the $\mathrm{UN}$ issued an ultimatum directly to the UPC's leadership in Bambari and made it clear that they would be willing to use force if they did not leave town. In the words of Alain Sitchet, the UN's local Head of Office, "We are ready, willing and able to take over the city and we will do it...Bambari is going to be a weapon-free city" (Kleinfield 2017). Rather than risk being forced out by MINUSCA's forces, the UPC's top commander, Ali Darassa, voluntarily withdrew from Bambari on 22 February and retreated to the southeast along with a number of his fighters. Although his withdrawal did not prevent the second FPRC attack on the city, which took place four days later, no further attempts were made to capture Bambari after this point. ${ }^{99}$

\footnotetext{
${ }^{99}$ It is also worth noting that the small detachment of FPRC fighters may not have been aware that the UPC's leadership had already been forced to leave town. Their attempt to infiltrate the city shortly
} 
Instead, the FPRC chose to withdraw from the area and pursue the fleeing UPC, despite the preparations that they had been making for a renewed offensive on the city by arming youth in Ippy (MINUSCA 2017a). The fact that a third attack did not emerge is therefore indicative of a shift in the cost-benefit calculations made by the FPRC's leadership, which then helped MINUSCA to establish a credible deterrent.

Second, the UN also took steps to increase the credibility of its coercive threats during this time period by increasing the relative quantity and quality of its peacekeeping personnel. Prior to the outbreak of conflict, the UN's presence in the area consisted of a single infantry battalion in Bambari plus an additional battalion, along with support personnel, at its sector headquarters in Bria, located approximately 200 kilometres to the northeast. Although these troops helped to mitigate the severity of violence during the initial stages of the FPRC's campaign against the UPC, the UN feared that they would be insufficient to stop the coalition's advance on Bambari itself (MINUSCA 2017e, 36). To reinforce their position, the UN dispatched armed helicopters from Bangui prior to the first deterrent action on 11 February and then followed up on 17 February by deploying additional ground forces as well. The total number of reinforcements was kept relatively small, primarily due to the need to facilitate their deployment via helicopter, but they consisted of the well-trained and highly motivated Bangladeshi SOF and Portuguese QRF. These high quality troops were then available to help rebuff the FPRC's second attack via brute force and to help compel the UPC's leadership to leave town, as well as to serve as a deterrent against a potential third attack. If neither the armed helicopters nor the high

thereafter may have therefore been launched in response to previously given orders, which would have been issued without the updated cost-benefit calculations made possible by this recent development. 
quality troops had arrived, it is unlikely that the local battalion of Mauritanian peacekeepers would have been able to achieve any of those tasks without the risk of additional bloodshed.

Third, the UN's coercive efforts were aided by the fact that neither side in this conflict possessed overriding incentives to use violence. For the FPRC, their primary motivation for attacking Bambari was to diminish the UPC's influence in the region and force its leader, Ali Darassa, to rejoin the Séléka alliance (UNSC 2017a, 14). Gaining control of the city's lucrative markets and trading centres would have been an added bonus, but it was not a core objective of the coalition's campaign. Thus, by pre-emptively removing the UPC's leadership from Bambari, the UN successfully decreased the potential benefits that the FPRC would have expected to gain from an attack on the city and provided them with an incentive to take their forces elsewhere instead. When combined with the added danger posed by the UN's helicopters and reinforcements, it is not surprising that the FPRC chose to withdraw from the city rather than risk the potential costs of an unnecessary third attack. Similarly, the UPC's decision to abandon the city would have been informed by the continued risks associated with remaining. Rather than risk being weakened in a confrontation with MINUSCA and then set upon by the FPRC, they were instead provided with an opportunity to retreat into the southeast. The added benefit from this plan was that the UN's presence in Bambari served as a protective buffer between the two forces, which would have made it more difficult for the FPRC to set out in immediate pursuit. So, even though losing their main stronghold was not an ideal outcome for the UPC, the chance to live and fight another day would have made an enticing offer when compared to the potential harm associated with MINUSCA's compellent threat. This conflict episode is therefore a perfect example of how coercive interaction between 
peacekeepers and conflict actors can lead to decreased levels of violence, as well as the advantages provided by localized increases in the relative quantity and quality of the UN's peacekeeping personnel.

\subsubsection{Attack on Alindao IDP camp (15 November 2018)}

The town of Alindao is located in the southeastern prefecture of Basse-Kotto, where it occupies a strategic junction for all road traffic travelling between Bambari or Bria to the north and Bangassou to the southeast. Despite having a majority Christian population, the town itself had served as a major military stronghold for the Muslim UPC since their expulsion from Bambari by the UN in February 2017. However, the surrounding countryside largely remained under the control of various anti-balaka groups, whose ostensible purpose was to protect the area's Christian population from the threat posed by the UPC. Due to the continued tension between these two groups, which had resulted in anywhere from 193 to 257 civilian fatalities between May and August 2017 alone, a large number of Christian civilians decided to take refuge at one of the two IDP camps on the outskirts of Alindao (MINUSCA 2019, 2-3). As of November 2018, the larger of these two camps contained approximately 20,000 civilians and was located near the town's cathedral, whereas the smaller of these two camps held only 3,000 civilians and was located next to Elim church (MINUSCA 2019, 3). Although both of these camps were tolerated by the UPC and benefitted from UN protection, the cathedral IDP camp became increasingly problematic over time because it was often used as a refuge by members of the local antibalaka. When tensions between these two groups boiled over on the morning of 15 November 2018, the result was an attack on the cathedral IDP camp by the UPC and 
members of a local Muslim militia that cost the lives of at least 112 civilians, including 44 women and 19 children (MINUSCA 2019, 1).

The attack on Alindao's cathedral IDP camp began at approximately 8:00 AM on the morning of 15 November 2018 and lasted until shortly after 4:00 PM. The immediate cause of the attack was the killing of two Muslim civilians by anti-balaka militants, one of whom had been killed the previous day and the other earlier that morning (MINUSCA 2019, 4). According to Amnesty International, it was the delivery of this second body to be washed at a nearby mosque that "sparked the outrage that generated the attack" (AI 2018 , 9). After taking a moment to get organized, a mixed force of roughly $200-400$ UPC fighters and local militia arrived at the northwestern edge of the cathedral IDP camp around 8:00 AM (MINUSCA 2019, 3-4). They then engaged in a two-hour firefight with around a dozen members of the camp's anti-balaka group while advancing towards the cathedral in the southeast, after which they managed to break through the resistance and push further into the camp. This initial assault was quickly followed up by a second wave of attackers, which consisted primarily of local Muslim civilians and militia who were interested in looting the IDPs' possessions as well as church and NGO property (MINUSCA 2019, 5). A group of UPC reinforcements from nearby Bokolobo then arrived later on that afternoon, initially joining in on the looting before setting fire to the camp and withdrawing around 4:00 PM. Their withdrawal was then followed by the return of the local anti-balaka group, who proceeded to loot anything of value that the UPC and its allies had left behind rather than offering support to the camp's residents. The looting then continued into the following day, until it was stopped by the arrival of a small force of Burundian peacekeepers from a nearby location who were able to help secure the camp and the surrounding area. 
Throughout the course of these events, the response from MINUSCA's local garrison was virtually nonexistent. A total of 35 Mauritanian peacekeepers were stationed at the cathedral IDP camp on the morning of the attack; their armaments consisted of automatic weapons and armored personnel carriers (MINUSCA 2019, 5). Shortly after the attack began, they abandoned three of the four sentry posts that they had established along the perimeter of the camp and retreated to the relative safety of their central base. Although there are disputing accounts regarding their actions prior to this point, with the peacekeepers claiming that two sentry posts had fired warning shots before withdrawing and the camp's residents insisting that they had not, the end result was the same (MINUSCA 2019, 10; AI 2018). Rather than deterring the initial attack in the morning or compelling the attackers to leave later that afternoon, the peacekeepers decided to abandon the camp to its fate and made no effort to leave their base until reinforcements arrived the following day. Having said that, they did take steps to shelter somewhere between several dozen and 1,000 IDPs within the confines of their base during this time period, so they did not neglect their protective duties entirely (MINUSCA 2019, 7). But their actions left the camp's 19,000 other inhabitants to seek safety on their own, with the majority choosing to flee towards the UN's other base near Elim IDP camp on the opposite side of town or into the surrounding countryside.

Although there are a number of possible explanations for the failure of MINUSCA's protective efforts in this case, there are four factors in particular that are worth exploring in additional depth. First, the local garrison of peacekeepers may have simply lacked sufficient personnel to mount a credible deterrent. After all, there were only 35 peacekeepers stationed in the camp on the morning of the attack, as opposed to 
somewhere between $200-400$ combatants on the other side. The resulting imbalance in terms of brute force could have then diminished the credibility of the UN's deterrent posture, regardless of the actions taken by its peacekeeping personnel. In fact, this is the position taken by one of MINUSCA's spokesmen, Vladimir Monteiro, one month following the attack, who suggested that the size imbalance between the two forces would have made it impossible for them to contain the spread of violence (AI 2018, 5). However, this explanation begins to fall apart when the performance of the local anti-balaka is taken into account, as they were able to hold off the entire attacking force for two full hours with only a dozen fighters (MINUSCA 2019, 5). So it is possible that a lack of numbers played a role in the peacekeepers' own calculations, but the evidence suggests that a more robust response could have resulted in a stronger deterrent.

Second, a related explanation is that the Mauritanian peacekeepers stationed at the camp were not sufficiently trained or equipped to handle such a large numerical disparity. Rather than possessing the skills of elite special forces or paratroopers, who formed the bulk of MINUSCA's rapid response capability, the peacekeepers stationed in the camp were just regular soldiers. They also lacked the kind of technological advantage employed during previous incidents of coercive action, such as aerial combat support. But, again, the performance of the anti-balaka fighters is instructive in this regard because they were able to hold off the attacking forces with little more than artisanal rifles, despite their lack of formal military training (MINUSCA 2019, 5). They were also only forced to retreat after they had run out of ammunition, which suggests that they could have held out longer if they had been better supplied. By contrast, the Mauritanians were equipped with automatic rifles and possessed armored personnel carriers, which would have offered them a clear 
qualitative advantage over their attackers (AI 2018, 5). So it is unlikely that a lack of capabilities can explain the failure of deterrence in this case either, even though the local garrison did not consist of MINUSCA's most highly trained or best equipped personnel.

Third, an alternative explanation is that the sense of outrage and desire for revenge felt by the attacking forces would have made them more difficult to deter than normal. The fact that their continued survival did not depend on the success of the attack means that deterrence should still have been possible, but it may have required more than the few scattered warning shots that the peacekeepers claim to have fired. Although it is difficult to discount this argument entirely, at least with respect to the initial phase of the assault, it does little to explain the lack of action by the Mauritanian peacekeepers later on that day. Once the anti-balaka had been forced out of the camp and vengeance had been achieved, tempers would have presumably cooled during the looting phase of the attack and made the relevant individuals more amenable to coercion. At that point, a compellent push by the UN's peacekeepers may have been sufficient to force the attackers out of the camp, the majority of whom would have presumably placed a higher value on their lives than an opportunity for further plunder. In fact, the ability of the small Burundian contingent to clamp down on looting the following day, despite consisting of only 21 personnel, suggests that at least some of the individuals involved were coercible (MINUSCA 2019, 10). The failure of deterrence, and lack of compellence, in this case is therefore difficult to ascribe solely to the incentives held by the relevant conflict actors. This suggests that some other factor must have also been at work.

The fourth, and most compelling, explanation for MINUSCA's failure is that the Mauritanian peacekeepers lacked the willingness to mount a credible deterrent. Their 
actions in this case suggest that they valued their own self-preservation more highly than the protection of the camp or its civilian population, despite their mandate to take all necessary means to stop on-going violence. On the one hand, it is hard to fault the local commander for prioritizing the lives of his soldiers over those of the camp's inhabitants. The Mauritanian battalion as a whole had suffered at least 2 fatalities and 20 injuries since the start of 2018 (UNSF 2018f, 150-158), in addition to being ambushed several times within the immediate vicinity of Alindao. So retreating to safety almost immediately, whether on the initiative of the local commander or due to standing orders from back home, may have seemed like the most rational thing to do. ${ }^{100}$ On the other hand, it is equally hard to ignore the allegations that this particular contingent had regularly neglected its duties in the past. Interviews conducted by Amnesty International in the wake of the attacks suggest that the Mauritanians rarely patrolled the camp, refused to investigate disturbances involving audible gun shots, neglected to confiscate arms carried openly by camp residents and even delegated some of their duties to a 'security team' consisting of anti-balaka fighters (AI 2018, 7-8). Their performance was also compared unfavourably with that of the camp's previous contingent of Burundian peacekeepers, who the locals indicated were more diligent in performing their duties and "noticeably more robust and aggressive when handling possible incursions by the UPC" (AI 2018, 7). ${ }^{101}$ Therefore, even if the

\footnotetext{
${ }^{100}$ Although the existence of such standing orders is speculative, it would be one possible explanation for the similarities between this incident and another one that took place near Ippy on 6 December 2018. Despite being protected by a different contingent of Mauritanian peacekeepers, they displayed similarly passive behavior when the IDP camp that they were guarding was attacked by the UPC. An eyewitness interviewed by Amnesty International is reported to have said the following: "the MINUSCA stayed in front of the church. They stayed watching only. They didn't do anything. [It's] the Mauritanian contingent" (AI 2018, 12).

${ }^{101}$ There were even allegations that a peacekeeper had allowed his weapon to be confiscated by an anti-balaka fighter for a short period of time, which the camp's residents took as a sign of the "troops' weakness and passivity" (AI 2018, 7). Given the close connection that existed between the cathedral IDP
} 
peacekeepers did fire warning shots at the attackers as they claimed, the credibility of their deterrent would have been undermined by a combination of their past behaviour and hasty retreat.

\subsubsection{Security vacuum in Mambere-Kadei (2017)}

The prefecture of Mambere-Kadei is located in southwestern CAR, along the border with Cameroon to the west. Its capital, Berberati, is one of the largest cities in the country and sits along one of the two main supply routes in and out of Cameroon, whose seaport of Doula is the entry point for most of CAR's imports. Due to the strategic importance of this route, as well as the large civilian population in the area, the UN has maintained a presence in Berberati since the early months of its operation. Its first contingent of peacekeepers arrived in the city around February 2015, with their primary objective being to secure the road between Berberati and the border town of Gamboula. In addition, these peacekeepers were also expected to stabilize the surrounding countryside and prevent the emergence of the kind of transhumance-related violence that plagued the northwest. Although they were only partially successful at achieving these goals during the first year of their deployment, the security situation in the area gradually improved over time and remained relatively calm throughout most of 2016. However, local stakeholders reported a deterioration in the prefecture's security situation starting in early-2017, which coincided with the return of Fulani pastoralists to the area after a lengthy absence. Tensions between these Muslim cattle-herders and the area's Christian anti-balaka groups then 
escalated in late-2017, leading to increased violence in the western half of the prefecture that continued into the following year.

The destabilization of western Mambere-Kadei began during the dry season from December 2016 - May 2017, during which approximately 6,500 Fulani cattle-herders returned to the area from neighbouring Cameroon. Most of these individuals had been driven out of the country following clashes with the anti-balaka in 2015, but negotiations to secure a "gradual and limited return of pastoralists" to the area had begun by February 2016 (IPIS 2018, 71). Despite the success of these negotiations, the returning herders found themselves subject to a number of "conditionalities" levied by the area's anti-balaka groups upon entering the country (IPIS 2018, 71). Interviews conducted with pastoralist operators suggest that approximately 130 oxen were stolen in the course of the returns process, on top of the roughly 50,000 FAFC (roughly $\$ 80$ in 2017 USD) charged per herd in exchange for "security" along the way (IPIS 2018, 71). Although the long-term implications of these charges were not immediately clear, the insecurity that these herders felt upon their return set off a chain of events that culminated in the creation of a new self-defence group in late2017.

This new group, known as Siriri, was similar to Retour, Réclamation et Réhabilitation (R3) in the northwest, in the sense that its ostensible purpose was to protect Muslim cattle-herders from the anti-balaka (UNSC 2018a, 24-26). But its objective quickly shifted from communal protection to outright predation, which threatened the anti-balaka's control over the lucrative cattle trade in the area as well as their interests in nearby gold and diamond mines. The end result was a notable decline in the security situation in western Mambere-Kadei, with armed clashes soon breaking out between the two groups. These 
clashes then continued into 2018, with most violence concentrated in a corridor along the Cameroonian border located roughly 100 kilometres west and northwest of the UN's main base in Berberati.

The most puzzling element of this entire episode is that the returning Fulani herders felt so insecure that they decided to create an entirely new armed group for protection, despite the presence of nearby peacekeeping personnel. However, upon closer inspection, an explanation is offered in the form of an underperforming Congolese battalion, whose quantitative and qualitative deficiencies created a security vacuum in the region that the formation of Siriri was intended to fill.

First, before highlighting this battalion's many quality-related issues, it is worth noting that its presence in Mambere-Kadei was relatively weak due to a lack of available personnel. After deploying to Berberati with a total of 855 peacekeepers in February 2015, the battalion's overall troop strength stood at only 629 when the Fulani began to return at the start of $2017 .{ }^{102}$ The majority of this $26 \%$ drop was due to the repatriation of peacekeepers following allegations of sexual exploitation and abuse, with more than 100 troops sent home in July 2016 alone (MINUSCA 2017b, 8). Since none of these troops were replaced over the course of the following year, the battalion would have been forced to decrease its activities in the surrounding area due to a lack of personnel. Although choosing which activities to scale back would have been difficult under any circumstances, the Congolese battalion faced an additional challenge at this time because of its relatively large area of operations (AoR). Rather than being concerned solely with the area around

\footnotetext{
102 These personnel figures were derived from the monthly contribution reports available on the UN DPKO's website: https://peacekeeping.un.org/en/troop-and-police-contributors.
} 
Berberati, its personnel had also been assigned responsibility for other locations in southwestern CAR as well. In March 2017, for example, there were 108 troops from the Congolese battalion guarding the southwestern route into Bangui while stationed in Mbaiki, which is located approximately 400 kilometres away from Beberati by road (MINUSCA 2017b, 9). These troops were joined by an additional 182 personnel stationed along the northeastern and northwestern routes into the city, with the most distant contingent located in the town of Sibut roughly 700 kilometres away from their main base (MINUSCA 2017b, 9). The combined effect of these distant deployments and the misconduct-related repatriations left the Congolese battalion with only 339 troops for use in the area surrounding Berberati, some of whom would have been staff officers assigned to battalion headquarters rather than the kind of troops that could be deployed in the field. Given the small number of troops available for protective activities, it is not surprising that the Fulani herders experienced a high level of insecurity upon their return.

Second, the performance of the Congolese battalion was also severely limited due to critical capability shortfalls in terms of both equipment and personnel. One of the most serious issues faced by the battalion was a lack of available ground vehicles, with only 18 out of its 114 vehicles considered to be serviceable in March 2017 (MINUSCA 2017b, 1819). Of the remaining 96 vehicles, a total of 52 had broken down entirely and were completely unavailable, whereas the other 44 remained in operation despite their need for urgent maintenance (MINUSCA 2017b, 18-19). As a result, a UN evaluation report conducted at the time noted that the majority of the battalion's vehicles were "vulnerable and susceptible to break down at any moment," which limited its ability to conduct adequate patrols and led to numerous issues along the road (MINUSCA 2017b, 19). Given 
the large size of the battalion's AoR, the long distances between MINUSCA's outposts and the poor road conditions in the area, the authors of the report were forced to conclude that "this situation renders the unit incapable of performing correctly its mandated tasks" (MINUSCA 2017b, 4). Even without the complications posed by its lack of vehicles, the report also noted that the battalion's rapid response capabilities were significantly below standard. When the evaluators conducted an alert exercise involving the deployment of a QRF to Berberati, it took more than one hour for the small force of seven peacekeepers to get ready for the operation and exit the camp (MINUSCA 2017b, 25). Issues were also identified with regard to the battalion's situational awareness, sustainment capabilities and ability to project force, resulting in an overall assessment that "the battalion does not have the ability to dominate its AoR or to react to incidents of exactions perpetrated by armed groups" (MINUSCA 2017b, 25). This assessment is fairly damning as far as the Fulani would have been concerned and goes a long way towards explaining why they felt the need to fill the resulting security vacuum.

Third, even if the Congolese battalion had possessed sufficient troops and capabilities to secure its AoR, its performance would have been undermined by the overall state of its peacekeeping personnel. The operational readiness assessment conducted in March 2017 noted that "mistrust and disputes" had strained the relationship between the Battalion Commander and his deputy and company commanders, which had negatively impacted the morale and discipline of the battalion as a whole (MINUSCA 2017b, 3-4). As a result, the report noted that "most of the personnel spend the day in idleness and unfitting military attire," without taking the steps necessary to secure even the perimeter of their own camp let alone the surrounding countryside (MINUSCA 2017b, 3-4). By May 
2017, a memo sent to the DPKO by MINUSCA's Force Commander indicated that the situation had become so dire that "the battalion is no longer trustable because of poor leadership, lack of discipline, and operational deficiencies" (Kelta 2017). Despite corrective efforts on his part, which involved the delivery of six "blame letters" to the Battalion Commander since the start of 2017, the situation deteriorated to the point where the entire battalion had to be repatriated in July 2017 (Kelta 2017). ${ }^{103}$ A battalion of Tanzanian peacekeepers was then assigned to the area in August 2017, with their full complement of 452 troops deployed by the start of the dry season at the end of the year. ${ }^{104}$ Once deployed, these troops were much more proactive when it came to performing their assigned duties, which included regular patrols along the Cameroonian border stretching from Gamboula to Noufou. ${ }^{105}$ Nonetheless, the security vacuum created by the departing Congolese troops had already done its damage, leading to the emergence of Siriri towards the end of 2017. The newly deployed Tanzanian troops were then forced to deal with this development over the course of the following year, with the success of coercive actions like Operation Jinjet from April to June 2018 largely serving to contain the spread of the group's influence (UNSC 2018a, 24-25).

In sum, the coercive dynamics explored in these conflict episodes highlight some of the ways in which MINUSCA's peacekeepers can impact the use of violence. The first episode shows the importance of localized increases in the relative quantity and quality of

\footnotetext{
${ }^{103}$ It is also worth noting that more than five Congolese delegations were dispatched to CAR in an attempt to address these shortcomings, which suggests that their inaction was not the result of deliberate government policy.

${ }^{104}$ These personnel figures were derived from the monthly contribution reports available on the UN DPKO's website: https://peacekeeping.un.org/en/troop-and-police-contributors.

${ }^{105}$ An example of the Tanzanian peacekeepers' patrol route and associated behavior can be found in a short video posted to UNifeed: https:/www.unmultimedia.org/tv/unifeed/asset/2398/2398582/.
} 
peacekeeping personnel, the second episode demonstrates the risks associated with deploying poorly motivated personnel, and the third episode suggests that the deployment of personnel who fail to meet a certain qualitative threshold may do more harm than good. When considered as a whole, these three episodes also provide additional evidence in support of the theoretical model developed in this dissertation, which emphasizes that the UN's ability to manage on-going violence is highly dependent on whether it can successfully coerce local conflict actors.

\subsection{Discussion and Conclusion}

The primary goal of the process-tracing exercise presented in this chapter was to identify how and why an increase in the relative quality of UN peacekeepers results in decreased levels of violence. In doing so, the intent was to assess the accuracy of the theoretical model that lies at the heart of this dissertation as well as the results of the previous two quantitative chapters. Although this exercise was limited to only the single case of MINUSCA in CAR, the diversity of this operation's underlying conflict environment provided a substantial amount of evidence in favour of the hypothesized causal relationship. Both the operational-level narrative and the discrete conflict episodes demonstrated that these kinds of coercive dynamics exist and that the success or failure of the UN's coercive acts depends, in part, on the relative quantity and quality of its peacekeeping personnel. Below, I outline three of the main findings from this exercise, which I then expand upon further in the concluding chapter that follows.

First, this case contains numerous examples of compellent and deterrent behaviour on the part of the UN's peacekeepers, at both the operational-level and the local-level. 
Although many of these examples involved the use of armed force, whether defensively or offensively, MINUSCA also made repeated attempts to communicate with targeted conflict actors pre-emptively so that it could avoid the need to take such drastic steps. Many of its threats of harm were also paired with assurances of positive inducements, which is exactly the kind of behaviour expected by the theoretical model developed in Chapter 3 . Similarly, this case highlights several examples of coercive behaviour on the part of CAR's conflict actors, both with respect to rival armed groups and MINUSCA's personnel. Some groups chose to engage in counter-escalation when targeted by one of MINUSCA's threats, such as the FPRC during the incident in Bambari, whereas others simply asserted their dominance through the use of brute force. One of the main takeaways from this case study is therefore that these kinds of coercive dynamics actually exist, which provides additional insight into the nature of the causal relationship between peacekeepers and civil war violence.

Second, the experience of MINUSCA in CAR also indicates that the success or failure of the UN's coercive acts is influenced by the relative quantity and quality of its peacekeeping personnel. In terms of quantity, the overall lesson was that the UN can only do so much without sufficient personnel. The drawdown of international troops in the aftermath of CAR's national elections left MINUSCA scrambling for replacements once conflict resumed, which it proved unable to obtain quickly due to the reticence of individual TCCs. The need to operate over such a vast area also stretched MINUSCA's resources to the limit, despite the adoption of a more mobile force posture designed to maximize the effectiveness of its available personnel. Nonetheless, when MINUSCA was able to back up its coercive actions with the deployment of additional troops, it proved able to dissuade 
conflict actors from using violence. These findings provide support for Hypothesis 1 from Chapter 3 (i.e., The higher the quantity of peacekeeping personnel deployed to an operation, the lower the level of violence).

In terms of quality, the critical capability shortfalls faced by many of MINUSCA's re-hatted troops initially limited its ability to engage in coercive operations without French or EU assistance. It was only after MINUSCA had managed to address these issues, as well as to obtain additional capabilities of its own, that its ability to operate independently improved. Even then, its ability to coerce conflict actors successfully often hinged on the relative performance of small groups of peacekeepers. Some of these troops were welltrained and highly motivated, which made them more effective at performing their assigned tasks, whereas others only reluctantly performed their duties and were unwilling to risk their lives in combat. These findings provide support for Hypothesis 2 from Chapter 3 (i.e., The higher the quality of peacekeeping personnel deployed to an operation, the lower the level of violence). Although the range of examples chosen was far from exhaustive, the fine-grained evidence used to generate these findings nicely complements the more generalizable results presented in the previous two chapters.

Third, this case study also sheds light on some of the contradictory results reported in the quantitative portion of this dissertation. The most puzzling of these results was the statistical and substantive significance of "elite" troops at the state-level but their apparent insignificance at the local-level. Given the central thesis of this entire study, as well as the findings related to personnel quality more generally, it would be highly problematic to find that the UN's best troops tend to perform no more effectively than the rest. However, a simple explanation for this apparent contradiction emerges when the experience of 
MINUSCA is examined in additional detail, primarily due to the manner in which such elite troops tend to be used in the field. Since the highest quality units in MINUSCA's case were employed in more mobile duties, such as the Portuguese QRF, it is not at all surprising that their impact failed to register in the geospatial analysis. The grid-based approach adopted in that chapter was not well-suited to evaluating the impact of highly mobile peacekeepers being dispatched from a central base, particularly since the UN's deployment maps were only available on a quarterly basis. By contrast, the state-level analysis would not have had any problems accounting for the aggregate impact of such troops, regardless of how often they were shifted from one hot spot to the next. The likely explanation is therefore that the results of the state-level analysis are correct in this instance and that the UN's highest quality troops are in fact more effective on average.

Similarly, this case study also helps to explain the contradictory results reported by the quantitative models with regard to the UN's relationship with battlefield violence. At the state-level, the UN was shown to be effective at reducing overall levels of battle-related fatalities, whereas at the local-level it was merely capable of reducing fatality rates in a specific location. To explain this apparent contradiction, it is useful to reference the UN's performance during its successful defence of Bambari. In this context, an increase in the relative quantity and quality of MINUSCA's troops helped it to avoid an armed clash in the streets of Bambari, which provides support for the results of both the local-level and state-level models. However, rather than decreasing overall levels of violence, the successful defence of the city simply shifted the conflict between the FPRC and UPC further south, where they continued to fight. Therefore, this example provides an additional measure of support for the results of the local-level models, which suggest that 
peacekeepers are capable of displacing battlefield violence in this manner but not of stopping it altogether. Having said that, it is likely that the UN is also capable of reducing overall levels of battlefield violence in a conflict, despite the example provided by Bambari. But this effect may simply be tied up in the kinds of operational-level factors that are difficult to capture in an analysis bound by quarterly observations of discrete grid cells, whether military or diplomatic.

In conclusion, the main takeaway from this chapter is that the UN's ability to manage on-going violence is linked, at least in part, to its ability to coerce local conflict actors. These conflict actors can be influenced via the use of either threats or assurances, which are more effective when supported by the deployment of a large number of high quality personnel and less effective when supported by the deployment of a small number of low quality personnel. This chapter therefore provides additional support for the underlying accuracy of the causal model developed in Chapter 3, as well as the overall argument advanced by this dissertation.

This chapter also makes four main contributions to the literature on peacekeeper quality. First, it represents the first attempt to evaluate the relationship between peacekeeper quality and civil war violence using a qualitative case study. Previous case study research on operational effectiveness may have mentioned the topic of peacekeeper quality, but there has yet to be an explicit attempt to trace the relationship between this factor and the severity of on-going violence. Second, it provides additional support for a definition of peacekeeper quality that accounts for more than just the raw military capabilities of the personnel in question, as well as for a causal model of operational effectiveness that relies on coercive interaction between peacekeepers and conflict actors. 
Third, it explores the unique conflict dynamics of an understudied example of UN intervention, which also provides insights into the efficacy of re-hatting troops from previously deployed operations and the benefits of working with other international forces. And fourth, it contributes to a more complete and nuanced assessment of the relationship between peacekeeper quality and violence by complementing the quantitative analysis conducted in the previous two chapters. In the following chapter, I expand on this fourth point by presenting a summative conclusion of this study's overall results and then identifying some potential avenues for future research. 


\section{Chapter 7: Discussion and Conclusion}

At the outset of this dissertation, I began by asking why some groups of peacekeepers are more effective at managing on-going violence than others. During the crisis in Juba, for example, UN peacekeepers largely withdrew to the protective confines of their compounds and refused to engage in more proactive forms of intervention, whereas in Bambari they engaged directly with local conflict actors and prevented a deadly attack on the city. I then pointed out that this variation in effectiveness is problematic because the need to manage on-going violence, whether on or off the battlefield, has become one of the most important tasks assigned to UN peacekeeping operations today. The need to understand why some groups of peacekeepers are more effective than others is therefore a central concern of both academics and policy makers, particularly given the implications that any shortcomings in this regard can have for the wellbeing of civilian populations around the world.

Previous attempts to answer this question by scholars and peacekeeping professionals have pointed to a wide range of factors. These factors include the quantity, profession and geographic distribution of peacekeeping forces on the ground, the nature of the conflict environment and the relative quality of the UN's military personnel. While it has been straightforward for researchers to control for size and conflict environment in their studies, determining whether or how the "quality" of UN peacekeepers matters remains understudied and elusive. As a result, this dissertation has taken up the challenge of better understanding and explaining how variation in peacekeeper quality affects the UN's ability to manage on-going violence. More importantly, it has also brought these various factors together to offer a more complete and satisfying explanation of operational 
effectiveness than provided by the sole previous study on this topic. I have argued that higher quality peacekeepers are more effective than lower quality peacekeepers because they have an easier time coercing local conflict actors, whose incentives to use violence are a critical element of any discussion related to effectiveness. I have also tested this argument using a combination of quantitative and qualitative methods, all of which have demonstrated that the UN's ability to manage on-going violence is determined, in part, by the relative quality of its peacekeeping personnel. Below, I briefly summarize the results of these tests and discuss the core findings of this study. I then identify some of the implications that these findings have in terms of both theory and policy, before concluding this dissertation by suggesting an agenda for future research.

\subsection{Main findings}

The main takeaway from this dissertation is that the UN's ability to manage ongoing violence depends, in part, on the relative quality of its peacekeeping personnel. I have explained what quality is and how it works, in addition to developing a novel causal model of operational effectiveness. I have also shown that variation in peacekeeper quality affects outcomes at both the state-level and the local-level, which suggests that a relationship between peacekeeper quality and operational effectiveness does in fact exist. In Chapter Four, for example, I showed that variation in average operational quality has an effect on the severity of civil war violence at the state-level, based on a dataset of all intrastate conflicts in sub-Saharan Africa from 1991-2017. And in Chapter Five, I showed that variation in the average quality of individual groups of peacekeepers has an effect on the severity of violence at the local-level, based on a geospatial analysis of three operational 
environments from 2010-2017. I then verified the accuracy of these quantitative results by presenting a process-tracing case study of MINUSCA in Chapter Six, which also confirmed the existence of the kind of coercive dynamics theorized in Chapter Three. Collectively, the results of these chapters provide a strong degree of support for the existence of a relationship between peacekeeper quality and civil war violence, which exists independently of related factors such as the quantity, profession and location of the relevant personnel. They also provide a strong degree of support in favour of Hypothesis 2 from Chapter 3, as noted in the summary of results listed in Table 9, which expected that violence would decrease as quality increased. Overall, then, the core takeaway from this dissertation is that quality matters, which represents a significant contribution to the literature on operational effectiveness.

Although a more detailed discussion of individual results can be found at the end of each chapter, there are four additional findings that are worth highlighting here. First, given the stated aim of this study, it is significant that the UN's highest quality peacekeepers were found to be the most effective at decreasing the severity of on-going violence. The slope analysis conducted in the two quantitative chapters showed that the best peacekeepers are likely to be both highly capable and highly willing to act when faced with violence, which is precisely what was expected by Hypothesis 3. Further support for this hypothesis is linked to the fact that both the state-level analysis and the qualitative case study found that "elite" troops are significantly more effective than average troops, which allows them to have an outsized effect on violence. As a result, the most effective peacekeepers are likely to possess a combination of skills, capabilities and incentives that set them apart from their peers. 
Table 9 - Summary of results for chapters four, five and six

\begin{tabular}{|l|c|c|}
\hline \multicolumn{1}{|c|}{ Hypotheses } & Result & Evidence \\
\hline $\begin{array}{l}\text { Hypothesis 1: The higher the quantity of } \\
\text { peacekeeping personnel deployed to an } \\
\text { operation, the lower the level of violence. }\end{array}$ & Strong support & Chapter 4,5 \& 6 \\
\hline $\begin{array}{l}\text { Hypothesis 2: The higher the quality of } \\
\text { peacekeeping personnel deployed to an } \\
\text { operation, the lower the level of violence. }\end{array}$ & Strong support & Chapter 4, 5 \& 6 \\
\hline $\begin{array}{l}\text { Hypothesis 3: When peacekeepers possess high } \\
\text { capabilities and a high willingness to act, then } \\
\text { they should be highly effective at managing } \\
\text { violence. }\end{array}$ & Strong support & Chapter 4 \& 6 \\
\hline $\begin{array}{l}\text { Hypothesis 4: When peacekeepers possess high } \\
\text { capabilities and a low willingness to act, then } \\
\text { they should be moderately effective at managing } \\
\text { violence. }\end{array}$ & Weak support & Chapter 4 \& 5 \\
\hline $\begin{array}{l}\text { Hypothesis 5: When peacekeepers possess low } \\
\text { capabilities and a high willingness to act, then } \\
\text { they should be moderately effective at managing } \\
\text { violence. }\end{array}$ & Weak support & Chapter 4 \& 5 \\
\hline $\begin{array}{l}\text { Hypothesis 6: When peacekeepers possess low } \\
\text { capabilities and a low willingness to act, then } \\
\text { they should be ineffective at managing violence. }\end{array}$ & Moderate support & Chapter 6 \\
\hline
\end{tabular}

Having said that, it is important to note that the local-level analysis failed to find a similar effect in this regard, despite the pattern suggested by its slope analysis. This disparity is problematic but it is likely due to the highly mobile nature of such troops, who tend to be shifted rapidly from one crisis location to the next, making them difficult to evaluate using a more geographically disaggregated approach. Based on the weight of the evidence, therefore, one of the core findings of this dissertation is that the UN's highest quality peacekeepers are more effective at managing on-going violence than its average quality peacekeepers.

Second, the evidence is less straightforward when it comes to determining the relative effectiveness of the UN's lowest quality peacekeepers. In the case study chapter, anecdotal evidence at both the state-level and the local-level indicated that the worst 
performing troops tend to suffer from critical capability shortfalls and abysmal morale, which is exactly as expected. But the results of the quantitative analysis were less clear cut, with little evidence to suggest that the lowest quality troops were any worse than more average quality troops when it came to their performance. As a result, these findings provide a moderate level of support for Hypothesis 6, which expected that troops with low capabilities and a low willingness to act would only be minimally effective at managing violence.

Similarly, a clear picture failed to emerge regarding the effectiveness of troops who ranked highly in one aspect of peacekeeper quality but poorly in the other. The slope analysis contained in the two quantitative chapters suggests that the worst performers are highly capable troops who are unwilling to act, which contradicts the expectation of moderate effectiveness in Hypothesis 4. And it also suggests that the performance of the most and least willing troops tends to be similar at lower levels of capabilities, which contradicts the expectation of moderate effectiveness in Hypothesis 5. Although the case study chapter does offer some level of insight into these questions, such as when UN troops were unwilling to halt violence near Alindao despite possessing sufficient capabilities, both of these results are nonetheless quite puzzling. Given this lack of clarity, it would be useful to conduct additional research into the interaction between these two core components of peacekeeper quality, the nature of which is expanded upon below.

Third, the results of this dissertation also demonstrate that the quantity of deployed personnel remains a core determinant of operational effectiveness when controlling for the effects of peacekeeper quality. The state-level analysis shows that variation in the size of an operation has an effect on the severity of one-sided violence across the conflict as a 
whole, whereas the local-level analysis shows that variation in the number of personnel stationed in a specific location has an effect on nearby rates of civilian killing. These results were also corroborated by the analysis contained in the qualitative case study, which showed that the UN's ability to manage on-going violence depends on both the overall number of troops in the country as well as the manner in which those troops are distributed on the ground. As a result, this dissertation provides a strong degree of support for Hypothesis 1, which expected that the UN's ability to manage on-going violence would vary based on the quantity of deployed personnel.

In addition, it is also worth noting that both the state-level and local-level analysis found that variation in professional composition played an equally large role in this process. At the state-level, operations tended to be more effective if they contained a higher proportion of combat personnel relative to unarmed observers or civilian police. Whereas at the local-level, military peacekeepers tended to be more effective if they were suited to direct confrontation with nearby conflict actors, such as infantry or armor, rather than more supportive roles, such as engineers or logisticians. The newfound significance of peacekeeper quality as an explanatory variable should therefore be viewed as complementing existing explanations of effectiveness, such as the overall size and professional composition of an operation, rather than supplanting them entirely.

Fourth, the final point worth emphasizing is that peacekeepers do not appear to be equally effective at managing all types of civil war violence. At the state-level, the substantive effect of variation in either the size or quality of an operation is significantly greater in the context of one-sided violence than it is when dealing with battlefield violence. These results suggest that the UN is capable of mitigating the overall severity of both types 
of violence, but that it is better at protecting civilians from harm than it is at preventing fighting. Similarly, the local-level analysis suggests that variation in the proportion of high quality troops who are suited to combat can create a ripple effect that impacts overall levels of one-sided violence, whereas the same factors are only capable of producing a localized effect when considered in the context of battlefield violence. These results suggest that the presence of peacekeepers plays a major role in protecting civilians from harm, but that they are only capable of mitigating the severity of battlefield violence in nearby areas rather than eliminating it altogether.

Having said that, the local-level results are likely to neglect the potential impact of state-level assets, such as elite personnel or attack helicopters, that may be redeployed in rapid succession to address potential hot spots around the country. So the fact that they point to a more limited effect on battlefield violence than suggested by the state-level analysis should be considered in this light. Nonetheless, the anecdotal evidence gleaned from MINUSCA's experience in CAR provides further support for the idea that peacekeepers are better at protecting civilians from harm than they are at halting the use of battlefield violence, particularly if the combatants have the option of simply moving their fighting elsewhere. The overall impression is therefore of an organization that is more effective at addressing one-sided violence than it is at addressing battlefield violence, despite both types of violence being commonplace in the context of on-going conflict.

\subsection{Implications for theory}

The primary implication of this study for theory is that it provides additional support for the argument that quality matters. In addition, it also demonstrates how quality 
matters, which is a question that had yet to be adequately addressed in the literature on operational effectiveness. As noted in Chapter 2, this literature is largely anecdotal in nature and includes only a single study that looks explicitly at the relationship between peacekeeper quality and violence (Haass and Ansorg 2018). Although this study makes a valuable contribution, the relatively narrow scope of its inquiry prevents it from establishing a broad consensus regarding the link between peacekeeper quality and operational effectiveness.

To this end, the evidence contained in this dissertation makes four main contributions towards building this consensus. First, it provides additional support for the findings of the sole previous study on this topic by confirming that variation in peacekeeper quality has an effect on the severity of one-sided violence at the state-level. Second, it expands upon these findings by showing that variation in peacekeeper quality has an effect on the severity of one-sided violence at the local-level as well. Third, it moves beyond the previous study's focus on violence against civilians by showing that variation in peacekeeper quality also affects the severity of battlefield violence, at both the state-level and the local-level. And fourth, it uses insights from a relevant example of UN peacekeeping to pinpoint the precise manner in which qualitative variation can lead to increased or decreased levels of violence. Although each of the tests that generated this evidence necessarily suffer from their own caveats and shortcomings, the combined weight of these findings nonetheless represents a significant step forward for the study of operational effectiveness. Any future attempt to evaluate the relationship between peacekeepers and violence would therefore be lacking if it neglected to consider the potential contribution made by variation in peacekeeper quality. 
In addition, this study has also established that 'quality' in a peacekeeping context consists of more than just the raw military capabilities of the relevant personnel. Instead, it also involves a willingness to act when faced with violence, without which even the most capable personnel will be ineffective. Although the precise nuances by which this mechanism operates are difficult to isolate, the literature reviewed in Chapter Three suggests that it is primarily influenced by the personal experiences of the peacekeepers in question and the policy objectives of their home governments. In the quantitative chapters, I attempted to capture both of these factors using a proxy indicator based on whether the peacekeepers deployed to an operation came from countries that respected the physical integrity rights of their citizens. While admittedly imperfect, the fact that this indicator returned a statistically and substantively significant relationship with violence that was distinct from the chosen proxy for military capability is nonetheless an important finding, particularly since the interaction between these two factors found that more capable peacekeepers become more effective as their relative willingness increases. Similarly, the case study chapter included numerous examples of a link between the incentive structures possessed by different groups of peacekeepers and their willingness to manage on-going violence, which was distinct from their overall military capabilities. This analysis could have also benefited from further depth and precision, but it nonetheless provides additional support for the idea that something other than raw military capabilities matters in a peacekeeping context. As a result, one of the main theoretical implications of this study is that future research should adopt a similarly broad definition of peacekeeper quality. 


\subsection{Implications for policy}

The primary implication of this study for policy is that it provides additional support for the UN's efforts to improve the overall quality of its peacekeeping personnel. As noted in Chapter Three, the UN has made repeated references to the importance of peacekeeper quality over the past few decades, both in terms of the material capabilities possessed by the troops in question and their relative willingness to act. It has also invested considerable resources into the development of guidance documents related to the more practical elements of peacekeeping, as well as worked with troop contributing countries to ensure that their personnel are adequately trained, equipped and motivated before they are deployed. Given that the results of this study demonstrate that quality does indeed matter, the UN should continue to pursue these kinds of initiatives in the future. It should also continue to reach out to member states that possess particularly high-quality militaries, both to obtain advanced technological capabilities and to recruit small groups of elite personnel, as well as work to limit the imposition of constraints on the range of actions available to its peacekeeping personnel. At the same time, however, the UN should be careful not to set its expectations too high. The quantitative analysis contained in Chapter Four suggests that the deployment of more peacekeepers is almost always better than the deployment of less peacekeepers, regardless of their underlying quality. It should therefore avoid taking steps that would lead to a significant decrease in the number of available peacekeepers, while also working with troop contributing countries to improve the overall quality of their personnel and holding the worst performing peacekeepers to account.

This study also shows that the UN is capable of operating effectively in the midst of on-going violence. It may not always be perfect in this regard but, with the right 
personnel and the right equipment, it is capable of mitigating the severity of both battlefield violence and one-sided violence against civilians. This finding is important because the contemporary debate regarding whether the UN should intervene in situations involving on-going violence partially hinges on the question of whether it possesses the capability to carry out such operations effectively, as discussed in Chapter Two. While there may be other reasons for the UN to avoid intervening in cases of on-going violence, the evidence contained in this dissertation suggests that it should not use a potential lack of effectiveness as an excuse not to do so.

In addition, it is also worth noting that much of the UN's success in this regard appears to be linked to its use of coercion, whether to deter conflict actors from committing violent acts in the first place or to compel them to stop once they have begun. Although the use of such tools represents a departure from more traditional forms of peacekeeping, the case study presented in Chapter Six contains numerous examples in which deterrent or compellent behaviour on the part of peacekeepers has helped to save lives. Since the effective use of coercion necessarily depends on a clear understanding of the incentives possessed by local conflict actors, the UN should therefore accelerate its development of operational intelligence and analysis capabilities in order to support the efforts of its peacekeepers in the field. In doing so, it should be able to improve its ability to operate in the midst of on-going violence even further, which would go a long way toward settling the debate regarding whether it should be intervening in such violent contexts at all. 


\subsection{Agenda for future research}

Any future research on this topic would benefit from inquiry into one of two areas.

First, it would be useful if future studies could analyze the constituent components of peacekeeper quality in additional depth. The approach adopted in this dissertation has pushed inquiry into this topic one step forward but it is not without its limitations. In terms of professional capabilities, for example, the quantitative portions of this study used a proxy based on military spending per active soldier to determine the relative levels of training and equipment possessed by peacekeepers from different militaries. Although this proxy offered a reasonable way to estimate this information, the fact that it is based on national averages rather than a more nuanced assessment of the personnel in question means that it is far from perfect. As a result, it would be useful for future research to focus more explicitly on the precise capabilities possessed by different groups of peacekeepers in the field, in order to tease out the kinds of details that were hinted at in the case study presented in Chapter Six. It would also be worthwhile to evaluate the role played by potentially related factors, such as the level of pre-deployment training received by the troops in question and whether more experienced peacekeepers have an advantage over less experienced peacekeepers in a UN context.

Similarly, the proxy indicator used to measure whether peacekeepers were willing to act or not was also based on national averages rather than a more contextualized assessment, which has the potential to mask variation from one group of peacekeepers to the next. Attempting to infer the policy preferences of troop contributing countries from their human rights records may have also masked the effects of specific national caveats, whether formal or informal, that could explain variation in the behaviour of peacekeepers 
from seemingly similar countries. Although this kind of information is difficult to gather without observing peacekeepers in the field or communicating with UN officials, its inclusion in future research would likely help to explain some of the puzzling results highlighted above.

Second, now that there is a clearer sense that variation in peacekeeper quality does contribute to operational effectiveness, it would be useful to identify some concrete steps that the UN can take to improve the quality of its peacekeepers over time. As noted in Chapter Two, many of the objections raised against its decision to begin operating in the midst of on-going conflict were practical in nature, with an emphasis placed on the inherent structural, financial and organizational constraints built into the UN system. The evidence contained in this dissertation suggests that the $\mathrm{UN}$ is capable of overcoming these limitations if it is provided with the right tools, but it was not designed to identify what steps the UN can take to improve the quality of its peacekeepers nor to determine how far these steps will allow it to go. It would be helpful, therefore, to evaluate the efficacy of recent UN initiatives designed to increase the responsiveness of its peacekeepers, such as the Comprehensive Performance Assessment System piloted by MINUSCA, as well as to glean insights from the performance of non-UN operations that have been deployed under similar conditions. If it turns out that there is an upper limit to the UN's operational potential, then it may need to adjust its expectations accordingly and adopt a less ambitious approach to situations involving on-going violence.

Alternatively, the evidence contained in Chapter Six suggests that the UN may be able to overcome its qualitative limitations by deploying alongside non-UN forces from advanced militaries, such as the French and EU forces in CAR. Although this division of 
labour may not be sustainable in the long-run, particularly if the conflict in question does not affect the interests of a major military power, it would be worthwhile to dig into this practice more explicitly, with a particular eye on how it could help to compensate for the UN's qualitative shortcomings. Overall, then, the next steps in terms of research should be to analyze the constituent components of peacekeeper quality in additional depth and to identify how much the quality of the UN's personnel can reasonably be improved.

In conclusion, the main takeaway from this dissertation is that some peacekeepers are more effective at managing on-going violence than others due to variation in the underlying quality of the relevant personnel. The effects of this relationship were observed at both the state-level and the local-level, using a mixture of quantitative and qualitative methods.

In addition, this dissertation also demonstrates that the UN's highest quality peacekeepers are its most effective, that the quantity of deployed personnel continues to have an effect on violence when controlling for quality, and that peacekeepers are better at protecting civilians from harm than they are at mitigating the severity of battlefield violence. However, the evidence regarding the performance of the UN's lowest quality troops was less definitive, as was the evidence regarding the performance of troops who were ranked highly in one aspect of peacekeeper quality but not the other. In terms of theory, the main implication of this study is that quality matters. It should therefore be accounted for in future studies of operational effectiveness, which should also adopt a similarly broad definition of the term 'quality' that accounts for more than just raw military capabilities. In terms of policy, the findings with regard to peacekeeper quality suggest that the UN should continue its long-term efforts to improve the overall quality of its 
peacekeeping operations. It should also continue to intervene in situations involving ongoing violence, where its efforts appear to be doing more good than harm. Finally, the nascent state of the literature on peacekeeper quality means that there is still ample room for additional research on this topic, despite the contribution made by this study. Potential areas of interest include a more in-depth analysis of the constituent components of peacekeeper quality, as well as research into what steps the UN can take to improve the overall quality of its peacekeeping personnel and how far these steps will allow it to go in the future. 


\section{Appendices}

Appendix A - Model results from Chapter 4 with and without quality indicators

\begin{tabular}{|c|c|c|c|c|c|c|}
\hline & $\begin{array}{c}\text { (1) } \\
\text { Battlefield } \\
\text { Violence } \\
\text { (all conflict- } \\
\text { months) } \\
\end{array}$ & $\begin{array}{c}(2) \\
\text { Battlefield } \\
\text { Violence } \\
\text { (all conflict- } \\
\text { months) } \\
\end{array}$ & $\begin{array}{c}(3) \\
\text { Battlefield } \\
\text { Violence } \\
\text { (all conflict- } \\
\text { months) } \\
\end{array}$ & $\begin{array}{c}(4) \\
\text { Battlefield } \\
\text { Violence } \\
\text { (PK conflict- } \\
\text { months) } \\
\end{array}$ & $\begin{array}{c}(5) \\
\text { Battlefield } \\
\text { Violence } \\
\text { (PK conflict- } \\
\text { months) } \\
\end{array}$ & $\begin{array}{c}(6) \\
\text { Battlefield } \\
\text { Violence } \\
\text { (PK conflict- } \\
\text { months) } \\
\end{array}$ \\
\hline Total peacekeepers $(1000 \mathrm{~s})$ & $\begin{array}{c}0.991 \\
(-1.42)\end{array}$ & $\begin{array}{c}0.993 \\
(-0.89)\end{array}$ & $\begin{array}{c}0.995 \\
(-0.65)\end{array}$ & $\begin{array}{c}0.994 \\
(-0.78)\end{array}$ & $\begin{array}{c}0.999 \\
(-0.09)\end{array}$ & $\begin{array}{c}1.001 \\
(0.15)\end{array}$ \\
\hline Military (\%) & $\begin{array}{c}0.999 \\
(-1.16)\end{array}$ & $\begin{array}{c}0.994^{* * *} \\
(-2.74)\end{array}$ & $\begin{array}{c}0.992^{* * *} \\
(-3.38)\end{array}$ & $\begin{array}{c}0.999 \\
(-0.80)\end{array}$ & $\begin{array}{c}0.993^{* * *} \\
(-2.72)\end{array}$ & $\begin{array}{c}0.992^{* * *} \\
(-3.06)\end{array}$ \\
\hline Police (\%) & $\begin{array}{c}1.007^{* * *} \\
(3.08)\end{array}$ & $\begin{array}{c}1.000 \\
(-0.09)\end{array}$ & $\begin{array}{l}1.002 \\
(0.44)\end{array}$ & $\begin{array}{l}1.005 \\
(1.64)\end{array}$ & $\begin{array}{c}0.998 \\
(-0.56)\end{array}$ & $\begin{array}{c}1.000 \\
(-0.10)\end{array}$ \\
\hline Capability (\$1000s) & & $\begin{array}{l}1.004 \\
(1.60)\end{array}$ & $\begin{array}{c}1.026^{* * *} \\
(4.37)\end{array}$ & & $\begin{array}{l}1.002 \\
(0.83)\end{array}$ & $\begin{array}{c}1.018^{* * *} \\
(2.87)\end{array}$ \\
\hline Willingness & & $\begin{array}{c}0.985 \\
(-0.36)\end{array}$ & $\begin{array}{l}1.115^{* *} \\
(2.11)\end{array}$ & & $\begin{array}{l}1.014 \\
(0.31)\end{array}$ & $\begin{array}{l}1.110^{*} \\
(1.89)\end{array}$ \\
\hline Capability X Willingness & & & $\begin{array}{c}0.994^{* * *} \\
(-3.87)\end{array}$ & & & $\begin{array}{c}0.995^{* * *} \\
(-2.69)\end{array}$ \\
\hline Conflict Type & $\begin{array}{l}0.390^{* * *} \\
(-17.18)\end{array}$ & $\begin{array}{l}0.391^{* * *} \\
(-17.12)\end{array}$ & $\begin{array}{l}0.387^{* * *} \\
(-17.29)\end{array}$ & $\begin{array}{c}0.510^{* * *} \\
(-5.78)\end{array}$ & $\begin{array}{c}0.499^{* * *} \\
(-5.89)\end{array}$ & $\begin{array}{c}0.481^{* * *} \\
(-6.16)\end{array}$ \\
\hline Population (log) & $\begin{array}{l}1.502^{* * *} \\
(18.54)\end{array}$ & $\begin{array}{l}1.502^{* * *} \\
(18.53)\end{array}$ & $\begin{array}{l}1.502^{* * *} \\
(18.51)\end{array}$ & $\begin{array}{c}1.409^{* * *} \\
(5.25)\end{array}$ & $\begin{array}{c}1.389^{* * *} \\
(5.13)\end{array}$ & $\begin{array}{c}1.373^{* * *} \\
(4.88)\end{array}$ \\
\hline Personnel present & & $\begin{array}{l}1.531^{* *} \\
(2.49)\end{array}$ & $\begin{array}{c}0.974 \\
(-0.12)\end{array}$ & & $\begin{array}{c}2.510^{* * *} \\
(3.15)\end{array}$ & $\begin{array}{l}1.728 \\
(1.64)\end{array}$ \\
\hline Observations & 5866 & 5866 & 5866 & 1201 & 1201 & 1201 \\
\hline Number of conflicts & 53 & 53 & 53 & 19 & 19 & 19 \\
\hline Wald chi2 & 463.2 & 477.0 & 497.4 & 63.06 & 77.18 & 85.56 \\
\hline Prob $>$ chi2 & $6.97 \mathrm{e}-98$ & $5.93 e-98$ & $2.10 \mathrm{e}-101$ & $2.83 \mathrm{e}-12$ & $1.80 \mathrm{e}-13$ & $1.26 \mathrm{e}-14$ \\
\hline
\end{tabular}

Incident rate ratios; t-statistics in parentheses; ${ }^{*} p<0.10,{ }^{* *} p<0.05,{ }^{* * *} p<0.01$ 


\begin{tabular}{|c|c|c|c|c|c|c|}
\hline & $\begin{array}{c}\text { (1) } \\
\text { One-sided } \\
\text { Violence } \\
\text { (all conflict- } \\
\text { months) } \\
\end{array}$ & $\begin{array}{c}\text { (2) } \\
\text { One-sided } \\
\text { Violence } \\
\text { (all conflict- } \\
\text { months) } \\
\end{array}$ & $\begin{array}{c}\text { (3) } \\
\text { One-sided } \\
\text { Violence } \\
\text { (all conflict- } \\
\text { months) } \\
\end{array}$ & $\begin{array}{c}\text { (4) } \\
\text { One-sided } \\
\text { Violence } \\
\text { (PK conflict- } \\
\text { months) } \\
\end{array}$ & $\begin{array}{c}(5) \\
\text { One-sided } \\
\text { Violence } \\
\text { (PK conflict- } \\
\text { months) } \\
\end{array}$ & $\begin{array}{c}\text { (6) } \\
\text { One-sided } \\
\text { Violence } \\
\text { (PK conflict- } \\
\text { months) } \\
\end{array}$ \\
\hline Total peacekeepers $(1000 \mathrm{~s})$ & $\begin{array}{l}1.014^{* *} \\
(2.11)\end{array}$ & $\begin{array}{l}1.007 \\
(0.96) \\
\end{array}$ & $\begin{array}{l}1.012 \\
(1.56)\end{array}$ & $\begin{array}{c}0.970^{* * *} \\
(-3.66) \\
\end{array}$ & $\begin{array}{c}0.951^{* * *} \\
(-4.89) \\
\end{array}$ & $\begin{array}{c}0.955^{* * *} \\
(-4.39) \\
\end{array}$ \\
\hline Military (\%) & $\begin{array}{l}1.001 \\
(0.48)\end{array}$ & $\begin{array}{c}0.998 \\
(-0.87)\end{array}$ & $\begin{array}{l}0.994^{* *} \\
(-2.45)\end{array}$ & $\begin{array}{l}1.005^{* *} \\
(2.41)\end{array}$ & $\begin{array}{c}1.007^{* * *} \\
(2.61)\end{array}$ & $\begin{array}{l}1.004 \\
(1.25)\end{array}$ \\
\hline Police (\%) & $\begin{array}{c}1.000 \\
(-0.02)\end{array}$ & $\begin{array}{c}0.994 \\
(-1.62)\end{array}$ & $\begin{array}{c}0.993 \\
(-1.39) \\
\end{array}$ & $\begin{array}{l}1.006 \\
(1.23)\end{array}$ & $\begin{array}{l}1.008 \\
(1.39)\end{array}$ & $\begin{array}{l}1.005 \\
(0.71)\end{array}$ \\
\hline Capability (\$1000s) & & $\begin{array}{l}1.003 \\
(0.94)\end{array}$ & $\begin{array}{c}1.041^{* * *} \\
(5.37)\end{array}$ & & $\begin{array}{c}0.996 \\
(-1.00)\end{array}$ & $\begin{array}{l}1.013^{*} \\
(1.67)\end{array}$ \\
\hline Willingness & & $\begin{array}{c}0.870^{* * * *} \\
(-3.20) \\
\end{array}$ & $\begin{array}{l}1.163^{* *} \\
(2.12)\end{array}$ & & $\begin{array}{c}0.815^{* * *} \\
(-4.49) \\
\end{array}$ & $\begin{array}{c}0.950 \\
(-0.65) \\
\end{array}$ \\
\hline Capability X Willingness & & & $\begin{array}{c}0.986^{* * *} \\
(-5.07) \\
\end{array}$ & & & $\begin{array}{l}0.992^{* *} \\
(-2.38)\end{array}$ \\
\hline Conflict Type & $\begin{array}{c}0.637^{* * *} \\
(-7.26)\end{array}$ & $\begin{array}{c}0.651^{* * *} \\
(-6.87)\end{array}$ & $\begin{array}{c}0.647^{* * *} \\
(-6.95)\end{array}$ & $\begin{array}{c}0.912 \\
(-0.84)\end{array}$ & $\begin{array}{l}1.035 \\
(0.30)\end{array}$ & $\begin{array}{l}1.029 \\
(0.25)\end{array}$ \\
\hline Population $_{(\log )}$ & $\begin{array}{c}1.267^{* * *} \\
(8.71)\end{array}$ & $\begin{array}{c}1.265^{* * *} \\
(8.66)\end{array}$ & $\begin{array}{c}1.259^{* * *} \\
(8.45)\end{array}$ & $\begin{array}{c}2.283^{* * * *} \\
(10.80) \\
\end{array}$ & $\begin{array}{c}2.278^{* * *} \\
(10.45) \\
\end{array}$ & $\begin{array}{l}2.277^{* * *} \\
(10.35) \\
\end{array}$ \\
\hline Personnel present & & $\begin{array}{c}2.008^{* * *} \\
(3.96)\end{array}$ & $\begin{array}{c}0.940 \\
(-0.23)\end{array}$ & & $\begin{array}{c}5.215^{* * *} \\
(4.13)\end{array}$ & $\begin{array}{c}3.944^{* * * *} \\
(3.22)\end{array}$ \\
\hline Observations & 5479 & 5479 & 5479 & 1168 & 1168 & 1168 \\
\hline Number of conflicts & 46 & 46 & 46 & 18 & 18 & 18 \\
\hline Wald chi2 & 157.7 & 183.4 & 218.0 & 136.7 & 167.5 & 169.3 \\
\hline Prob $>$ chi 2 & $3.04 \mathrm{e}-32$ & $2.02 \mathrm{e}-35$ & $5.57 \mathrm{e}-42$ & $8.94 \mathrm{e}-28$ & $4.39 \mathrm{e}-32$ & $8.68 \mathrm{e}-32$ \\
\hline
\end{tabular}

Incident rate ratios; t-statistics in parentheses; $* p<0.10,{ }^{* *} p<0.05, * * * p<0.01$ 
Appendix B - Model results from Chapter 5 with and without quality indicators

\begin{tabular}{|c|c|c|c|c|c|c|}
\hline & $\begin{array}{c}\text { (1) } \\
\text { Battlefield } \\
\text { violence } \\
\text { (all grid cells) } \\
\end{array}$ & & $\begin{array}{c}(2) \\
\text { Battlefield } \\
\text { violence } \\
\text { (all grid cells) } \\
\end{array}$ & & $\begin{array}{c}(3) \\
\text { Battlefield } \\
\text { violence } \\
\text { (all grid cells) }\end{array}$ & \\
\hline \multicolumn{7}{|l|}{ Direct effects } \\
\hline Total peacekeepers & 0.0418 & $(1.48)$ & 0.0318 & $(1.10)$ & 0.0313 & $(1.09)$ \\
\hline Combat $(\%)$ & $-0.0248^{* * *}$ & $(-6.44)$ & $-0.0285^{* * *}$ & $(-7.01)$ & $-0.0304^{* * *}$ & $(-7.29)$ \\
\hline Police $(\%)$ & $-0.0315^{* * *}$ & $(-4.65)$ & $-0.0324^{* * *}$ & $(-4.82)$ & $-0.0309^{* * *}$ & $(-4.57)$ \\
\hline Capability & & & 0.00382 & $(0.52)$ & $0.0222^{*}$ & $(1.93)$ \\
\hline Willingness & & & $0.154^{* * *}$ & $(2.95)$ & $0.321^{* * *}$ & $(3.36)$ \\
\hline Capability X Willingness & & & & & $-0.00800^{* *}$ & $(-2.08)$ \\
\hline Conflict & $0.150^{* * *}$ & $(3.57)$ & $0.0544^{* * *}$ & $(3.43)$ & $0.0544^{* * *}$ & $(3.43)$ \\
\hline Personnel present & $2.331^{* * *}$ & $(6.11)$ & $2.256^{* * *}$ & $(5.95)$ & $1.960^{* * *}$ & $(4.85)$ \\
\hline \multicolumn{7}{|l|}{ Indirect effects } \\
\hline$\overline{\text { Total peacekeepers }}$ & -0.0656 & $(-0.61)$ & -0.0196 & $(-0.26)$ & -0.0153 & $(-0.20)$ \\
\hline Combat $(\%)$ & -0.00234 & $(-0.17)$ & 0.0159 & $(1.61)$ & $0.0184^{*}$ & $(1.81)$ \\
\hline Police $(\%)$ & 0.00124 & $(0.05)$ & 0.0194 & $(1.21)$ & 0.0170 & $(1.06)$ \\
\hline Capability & & & -0.0227 & $(-1.31)$ & -0.0476 & $(-1.64)$ \\
\hline Willingness & & & 0.126 & $(1.04)$ & -0.0947 & $(-0.42)$ \\
\hline Capability X Willingness & & & & & 0.0105 & $(1.11)$ \\
\hline Personnel present & 0.0374 & $(0.03)$ & $-1.646^{*}$ & $(-1.74)$ & -1.263 & $(-1.27)$ \\
\hline Spatial lag of DV & $-0.560^{* * *}$ & $(-18.96)$ & $0.479^{* * *}$ & $(24.06)$ & $0.478^{* * *}$ & $(24.05)$ \\
\hline Spatial lag of error term & $0.481^{* * *}$ & $(24.37)$ & $-0.558^{* * *}$ & $(-18.78)$ & $-0.558^{* * *}$ & $(-18.77)$ \\
\hline Std. dev. of errors & $1.959^{* * *}$ & $(203.11)$ & $1.960^{* * *}$ & $(203.06)$ & $1.959^{* * *}$ & $(203.05)$ \\
\hline Observations & 36394 & & 36394 & & 36394 & \\
\hline Number of grids & 1174 & & 1174 & & 1174 & \\
\hline Wald chi2 & 457.5 & & 737.2 & & 740.8 & \\
\hline Prob $>$ chi 2 & $5.35 e-92$ & & $2.95 \mathrm{e}-148$ & & $2.72 \mathrm{e}-147$ & \\
\hline Wald test of spatial terms & 662.3 & & 655.4 & & 655.0 & \\
\hline Prob $>$ chi 2 & $8.57 \mathrm{e}-140$ & & $2.82 \mathrm{e}-136$ & & $3.19 \mathrm{e}-135$ & \\
\hline
\end{tabular}

Z-statistics in parentheses, ${ }^{*} p<0.10,{ }^{* *} p<0.05,{ }^{* * *} p<0.01$ 


\begin{tabular}{|c|c|c|c|c|c|c|}
\hline & $\begin{array}{c}(1) \\
\text { One-sided } \\
\text { violence } \\
\text { (all grid cells) }\end{array}$ & & $\begin{array}{c}(2) \\
\text { One-sided } \\
\text { violence } \\
\text { (all grid cells) }\end{array}$ & & $\begin{array}{c}(3) \\
\text { One-sided } \\
\text { violence } \\
\text { (all grid cells) }\end{array}$ & \\
\hline \multicolumn{7}{|l|}{ Direct effects } \\
\hline Total peacekeepers & $-0.0534^{* * *}$ & $(-2.87)$ & $-0.0560^{* * *}$ & $(-2.92)$ & $-0.0556^{* * *}$ & $(-2.89)$ \\
\hline Combat $(\%)$ & $-0.00814^{* * *}$ & $(-3.22)$ & $-0.00898^{* * *}$ & $(-3.30)$ & $-0.00888^{* * *}$ & $(-3.18)$ \\
\hline Police $(\%)$ & $-0.00908^{* *}$ & $(-2.02)$ & $-0.00896^{* *}$ & $(-1.99)$ & $-0.00913^{* *}$ & $(-2.02)$ \\
\hline Capability & & & 0.00524 & $(1.06)$ & 0.00400 & $(0.52)$ \\
\hline Willingness & & & 0.00542 & $(0.15)$ & -0.00634 & $(-0.10)$ \\
\hline Capability X Willingness & & & & & 0.000504 & $(0.20)$ \\
\hline Conflict & $0.0262^{* * *}$ & $(2.95)$ & $0.0259^{* * *}$ & $(2.91)$ & $0.0252^{* * *}$ & $(2.83)$ \\
\hline Personnel present & $0.883^{* * *}$ & $(3.53)$ & $0.850^{* * *}$ & $(3.35)$ & $0.873^{* * *}$ & $(3.22)$ \\
\hline \multicolumn{7}{|l|}{ Indirect effects } \\
\hline$\overline{\text { Total peacekeepers }}$ & 0.0182 & $(0.40)$ & 0.0234 & $(0.51)$ & 0.0164 & $(0.36)$ \\
\hline Combat (\%) & -0.00251 & $(-0.43)$ & -0.00230 & $(-0.38)$ & -0.00558 & $(-0.88)$ \\
\hline Police $(\%)$ & -0.00581 & $(-0.59)$ & -0.00570 & $(-0.58)$ & -0.00306 & $(-0.31)$ \\
\hline Capability & & & -0.0101 & $(-0.93)$ & 0.0199 & $(1.11)$ \\
\hline Willingness & & & 0.101 & $(1.34)$ & $0.346^{* *}$ & $(2.44)$ \\
\hline Capability X Willingness & & & & & $-0.0121^{* *}$ & $(-2.05)$ \\
\hline Personnel present & 0.208 & $(0.36)$ & 0.128 & $(0.22)$ & -0.269 & $(-0.44)$ \\
\hline Spatial lag of DV & $0.675^{* * *}$ & $(64.50)$ & $0.675^{* * *}$ & $(64.42)$ & $0.674^{* * *}$ & $(64.18)$ \\
\hline Spatial lag of error term & $-0.807^{* * *}$ & $(-40.11)$ & $-0.807^{* * *}$ & $(-40.07)$ & $-0.806^{* * *}$ & $(-39.96)$ \\
\hline Std. dev. of errors & $1.271^{* * *}$ & $(209.22)$ & $1.271^{* * *}$ & $(209.20)$ & $1.271^{* * *}$ & $(209.17)$ \\
\hline Observations & 36394 & & 36394 & & 36394 & \\
\hline Number of grid cells & 1174 & & 1174 & & 1174 & \\
\hline Wald chi2 & 4290.8 & & 4295.3 & & 4295.0 & \\
\hline Prob $>$ chi 2 & 0 & & 0 & & 0 & \\
\hline Wald test of spatial terms & 4592.0 & & 4592.3 & & 4583.0 & \\
\hline Prob $>$ chi 2 & 0 & & 0 & & 0 & \\
\hline
\end{tabular}




\section{References}

Africa Defence Forum. 2017. "Complex Missions Simple Technology: U.N. Police and Soldiers Can Enhance Peacekeeping with Off-the-Shelf Tools." 30 December. https://adf-magazine.com/complex-missions-simple-technology/.

Albrecht, Peter, and Cathy Haenlein. 2016. "Fragmented Peacekeeping: The African Union in Somalia." The RUSI Journal 161, no. 1: 50-61.

Albrecht, Peter. 2015. "Fragmented Peacekeeping: Regional Interests Define the African Union Mission in Somalia.” DIIS Policy Brief (November): 104.

Amnesty International. 2018. “'Everything was in flames:' The attack on a displaced persons camp in Alindao." https://www.amnesty.org/en/documents/afr19/9573/2018/en/.

Auerswald, David P., and Stephen M. Saideman. 2014. NATO in Afghanistan: Fighting Together, Fighting Alone. Princeton: Princeton University Press.

Autesserre, Séverine. 2014. Peaceland: Conflict Resolution and the Everyday Politics of International Intervention. New York: Cambridge University Press.

Azam, Jean-Paul, and Anke Hoeffler. 2002. "Violence Against Civilians in Civil Wars: Looting or Terror?" Journal of Peace Research 39, no. 4: 461-48.

Azam, Jean-Paul. 2006. "On thugs and heroes: Why warlords victimize their own civilians." Economics of Governance 7, no. 1 (January): 53-73.

Balcells, Laia. 2010. "Rivalry and Revenge: Violence Against Civilians in Conventional Civil Wars." International Studies Quarterly 54, no. 2: 291-313.

---. 2011. "Continuation of Politics by Two Means: Direct and Indirect Violence in Civil War." Journal of Conflict Resolution 55, no. 3: 397-422.

Beardsley, Kyle, and Kristian Skrede Gledistch. 2015. "Peacekeeping as Conflict Containment." International Studies Review 17: 67-89.

Bellamy, Alex J., and Charles T. Hunt. 2015. "Twenty-first century UN peace operations: protection, force and the changing security environment." International Affairs 91, no. 6: 1277-1298.

Bellamy, Alex J., and Paul D. Williams. 2013. "Introduction: The Politics and Challenges of Providing Peacekeepers." In Providing Peacekeepers: The Politics, Challenges, and Future of United Nations Peacekeeping Contributions, edited by Alex J. Bellamy and Paul D. Williams, 1-24. Oxford: Oxford University Press. 
Berdal, Mats, and David Ucko. 2015. "The Use of Force in UN Peacekeeping Operations." The RUSI Journal 160, no. 1: 6-12.

Blocq, Daniel S. 2006. "The Fog of UN Peacekeeping: Ethical Issues regarding the use of Force to protect Civilians in UN Operations." Journal of Military Ethics 5, no. 3: 201-213.

---. 2010. "Western Soldiers and the Protection of Local Civilians in UN Peacekeeping Operations: Is a Nationalist Orientation in the Armed Forces Hindering Our Preparedness to Fight?” Armed Forces \& Society 36, no. 2: 290-309.

Bove, Vincenzo, and Andrea Ruggeri. 2016. "Kinds of Blue: Diversity in UN Peacekeeping Missions and Civilian Protection." British Journal of Political Science 46: 681-700.

---. 2019. "Peacekeeping Effectiveness and Blue Helmets' Distance from Locals." Journal of Conflict Resolution 63, no. 7: 1630-1655.

Boyle, Michael J. 2009. "Bargaining, Fear, and Denial: Explaining Violence Against Civilians in Iraq 2004-2007." Terrorism and Political Violence 21, no. 2: 261287.

Bratt, Duane. 1997. "Explaining Peacekeeping Performance: The UN in International Conflicts." International Peacekeeping 4, no. 3: 45-70.

Britt, Thomas W. 2003. "Can Participation in Peacekeeping Missions Be Beneficial? The Importance of Meaning as a Function of Attitudes and Identity." In The Psychology of the Peacekeeper, edited by Thomas W. Britt and Amy B. Adler, 71-88. Westport, Connecticut: Praeger.

Brown, Michael E. 2001. "Ethnic and Internal Conflicts: Causes and Implications." In Turbulent Peace: The Challenges of Managing International Conflict, edited by Chester A. Crocker and Fen Osler Hampson with Pamela R. Aall, 209-226. Washington, DC: United States Institute of Peace Press.

Byman, Daniel, and Matthew Waxman. 2002. The Dynamics of Coercion: American Foreign Policy and the Limits of Military Might. Cambridge, UK: Cambridge University Press.

Byman, Daniel, and Stephen Van Evera. 1998. "Why They Fight: Hypotheses on the Origins of Contemporary Deadly Conflicts." Security Studies 7, no. 3 (Spring): 150 .

Center for Civilians in Conflict. 2016. Under Fire: The July 2016 Violence in Juba and UN Response. https://civiliansinconflict.org/wp-content/uploads/2017/09/civicjuba-violence-report-october-2016.pdf. 
Cingranelli, David L., and David L. Richards. 2010. "The Cingranelli and Richards (CIRI) Human Rights Data Project.” Human Rights Quarterly 32, no. 2 (May): 401-424.

Cinq-Mars, Evan. 2018. “'Action for Peacekeeping’ Reform Comes Too Late for Civilians in the Central African Republic." Center for Civilians in Conflict, 13 December. https://civiliansinconflict.org/blog/a4p-too-late-for-civilians-in-thecar/.

Claude, Inis L. Jr. 1984. Swords into Plowshares: The Problems and Progress of International Organization. 4th ed. New York: Random House.

Cohen, Dara. 2013a. "Explaining Rape during Civil War: Cross-National Evidence (1980-2009)." American Political Science Review 107, no. 3 (August): 461-477.

---. 2013b. "Female Combatants and the Perpetration of Violence: Wartime Rape in the Sierra Leone Civil War." World Politics 65, no. 3 (July): 383-415.

Costalli, Stefano. 2014. "Does Peacekeeping Work? A Disaggregated Analysis of Deployment and Violence Reduction in the Bosnian War." British Journal of Political Science 44, no. 2: 357-380.

Cresswell, John W., and Vicki L. Plano Clark. 2011. Designing and Conducting Mixed Methods Research. 2nd ed. Los Angeles: Sage Publications, Inc.

Cronin-Furman, Kate. 2013. "Managing Expectations: International Criminal Trials and the Prospects for Deterrence of Mass Atrocity." The International Journal of Transitional Justice 7, no. 3: 1-21.

Daniel, Donald C. F. 2013. "Contemporary Patterns in Peace Operations, 2000-2010.” In Providing Peacekeepers: The Politics, Challenges, and Future of United Nations Peacekeeping Contributions, edited by Alex J. Bellamy and Paul D. Williams, 2546. Oxford: Oxford University Press.

Darmofal, David. 2015. Spatial Analysis for the Social Sciences. Cambridge University Press.

De Coning, Cedric, and Karsten Friis. 2011. "Coherence and Coordination: The Limits of the Comprehensive Approach." Journal of International Peacekeeping 15: 243272.

Department of Peacekeeping Operations. 2006. Joint Operations Centres and Joint Mission Analysis Centres.

---. 2008. Authority, Command and Control in United Nations Peacekeeping Operations. 
---. 2009a. A New Partnership Agenda: Charting a New Horizon for UN Peacekeeping. New York: United Nations.

---. 2009b. Formed Police Units in United Nations Peacekeeping Operations.

---. 2010. "Draft DPKO/DFS Operational Concept on the Protection of Civilians in United Nations Peacekeeping Operations." http://www.peacekeeping.org.uk/wpcontent/uploads/2013/02/100129-DPKO-DFS-POC-OperationalConcept.pdf?LMCL=seNKLd.

---. 2012. United Nations Infantry Battalion Manual. Vols. 1 and 2. New York: United Nations.

---. 2015a. Protection of Civilians: Implementing Guidelines for Military Components of United Nations Peacekeeping Missions.

---. 2015b. United Nations Peacekeeping Missions Military Reconnaissance Unit Manual.

---. 2016. "UN Mission's Contributions by Country." https://peacekeeping.un.org/en/troop-and-police-contributors,

---. 2019. "Data." Last modified 31 August 2019. https://peacekeeping.un.org/en/data.

Di Razza, Namie. 2016. “France's CAR Departure Creates Uphill Battle for UN.” IPI Global Observatory, 14 November. https://theglobalobservatory.org/2016/11/sangris-central-african-republic-francepeacekeeping/

Downes, Alexander B. 2007. "Draining the Sea by Filling the Graves: Investigating the Effectiveness of Indiscriminate Violence as a Counterinsurgency Strategy." Civil Wars 9, no. 4 (December): 420-444.

Duursma, Allard, and Roisin Read. 2017. "Modelling Violence as Disease? Exploring the Possibilities of Epidemiological Analysis for Peacekeeping Data in Darfur." International Peacekeeping 24, no. 5: 733-755.

Fearon, James D., and David D. Laitin. 2003. "Ethnicity, Insurgency, and Civil War." American Political Science Review 97, no. 1 (February): 75-90.

Findlay, Trevor. 2002. The Use of Force in UN Peace Operations. Oxford, UK: SIPRI and Oxford University Press.

Fjelde, Hanne, and Lisa Hultman. 2014. "Weakening the Enemy: A Disaggregated Study of Violence against Civilians in Africa." Journal of Conflict Resolution 58, no. 7: $1230-1257$. 
Fjelde, Hanne, Lisa Hultman, and Desiree Nilsson. 2019. "Protection Through Presence: UN Peacekeeping and the Costs of Targeting Civilians." International Organization 73, no.1: 103-131.

Fortna, Virginia Page. 2008. Does Peacekeeping Work? Shaping Belligerents' Choices after Civil War. Princeton: Princeton University Press.

Fotheringham, A. Stewart, Chris Brunsdon, and Martin Charlton. 2002. Geographically Weighted Regression: The Analysis of Spatially Varying Relationships. Chichester: John Wiley \& Sons Ltd.

Fotheringham, A. Stewart, Ricardo Crespot, and Jing Yao. 2015. "Geographical and Temporal Weighted Regression (GTWR).” Geographical Analysis 47: 431-452.

Franke, Volker C. 2003. "The Social Identity of Peacekeeping." In The Psychology of the Peacekeeper, edited by Thomas W. Britt and Amy B. Adler, 31-52. Westport, Connecticut: Praeger.

Galantino, Maria Grazia. 2003. "Work Motivation and the Peacekeeper." In The Psychology of the Peacekeeper, edited by Thomas W. Britt and Amy B. Adler, 111-126. Westport, Connecticut: Praeger.

Goulding, Marrack. 1993. "The Evolution of United Nations Peacekeeping." International Affairs 60, no. 3 (July): 451-464.

Griffith, Daniel A. 2003. Spatial Autocorrelation and Spatial Filtering: Gaining Understanding Through Theory and Scientific Visualization. Berlin: Springer.

Haass, Felix, and Nadine Ansorg. 2018. "Better peacekeepers, better protection? Troop quality of United Nations peace operations and violence against civilians." Journal of Peace Research 55, no. 6: 742-758.

Harff, Barbara. 2003. "No Lessons Learned from the Holocaust? Assessing Risks of Genocide and Political Mass Murder since 1955." American Political Science Review 97, no. 1 (February): 57-73.

Hedlund, Erik, and Joseph Soeters. 2010. "Reflections on Swedish Peacekeepers' SelfImage and Dilemmas of Peacekeeping." International Peacekeeping 17, no. 3: 408-414.

Hedlund, Erik. 2011. "What Motivates Swedish Soldiers to Participate in Peacekeeping Missions: Research Note." Armed Forces \& Society 37, no. 1: 180-190.

Hemez, Maj. Remy. 2016. “Operation Sangaris: A Case Study in Limited Military Intervention." Military Review (November-December): 72-80. 
Herreros, Francisco, and Henar Criado. 2009. "Pre-emptive or Arbitrary: Two Forms of Lethal Violence in Civil War." Journal of Conflict Resolution 53, no. 3 (June): 419-445.

Hilbe, Joseph M. 2014. Modeling Count Data. Cambridge University Press.

Hills, Alice. 2001. "The inherent limits of military forces in policing peace operations." International Peacekeeping 8, no. 3 (2001): 79-98.

Holt, Victoria, Glyn Taylor, and Max Kelly. 2009. Protecting Civilians in the Context of UN Peacekeeping Operations: Successes, Setbacks and Remaining Challenges. New York: United Nations.

Hultman, Lisa, Jacob Kathman, and Megan Shannon. 2013. "United Nations Peacekeeping and Civilian Protection in Civil War." American Journal of Political Science 57, no. 4: 875-891.

---. 2014. "Beyond Keeping Peace: United Nations Effectiveness in the Midst of Fighting." American Political Science Review 108, no. 4: 737-753.

Hultman, Lisa. 2007. "Battle Losses and Rebel Violence: Raising the Costs for Fighting." Terrorism and Political Violence 19, no. 2: 205-222.

---. 2009. "The Power to Hurt in Civil War: The Strategic Aim of RENAMO Violence." Journal of South African Studies 35, no.4: 821-834.

---. 2010. “Keeping Peace or Spurring Violence? Unintended Effects of Peace Operations on Violence Against Civilians." Civil Wars 12, no. 1-2: 29-46.

Human Rights Watch. 2013a. "I Can Still Smell the Dead: The Forgotten Human Rights Crisis in the Central African Republic.” (September): 1-79.

---. 2013b. "They Came to Kill: Escalating Atrocities in the Central African Republic." (December): 1-43.

Humphreys, Macarten, and Jeremy M. Weinstein. 2006. "Handling and Manhandling Civilians in Civil War." American Political Science Review 100, no. 3 (August): 429-447.

Hunt, Charles T. 2017. "All necessary means to what ends? The unintended consequences of the 'robust turn' in UN peace operations." International Peacekeeping 24, no. 1: 108-131.

International Crisis Group. 2013a. "Central African Republic: Better Late Than Never." Africa Briefing, no. 96 (December): 1-15. 
---. 2013b. "Central African Republic: Priorities of the Transition." Crisis Group Africa Report, no. 203 (June): 1-42.

---. 2014a. "The Central African Crisis: From Predation to Stablisation." Africa Report, no. 219 (June): 1-37.

---. 2014b. “The Central African Republic's Hidden Conflict.” Africa Briefing, no. 105 (December): 1-18.

---. 2015. "Central African Republic: The Roots of Violence." Africa Report, no. 230 (September): 1-41.

International Peace Information Service. 2018. "Central African Republic: A Conflict Mapping." http://ipisresearch.be/wp-content/uploads/2018/09/1809-CARconflict-mapping_web.pdf.

Jett, Dennis. 1999. Why Peacekeeping Fails. New York: Palgrave Macmillan.

Jo, Hyeran, and Beth A. Simmons. 2016. "Can the International Criminal Court Deter Atrocity." International Organization 70, no. 3 (Summer): 443-475.

Jo, Hyeran. 2015. Compliant Rebels: Rebel Groups and International Law in World Politics. Cambridge: Cambridge University Press.

Junk, Julian. 2012. "Function Follows Form: The Organizational Design of Peace Operations."

Journal of Intervention and Statebuilding 6, no. 3: 299-324.

Juvan, Jelena, and Janja Vuga. 2011. "What motivates Slovenian 'peacekeepers'?" International Peacekeeping 18, no. 1: 96-109.

Kalyvas, Stathis N. 1999. "Wanton and Senseless? The Logic of Massacres in Algeria." Rationality and Society 11, no. 3: 243-285.

---. 2003. "The Ontology of 'Political Violence': Action and Identity in Civil Wars." Perspectives on Politics 1, no. 3 (September): 475-494.

---. 2006. The Logic of Violence in Civil War. Cambridge, UK: Cambridge University Press.

Kalyvas, Stathis N., and Matthew Adam Kocher. 2009. "The Dynamics of Violence in Vietnam: An Analysis of the Hamlet Evaluation System (HES)." Journal of Peace Research 46, no. 3: 335-355. 
Karlsrud, John. 2013. "Special Representatives of the Secretary-General as Norm Arbitrators? Understanding Bottom-up Authority in UN Peacekeeping." Global Governance 19: 525-544.

---. 2015. "The UN at war: examining the consequences of peace-enforcement mandates for the UN peacekeeping operations in the CAR, the DRC and Mali." Third World Quarterly 36, no. 1: 40-54.

---. 2017. “Towards UN counter-terrorism operations?” Third World Quarterly 38, no. 6: 1215-1231.

Kathman, Jacob D. 2013. "United Nations Peacekeeping Personnel Commitments, 19902011." Conflict Management and Peace Science 30, no. 5: 532-549.

Kathman, Jacob D., and Reed M. Wood. 2016. "Stopping the Killing During the "Peace": Peacekeeping and the Severity of Postconflict Civilian Victimization." Foreign Policy Analysis 12, no. 2 (April): 149-169.

Kaufmann, Chaim. 1996. "Possible and Impossible Solutions to Ethnic Civil Wars." International Security 20, no. 4: 136-175.

Kelly, Fergus. 2019. "Portugal paratroops in five-hour firefight with UPC militia in Central African Republic." The Defence Post, 10 January. https://hedefensepost.com/2019/01/10/portugal-paratroopers-5-hour-firefightupc-bambari-central-african-republic/.

Kelta, Lt. Gen. Balla. 2017. "MINUSCA - Lack of professionalism of the Congolese contingent."

https://static1.squarespace.com/static/514a0127e4b04d7440e8045d/t/593704c246 c3c490c3ee0b24/1496777924587/CAR+memo.pdf.

Kleinfield, Philip. 2017. “Central African Republic: What's gone wrong?” The New Humanitarian, 24 February. http://www.thenewhumanitarian.org/analysis/2017/02/24/central-african-republicwhat-s-gone-wrong.

Kold, Claus. 2013. "Warriors or Peace Soldiers?” International Journal of Peace Studies 18, no. 1: 27-54.

Kreps, Sarah, and Sarah Maxey. 2018. "Mechanisms of Morality: Sources of Support for Humanitarian Intervention.” Journal of Conflict Resolution 62, no. 8: 1814-1842.

Lacina, Bethany, and Nils Petter Gleditsch. 2005. "Monitoring Trends in Global Combat: A New Dataset of Battle Deaths." European Journal of Population 21, no. 2-3 (June): 145-166. 
Lanchester, F. W. 1916. Aircraft in Warfare: The Dawn of the Fourth Arm. London, UK: Constable and Company Limited.

Lee, Lung-fei, and Jihai Yu. 2010. "Estimation of spatial autoregressive panel data models with fixed effects." Journal of Econometrics 154: 165-185.

Lilja, Jannie, and Lisa Hultman. 2011. "Intraethnic Dominance and Control: Violence Against Co-Ethnics in the Early Sri Lankan Civil War." Security Studies 20, no. 2: 171-197.

Lipow, Jonathan, and Eli Feinerman. 2001. "Better weapons or better troops?" Defence and Peace Economics 12, no. 4: 271-284.

Lipow, Jonathan, and Yakir Plessner. 2008. "Tax efficiency and quality/quantity tradeoffs in defense procurement." Defence and Peace Economics 19, no. 1:21-26.

Lipson, Michael. 2007. “Peacekeeping: Organized Hypocrisy?” European Journal of International Relations 13, no. 5: 5-34.

Lyall, Jason. 2009. "Does Indiscriminate Violence Incite Insurgent Attacks? Evidence from Chechnya." Journal of Conflict Resolution 53, no. 3 (June): 331-362.

Maguen, Shira, and Brett T. Litz. 2006. "Predictors of Morale in U.S. Peacekeepers." Journal of Applied Social Psychology 36, no. 4: 820-836.

Manekin, Devorah. 2013. "Violence Against Civilians in the Second Intifada: The Moderating Effect of Armed Group Structure on Opportunistic Violence." Comparative Political Studies 46, no. 10: 1273-1300.

McCormick, Ty. 2015. “One Day, We Will Start a Big War.” Foreign Policy. https://foreignpolicy.com/2015/10/28/one-day-we-will-start-a-big-war-centralafrican-republic-un-violence/.

Mihai, Croicu, and Raplh Sundberg. 2018. "UCDP Georeferenced Event Dataset Codebook: Version 18.1." Department of Peace and Conflict Research, Uppsala University.

Ministère de la Défense. 2015. "Sangaris: situation update, 19 February." https://www.defense.gouv.fr/english/operations/terminees/sangaris/actualites/sang aris-situation-update-19-february.

---. 2016. "Dossier de presse: Operation Sangaris." https://www.defense.gouv.fr/layout/set/popup/content/download/388227/5766370 /version/4/file/20160713+DP+Sangaris+VF.pdf. 
MINUSCA. 2014. "The Head of MINUSCA strongly condemns the attack against UN peacekeepers in Bangui.” Press Release, CP\#017/2014 (9 October).

https://minusca.unmissions.org/en/head-minusca-strongly-condemns-attackagainst-un-peacekeepers-bangui-press-release-0172014.

---. 2017a. "MINUSCA concerned about distribution of weapons to youth in Ippy." https://minusca.unmissions.org/en/minusca-concerned-about-distributionweapons-youth-ippy.

---. 2017b. "MINUSCA FHQ: In mission operational readiness assessment of COGBAT3 14-16 Mars 2017." https://static1.squarespace.com/static/514a0127e4b04d7440e8045d/t/593704a257 9fb37a23567889/1496777906180/MINUSCA+ORA.pdf.

---. 2017c. "MINUSCA warns FPRC coalition about intimidation of IDPs in Ippy." https://minusca.unmissions.org/en/minusca-warns-fprc-coalition-aboutintimidation-idps-ippy.

---. 2017d. "Renewed Attacks on Civilians and MINUSCA in Southeastern Central African Republic." Press Release, 13 May. https://minusca.unmissions.org/en/renewed-attacks-civilians-and-minuscasoutheastern-central-african-republic.

---. 2017e. Violations and Abuses of Human Rights and Violations of International Humanitarian Law by the FPRC Coalition and the UPC in Haute-Kotto and Ouaka between 21 November 2016 and 21 February 2017. https://minusca.unmissions.org/sites/default/files/fprc_upc_bria_bakala_report_16 oct2017_copy.pdf.

---. 2018. "MINUSCA strongly condemns attack by the UPC and FPRC armed groups on hospital in Ippy Ouaka prefecture." Press Release, 5 February. https://peacekeeping.un.org/en/minusca-strongly-condemns-attack-upc-and-fprcarmed-groups-hospital-ippy-ouaka-prefecture.

---. 2019. Attack on the Displace Persons' Camp in Alindao, Basse-Kotto Prefecture, on 15 November 2018: Breaches of International Humanitarian Law and Atrocity Crimes Committed by the UPC and anti-Balaka associated militias. https://minusca.unmissions.org/sites/default/files/minusca_human_rights_division s_report_on_alindao.pdf.

Nadin, Peter, Patrick Cammaert and Vesselin Popovski. 2014. "Role and development of robust peacekeeping." Adelphi Series 54, no. 449: 75-102.

Narol, Raoul. 1965. "Galton's Problem: The logic of cross-cultural analysis." Social Research 32, no. 4 (Winter): 428-451. 
Nilsson, Claes, and Cecilia Hull Wiklund. 2014. "Looking to Contribute: A Guide to the UN Force Generation System for Prospective Troop Contributors.” FOI (June): 138.

Office of Internal Oversight Services. 2016. "Audit of air operations in the United Nations Multidimensional Integrated Stabilization Mission in the Central African Republic.” Report 2016/168, Assignment No. AP2015/637/06 (December).

---. 2018. "Evaluation of re-hatting in the United Nations Multidimensional Integrated Stabilization Mission in Mali (MINUSCA) and the United Nations Multidimensional Integrated Stabilization Mission in the Central African Republic (MINUSCA).” Evaluation Report, Assignment No. IED-18-002 (February).

Office of the United Nations High Commissioner for Human Rights. 2017. Report of the Mapping Project documenting serious violations of international human rights law and international humanitarian law committed within the territory of the Central African Republic between January 2003 and December 2015.

Otto, Sabine. 2013. "Coding one-sided violence from media reports.” Cooperation and Conflict 48, no. 4: 556-566.

Peter, Mateja. 2015. "Between Doctrine and Practice: The UN Peacekeeping Dilemma." Global Governance 21 (351-370).

Peterson, Timothy M., and Leah Graham. 2011. "Shared Human Rights Norms and Military Conflict.” Journal of Conflict Resolution 55, no. 2: 248-273.

Posen, Barry R. 1993. "The Security Dilemma and Ethnic Conflict.” Survival 35, no. 1: $27-47$.

Powers, Matthew, Bryce Reeder and Ashly Townsen. 2015. "Hot Spot Peacekeeping." International Studies Review 17: 46-66.

Reuters. 2017. "U.N. air strikes in Central African Republic kill several militia.” 12 February. https://www.reuters.com/article/us-centralafrica-violenceidUSKBN15R0WC?il=0.

Risse-Kappen, Thomas. 2016. "Public opinion, domestic structure, and foreign policy in liberal democracies (1991)." In Domestic Politics and Norm Diffusion in International Relations: Ideas do not float freely, edited by Thomas Risse, 25-54. Routledge.

Rogerson, William P. 1990. "Quality vs. Quantity in Military Procurement." The American Economic Review 80, no. 1 (March): 83-92. 
Rudolf, Peter. 2017. "UN Peace Operations and the Use of Military Force." Survival 59, no. 3: 161-182.

Ruggeri, Andrea, Han Dorussen, and Theodora Ismene Gizelis. 2017. "Winning the Peace Locally: UN Peacekeeping and Local Conflict.” International Organization 71, no. 1: 163-185.

---. 2018. "On the Frontline Every Day? Subnational Deployment of United Nations Peacekeepers." British Journal of Political Science 48, no. 4: 1005-1025.

Ruggeri, Andrea, Ismene Gizelis, and Han Dorussen. 2011. "The Logic of Sub-national Deployment of UN Peacekeepers." Paper presented at the ECPR Geneva Conference, Reykjavik 2011.

Ruggie, John Gerard. 1993. "Wandering in the Void: Charting the U.N.'s New Strategic Role." Foreign Affairs (November/December).

https://www.foreignaffairs.com/articles/1993-12-01/wandering-void-charting-unsnew-strategic-role.

Schelling, Thomas C. 1960. The Strategy of Conflict. Cambridge, Massachusetts: Harvard Unviersity.

---. 1966. Arms and Influence. New Haven, Connecticut: Yale University Press.

Sion, Liora. 2006. “"Too Sweet and Innocent for War'? Dutch Peacekeepers and the Use of Violence." Armed Forces \& Society 32, no. 3: 454-474.

Sloan, Hames. 2014. "The Evolution of the Use of Force in UN Peacekeeping." Journal of Strategic Studies 37, no. 5: 674-702.

Smith, Adam C., and Arthur Boutellis. 2013. "Rethinking Force Generation: Filling the Capability Gaps in UN Peacekeeping." International Peace Institute (May): 1-18.

Sobek, David, M. Rodwan Abouharb, and Christopher G. Ingram. 2006. "The Human Rights Peace: How the Respect for Human Rights at Home Leads to Peace Abroad." The Journal of Politics 68, no. 3 (August): 519-529.

Stutt, William. 2006. "Force Generation in the United Nations." Blue Helmet Review: 8391.

Sullivan, Christopher Michael. 2012. "Blood in the Village: A Local-Level Investigation of State Massacres." Conflict Management and Peace Science 29, no. 4: 373-396.

Sundberg, Raplh, and Erik Melander. 2013. "Introducing the UCDP Georeferenced Event Dataset." Journal of Peace Research 50, no. 4: 523-532. 
Tardy, Thierry. 2011. "A Critique of Robust Peacekeeping in Contemporary Peace Operations.” International Peacekeeping 18, no. 2: 152-167.

Taylor, James G. 1980. Lanchester-type Models of Warfare. Vols. 1 and 2. https://apps.dtic.mil/dtic/tr/fulltext/u2/a090842.pdf.

Teddlie, Charles, and Abbas Tashakkori. 2009. Foundations of Mixed Methods Research: Integrating Quantitative and Qualitative Approaches in the Social and Behavioral Sciences. Los Angeles: Sage Publications, Inc.

The Portugal News. 2017. "President congratulates Portuguese commandos in Bambari." 9 March. https://www.theportugalnews.com/news/president-congratulatesportuguese-commandos-in-bambari/41303.

Themner, Lotta. 2018. "UCDP/PRIO Armed Conflict Dataset Codebook: Version 18.1." Department of Peace and Conflict Research, Uppsala University.

Tobler, W. R. "A Computer Movie Simulating Urban Growth in the Detroit Region." Economic Geography 46 (June): 234-240.

Tollefsen, Andreas Foro, Havard Strand, and Halvard Buhaug. 2012. "PRIO-GRID: A unified spatial data structure.” Journal of Peace Research 49, no.2: 363-374.

Tomz, Michael, and Jessica L. P. Weeks. 2018. "Human Rights and Public Support for War." Stanford Center on Global Poverty and Development, Working Paper No. 1026. https://kingcenter.stanford.edu/sites/default/files/publications/1026wp.pdf.

Townsen, Ashly and Bryce Reeder. 2014. "Where Do Peacekeepers Go When They Go?" Journal of International Peacekeeping 18, no. 1-2: 69-91.

Troy, Jodok. 2017. "Virtue Ethics and United Nations Peacekeeping Missions." SSRN. https://papers.ssrn.com/sol3/papers.cfm?abstract_id=2982671.

Tull, Denis M. 2017. "The Limits and Unintended Consequences of UN Peace Enforcement: The Force Intervention Brigade in the DR Congo." International Peacekeeping 25, no. 2: 167-190.

United Nations Security Council. 2013a. Report of the Secretary-General on the Central African Republic submitted pursuant to paragraph 22 of Security Council resolution 2121. S/2013/677 (November).

---. 2013b. Resolution 2127. S/RES/2127. New York: UN, 5 December.

---. 2014a. Reports of the Secretary-General on the situation in the Central African Republic. S/2014/857 (November). 
---. 2014b. Resolution 2149. S/RES/2149. New York: UN, 10 April.

---. 2015a. Final report of the Panel of Experts on the Central African Republic extended pursuant to Security Council resolution 2196 (2015). S/2015/936 (December).

---. 2015b. Report of the Secretary-General on the situation in the Central African Republic. S/2015/227 (April).

---. 2015c. Report of the Secretary-General on the situation in the Central African Republic. S/2015/576 (July).

---. 2015d. Report of the Secretary-General on the situation in the Central African Republic. S/2015/918 (November).

---. 2016a. Executive summary of the independent special investigation into the violence in Juba in 2016 and the response by the United Nations Mission in South Sudan. S/2016/924.

---. 2016b. Report of the Secretary-General on the situation in the Central African Republic. S/2016/305 (April).

---. 2016c. Report of the Secretary-General on the situation in the Central African Republic. S/2016/824 (September).

---. 2016d. Special Report of the Secretary-General on the strategic review of the United Nations Multidimensional Integrated Stabilization Mission in the Central African Republic. S/2016/565 (June).

---. 2017a. Midterm report of the Panel of Experts on the Central African Republic extended pursuant to Security Council resolution 2339. S/2017/639.

---. 2017b. Report of the Secretary-General on the Central African Republic. S/2017/94 (February).

---. 2017c. Report of the Secretary-General on the Central African Republic. S/2017/473.

---. 2017d. Resolution 2387. S/RES/2387. New York: UN, 15 November.

---. 2018a. Final report of the Panel of Experts on the Central African Republic extended pursuant to Security Council resolution 2399 (2018). S/2018/1119 (December).

---. 2018b. Report of the Secretary-General on the Central African Republic, 15 June-15 October 2018. S/2018/922 (October).

United Nations. 2000a. Report of the Panel on United Nations Peace Operations. $\mathrm{A} / 55 / 305-\mathrm{S} / 2000 / 809$. 
---. 2000b. United Nations Military Symbols Handbook. New York: United Nations.

---. 2008. United Nations Peacekeeping Operations: Principles and Guidelines. New York: United Nations.

---. 2011. Manual on Policies and Procedures Concerning the Reimbursement and Control of Contingent-Owned Equipment of Troop/Police Contributors Participating in Peacekeeping Missions (COE Manual). A/C.5/66/8.

---. 2015. Report of the High-level Independent Panel on Peace Operations on uniting our strengths for peace: politics, partnership and people. A/70/95-S/2015/446.

Valentino, Benjamin, Paul Huth, and Dylan Balch-Lindsay. "Draining the Sea: Mass Killing and Guerrilla Warfare." International Organization 58, no. 2 (April): 375407.

Van Evera, Stephen. 1997. Guide to Methods for Students of Political Science. Ithaca: Cornell University Press.

Walter, Barbara F. 1999. "Designing Transitions from Civil War: Demobilization, Democratization, and Commitments to Peace." International Security 24, no. 1 (Summer): 127-155.

---. 2002. Committing to Peace: The Successful Settlement of Civil Wars. Princeton, New Jersey: Princeton University Press.

Washburn, Alan, and Moshe Kress. 2009. Combat Modeling. Dordrecht; Springer.

Weidmann, Nils B. 2015. "On the Accuracy of Media-based Conflict Event Data." Journal of Conflict Resolution 59, no. 6: 1129-1149.

Weinlich, Silke. 2012. "(Re)generating Peacekeeping Authority: The Brahimi Process." Journal of Intervention and Statebuilding 6, no. 3: 257-277.

Weinstein, Jeremy. 2007. Inside Rebellion: The Politics of Insurgent Violence. Cambridge, UK: Cambridge University Press.

Wood, Elisabeth Jean. 2006. "Variation in Sexual Violence during War." Politics \& Society 34, no. 3 (September): 307-341.

---. 2009. "Armed Groups and Sexual Violence: When is Wartime Rape Rare?" Politics \& Society 37, no. 1 (March): 131-162.

Wood, Reed M., and Jacob D. Kathman. 2014. "Too Much of a Bad Thing? Civilian Victimization and Bargaining in Civil War." British Journal of Political Science 44, no. 3 (July): 685-706. 
Wrigge, Staffan, Arne Fransén, and Lars Wigg. 1995. The Lanchester Theory of Combat and Some Related Subjects: A Bibilography 1900-1993. Stockholm: National Defence Research Establishment.

https://apps.dtic.mil/dtic/tr/fulltext/u2/a302237.pdf.

Yu, Danlin. 2010. "Exploring spatiotemporally varying regressed relationships: the geographically weighted panel regression analysis." The International Archives of the Photogrammetry, Remote Sensing and Spatial Information Sciences 38, Part II: $134-139$. 